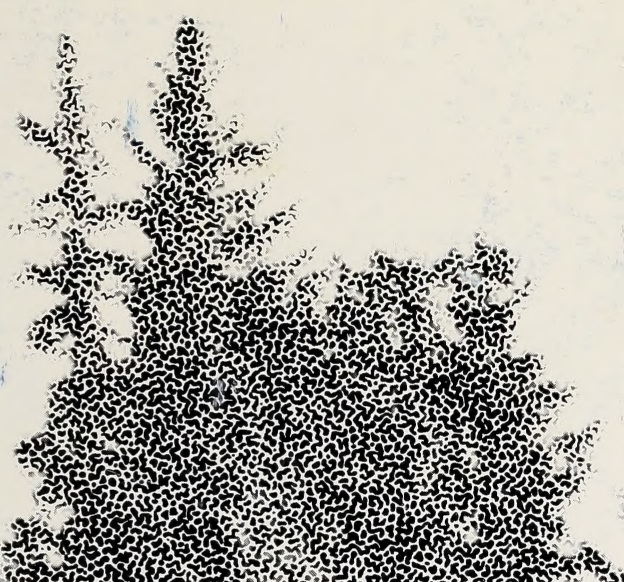

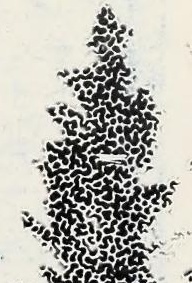

sids

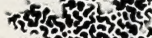

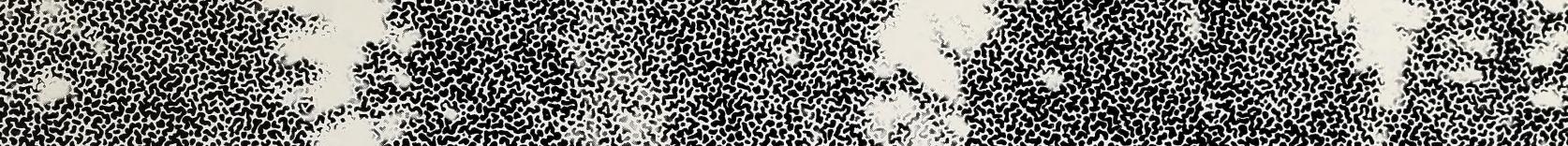
F

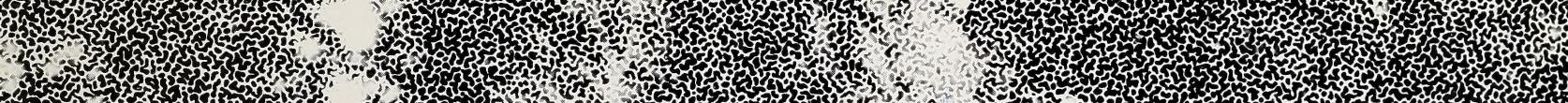

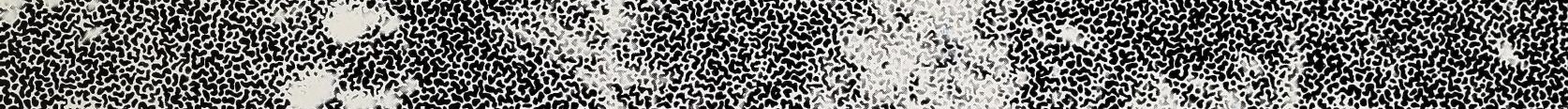
201 3. Hot 40 170 . 253 .

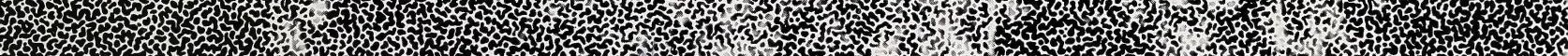
(1)

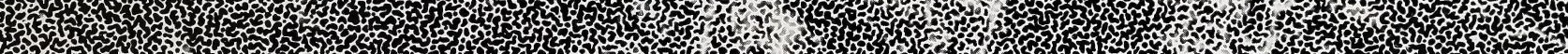
10,1 . H

\title{
PROCEEDINGS \\ "MAINTAINING AN EDGE" \\ A CONFERENCE ON THE FOREST \\ INDUSTRY TECHNOLOGY FOR THE 1990'
}

by

Info-Tech1

Alberta Forest Industry
Development Division

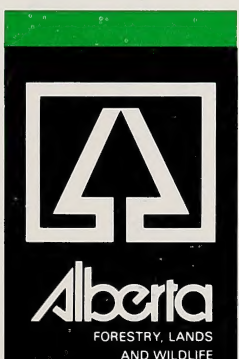



PROCEEDINGS

"MAINTAINING AN EDGE"

A CONFERENCE ON THE FOREST

INDUSTRY TECHNOLOGY FOR THE 1990'S

by

$$
\begin{aligned}
& \text { Info-Techl } \\
& \text { Alberta Forest Industry } \\
& \text { Development Division }
\end{aligned}
$$

October 25-26, 1989

1Calgary, Alberta

2Edmonton, Alberta 


\section{SCLAIMER}

The printing of the proceedings of the "Maintaining an Edge" conference was funded under the Forest Products Research Program of the Forest Industry Development Division of the Department of Forestry, Lands \& Wildilfe.

The responsibility for the contents of these proceedings is not the individual author's alone and the conclusions reached herein do not necessarily reflect the opinions of the provincial government which funded the printing of the proceedings.

Aditional copies of this publication are available at no charge from:

Forestry, Lands and Wildife

Forest Industry Development Division

108th Street Building

\#930, 9942 - 108th Street

Edmonton, Alberta

T5K 2J5 
PAGE NO.

Disclaimer

Acknowledgement

Welcome and Opening Remarks

J.A. Brennan, Executive Officer, Forest Industry

Development Division, Alberta Forestry, Lands \& Wilalife

Keynote speech

Peter E. Woodbridge, President, Woodbridge, Reed \& Associates

\section{SESSION I}

\section{State-of-the-art Technology Review}

Moderator: R. Beard, General Manager, Grande Cache Forest Products Ltd.

Innovations Solving Harvesting, Transportation, and Silvaculture Problems

A.W. J. Sinclair, Manager, Western Division, Forest Engineeering Research Institute of Canada

Sawmills: Increased Recovery, Reduced Manning

G. J. Schwab, Woodpro Engineering Ltd.

Plywood in the Nineties

G. Sleet, Director, Quality Services Division,

American Plywood Association

Composites

T. M. Maloney, Director, Wood Materials \& Engineering

Laboratory, Washington State University

Pulping Technology for Conservation of Energy and

Environment

E. Sebbas, Senior Process Engineer,

Ekono Consultants Ltd.

Sawmilling in the $90^{\prime} \mathrm{s}$

R. J. Craig, President, Carroll-Hatch

(International) Ltd. 
Digitized by the Internet Archive in 2016 


\section{ACKNOWIEDGMENTS}

The steering Committee consists of Mr. P. Faloon, Manager, Info-Tech, Mr. T. Szabo, Manager, Forest Products Research, Alberta Forest Industry Development Division, Mr. N. Gartaganis, Director, Financial and Economic Analysis, Alberta Forest Industry Development Division and Mr. R. Simpson, Director, Forest Industry, Alberta Forest Industry Development Division. This Committee wishes to express their gratitude to the following sponsors that made this conference highly successful:

- Alberta Forestry, Lands and Wildlife

- Alberta Forest Products Association

- Alberta Research Council

- Council of Forest Industries of British Columbia (COFI)

- Forest Engineering Research Institute of Canada (FERIC)

- Forestry Canada

- Forintek Canada Corp.

- The Pulp and Paper Research Institute of Canada (PAPRICAN)

- Swedish Institute of Sawmilling Technology

- University of Alberta 


$$
\text { - }
$$




\section{WELCOME AND OPENING REMARKS \\ BY THE CHAIRMAN \\ J. A. BRENNAN \\ EXECUTIVE OFFICER}

ALBERTA FOREST INDUSTRY DEVELOPMENT DIVISION

Ladies and gentlemen! Welcome to Edmonton and to the conference on Forest Industries Technology for the 1990's associated with Alberta's First Annual International Forestry Show. Over the next two days you will see and hear a number of internationally recognized people speak on state-of-the-art technologies and how to maintain a leading edge in the technology to ensure prosperity as a business in the future.

Things are changing and this is particularly true for the forestry developments in Alberta.

Until a few years ago, only $4 \%$ of Alberta's aspen resource was utilized. Today, it is about $12 \%$ i.e., $12 \%$ of the total allowable annual cut. Thus, there has been a 2- to 3-fold increase in just a few short years. The potential for additional large-scale utilization is very apparent. The realization of the full potential of this under-utilized aspen resource would make a major contribution to the diversification of the forest products industry, and hence to the rejuvenation and diversification of the Provincial economy as well.

The development of the primary forest products industry is well on its way. This can clearly be shown by the following projects since 1985:

- a medium density fiberboard (MDF) plant,

- two new oriented strandboard plants,

- the expansion of the bleached kraft pulp mill in Hinton,

- a new CTMP mill in Whitecourt,

- a new CTMP mill Slave Lake,

- a new CTMP newsprint mill in Whitecourt,

- a new bleached kraft pulp mill in Peace River,

- a new bleached kraft pulp mill in the Athabasca-Lac La Biche area,

- the expansion of Proctor and Gamble's bleached kraft pulp mill in Grande Prairie, and

- new sawmills in Manning and Lac La Biche.

In total, committed investment reaches $\$ 3.4$ billion. 
In each of these projects the best available technology is being used to ensure environmental friendiness and a leading edge in the technology as well as the market place.

In order to get full benefit of the forest industry development, we feel it is time to put more emphasis on the secondary forest products sector and the supplies industry sectors to both the primary and the secondary forest industries. The combined employment in the supplies and the secondary forest products industries is estimated to be over double in comparison to that of the primary forest industry.

The Government of Alberta is committed to sustainable economic development from all aspects including environment and technology. We feel the future of the industry depends on its relation to the market and how well it can maintain a leading edge in its business.

We encourage you all to participate in the discussions and questioning of the speakers. Have a good conference, do not forget to visit the show and we hope to see you next year. 


\section{KEYNOTE SPEECH}

\section{by PETER E. WOODBRIDGE}

New technologies and the seemingly relentless pace of technological change are everywhere in our lives. In fact, it is hard to identify an area of human activity where they are not having an influence upon us. In some instances keeping up with technology has become something of a 'cult'. The word technology and derivatives of it, such as 'high tech', and the poorly regarded 'low tech', as well as 'technology transfer' and 'technological obsolescence' trip easily off the tongues of politicians and businessmen alike. There is little doubt that technology is one of the strongest driving forces behind our lives, our work, our lifestyles. It affects the food we eat, the air we breathe, the water we drink, the way we think, and the way we perceive and solve problems.

Let us have no doubt, however, about the relationship between technology and ourselves. Not many years ago, mankind drove technology. Today, all too often, the reverse is true. Having opened Pandora's box in the 20th Century, we're having to run faster and faster to keep pace with technological developments and their impacts. We're still trying to find out about, and cope with the direct, indirect and side-effects of technology. We can't close the lid, nor should we try. We shouldn't try because at the centre of all this is the real issue which we have no choice but to resolve satisfactorily. This is not technology, as such, but the pace of technological change and its impacts. More specifically, the MANAGEMENT of technological change.

Students of the English language tell us that the word 'technology' is derived from the Greek words meaning art ('tekhne') and systematic treatment ('tekhnologia'). So we can see that technology, as well as its management, can be considered as being both an art and a science.

This is the theme of what I would like to talk about today. My message is simple to state. It is that technology in the forest industry cannot be developed in isolation from considerations about how to achieve and manage the changes it can and probably will bring about. In the forest industry, we as technologists deserve a great deal of credit for our achievements in new product and process development. We rate high marks also in initiatives in the application of new technology. These include, for example, efforts to reduce institutional barriers and the development of methods to adopt and apply "better mousetraps". 
Society will be increasingly less tolerant, however, of failures to achieve technological development and of failures to manage the overall process of technological change. This is because the major impacts and the ripple effects are affecting more and more people in the "global village".

So the message is this. We have a major opportunity in the 1990s. The theme of this conference, "Maintaining an Edge" is a well phrased challenge for the forest products sector. But, we face major constrainis. We need to plan our way through. Issues, such as harvesting and manufacturing technologies, for example, have to be coordinated with rapidly more demanding environmental standards. They have to take account of the need for adequate forest regeneration, and prospects for new product potential. The real challenge, ladies and gentlemen, is not technology itself but the management of technological change.

The themes I will present to you today are shown in Slide 1.

\section{SLIDE \#1}

\section{OUTLINE}

1. Global Perspective: Magnitude of the Opportunity next 20 years

2. Global Perspective: Driving Forces Behind Technological Changes

3. Supporting "Cultures", Institutions and Facilities.

4. Potential Impacts Upon, and Gains to,

(a) The Innovator and

(b) The Imitator 
Later, in closing, I would also like to say a few words in support of Alberta's performance as far as forest sector technological development is concerned. In my opinion, and in the opinion of a lot of other people in our industry worldwide, Alberta has worked hard to develop a clear vision of the technological changes which are occurring. It has acted decisively and successfully on them. Alberta deserves a great deal more credit than it has received recently from the media for its technological leadership and its development policies in the forest sector. I hope that this will become evident in this conference.

\section{Global Perspective: Magnitude of the Opoortunity}

In 1988 the Government of Canada, Canadian Forestry Service, published a major report which we prepared entitled "Canada's Forest Industry, The Next Twenty Years: Prospects \& Priorities". Many of you are aware of this report and its contents, so I will simply repeat some of its most important conclusions. These are that:

- Canada's forest sector is undergoing rapid changes in terms of its role and competitiveness in the world.

- The former ' 3 Engines of Growth' (exports of softwood lumber, newsprint and softwood market pulp) are slowing down.

- They will not contribute at the same pace in the future as they have in the past to the growth of Canada's national and regional economies.

- The global demand outlook for forest products nevertheless is very encouraging. Forest products globally is a 'growth business' and has good prospects to continue that way well into the 21 st-Century and beyond.

- New, and sometimes stronger, competitors have become suppliers. Canada no longer enjoys, along with a few other traditional suppliers, the monopoly position it once had in primary commodity trade internationally.

- Globally, the technological performance of any country in the forest products industry can be judged in terms of its response to process changes and to product innovation. 
- Canada's technological performance has been adequate in relation to the narrow range of products it produces (i.e. the ' 3 Engines of Growth'). Almost all of our research and development ('R\&D') efforts, however, have been focussed on production cost reductions, production process improvements, productivity and economy of scale.

- As far as new product innovations and their application, Canada's technological performance consistently has fallen well below the pace set by our competition in the Nordic countries, the European Community, the United States and Japan.

- Largely because of a very comfortable world trading position and plentiful resources, we simply have not had to try very hard in the past to "made a buck".

- Needless to say, that complacency is no longer appropriate. Trading and competitive circumstances have been changing and our technological response has not kept pace.

- Based on the CFS Report's analysis of the global market opportunities and Canada's resources, its manufacturing base and its competitive prospects, we should be very optimistic. There are some tremendous new trade opportunities awaiting us.

- Although it has become "motherhood" at management conferences to talk about the need to fight to win these opportunities against stiff international competition, this is precisely what the CFS Report also concludes.

- The CFS Report details where these opportunities are and how they can be achieved. It states clearly, however, that Canada's attitudes to technological innovative, as distinct from imitation, will have to improve dramatically.

- Encouragingly, the CFS Report also concludes from its analysis of recent changes in Canada's forest sector that there are signs that this is beginning to happen.

- As far as forest sector development policies are concerned, the Province of Alberta has taken a very enviable lead in Canada. Other speakers have listed these achievements. Alberta's list of technological 'Firsts' recently has attracted global acciaim. Unfortunately, most of this acclaim is from outside Alberta. 
- Much, much more needs to be achieved in developing an appropriate base that will lead us to, and sustain us in, technological leadership in Canada if we are to be a significant player in the 21st Century.

\section{Global Perspective: Driving Forces Behind Technological Changes}

Slide \#2 presents some of the major driving forces underlying the pace of forest sector technological changes. These include the 'macro', global economic growth factors which are the fundamental determinants of the need for technological changes and their application. Rates of economic growth in the world's major developed economies clearly are important. Increasingly important is the widening global base of economic activity to other newly industrialized economies.

SLIDE \#2

\section{Some "DRIVING FORCES" in Forest Industry Technologies}

1. Global Economic Activity

- Global GDP growth rates

- Absolute scale and diversity

2. Pace and Form of Economic, Social and Political Restructuring

- Globally

- Regionally

3. Shifts in Raw Material Availability and Costs

4. Activity in Other Sectors Which Has "Major Impacts" or "Ripple Effects" on the Forest Industry.

Recent and current global restructuring includes the elimination of trade barriers and reduction in 'special treatment' activities for economic development. Shifts in raw material availability 
have been occurring and comparative cost structures have shifted because of 'internal' and 'external' influences.

Most importantly, from a technological perspective, the forest sector has been the net beneficiary of technological changes in other sectors which have had, variably, either major impacts or at minimum "ripple effects" on our sector.

Later, I will refer to the need in an economy for supporting cultures and activities, and ultimately I will make a contrast between the example set by the Nordic equipment supply industry and its long-standing supportive cultures and the resulting Nordic technological leadership in certain growth technologies in the forest sector.

My concluding point is that it is naive for Canada, as a major trading nation, to wander abstractly into the $21 \mathrm{st}$ Century in its economic and supporting policies, without a clear vision of its own 'home-grown' potential for "distinctive excellence" as far as forest sector technological oppormunities are concerned.

SLIDE \#3

Many "Technological 1st's" by the Forest Industry

Product/Process

M.D.F.

O.S.B. \& L.V.L.

C.T.M.P.

Oxygen Bleaching
Application

Furniture Manufacturing

Structural Uses

Potentially, wide range of papers and paperboards

Partial Displacement of $\mathrm{ClO} 2$ Bleaching

As well as numerous other potentially very valuable products and processes "Whose Time Has Yet To Come" 


\section{...But Many are "Driven" or Made Possible by}

\section{"Outside" Forces}

\section{Major Impacts}

\section{Product or Process:}

- Mill Automation

- Increase Use of Short-fibres in Papermaking

- New Grades of Paper

- Recycled Fibre Use

- Energy Efficient Processes

\section{Ripple Effects}

\section{Product or Process:}

- Treated Lumber

- Trusses

- New Resins in Panelboards

\section{Driving Force:}

- 'Robotics' \& automation technology sectors

- Advances in high speed papermaking equipment

- Demand for colour printing (printing \& advertising sectors)

- Socio-economic trends and environmental legislation

- Energy prices and environmental trends

\section{Driving Force:}

- Chemicals industry

- Metal plate manufacturers

- Chemicals industry

Slides \#3 and \#4 identify just a few of the technological achievements of the forest sector globally. They illustrate the point that many of these really have been made possible primarily because of outside forces.

Within the forest sector, some nations lead in technological applications and others follow. Generally speaking, however, the sector as a whole tends to be an 'imitator' rather than an 'innovator'. To some extent this is inevitable, because of the sheer economy of scale necessary to apply major thrusts of technology, such as automation. The supporting technologies which have developed alongside NASA and other space programs, for example, have had a major ripple effect across a multitude of sectors, not only forest products. 


\section{Many "Techno-Marketing Initiatives" by the Forest Industry}

- Reduction of institutional barriers to a new product or process

e.g. - tariff barriers

- non-tariff barriers

- restrictive building codes

- Facilitating the adoption and application of "Better Mousetraps"

e.g. - improved understanding and analyses

- reduction of pre-development costs

- minimization of start-up risks and costs

- codes and standards

- funding of supporting facilities

Even if the global forest sector cannot, in all instances, be credited with initiating technological changes, it certainly has not resisted them. There are few primary resource based sectors in the world economy which are affected as much by the almost daily process and product technology changes which are occurring. Moreover, forest sector companies, particularly most of those in Canada, have been supportive of techno-marketing initiatives (Slide \#5). These refer to Canada's support of GATT tariff reductions, the Canadian forest sector's support of the Canada-US Free Trade Agreements and related efforts to "level the playing field", as well as increasing the quality of products and services at declining real cost to the consumer.

As the process of change continues, technologists in the forest sector face a multitude of potential constraints (Slide \#6). Vice-Presidents of Technology within Canada's forest companies often have a particularly difficult time. To be the pioneer of $R \& D$ costs money. The pay-offs are uncertain and advances achieved in technological leadership rarely benefit any single company or group for very long. Technological obsolescence sets in very quickly. The marketplace is volatile and mitigates against risk-taking. In addition, even though environmental "resistance" to some greenfield projects ought to be perceived as a net benefit to the sector over the longer term, the short term impacts are to increase the costs of development construction and operation, or to stall development altogether. These are tough, but challenging times for technologists! 
SLIDE \#6

..Some Constraints Facing Technologists in the 1990s

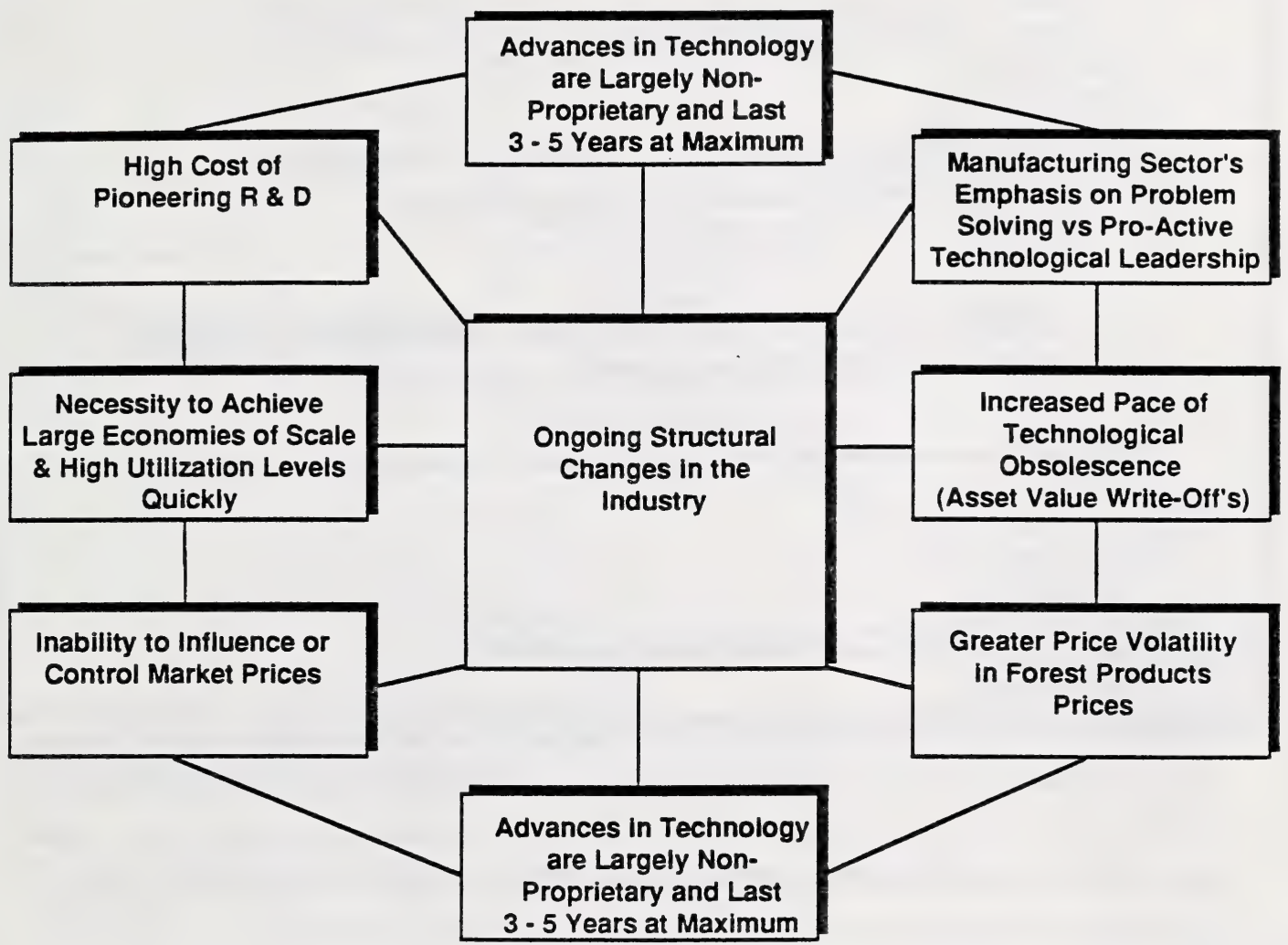

Perhaps it is stating the obvious, but it is essential for the long term viability of Canada's forest sector to be technologicallly active and innovative. It can be successful in this endeavour, however, only if it manages this process well and so long as the process itself is based on wellthought out plans and policies to achieve specific objectives (Slide \#7). 


\section{Don't Stop Inventing and Innovating}

\section{But Do.......}

1. Think about how best to manage, and direct the process of technological change

2. Apply resources behind a well thought out business plan to help achieve specific objectives.

3. Supporting "Cultures", Institutions and Facilities:

Healthy technological development in a sector such as forest products cannot exist in isolation from a supporting culture and reinforcing institutions and facilities. You don't have to look far beyond current editions of 'Business Week' to find the considerable concern within North America's business community about the lack of this type of support for its industrial base.

There appears to be an increasing recognition in Canada of this relationship, and the need to improve on past performance. In the forest sector worldwide, it seems clear that the best technological performances are attained where these supporting cultures and reinforcing instrutions and facilities are conciously planned and encouraged. 


\section{Technological Leadership: Supporting "Cultures", Institutions and Facilities}

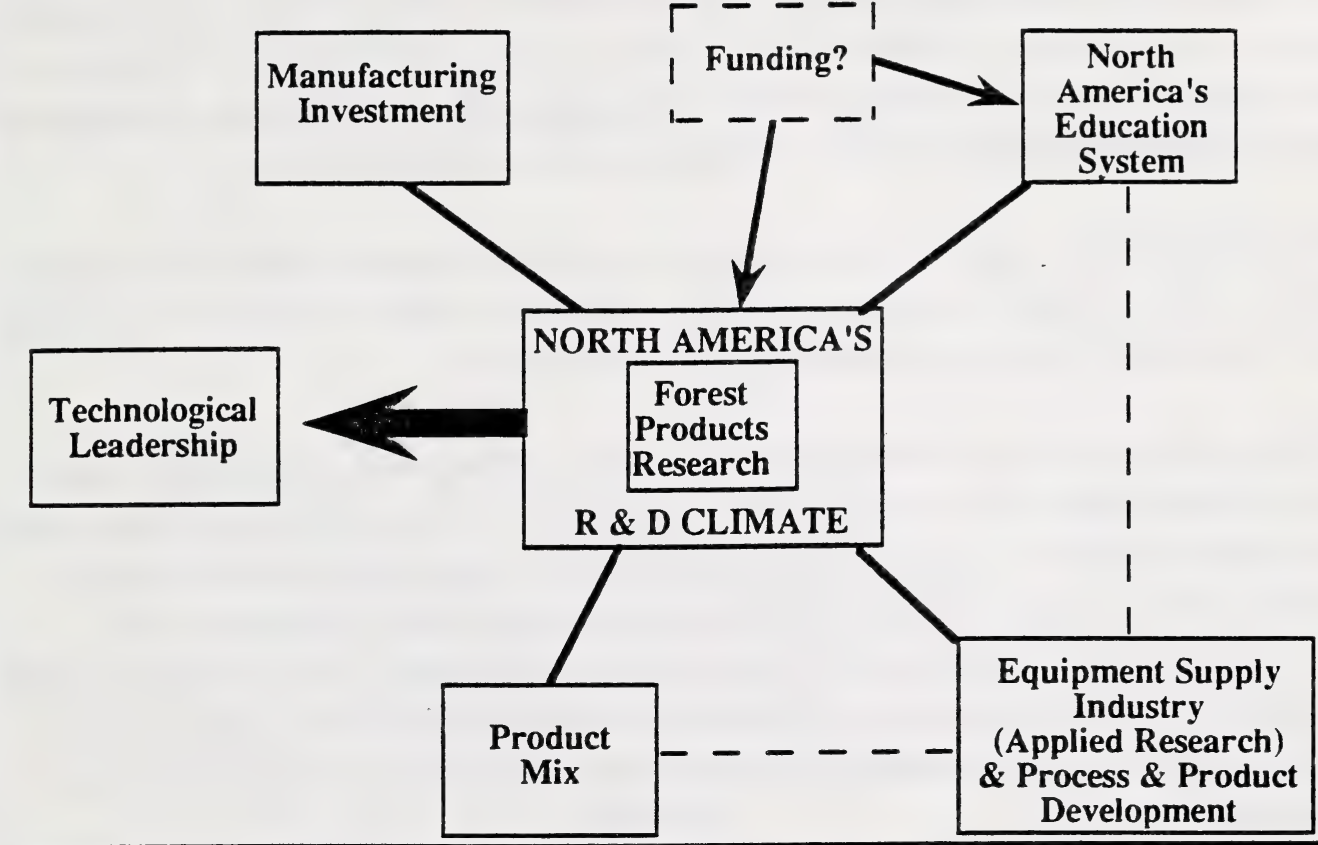

\section{The Innovator and the Imitator:}

Economic history shows us that successful nations have at times in their development been both imitators of existing technology and initiators. There is some evidence of a 'life-cycle' in this regard, as far as individual sectors can benefit from and contribute to overall economic growth.

Imitation can be a sensible policy, but ultimately it is a temporary 'stop-gap' solution. Various nations in recent history have adopted existing technology from others "at 10 cents on the dollar" and have improved upon it, only to emerge later as the technological leaders.

In a sector as basic to Canada as is forest products, it is a source of real concern that Canada has lost the technological leadership it once undoubtedly had in many areas forest products eequipment supply, education and many areas of consulting. 


\section{Alberta's Technoloxical Performance}

I believe that Alberta has done an outstanding job of developing a supportive culture for technological innovation in forest products. The Government of Alberta, and various provincial and federal institutions, as well as many of the forest products companies here, have been able to attract and construct in Alberta some of the best, most technologically advanced and environmentally compatible projects available during the 1980's and 1990's in the forest products sector. This has been achieved against siff global comperition for these projects.

These projects were sought after careful analyses of Alberta's resource position in Canada and globally. These analyses also looked at market opportunities, future comparative cost prospects and the potential for long term sustainable, balanced development.

What has been achieved by Alberta in the last few years is nothing short of remarkable. I believe that the history books will show that it will have been one of the three notable eras of rapid regional development of the forest sector in Canada (Slide \#9). The others were the newsprint and pulp expansion boom between 1910 and 1930 in Quebec and eastern Canada, stimulated by the reduction and eventual elimination of US tariffs on Canadian newsprint. The second was the 1960 to mid-1970's expansion boom in the BC Interior in market pulp and softwood lumber. The stimulus for this was rapid demand growth notably in the US for market pulp and lumber (new housing).

SLIDE \#9

\section{Canada: 3 Notable Eras of Rapid Regional-Development}

\section{Stimulus}

\#1 1908 Reduction of US Tariffs on Canadian Newsprint

+ 1913 Elimination of US Tariffs on Canadian Newsprint

\#2 Post WW 2 Demand Boost for Market Pulp and New Housing

\#3 Facilitating Factors, but Mainly Government of Alberta Development Initiatives
Effect

$1910-1930$

Newsprint \& Pulp

Expansion Boom in

Quebec\&E. Canada

$1960-1970$

B.C. Interior

Expansion Boom

Mid 1980's

Expansion Boom in Aspen/Sottwood Use in Alberta 
Based, I believe, initially on the need to diversify its economy, but with the recognition of the opportunities presented by export markets in the Pacific Rim and the Canada-US Free Trade Agreement, Alberta perceived and achieved its own 'home-grown' development boom starting in the mid-1980's. We wish it every success as these forward-thinking policies bear fruit in the years to come.

Mr. Chairman, Ladies and Gentlemen, thank you. 

INNOVATIONS SOLVING HARVESTING, TRANSPORTATION, AND SILVICULTURAL PROBLEMS

BY

ALEX W.J. SINCLAIR

MANAGER, WESTERN DIVISION

FOREST ENGINEERING RESEARCH INSTITUTE OF CANADA

\section{ABSTRACT}

This paper briefly describes the operation of the Forest Engineering Research Institute of Canada (FERIC) and how FERIC's research program is developed to address industry's problems. Several problems are given, in a case study approach, and then FERIC's approach to solving each problem is described. Joint-venturing with manufacturers and other agencies is highlighted both as a means to develop solutions and to encourage Canadian manufacture of equipment. Finally, some examples are given of future forest-industry problems and FERIC's initiatives to solve these problems. 


\section{INNOVATIONS FOR SOLVING HARVESTING, TRANSPORTATION, AND SILVICULTURAL PROBLEMS}

The Forest Engineering Research Institute of Canada (FERIC) was founded in 1975. It is a non-profit, private research institute jointly funded by the forest industry and the provincial and federal forestry ministries. FERIC's mandate is to conduct research and development aimed at improving the efficiency of operations relating to the harvesting and transportation of wood and the growing of trees.

Currently, we have about 85 people on staff, we have a Head Office and Eastern Division office located in Pointe Claire and a Western Division office located in Vancouver, and we have an annual budget of about $\$ 7$ million. Our research program is developed by our staff with the advice of research advisory committees consisting of representatives from each of our member companies. These research advisory committees ensure that our research program addresses the major problems facing our sector of the forest-products industry. Recently these committees, FERIC research staff, and our Board of Directors developed and approved a new Strategic Plan for FERIC research that addresses future industry problems.

Today, I wish to highlight some of the innovations that FERIC has introduced or is developing to solve industry problems.

1. Problem: Small-Diameter, Low-Quality Timber Stands.

In many parts of Canada, small-diameter, low-quality timber stands are not being harvested because the cost is greater than the value. These stands are stagnating and not contributing any growth to our inventory of timber. These stands could be a source of fibre for the pulp mills if an economical way could be found to harvest them. 
Solution:

Weyerhaeuser's Research Centre in the state of Washington had developed a double-drum, horizontal flail for multiple-stem delimbing and debarking of small-diameter trees in the Southeastern part of the U.S. The technology appeared to be a solution to Canada's problems if the same production rates and bark contents could be achieved when processing frozen trees.

A month-long field trial was set up at Weldwood's operations in Hinton, Alberta with funding from Forestry Canada and the Alberta Ministry of Forestry, Lands and Wildlife. The trial proved that the technology can be applied successfully to Canadian species of trees and under Canadian operating conditions. The results of this test have been published and are available from Forestry Canada. Based on these trials and the concept, an Alberta company has already purchased a double-drum, horizontal flail for its harvesting operations.

2. Problem: Incorrect Trouble-Shooting of Hydraulic Problems.

When a machine breaks down in the field, repair and maintenance and downtime costs are high. Most of the breakdowns are caused by the hydraulic systems. Though the hydraulic systems on current logging machines are efficient, they are also quite complex and mechanics have difficulty diagnosing the cause of the problems. In most cases, mechanics will replace a succession of parts until the problem is finally resolved. This causes higher repair and parts costs and higher downtime costs than necessary. 
Solution:

AAL Autometrics of Victoria had developed a hand-held device that used expert-system or artificial-intelligence technology to specify site-preparation treatments. FERIC reasoned that the same could be done for trouble-shooting hydraulic problems in the field. We established a joint-venture project with AAL Autometrics, MacMillan Bloedel Limited, and Finning Tractor Lid. Basically, we are putting the Caterpillar service manual "into" the band-held device. The unit is just being tested now and promises to be a real aid to fieid mechanics. They will be able to refer to the best hydraulic trouble-shooting advice available by using a machine about the size of a video cassette.

3. Problem: Productivity Limit of Feller-Bunchers.

With the introduction of circular saws and rim saws, feller-bunchers achieved a new production plateau. Although the machines have very high productive capability, operator fatigue sets the productivity capacity. Also, experienced operators are difficult to find and it takes considerable time to train a new operator to become proficient. When an operator quits, production is seriously hampered.

Solution:

Robotics Systems International had developed robot arms for underwater exploration and for repairing underwater drilling equipment. It was interested in applying this technology to other industries. It teamed with the University of British Columbia's Electrical Engineering Department and MacMillan Bloedel Research to apply resolved-motion control to an excavator. The prototype testing was 
successful and showed that an excavator could be controlled with a single lever. Also, it was very easy to train operators. FERIC felt this technology could be applied to a feller-buncher where the duty cycle is more demanding and operator skill requirements are greater. Funding was received from the B.C. Advanced Systems Institute and work is underway to put resolved-motion control on a fellerbuncher. The first machine should be ready for testing in the Spring of 1990 . We are hoping for a productivity and training breakthrough.

4. Problem: Equipment Rollover Injuries and Deaths.

By law, mobile-equipment operators are required to wear seatbelts. However, many of them do not; the worst offenders are skidder operators. The skidder operator, particularly when using chokers, repeatedly gets in and out of his cab and finds that putting on and taking off his seatbelt reduces his productivity. As a result, every year several operators are killed, and many more injured.

Solution:

One of our researchers noticed that a children's amusement ride at Expo 86 used an arm assembly to keep the child in the chair as the ride went through its gyrations. He reasoned that the same concept could be used to keep a machine operator in his seat. If the arm could be made to be simple, quick, and reliable, then it would be used by the operators. We worked with the operators and logging supervisors to design the seat and arm. FERIC received research funding from the B.C. Science Council, and joint-ventured with ICL Engineering who will manufacture the seat. Curiously, none of the manufacturers of skidders were interested in joint-venturing. 
We are currently testing the first prototype and it has been well accepted and used by the operators. It will probably be ready for the market in late 1990 and made by a Canadian manufacturer.

5. Problem: Overstocked Stands of Lodgepole Pine.

In many areas of B.C. and Alberta, lodgepole pine will restock itself aaturally. However, the stocking levels are much too high and, if left unattended, the pine will stagnate. Deasities can be as high as 80000 stems per hectare where 3000 to 6000 stems per hectare are desirable. The forest companies are responsible for thinning these stands to the 6000 stem-per-hectare level. The costs of manual-thinning methods would be prohibitive.

Solution:

One method of thianing that holds promise is to remove alternate, two-metre-wide strips mechanically. This automatically cuts the stand density by balf and also allows access strips for workers to manually thin out the remaining trees with spacing saws. FERIC spent three years examining treatment techniques, the terrain, slash levels, various stand densities and ages, and existing thinning machines. A survey was conducted to estimate the potential market for machinery. FERIC felt shortcomings in existing carriers and cutting attachments could be overcome and, as a result, acceptable thinning costs could be achieved. Forestry Canada supplied financial assistance and we joint-ventured with Weldco-Beales and John Deere to build the machine. It is undergoing field tests at present, and all results to date are positive. It is hoped, in 1990, an attachment and machine will be available to thin overstocked lodgepole pine successfully. 
This has been a highlight of developments that FERIC has made, or is making, to solve industry problems. It should be mentioned that each of these developments has been preceded by hours of painstaking time studies, evaluations, and brain-storming sessions, which are a necessary part of innovation. It should also be mentioned that, because this is a Western equipment show, I have emphasized developments in Western Canada. Our Eastern Division is also very active and successful in solving industry's problems. Because of innovative work done in our Eastern Division, FERIC holds the patents on circular-saw felling heads which have revolutionized mechanical falling in North America. Eastern Division was instrumental in introducing wide tires which permit all-season logging in wet areas, it has promoted the roll-stroke concept for delimbing trees, and it has also developed portable bridges for forestry access. Currently the Eastern Division is developing a strip-thinning machine suited to Eastern conditions, and it has a list of development projects just as impressive as that of the Western Division. Because FERIC is a national research institute, the developments in both Divisions are transferred and applied throughout Canada. Recently, for example, Western loggers on FERIC-organized tours spent time in Northern Quebec and the Maritimes examining how small trees are harvested in these areas. The technology flows back and forth between the regions as a direct result of FERIC's national scope.

In the future, FERIC will continue to assist in solving industry problems identified by its own researchers and by its member companies.

In Alberta, FERIC has just started evaluating the problems of mixedwood harvesting. We have received support from our member companies, Forestry Canada, and Alberta Forestry, Lands and Wildlife, and this year have conducted a series of in-depth field tests. We will continue our efforts in mixedwood harvesting until we find a method that minimizes harvesting and silvicultural costs while protecting the understorey trees. 
Our forest resource is limited. We must find ways to both maximize fibre and value recovery. Although these two objectives often conflict with each other, we believe there is a middle course that will allow both objectives to be achieved. We are currentiy establishing projects in this area.

Environmental concerns about the forest industry are daily items in the newspaper. Harvesting and silviculture have potential problems related to wildlife habitat, soil disturbance, fisheries values, recreation, and water suppiy. FERIC has an active program in this area and it will continute. The main problem in addressing environmental issues is the lack of data and clear cause/effect relationships. Fortunately, government agencies in Alberta and B.C. recognize this and work cooperatively with FERIC and our member companies in our environmental studies. Through this process, strong technical input is given before policy and regulations are developed and implemented.

In conclusion, it is hoped this highlight of FERIC developments has given you more insight into how FERIC has addressed, is addressing, and will address forest-industry problems. Fortunately, we have a research advisory committee network that assures that we address real problems. Also, we have a Strategic Plan that has identified future problems, some of which have been discussed. This longer-term plan will keep our annual research programs focused on targets. Finally, our member companies and the provincial and federal forest services give us strong support. This is a very challenging period in our industry, and FERIC is happy to be part of addressing the challenge. 
SAWMILL: Increased Recovery, Reduced Manning

BY

GREGORY J. SCHWAB, P. ENG.

PROJECT ENGINEER

WOODPRO ENGINEERING LTD.

Throughout the history of sawmiling, technology has been introduced to address typically one of two variables. The recovery of lumber and value from the timber, or to increase the production to labour ratio.

For future technology to be viable in the sawmiling industry $1 t$ w1ll address one, or both of these variables. 
Sarm1118: Increased recovery, reduced manning.

\begin{abstract}
Throughout this presentation I vill be referring to two espects: "increased recovery", and "reduced manming." For sawilis 1rcreased recovery is increesed set lumber production, or increased net product value, both measure againgt urit volume of tree stem processed. Reduced manning means an increased ratio os productivity measured against the number of man hours reguised to produce it. Increasing the productivity can be accomplished using two distinet means: 1) reduction of manpower for a fixed production rate, or 2l increaeing the total production while maintalning the same labour 1nput, that 18 1ncreased worker product1vity.
\end{abstract}

Is lumber manufacturing, or sawilling, techrologieal changes have been introduced primerily for the profit 1ncrease reelized by either lncreased recovery or increased worker produetivity. The two variables, the eost of labour, and the cost of raw materlals, typically are the most basic economic realities is operating a savmil1. Thus future technological changes will be viable If they address one or both of these variables. The history of lumber manufacturing demonstrates this prisciple.

The primary method of lumber manufacturing after the ison saw was invented was pit saving or whip gawing. The log was placed over a pit or on an elevated platform. The pitsawyers required both strength and skill to guide the sax through the log. A pair of sawyers could produce around 200 board feet $1 \mathrm{~s}$ a 10 hour vorking day. This method of lumber manufacturing was used is Roman times 
and was predominant until the $1800^{\prime}$ s. At its peak there were large lumber companies in the United States employing as many as two hundred pit sawyers.

The first sawmilis used wind and water to drive the saw in place of the two men. The higher power output of the waterwheel or windmill was used to drive a single saw or a gang of saws in a wooden frame. Simple carriages and devices were developed to 1nch the log along through the saw as it went up and down. One of these early sawills could produce over two thousand board feet per day with a ten men crex. During the Industrial Revolution the early sawmilis were driven by steam, but the saw was still pulled up and down by machine rather than by hand.

The circular saw was developed in the early 1800's. The radical technology of the circular saw allowed a continuous cutting action. The continuous rotation was in place of the up and down action of the sawrame. The circular saw probably had the single highest impact of any technology on sawilling. The incressed production wee incredible. An early ten man steam powered clrcular sawmill could produce 20,000 board feet in a 10 hour day. This was up to ten times better labour productivity than a frame-savill or as much lumber as 100 pit sawyers.

The earliest technical development to increase recovery, that I am aware of, was for very deep saw cuts. In the early 1860's deep saw cuts were made with up and down sash saws which were good on recovery, but poor on production, or with faster very large diameter circular 
saws. The thick kerf, necessary to keep the large diameter saws cuttisg true, tursed a lot of wood into savdust. There were two separate technical developments to ircrease recovery on deep euts.

Ore of these was the double circular read say arrangement. In the early $1870^{\circ} \mathrm{s}$ this arrangement of two saws, one above the other became standard. The two saws together had the eut depth requised but vith a thisser kerf and higher lumber secovery.

The other development 18 the $1870^{\prime} \mathrm{g}$ was the bandsax. The bendsaw was invented in the early 1800's, but 1 mplementation was slowed by the problem of procucing a continuous welded bard. By the 1870's the contisuous band problem bad been solved. The bandsaw was being used for 1 ts accurate this keff on deep cuts. Tensioned saws, florting strais adjustment, twis and even triple bandmills were being used in the $1880^{\circ} \mathrm{s}$.

From the $1880^{\prime} \mathrm{s}$ until after WW II there was very little technology development in sarmilis. Some of the large steam powered sawmils built in the 1880 's remained intact until the 1950's. Prior to WW II labour ras cheap and trees vere in plentiful supply close to the sawmils resulting in little concers for productivity and recovery.

In the 1950's and 1960's savmil labour costs rose rapidly. New technology was introduced to offset this rapidly rising cost of labour. One approach was to reduce the labour wile maintajaing production. Simple devices such as limit switches, tube type photo cells, 
and magnetic memory replaced many labourers. Edger sorters, tray sorters, and recently large bin sorters, with mechanical stackers greatly reduced green chain labour. Jobs such as the setterman, or carriage rider, were replaced with push button set works. Other common labour intensive jobs dissapeared.

The other method employed to increase production compared to the labour input has been to increase the Feed speeds and the saw rpm. Faster cutting speeds meant the machinery manufacturers had to develop better ways to Ëed lumber through machines, 1 mprove saw accuracy, and Ennerally manufacture equipment to closer tolerances. For saws to operate et higher rpm's, saw tension had to ¿E more accurate. Devices such as Armstrong's "Circular Ea: Stretcher Roll" were developed to accurately tension the saws from the spline out to the tooth gullet.

In the 1960 's the cutting machines produced more -.jmber but the accuracy of cut was still poor. Lumber menufactured to a tolerance of plus or minus one eighth $==$ an inch was good, many mills were worse than that. rarget slzes allowed for errors and the planermill $\equiv$ moved the excess.

Present machine manufacturers are maintaining the -risust for higher cutting speeds. The emphasis now is a-so to reduce saw kerf and improve sawing accuracy. These goals are higher recovery through reduced kerf less, smaller manufacturing target sizes, while malntainIng high production rates. Their efforts are being =ovused on factors such as kerf and blade thickness but 
also blade diameter, saw spline diameter, tooth composition, difection of saw rotation, saw guiding systems and thermal effects on saw tension. Bandmill efforts include: very high strain, automatic band tracking, strain damping, hydraulic and electronic technology and others. Present machine manufacturing goals ere thin kerf sawing variation of 2 to 3 thousandths of an inch for fixed circular saws: 5 to 6 thousandths for guided shiftirg saws; and 0 to 2 thousandths of an inch cut variation for band ตะพร.

Computers, scanners, and programmable logie controliers (PLC) have 1stroduced a different aspect into the 1ndustry. The computer can collect, store, and aralyse more 1nformation, faster and more accurately than a bumar being can asd a computer can operate more than one machire. The operator is no loner required to make decisions, but be becomes a facilitator who watches the computer and machine rur.

The 1rtroduction of "canter l1ne" technology has been possible vith these "high tech" developments of accurate setworks, scanners, PLC's, computers, and optimizer programs. Arrangements where a canter feeds difectly into a saw section to remove side boards and then gang saws, are one machine center replacing two or three machine centers. The direct benefit of these is increased productivity. One operator obtains the production previously requiring several operators and machine tailers. An example would be a scragg followed with a gang and board edger, eech typleally has its own operatar and tajler. All this is replaced with a chlpping canter, shiftlog saw, vertical arbor edger and only one operator. 
The "high tech" electronics controls the cutting process not humans. The scanner provides the data, the computer does the "thinking" and the accurate setworks enables the machine to automaticeliy perform predictable planned tasks. In comparison to a modern high tech computer controlled system, the older systems production was unpredictable as $1 t$ depended on characteristics of the log being cut and the accuracy of setworks, if any, thus human input was required at various stages to control the process.

The development of digital ball screw setworks, tempesonic cylinders, angular and linear positioners have dramatically increased setwork accuracy, and have also provided the opportunity to vary set target sizes at w11. In 1965 setwork accuracy was typically plus or minus one eighth of an inch or worse. Now electronically controlled setworks can be repeatedly accurate to plus or minus, two thousandths of an inch or better. The $1 \mathrm{~m}$ mediate benefit of this has been increased recovery through more accurate and smaller target sizes. Setworks are essential for a computer controlled cutting process. The computer requires coneletant repeatable accuracy to function properly. Thoee of ue who have worked with computers soon realize the information must be typed in letter for letter accurate or the computer does not respond correctly. The same with setworks, if they are not accurate the computer would be unable to predict or control the process.

The computer when used with a scanner can analyse the rood and produce solutions to a cutting problem many times faster than a human. Scanning technology, first 
used in Scandinavia and further developed in North America has been applied to optimizing programs on trimmers, board edgers, and canters. Scanning methods may be mechanical, istense light, neon lezers, and light emitting diodes. Camera scanners are capable of measurements to 10 thousandths of an 1 sch and some day may approach photographic resolution.

Mult1 saw trimmers ard board edgers are well suited to be equipped with seanser optimizer programs. Is the sawmil a trimmer man usualiy works at about 35 pieces per minute with a trim aceuracy of $75 \%$ to $85 \%$. At hygher production rates his accuracy drops. The trimmer man usually over-trims, when he under-trims the evidence is there to accuse him, but the over-trim evidence is eater by the chipper. A t-immer optimizer can operate at the maximum mechanical capacity of the trimmer with an accuracy of better thas $99 \%$.

Edger optimizers ere one of the most economic "hIgh tech" developments recently introduced into sawmills. A manualiy fed board edger with a good edger man can process approximately 10 to 12 boerds per munute with a correct cutting decision accuracy ranging from $65 \%$ to 86\%. An edger optimizer ean feed at the peak capacity of the perticuler edger with a cut decision accuracy of $98 \%$ or better. A recovery increase approaching $27 \%$ at the edger has been typically reported.

In many edger and trimmer optimizer 1nstallations the production of the entire mill has increased. This is because the old edger and trimsaws were bottle necks. The higher capacities of the optimizers freed the mill to 
produce more lumber.

Cant optimizers sçan the $\mathrm{log}$ prior to it being fed into the primary breakdown. The computer orients the log to obtain the best opening face. It also positions the canter set works. The cant optimizer program takes in to account the log diameter, taper, shape, sweep, crook and length of the log. The computer, in twenty miliiseconds, can analyze all this data, control the log, and setworks, and make a decision superior to judgment of an experienced sawyer. Studies have shown the cant optimizer programs are most effective on logs smaller than 20 inchee in diameter. Increases in recovery range from $5 \%$ to $25 \%$ depending upon log diameter and quality.

Tree stem handling and log handling in a sawmill are the most difficult, but the log merchandizing system offers the most potential for increased recovery. The reason for both the log handling problems and the recovery potential is the material is in its roughest state, and no two trees are the same.

Log handling is difficult because of variations In diameter, ehape, length, eweep, butt flare, etc. Comparing log handling to a lumber handling system where fixed sizes and lengths are manufactured illustrates the problems. European technology has alded in log handing problems. Butt reducers were first used on a large scale in Europe, whereas the Canadian practice was to slash the flare butt off. Another example of European technology has been a simple solution to the log unscrambling and singulating in the step feeder, recently introduced in Canada from Sweden by Woodpro Engineering. Other log 
handling technology being imported from Scandinavia is the concept of log sorting. In this respect the scandisavians have developed conveyors where the log is cradled and then dropped to one side or the other. Log sorting 1ncreeses production by providing long running perlods of the same diameter class being feed to the canter. A 5\% recovery increese and $40 \%$ production inerease is reported in Seandinavian milis with log sort1.8.

The irfirite variation of trees in the log yard also present the possiblity to maximize lumber value recovery. A rell krown American consultant is guoted as sayisg, "The farther you go from the trimmer towards the log yard, the more recovery potertial there is, both in value and in volume." I The urbucked tree has many variables thet wil determine the final value af the end products. Length is the only varlable that cas be controlied in the sawmil. Once the log $1 \mathrm{~s}$ bucked-that one controliable variable 18 fixed. Computer controlled log bueking can take 1nto account many variables such as: diameter, crook, sweep, cutting machines capabilities, the potential lumber in a log, as well as price and merket conditions of lumber sizes and lengths. A number of possible solutions can be calculated by the computer before the log 18 bucked. It is cleer that most people could not visulize the complexity of the problem, nor attempt to optimize the solutions. Corsultants suggest a 10\% recovery increase is achievable using computerized. Don MeVey, Manager of Lakeland Milis Ltd. In Prince George has often sald, "Accuracy, Quality, Quantity, and It all starts in the bush." 2. Don indicates the focus on optimizing recovery and value is beyond the log yard is 
the bush. There appears to be great potential at maximizing value recovery using computerized log merchandizing.

A recent high tech development in planermilis is the Automatic Grade Mark Reader. The AGMR is directly replacing the trimmer man in planermilis. Both perform the same taek of reading the graderman's markings and entering them into the contral system. The trimmer man's job of reading the grade marks are prone to error. Forinteck Canada estimates $3 \%$ to $5 \%$ error for most trimmer men. The AGMR is reported to be in excess of $991 / 2 \%$ accurate. Typical results reported are increased sort, and grade accuracy, trim recovery, and production speed. The trimmer man is eliminated, but he is used as an additional grader to keep up with the increased production.

The AGMR in the planermill is a partial transition from visual grading to fully electronic grading. Electronic appearance grading is now being used in Europe where appearance $1 \mathrm{~s}$ important. Th1s type of appearance grading used in conjunction with optimized trimming and machine strese rating may eoon replace vieual grading. There are at leaet three different approaches being developed to do this.

The effort on value recovery is not only in the lumber products but also in the residual. Chips have become a major source of income for sawmilis. Chipping heads on canters and edgers have turned the kerf loss savdust into chips. Newer model chippers produce better quality chips with less fines and overs. The use of 
optimizing trimsaws in the sawmill has reduced chip production in planermilis. A counter flow screening process has recently been developed that increases the sereened chip quality while increasing the total amount of chips being covered from the screening process.

Hog fuel is presently an ineinerated waste item. As the warld price of energy increases and as pressure from envirommentaligts 1ncrease, the energy is sawmil waste wil be recovered in the form of electrieity, systhetie suel, pelletised stoker fuel, and others.

I have frequently mentloned and given examples of technology being developed 1n Europe. A significant factor $1 \Omega$ European techrology difference 18 the cost of logs. Unlike North Amerlea the Europeen old growth virgin forests have been gore for a long time. Theis cultuveted forests are not vast. Their logs are expensive. The Europeans heve been driven by economic necessity to 1nvest risk capital on the developement of technology to increase recovery, whlle maintaining worker productivity. The entire tree is utilized for lumber, pulp, fuel, ete. Canadians have extensively borrowed European technology is our globel economy.

Now Canadian interest in recovery is rapidiy $1 \Omega-$ creasing. Large diameter trees are disappeering forcing us to use smalier tree sizes. Easy access forests are now gone resulting in higher hervesting and trucking costs to the mills. Stumpage is continualiy increasing. Some people have sald we are unessy to try new techrology 
and are afraid to leave our comfort zone, but Canadians driven by economic necessity will continue to build on existing world technology.

Just as techonolgy has been introduced throughout the history of sawmiliing to address the two variables of increased recovery and increased labour productivity, Canadians will invest more in research and development, finding new technology to further increase recovery of both lumber volume and product value, and further increase worker productivity all while we maintain sawmiling as an economically viable industry. 


\section{END﹎Nㅡㅁ프토}

1. Reggie Landers, as quoted in Forest_Indugetrifies magazine, Sept., 1987, p. 32.

2. Dos MeVey, A statement typical of Don's theory made dusing private converstation with the author in August 1989.

\section{BIELIIGㅡ로소보.}

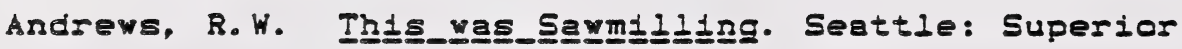
Pulishing Co., 1957

Borrac, Thomas, "Factors Influencing The Sawdrg Accuracy of Guided Savs" Paper by Denis Sawmill Equipment, Burraby, 1989

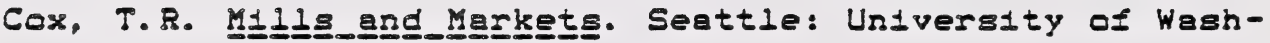
inton Press, 1974

Foriatek, Vancouver Staff, "Automatile Grade Readers Reduce Human Errors Substantially in BC Trials"

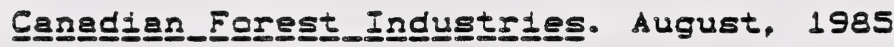

\footnotetext{
Griffin, G. Multiple Benefits Gained From Optimizing Package" and "Assessing Optimization Opportunities and Trends", Forest_Induut프롱 Sept., 1987
}

MacDonald, Paul. "Stellite To Become Standard On Mill

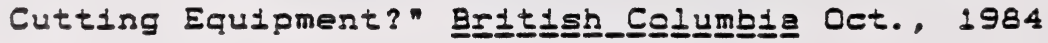


Porter, A.W. "Optimizing Log Bucking" Logging__end_San=

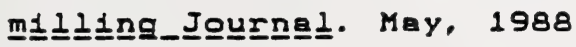

Schugg, Deborra, "Cant and Headrig Optimizers" Legging

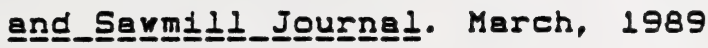

Soresnon, Jean. "At Grande Prairle Canfor Takes Fast Track To High Teck" Logging_and_Sarmi11]_Journal . Feb., 1989

Westergaard, Bob. "Optimizers Bump Production, Recovery

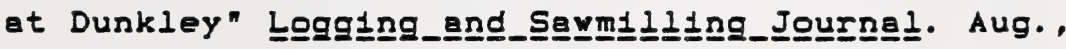
1985

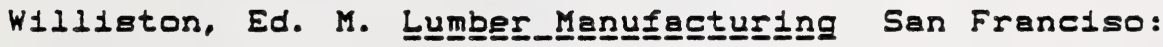
Miller Freeman, 1988

Whitrorth, Ron. "New Bandmill Technology" paper by Denis Savmill Equipment, Burnaby, 1979.

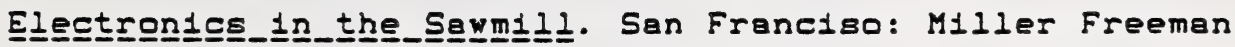
Publications, Inc., 1979

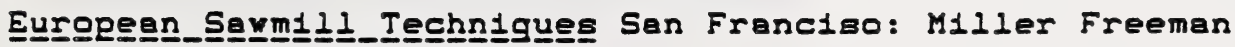
Publications Inc., 1975 


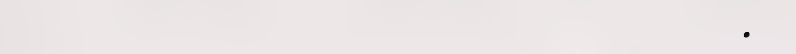


PLYWOOD IN THE NINETIES

BY

GEORGE SLEET

DIRECTOR, QUALITY SERVICES DIVISION

AMERICAN PLYWOOD ASSOCIATION

\section{ABSTRACT}

The decade of the nineties will see traditional plywood markets further threatened by plastic, concrete, steel, gypsum, and other substitute materials. To meet this competition, plywood producers must improve their existing products and make those products even more efficiently. A wide range of new equipment and process changes is available, and the manager is challenged to select those which best match his mill situation. 
PLYWOOD IN THE NINETIES

I'n George Sleet from American Plywood Association (APA). My job is Director of APA's Qualicy Services Division. My division monitors product quality in 124 APA member mills. We have 46 people on the road checking panels in the wills, and 27 people in seven laboratories around the country testing panels from those same mills. We are establishing an eighth laboratory in Duluth, Minnesota, which will be in operation in December.

So, I'Il involved in product quality for our members and product quality is vitally important to APA's primary mandate, product promotion. Simply stated, "so quality today, no market tomorrow."

But there's more to this plywood business than quality and promotion: you can't make quality panels in a mill that is closed! So, we at APA have tried to help our plywood mills remain competitive. We look for ways to improve mill efficiency; to use the labor, machinery, and especially the wood resources to their best advantage. We look for ways to improve the product to make it more competitive in the market. And we look for new products to fill existing or newly created markets.

The theme today is "Technology for the ' $90 \mathrm{~s}$ ", and the '90s are oniy 65 days away! With these points in mind, let's look at what progressive plywood mills are doing now, and what they need to do for the next few years to meet the threat of plastic, concrete, steel, gypsum, and all the other people that would love to have your markets. 
GREEN END

Many mills, notably Canadian mills, have spent a lot of money recently on $X-Y$ chargers, powered backrolls and nosebars, and improved carriage drives. Peels are better and recoveries are up, but there are still a few things that need to be done in the green end.

Certainly there are mills that could benefit from the centerless lathe technology. It's a simple fact that veneer is worth more than low value studs or chips. An APA mill in Texas is using that lathe and it's doing very well. It seems made to order for the inland British Columbia and Alberta mills. I know it has been tried and removed from one plant, but that was a Coastal mill. But the success of the lathe in Texas suggests that under the right conditions, it could add substantially to mill profitability.

Rotary clippers have removed one of the big green end bottlenecks, but more needs to be done. We need continuous detection of peel thickness and peel quality. One mechanical and one laser-based system are on the market, and 13 of the laser systems have been sold. Presently the thickness information is being supplied to the lathe operator on a video screen, but the next important step is direct closed-loop feedback to the lathe setworks. At a ribbon speed of 400 feet per minute, the laser measures thickness every $.030 "$ of travel, so roughness detection seems possible.

The big need at the clipper is a way to see closed defects. Our scanners now can see splits, knotholes, and open wane, but they can't see roughness, knots, pitch pockets, white speck, or closed wane areas. We sort for those visually after the sheet is clipped, 
when it's too late to optimize mill return. Plywood Research Foundation, a part of APA, is supporting work at two locations on closed defect detection, and I'm sure there is work under way in Canada too. It wor't be long before that's available.

Veneer incising has been examined as a way to speed up the drying process and prevent blows with high-moisture panels. Some of our southern pine mills are iaterested because incised veneer lays much flatter. This is important for some hardwoods, and for pine containing juvenile wood. Some southern mills would like to use foam glue, but wavy sheets are a problem in a core crowder. There are two comercially available incisors and both are being manufactured in Canada, so you're on top of that one.

\section{DRYERS}

Ioday's dryers are terrible. Even if they are properly sealed up and mantained, and very few are, they both physically and thermally damage the veneer. They produce both overdried and underdried veneer concinuously, and our present drying methods are, I believe, preventing improvements in adhesives. High humidity drying, steam drying, dehumidification drying with heat pumps are possibilities, but I know of no serious efforts in these areas for veneer.

\section{LAYUP}

The biggest opportunity in the layup area for Canadian mills is in performance standards. APA pioneered the concept of performance standards in 1981, and U.S. plywood mills have used this tool to react to the competition. Our mills are selling 15/32" plywood 
into markets that once demanded $1 / 2 "$, and $19 / 32^{\prime \prime}$ where the standard panel was $5 / 8 "$. When you realize that there is $6 \%$ less wood in a 15/32" panel, you'll see the advantage to the mill. Beyond the thickness, there are opportunities in species utilization and panel layups not permitted in the prescriptive "cookbook" PS-1 and CSA 0151.

You have a performance standard in place, CSA 0325. Are there advantages to producers of Canadian softwood plywood in that standard? I don't know, but you should look!

Several U.S. and Canadian producers are looking at a proposal that involves a major change in the way plywood is made. The proposer calls it Panel 100, and it involves a lot more than a change in layup. The mill would be very highly automated and the major features would be:

- Use 98" saw logs, no score knives.

- Produce only 1/8"x20"x98" veneers.

- No green or dry veneer storage, no redry.

- Sheathing only.

- Four shifts, 28 people including office, log yard.

- 12 workers on production line.

The mill is designed for small logs, 14" and under. It is intended to be the most resource- and labor-efficient plywood mill to date.

Another thing we're likely to see in a plywood mill in the '90s is steam injection pressing. You may recall that a few years ago Weyerhaeuser Company and Siempelkamp, a German press manufacturer, worked together to develop a steam injection press. In that 
system, live steam is injected directly into the surface of the panel during pressing. The objective is to get heat to the center of the panel quickly, perwitting shorter press times. That work was with OSB and particleboard, and there are several installations of that technology operating today. APA, through their affiliate Plywood Research Foundarion, is involved in two studies to see if the idea can be used for plywood.

One study at our Forest Products Lab in Madison showed that press time on 5/8" fir panels could be reduced by $25 \%$. It also showed that the steam does not adversely affect the glue bond, except at high inject1on pressures. We saw compression losses of $10 \%$ and more, but no effort was made in the study to miaimize compression.

In a related effort, one U.S. adhesive company is examining "closed" sream injection pressing. This method differs in that the perimeter of the platens are sealed so that the entire panel, edges included, is exposed to the steam. Laboratory results just released show that temperature rise in the center of $5 / 8$ " fir panels is even more rapid than with "normal" steam injection, and they show that press time reductions up to $50 \%$ may be possible. Verification of results in a full-size press and a plant trial are scheduled for completion by January 1990.

Both these studies seem to indicate that the final moisture content of the panel can be controlled by adjusting steam flow and pressure. Combine that control with a high moisture gluing program, and the final product will be even better suited to the end use. 
LVL

In the area of new products for plywood mills, the biggest promise is Laminated Veneer Lumber (LVL), which is really nothing more than plywood with all the grain running the same direction. The market continues to demand wide dimension lumber, and LVL technology can produce this lumber from very small trees.

Equipment is available today to peel six to eight inch diameter logs into veneer, glue those veneers into billets, and then saw those billets into wide dimension lumber. This laminated veneer lumber is strong, straight and square. It stays that way because the knots, burls and juvenile wood are distributed throughout the board. And in some areas of the country the product can compete today -- at today's prices - with solid-sawn lumber in widths over 10 inches.

Think about what that development alone means for the future of the plywood industry.

\section{SUMMARY}

There are many technology changes, some available now and some under development, that will help plywood mills be more efficient. And as we've seen, there are some that will pave the way for new products. These are all very important to the long-term prosperity of plywood mills, and the challenge to management is the wise selection from all these options.

But in the short term, prosperity will depend on the plywood industry giving the customer what he wants. We haven't always done that, and we're not doing it now. A lot of our product is still 
shipped to the market too dry, and you know the problems that can cause. The small percentage of panels that are shipped with poor glue bond cause problems way out of proportion to their volume. And with the changing resource, do panels made to a prescriptive standard have the strength and stiffuess to perform as they should?

Last week at an industry meeting in Athens, Georgia, Ron Hogan asked these same questions. Mr. Hogan is President of GeorgiaPacific, the world's largest plywood manufacturer. He noted "...our customers have accepted what we produce in enormous quantities, even though it has not always performed to the buyer's satisfaction.

But, will they continue to buy that less than perfect product in the years to come, in those same quantities so we can continue to make a profit? I don't thiak so...."

And I don't think so either. U.S. mills and Canadian mills can fix today's problems with a litrle concerted effort, and be in great position for a very promising future. Canadian mills have one major advantage, and that is Forintek. I admire the way Forintek gets ideas developed and into the plants. 


\section{COMPOSITES}

BY

\section{THOMAS M. MALONEY}

\section{DIRECTOR}

\section{WOOD MATERIALS AND ENGINEERING LABORATORY WASHINGTON STATE UNIVERSITY}

\section{ABSTRACT}

The composite wood materials of today are of fairly recent origin. This very large part of the forest products industry has largely been a development of the past $30-40$ years. Because of its newness, there is confusion over the definitions of wood composites. Some definitions of wood composites are offered in this paper, not from a marketing point of view, but from a view towards international understanding.

The 1990s will be a new decade of upgrading the manufacture of composites, improving composite quality, a greater use of composites, the development of new composites, and bringing composites and other wood materials into better and more efficient uses through reliability-based design. Many of the new techniques and products are already on the shelf in research laboratories awaiting commercialization. With a rapidly growing world population demanding wood products, a decreasing quality of the forest resource, and a static availability of easy-to-access forests, the future of composites is not only bright, but a vital need in many countries. 


\section{COMPOSITES}

\section{INTRODUCTION}

There is no worldwide agreement on the definition of composites nor is there an agreement within individual countries. Since we are considering the world siruation, this paper will be concerned with proposing a set of composite definicions first. These definitions are being made so that everyone understands the materials under discussion. They are not meant to conflict with marketing or association nomenclature. After the proposed definitions, a brief overview of raw materials will be followed by a discussion of production improvements. Next, some product improvements and possible new products will be mentioned. A discussion of opportunities, problems to be recognized and solved, and the worldwide need for composites will conciude this paper.

\section{DEEINITIONS}

For those involved in international trade, and for many in the domestic marketing field, the newer composicion and composite products are familiar names, but what they are and how they compete in the building and nonstructural field is not clearly understood. The purpose of this part of the paper is to describe these materials, what markets they now serve, and how they may affect today's markets as well as the markets of the future.

A great deal of confusion on terminology exists not only worldwide, but in the United States as well. The discussion on definitions found below has been mostly taken from a paper that was prepared for the IUFRO Eighteenth World congress (Maloney 1986). New information has been added. 
Currently, the term "composite" is used to describe any wood material glued together, ranging from fiberboard to laminated beams and components. It would seem to be a simple matter to have names that are understood universally for the many wood and lignocellulosic composite materials. The descriptive problem is mostly in the area of composition materials. About thirty years ago, fairly wellagreed-upon terminology (such as fiberboard, hardboard, and particleboard) seemed to be developing to go along with the well-accepted term "plywood." Since then, however--for technical, marketing, personal, or unknown reasons--many more names for these products have come into existence. With this plethora of technical terms has come enormous confusion, not only for the uninformed, but also for those deeply involved in the industry.

This part of the paper will: (1) discuss the family of composite products or materials, (2) review most of the terms used to date, and (3) try to point out where the product names overlap and confusion develops. A suggested general scheme for common nomenclature will be advanced, with full knowledge that many people will choose their own nomenclature no matter what is agreed upon by most of the industry.

\section{HISTORY}

\section{The Family Name}

The first problem encountered is what to call the entire family of products. "Composite" has already been suggested. I have used the term "composition materials" for many years to cover the products made of fibers and various types of particles. This includes molded as well as panel products, thus ruling out the term "composition board." Some people prefer "reconstituted wood" as the proper term, but not all of the aforementioned materials are made of wood. Bagasse and flax are 
popular raw materials, as are other nonwood materials. However, recently Reconstituted Wood Products covering particleboards, waferboard, oriented strand board (OSB), medium densiry fiberboard (MDF), hardboard, and insulation board has officially been designated as the Standard Industrial Classification for these products according to the U.S. Department of Commerce. However, this classificarion is not accepted internationally because of trade disputes. Another popular term is "engineered panels or materials." Many of the products, however, are not engineered; they are simply made from available raw materials to fit a need.

In recent years, the word "composite" has become the popular term for composition materials, but a better use of this word is to describe all glued materials. "Composite," according to the dictionary, means made of "distinct parts." All of the products being discussed are wood- or lignocellulosic-based, but many materiais are made of only one element (e.g., fiberboard). If there is any difference, it is in material geometry (e.g., veneer and flakes), not in the materials themselves. However, the term can be used as suggested, if everyone agrees. The problems come when describing subgroups such as particleboard.

To illustrate the confusion, the American Plywood Association (APA) defines a composite panel as one with veneer faces and a reconstituted wood core (American Plywood Association 1983). One U.S. company includes only particleboard and medium density fiberboard in its composite division. Other panel products are in other divisions.

Until recently, the U.S. Forest Products Laboratory in Madison, Wisconsin included all panel products, including plywood, laminated veneer lumber, and parallel laminared veneer (as well as particleboard, flakeboard, waferboard, oriented strand board, MDF, hardboard, fiberboard, and insulating board), in its research unit on surctural composite products. Plywood processing is now in another division of the Laboratory, but for organizational, not technical, reasons. 
The problem of nomenclature was recognized long ago. A lengthy discussion on "Product Description, Nomenclature and Definitions" was held at the First International Consultation on Insulation Board, Hardboard, and Particleboard sponsored jointly by the Food and Agriculture Organization (FAO) of the United Nations and the Economic Commissions for Europe in 1957 (Food and Agriculture Organization 1958). In this discussion, the definition problem is noted and conflicting descriptions are given. Since that time, the problems in describing products and developing international agreement have become, if anything, worse rather than better.

\section{Development of Names}

Plywood will not be included in this discussion, although it is one of the most important wood-based panel materials. It is made of large sheets of veneer and its description should not be confusing to anyone. Also excluded are other glued products such as parallel laminated veneer lumber and laminated beams, since there is little confusion about their description. The problems of confusion come with the many varieties of fiberboard, particleboard, waferboard, OSB, oriented strand lumber (OSL), molded products, and type of bonding systems.

Fiberboard: Low density fiberboard (insulating type) was invented in 1914, as was mineral- or cement-bonded board (Maloney 1977). Low-density fiberboard is specified in the United States as having a density of 0.16 to $0.50 \mathrm{~g} / \mathrm{cm}^{3}$ (American Hardboard Association 1985). Usually mineral-bonded products are considered separately from other types of panels because mineral-bonded boards have inorganic binders while all others have organic binders. Since mineral-bonded materials have completely different characteristics, such as a very high density (well over $1.0 \mathrm{~g} / \mathrm{cm}^{3}$ ), from other wood-based materials, they will not be considered in this discussion. 
Hardboard was invented in 1924 (Maloney 1977). In the United States, hardboard is specified as having a density of over $0.50 \mathrm{~g} / \mathrm{cm}^{3}$ (USDA 1973). Elsewhere in the world, medium density fiberboard (MDF) is made at densities between 0.40 and $0.80 \mathrm{~g} / \mathrm{cm}^{3}$ and high density fiberboard (hardboard) is made above $0.80 \mathrm{~g} / \mathrm{cm}^{3}$ in density.

The early definitions of fiberboard were associated exclusively with wetprocess boards. With the development of dry-process methods of producing fiberboard, starting in 1947 (Maloney 1977), the previous densiry classifications were still appropriate. MDF (now the common name for dry-process medium density fiberboard developed in the mid-1960s) can be made at much greater thicknesses than the wet-process types. MDF also has different properties and, unlike most of the other fiberboard types, has furniture as its principal market. In the United States, MDF is usually made at densiries between 0.64 and $0.80 \mathrm{~g} / \mathrm{cm}^{3}$, but there is no such specification in the standard (National Plywood Association 1986).

MDF is manufactured using a combination of particleboard and fiberboard technology, and at one time both the American Hardboard Association (AHA) and the National Parricleboard Association (NPA) in the United States claimed MDF as a product covered by their respective associations. The American National Standard for "Medium Density Fiberboard for Interior Use" (National Particleboard Association 1986) was agreed upon later by both associations, thus establishing type MDF as a new product. MDF was manufactured originally as a siding product and currently many companies are working on MDF for exterior uses. However, if MDF is made for exterior use in the furure, a new element of confusion may arise.

Particleboard: Particleboard manufacture started in the 1930s Maloney 1977) and has developed a wide range of descriptions, including chipboard, shavings board, and flakeboard. Some argue that waferboard and oriented strand 
board are also particleboards. Generally, the terminology describing particleboard is agreed upon worldwide fairly well:

[Particleboard is a] generic term for a panel manufactured from lignocellulose materials (usually wood), primarily in the form of discrete pieces or particles, as distinguished from fibers, combined with a synthetic resin or other suitable binder and bonded together under heat and pressure in a hot press by a process in which the entire interparticle bond is created by the added binder, and to which other materiais may have been added during manufacture to improve certain properties. Particleboards are further defined by the method of pressing. When the pressure is applied in the direction perpendicular to the faces, as in a conventional multi-platen hot press, they are defined as flat-platen-pressed; and when the applied pressure is parallel to the faces, they are defined as extruded. (American Society for Testing and Materials 1988)

Furthermore, there is agreement on most of the particle descriptions. According to the source quoted above, there are chips, curls, fibers, flakes, particles, sawdust, shavings, slivers, strands, wafers, and wood wool (excelsior). What is missing is a common particle-type "granule" which is found extensively in U.S. particleboard plants. This small particle is made by using hammermills or attrition mills and closely resembles a shaving.

ASTM (American Society for Testing and Materials 1988) has addressed the problem of flake and wafer description and has changed the definition of a flake. Their definition of a flake is now changed to "a small wood particle of predetermined thickness specifically produced as a primary function of specialized equipment . . . resembling a small piece of veneer." 
A strand is now defined as a wood flake having a minimum predetermined length-to-width ratio of $2: 1$. This could be a particle less than $0.040 \mathrm{in}$. in length or as much as the 3 in. or longer strands used in some plants.

The definition of "wafer" has been a problem. A wafer is a large flake and has been understood to be a relatively square particle usually about $40 \mathrm{~mm}$ long. The inventor of the waferboard process as well as the word "wafer" (James d'A. Clark 1955), stated that a wafer has tapered ends. However, the wafers produced today are not necessarily made with tapered ends. In recent years, plants have been producing "oriented waferboard," which means that these wafers are more like srands. Clark also stated that wafers can be narrow in width. Thus there has been considerable confusion over basic technology. However, ASTM has now defined a wafer as a wood flake having a predetermined length of at least $13 / 16$ in. (American Society of Tesing and Materiais 1988).

The Canadians have also struggled with the description of wafers and strands and definitions of the products made from them. Wafers are defined as (Canadian Standards Association 1985):

". . . a specific type of wood flake produced as a primary function of specialized equipment (i.e., waferizer) and having a controlled length of at least $30 \mathrm{~mm}$ along the grain direction, a controlled thickness, and a variable or controlled width. Each wafer is essentially flat and has the grain of the wood running predominanty in the plane of the wafer. In overall character, wafers resemble small pieces of thin veneer. Wafers may be purposely produced with a narrow width to facilitate alignment."

Strands are defined (Canadian Standards Association 1985) as "a specialized wafer having a length at least twice the width." Because strand, here, means a specialized wafer, the length has to be at least $13 / 16$ in. long. Thus, it 
really fits into the classification of a narrow wafer. However, only three Canadian plants now make a randomly oriented waferboard. All others are making OSB.

The ASTM D 1554-86 (American Society of Testing and Materials 1988) particle definitions were first developed in 1958. The two terms "fiberboard" and "particleboard," however, have not been used in all cases in the United States to cover these two groups of products according to its own ASTM definitions. Much of the rest of the world, however, has subscribed to this basic terminology.

In the United States and Canada, particleboard has come to mean boards made of planer shavings, sawdust, granules, small flakes, and small fines (undefined term). If such a board is used in house construction, it may be called structural particleboard (America Plywood Association 1983). Most of the board, however, is bonded with urea-formaldehyde resin and is used for furniture, cabinets, floor underlayment, and mobile home decking. In the rest of the world, most particleboard is made with small flakes.

This brief recitation of the development of terminology was not meant to be a complete discussion, which would be a lengthy discourse, but rather to illustrate the problems of nomenclature over the years, particularly in the United States, and to set the stage for describing the various materials.

\section{SUGGESTED STANDARDIZED TERMINOLOGY}

The position being taken is that all the materials under discussion are made up of elements that have been glued together. Their commonality is that they are composed of smaller pieces bonded or fused together. Thus, in the forest products field, the term "composite" seems most appropriate, covering any material made of smaller pieces and glued together. Within this family of materiais, several subgroups develop naturally. The differentiation between products within a 
subgroup could be on the basis of properties or uses rather than the type of particle or fiber used (e.g., roof sheathing, furniture panels, lumber) or by material description. The main subgroups of materiais are listed in Table 1.

The list found in Table 1 is not all inclusive, but shows that a logical organization of composite materials is possible. Any organization of subgroups has to be flexible so that new materials developed in the future can be placed easily in the composite materials family.

\section{RAW MATERIALS}

The forest resources, particularly in the United States and Canada, are vastly different from those available in the past. The old-growth forest is mostly gone and what old growth that is left is fairly small diameter stock. The secondand third-growth forests are being harvested at early ages. Much of this timber is fast grown. Also, because of the earlier harvest time, the new forest provides logs consisting of high volumes of juvenile wood (Smith and Briggs 1986). The juvenile wood is much lower in strength than marure wood and along with foster growing of the trees the result is usually a greater percentage of the forest harvest being lower in strength than found with old growth forests. However, composite materials offer methods for combining low-quality raw material with high-quality wood or other nonwood raw material resulting in a myriad of appropriate wood construction materials.

The softwoods and low-density hardwoods now used in the forest products plants in the United States and Canada are excellent for manufacturing the composites of today and tomorrow. Indeed, because of the availability of these resources, the infrastructure in place, the technology already developed or under development, and the need for composites in North America and internationally, the United States and Canada are in an enviable position to be, even more so than at the current time, suppliers of composite materials to the worid. 
Table 1.--The family of composite materials

\section{Veneer-Based Materials}

Plywood

Parallel laminated veneer (PLV)

Usually made in wide billets

(e.g., 27 inches)

Laminated veneer lumber ( $L V L$ )

Cut from PLV

Composition or Reconstituted Materials

COM-PLYR/Fiberboard/MDF

Hardboard/Insulation board

Oriented strand board (OSB)

Oriented waferboard(OWB)

Particleboard/Waferboard

Parallel strand or aligned material

Marriages of wood and other materials

(Oriented strand lumber [OSL])

Inorganic Bonded Materials

\section{$\underline{\text { Laminates }}$}

Laminated beams

Overlayed materials

Panels or shaped materials combined with nonwood materials such as metal, plastic, and fiberglass

Edge-Glued Material

Lumber panels

Components

I-beams

T-beam panels

Stress-skin panels 
The demand for composites will put a strain on North Americas forest resources. Already, as is well known, species are used which were considered virtually noncommercial not too many years ago. Aspen is an obvious example. However, an even more efficient use of the forest resource will be needed because of demand and to demonstrate good stewardships of the forest. If this is not done, preservationisis will try to use poor resource use as a strong reason to set aside even more of the forest as wildemess areas.

Much work is needed to make use of the higher density hardwoods such as the many varieties of oak. This immense U.S. resource cannot be used efficiently yet because of difficulty in preparing particles and because the resultant reconstituted composites are heavier than the ones made of softwoods and lowdensity hardwoods.

To make composites, one needs resin or glue. The dominant adhesives of urea-formaldehyde and phenol-formaldehyde will probably remain in the forefront, although there is a shortage of phenolic for a few years because of production problems. Isocyanates remain a strong binder system, particularly for special product lines. Combinations of these adhesive systems can be and are used in a number of products. Considerable work continues on nonpetrochemical adhesives such as the ones named above. Lignin and carbohydrate developments have received most of the attention in recent years. Any breakthrough in developing these adhesives as low-cost binder systems will be of enormous value to the composites industry.

The main raw material used in the composition board or reconstituted wood materials for resistance to water absorption is wax and this material remains as an important raw material. New developments and materials for decreasing water absorption and the consequent thickness swelling and linear expansion will also be of great value to the industry. Significant work has aiready been performed by 
Ernest Hsu (1987 and 1989) of Forintek and John Youngquist and Roger Rowell (1988) of the U.S. Forest Products Laboratory.

\section{PRODUCTION IMPROVEMENTS}

The most significant improvement in production that has occured in years has been in the 1980s. This production improvement has been in the new control systems using microprocessors and programmable logic controllers that will provide an even greater impact in improving production in the 1990s. Each machine center and process line in virtually every type of composite manufacture has been improved significantly recently. A number of recent papers have documented many of the production improvements (Walsh and Belliveau 1989, Ebert and Maurer 1989, Sturgeon and Lau 1989, Long 1989, and Schuldt and McCarthy 1989).

New developments in processing such as continuous pressing, steam inspection pressing, flakes for producing very long strands, better blenders, better sanders, etc., are many. Such equipment developments can rightfully be expected to continue.

\section{PRODUCT IMPROVEMENTS AND NEW PRODUCTS}

Most of the composite materials listed earlier have become important production items only during the past 30 years. Particleboard, MDF, OSB, waferboard, LVL, OSL, and parallel strand lumber (PSL) were either in their infancy or were still laboratory curiosities 30 years ago. Now, all of them are or will soon be important major products in worldwide commerce. One of the most important product improvements will have to be the reduction of water absorption and thickness swell and improved durability when exposed to the weather. All such improvements can be done now with production changes, increased levels of 
adhesives, and selected use of species. However, as long as most of these materials are considered as commodities, the increased cost of manufacture for improved product quality will probably not be economical.

What is needed is the development of market niches for improved products which will enable a manufacturer to produce value-added wood composites. More importantly, the greatest need and opportunity will be in the new, improved manufacture of houses, and in the nonresidential construction field.

New products will be limired only by the imagination of researchers, product developers, and manufacturers. A number of these products are on the verge of production right now. Examples can be found in the new marriages of wood and other materials, comugated composites such as Waveboard ${ }^{\mathrm{TM}}$ developed by the Alberta Research Council in Edmonton (Bach 1989), other moided structural materials, and lumberlike products. Already under production are lumberlike materials such as LVL (Fyie 1987) and Parallam ${ }^{\circledR}$ (Parker 1987). Parallam ${ }^{\circledR}$ is also a heavy timber replacement.

The lumberlike materials offer great opportunities. Weyerhaeuser is producing an OSL material used in fumiture frames. MacMillan Bloedel is building a plant to provide window frame materials. Grant Forest Products will soon produce OSL. The COM-PLY ${ }^{\circledR}$ plant of Arrowoods is under new management and the remodeled plant will soon be producing COMP-PLY ${ }^{\circledR}$ lumber (combinations of veneer as the lumber edges and OSL as the lumber core).

The OSL development is exciting. These products can be made in much longer lengths than conventional lumber. This eliminates joints in long components as well as the strength problems associated with the joints.

In considering the actual design values of OSL, some recent work done at Washington State University can be used as an example. Here, OSL, made from nominal 0.020 by 1.5 in. long strands, showed that such a product could justify 
a higher allowable tensile stress than has been assigned currently to visually graded, select structural Douglas fur lumber. This research was done on oriented flake material that was intended to substitute for sawn truss lumber (nominal 2 by 4 lumber) (Maloney 1984).

Testing of visually graded nominal 2 by 4 in. by $8 \mathrm{ft}$ Douglas fir select structural lumber (113 specimens) showed a range of tension values from 1,280 to 10,250 psi with a mean of 7,250 psi. According to the Western Wood Products Grading Rules (Western Wood Products Association 1980), the allowable working stress in tension for this product is 1,390 psi. Using the American Society for Testing Materials method D-2915 (American Society for Testing and Materials 1982) for determining the allowable working stresses visually graded material, the targeted test value for any of the material is 2,930 psi. Thus, some of the 113 boards were below the test value required to justify the allowable tension value for select structural lumber. Most of the material, however, was far above the minimum value and consequently, was much better than needed--a waste of quality material.

The OSL material had tensile strengths ranging from 3,260 to 3,780 psi (a very tight range or much better coefficient of variation in comparison to the sawn lumber). All values were well above the minimum design value of 1,390 psi. Much of the new OSL materials are being made with relatively long flakes (up to 12 in.). The above work shows that even with smaller flakes, high strength OSL can be produced.

\section{OPPORTUNITIES AND PROBLEMS}

Reliability-based design procedures which are already practiced with materials that compete with wood (steel and reinforced concrete) are under development presently for the wood industry. By developing design procedures which are the same as those generally used by engineers and architects, the use of 
wood materials will be understood better by those professionals who have not been trained in wood materials. At present, special training is needed for the design and use of wood, particularly in large structures. Unfortunately, few universities have offered such training to civil engineers and architects. The engineering professionals, whether trained in wood or not, will be competent in using wood once the reliability-based design procedures are developed and in place.

Another key to expanding the use of wood materials is nondestructive testing or evaluation (NDE). Stress-rated lumber has been used for many years in several applications such as trusses. PLV is an outstanding example of successful NDE. The rested veneers are layered in the LVL to produce the desired engineered properties in the final products. This manufacturing procedure would not be possible in consistently providing high-strength material without NDE.

New and improved NDE enhances the use of all wood materials in engineered building designs. This can expand the wood materials market due to the confidence developed in using engineered wood materials because of NDE. A great market yet to be exploited in the nonresidential market where large panels, e.g., 8 by $24 \mathrm{ft}$, can be used. More efficient construction is possible and a better building can result because of fewer joints due to using 8 by $24 \mathrm{ft}$ panels instead of $\operatorname{six} 4$ by $8 \mathrm{ft}$ panels.

What is not understood by many individuals in the industry is the need to understand and develop better connections--mechanical, adhesive, and mechanical adhesive. In many building cases, wood material strength is far greater than the corresponding connections used. Better connections have to be developed to help implement the new reliability-based design procedures to the advantage of composites and all other wood materials.

As new composite products and ways to use them develop, greater care in using the composites becomes mandatory. Many of the new uses will require 
manufacture of the final building or component under controlled conditions. Otherwise, misuse of the composites will result in failures and subsequent loss of confidence in them by engineers and users.

\section{PROBLEMS}

Timber supply can become a problem because of demand and reductions of available forest raw materials. As mentioned previously, complete use of the raw material is necessary to avoid political problems. Some of this material that is not now used extensively (such as low-quality species, very small roundwood, and dead trees) can be used as part or all of the particleboard, MDF, and hardboard raw material. Extensive research work has shown that dead lodgepole pine and white pine could be used for most types of composition boards (Maloney et al 1976). Dead raw material such as that mentioned has become important raw material in particleboard and hardboard plants. It is difficult, however, to produce wafers from dead logs because of the log's low moisture content. However, there may be a possibility of producing same strand furnish from this type of raw material.

Other composites, such as LVL, need a certain amount of high-quality wood to develop the higher strengths required. OSL and OSB also need a certain amount of higher-quality wood to make the higher-strength products. However, densification and adding extra resin can help improve the strength properties of these products.

It is very important, again, as mentioned previously, to develop more dimensionally stable composite products. Those products such as plywood, LVL, and laminated beams are much more stable because there is little compression of the material during manufacture. Densified products such as particleboard, MDF, waferboard, OSB, OSL, and hardboard expand much more when exposed to water. It is recognized not only by most of the industry, but also by the users that improvements are needed here if these materials are to be exposed to water. 


\section{WORLDWIDE NEED}

Major umber resources are still available in Russia and in a large amount of the tropics. Much of the Russian timber is small and the infrastructure is not in place to greatly expand production of wood materials and composites. The tropical forest areas are being harvested or destroyed by shifting agriculture. There is worldwide pressure on reducing the tropical forest exploitation because of the growing greenhouse effect. Tropical forest exploitation is considered a major cause of the warming of the earth.

This leaves the United States and Canada as major suppliers of wood materials to most of the world. More efficient use of the forest raw materials, more efficient production, and, therefore, more efficient use of all wood materials becomes imperative. The need will be growing and the rapidly expanding composites industry has a tremendous opportunity for supplying world needs at a profic.

\section{CONCLUSION}

Composites manufacture is a huge part of the forest products industry. Panel manufacture has been the dominant part of the industry. Now molded and lumberlike composites are becoming very important parts of the composites family. While there is some disagreement on terminology and definitions of composites, the basic technology is in place for manufacture. There are great research and development efforts underway throughout the world for improvement of composites and the development of new composites. If developments of the next 40 years can match the developments of the last 40 years, composite manufacture and use could become the dominant part of the forest products industry. 


\section{REFERENCES CITED}

American Hardboard Association. 1985. American National Standard--Celluosic Fiberboard. ANSI/AHA A194.1. American Hardboard Association. Palatine, II.

American Plywood Association. 1983. Performance Rated Panels. American Plywood Association. Tacoma, WA.

American Society for Testing and Materials. 1982. Standard Method for Evaluating Allowable Properties for Grades of Structural Lumber. ASTM D-2915. American Society for Testing and Materials. Philadelphia, PA.

American Society for Testing and Materials. 1988. Annual Book of ASTM Standards, Section 4: Construction, Vol. 04.09 Wood. ASTM D 1554-86. American Society for Testing and Materials. Philadelphia, PA. pp. 242244.

Bach, Lars. 1989. Flexure properties of corrugated waferboard. Paper presented at the 23rd International Particleboard/Composite Materials Symposium/Forest Products Research Technical Forum. Abstract printed in the Proceedings, Twenty-Third International Particleboard/Composite Materials Symposium, T. M. Maloney, Ed. Washington State University. Pullman, WA. p. 265.

Canadian Standards Association. 1985. Waferboard and Strandboard. National Standards of Canada CAN3-0437.0-M85. Canadian Standards Association. Rexdale, Ontario, Canada.

Clarke, James d'A. 1955. A new dry process multi-ply board. For. Prod. J. $5(4): 209-213$.

Ebert, Joe and Mauer, Hartmut. 1989. A new generation of particleboard plants. Proceedings, Twenty-Third International Particleboard/Composite Materials Symposium, T. M. Maloney, Ed. Washington State University. Pullman, WA. pp. 199-212.

Food and Agriculture Organization. 1958. Fiberboard and particleboard. Report of an International Consultation on Insulation Board, Hardboard, and Particleboard. Geneva, Switzerland. Food and Agriculture Organization, Rome. pp. 4-14. 
Fyie, Joseph A. 1988. Structural products of parallel laminated veneer lumber. Proceedings, Twenty-First International Particleboard/Composite Materials Symposium, T. M. Maloney, Ed. Washington State University. Pullman, WA. pp. 35-50.

Hsu, W. Emest. 1987. A process for stabilizing waferboard/OSB. Proceedings, Twenty-First International Particleboard/ Composite Materials Symposium, T. M. Maloney, Ed. Washington State University. Pullman, WA. pp. 219-236.

Hsu, W. Emest. 1989. Steam pretreatment for dimensionally stabilizing UFbonded particleboard. Proceedings, Twenty-Third International Particleboardl Composite Materials Symposium, T. M. Maloney, Ed. Washington State University. Pullman, WA. pp. 37-54.

Maloney, Thomas M; Talbott, John W.; Strickler, M. D.; Lentz, Martin T. 1976. Composition board from standing dead white pine and dead lodgepole pine. Proceedings, Tenth International Particleboard Symposium, T. M. Maloney, Ed. Washington State University. Pullman, WA. pp. 27-104.

Maloney, Thomas M. 1977. Modern Particleboard and Dry-Process Fiberboard Manufacturing. Miller Freeman Publications. San Francisco, CA. pp. 3139 and 179-181.

Maloney, Thomas M. 1984. Board development and use in the United States--do they relate to Europe? Proceedings New Available Techniques from the SPCI World Pulp and Paper Week conducted in Stockholm. The Swedish Association of Pulp and Paper Engineers. Stockholm, Sweden. pp. 554-561.

Maloney, Thomas M. 1986. Terminology and product definitions: a suggested approach to uniformity worldwide. International Union of Forest Research Organizations (IUFRO) XVIII World Congress Proceedings, Division 5 , Forest Products. Ljubljana, Yugoslavia. pp. 294-305. Obtain copies from IURFO Sectetariat, Vienna, Austria.

National Particleboard Association. 1986. Medium Densiry Fiberboard for Interior Use. ANSI/A208.2. National Particleboard Association. Gaithersburg, MD.

Parker, David J. 1987. Parallam ${ }^{\circledR}$ PSL: an evolution. Proceedings, Twenty-First International Particleboard/Composite Materials Symposium, T. M. Maloney, Ed. Washington State University. Pullman, WA. pp. 51-68. 
Schuldt, John P. and McCarthy, Earl T. 1989. The new direction: windows'based systems for monitoring and control. Proceedings, Twenty-Third International Particleboard/Composite Materials Symposium, T. M. Maloney, Ed. Washington State University. Pullman, WA. pp. 213-218.

Smith, W. Ramsey and Briggs, David G. 1986. Juvenile wood: has it come of age? Juvenile Wood What Does It Mean to Forest Management and Forest Products? Proceedings 47309. Forest Products Research Society. Madison, WI. pp. 5-11.

Sturgeon, Murray G. and Lau, Norman M. 1989. Continuous pressing medium density fibreboard at Nelson Pine Industries New Zealand. Proceedings, Twenty-Third International Particleboard/Composite Materials Symposium, T. M. Maloney, Ed. Washington State University. Pullman, WA. pp. 179-186.

Youngquist, John A. and Rowell, Roger M. 1988. Can chemical modification technology add value to your products? Proceedings, Twenty-Second International Particleboard/Composite Materials Symposium, T. M. Maloney, Ed. Washington State University. Pullman, WA. pp. 111-121.

Walsh, Herb G. and Belliveau, Don R. Evolution of the art of manufacturing OSB--a modern large new plant. Proceedings, Twenty-Third International Particleboard/Composite Materials Symposium, T. M. Maloney, Ed. Washington State University. Pullman, WA. pp. 129-140.

Western Wood Products Association. 1980. Standard Grading Rules for Western Lumber. Westem Wood Products Association. Portland, OR. p. 202. 

. 


\title{
PULPING TECHNOLOGY FOR CONSERVATION \\ OF ENERGY AND ENVIRONMENT
}

\begin{abstract}
BY
HEIKKI MANNISTO, PRESIDENT, ERONO CONSULTANTS ITD. EVA SEBBAS, SENIOR PROCESS ENGINEER, EKONO CONSULTANTS ITD.
\end{abstract}

\begin{abstract}
Conservation of energy and environment has been a prime objective in development of new pulp and paper process technologies during the past two decades. While energy cost and availability was the main concern in 1970 's, the main emphasis in the 1980's has been on environmental concerns.

Kraft pulp continues to be the main fibre supply for world paper production. Much of the kraft mill equipment and technology has changed during the past twenty years. As a result of changes in technology, the energy consumption patterns as well as effluent characteristics have drastically changed.
\end{abstract}


The world paper demand and supply is expected to grow $2-3 \%$ annually. The demand was $216 \mathrm{mili}$ ion tons in 1987 and is expected to grow to 290 million tons by the year 2010 (see Figure 1).

Figure 1. World Paper Demand up to year 2016

\section{WORLD PAPER DEMAND $1800-2016$}

MAIN TECHNICAL DEVELOPMENTS

\section{MILLION METRIC TONS}

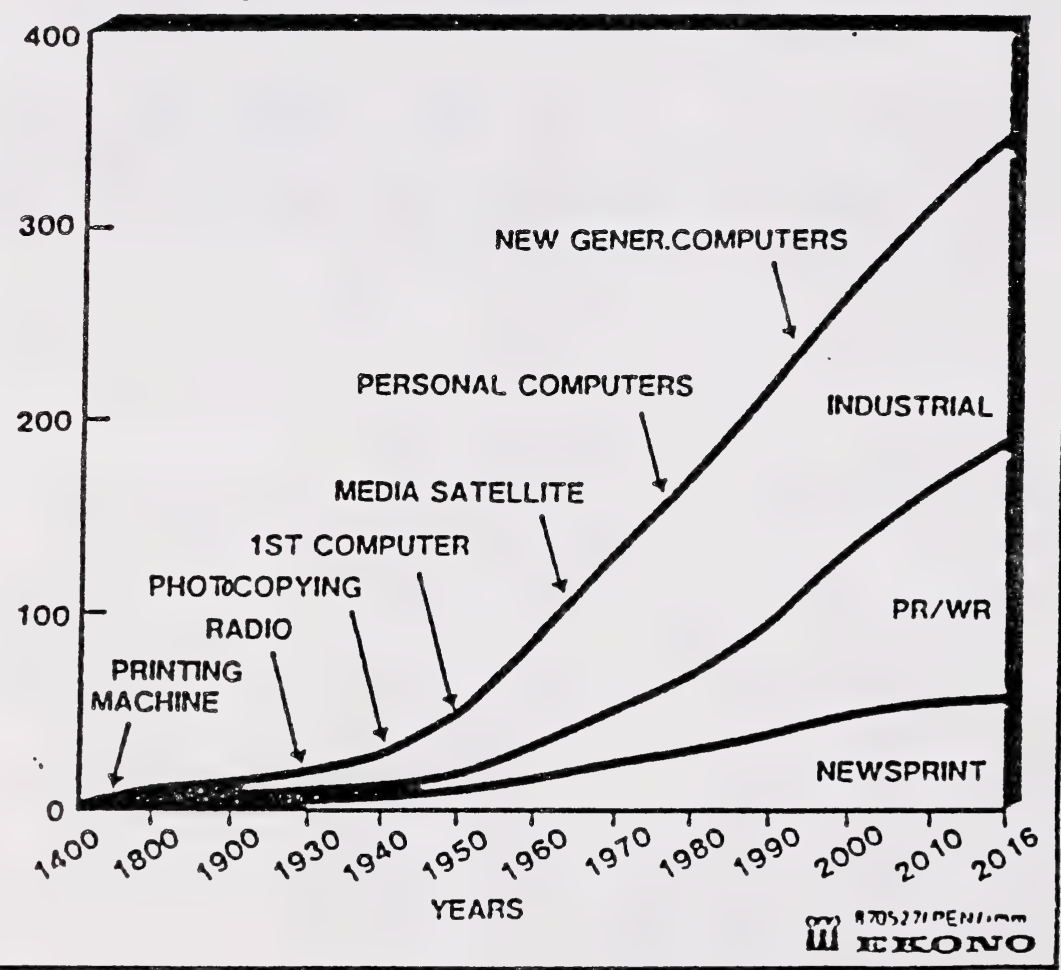


About 45-50\% of the fibre supply for paper manufacturing world wide is virgin chemical wood pulp. About $30 \%$ of the fibre supply is recycled fibre today, and the rest consists of mechanical wood pulp and other fibres. Of the virgin chemical fibre supply, about $60 \%$ is bleached kraft pulp. Unless drastic changes in consumption patterns take place, the portion of bleached chemical pulps is expected to grow.

Chemical pulping processes typically utilize the by-product fuels effectively and consequently are highly self sufficient for fuel supply. Because most of the water polluting material is being collected and used as fuels, the environmental, especially traditionally regulated effluent characteristics are relatively easily controlled to the levels that are acceptable to the recipients. Use of chlorine based chemicals for bleaching of chemical pulps has created concerns about chlorinated organic compounds. Many countries have or are planning to regulate the levels of these compounds to the recipients. While research is being carried out to develop new pulping and bleaching processes, it seems today likely that the kraft process will remain the main chemical pulping process for some time. Complete elimination of chlorine based chemicals may not be economically feasible either.

The following presentation gives an overview of the development of chemical pulping technology during the past two decades. Since kraft pulping is by far the most important of the chemical pulping methods, the focus will be on kraft pulping and bleaching and the impact of the new technologies on the energy and environmental aspects of kraft mills.

\section{General}

\section{ENERGY}

Pulping techniques and process conditions have a major impact on the plant energy balance. For example:

Pulping yield determines the amount of by-product fuel available.

Pulping method used may itself be a decisive factor in the plant steam and power demand (e.g. mechanical vs. chemical pulping).

- The extent of delignification of pulping affects the amount of chemicals and energy used in bleaching. 
- The pulping method used and the extent of delignification largely determine the pulping chemicals use and the energy consumption in the chemical conversion.

- Pulping and washing methods and efficiencies have a great impact on energy demand in evaporation and steam generation from the waste liquor.

- Pulping, whether chemical or mechanical, is a major source of secondary heat. The efficiency of heat recovery may have a profound impact on steam use in other process areas, e.g. in bleach plant.

Figure 2 illustrates the impact of pulping yield on the energy situation. In the typical chemical pulping yield area (45-70\%) the steam generation from waste liquor is always higher than the energy consumption in pulping and liquor recovery. In yield areas for mechanical and chemimechanical pulping (over $80 \%$ ) the energy consumption exceeds the by-product energy production. Figure 1 does not give any credit to the secondary heat recovery, which is possible in both chemical and mechanical pulping.

\section{Figure 2. Impact of Pulping Yield on the Plant Energy situation}

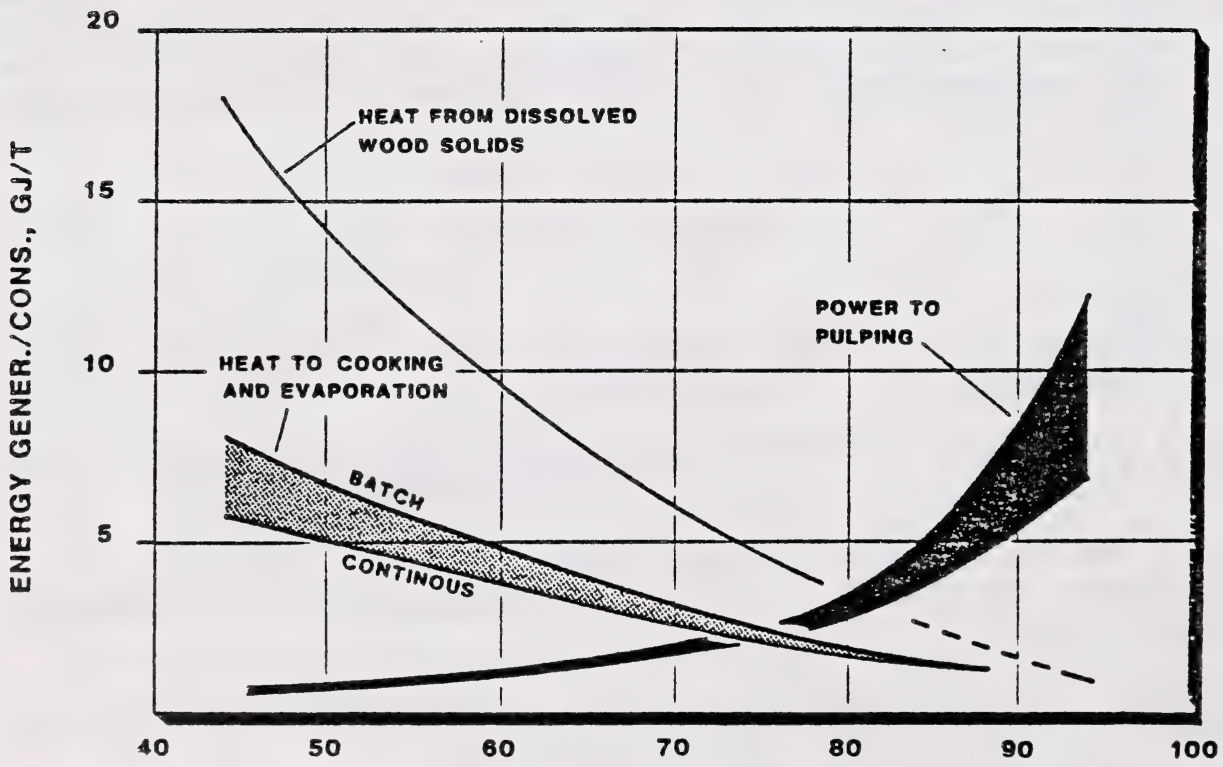

PULPING YIELD, \% OF WOOD 
Technology Impact on Energy Situation

Table 1 illustrates the energy balances of two bleached kraft market pulp mills; one designed in 1960's and the other in 1980's.

Table 1. Design Heat and Power Balances for Two Market Pulp Mills

\begin{tabular}{|c|c|c|}
\hline & 1960 Design & 1980 Design \\
\hline \multicolumn{3}{|c|}{ Heat Balances } \\
\hline \multicolumn{3}{|l|}{ Heat consumption } \\
\hline Digester & 4.0 & 2.3 \\
\hline Bleach Plant & 2.3 & 0.9 \\
\hline Pulp dryer & 4.8 & 4.1 \\
\hline Evaporation & 4.1 & 4.2 \\
\hline Water heating & 3.4 & 0.4 \\
\hline Recovery boiler auxiliary & 1.8 & 1.7 \\
\hline Miscellaneous & 4.2 & 1.8 \\
\hline Power generation & 3.0 & 3.2 \\
\hline Total & 27.6 & 18.6 \\
\hline \multicolumn{3}{|l|}{ Heat supply } \\
\hline From black liquor & 14.2 & 16.0 \\
\hline $\begin{array}{l}\text { From bark } \\
\text { oil }\end{array}$ & $\begin{array}{r}2.0 \\
11.4\end{array}$ & $\begin{array}{l}2.0 \\
0.6\end{array}$ \\
\hline Total & 27.6 & 18.6 \\
\hline \multirow{2}{*}{$\begin{array}{l}\text { Oil to lime kiln } \\
\text { oil to steam generation }\end{array}$} & 2.8 & 2.0 \\
\hline & 13.8 & 0.7 \\
\hline Total purchased fuel & 16.6 & 2.7 \\
\hline \multicolumn{3}{|c|}{ Power Balances } \\
\hline \multirow{4}{*}{$\begin{array}{l}\text { Power consumption } \\
\text { Power supply } \\
\text { Mechanical drives } \\
\text { Back-pressure power } \\
\text { Purchased power }\end{array}$} & 850 & 880 \\
\hline & 50 & $\ldots$ \\
\hline & 700 & 800 \\
\hline & 100 & 80 \\
\hline Total & 800 & 880 \\
\hline
\end{tabular}


There is a significant difference in the energy demand and supply between the mills, although the basic technology used is the same in most areas. Both use continuous digesters, but the use of extraction heat is more effective in the 1980 's mill. The brown stock washing in the new mill is a combination of high-heat washing and diffuser washing, while the old design is a combination of high-heat and arum filters. Both mills use conventional bleaching techniques. The main differences in bleaching are (a) the selection of construction material, which allows a higher degree of closure, (b) preheating of the chlorine dioxide solution, and (c) higher hot water temperature to the washer showers. The pulp dryers are similar, with the exception that the new mill uses low pressure steam for drying. The new mill has heat recovery systems that are far more efficient and which eliminate steam use for water heating almost completely and reduce steam use for space heating.

The old mill has a direct-contact evaporator for final black liquor concentration, while the new mill uses multiple-effect evaporation to reach $65 \%$ black liquor solids. The lime kiln in the new mill is a modern, long kiln with insulation and satellite coolers.

The new mill has higher boiler steam pressure and lower process steam pressures. Because of these pressure differences, the backpressure power yield is much higher in the new mill, which actually generates more back-pressure power, despite much lower use of process steam. Characteristic of design practices of the 1960's, the old mill uses mechanical drive turbines extensively, while the new mill utilizes all its potential for back-pressure power generation and uses electric motors in all places.

The design differences between the two mills result in drastic differences in purchased fuel, while purchased power is about the same for both mills. If the purchased fuel is oil at $\$ 2.50 / \mathrm{GJ}$, the difference in fuel cost is about $\$ 35.00 /$ ton of pulp. For a $300,000-t o n / y e a r$ mill, this would mean a difference of about $\$ 10$ milition in annual fuel costs.

\section{Future Trends}

As illustrated by Table 1 a kraft market pulp mill can be designed today so that the only major purchased energy supply is the Iime kiln fuel. Proven technology is available to use bark or hog fuel as the lime kiln fuel and make the kraft mill almost completely independent on fossil fuels. However, an investment in that technology cannot be justified based on today's fuel oil and natural gas prices. 
Once self sufficient for fuel and power, there is normally very little incentive for future energy efficiency improvements in a kraft market pulp mill. Integration of a paper mill to an existing kraft pulp mill could change the situation. In an integrated pulp and paper mill, any improvements in energy efficiency of the kraft pulping operations normally result in a reduction of overall energy cost. Integration of paper mills to kraft market pulp mills is expected to be a future trend and interest in developing energy efficient kraft pulping technology is expected to continue.

\section{ENVIRONMENT}

\section{General}

The potential harm of the pulp and paper industry to the environment has long been a concern by the industry, scientists, the public and authorities. Research being carried out on the short or long term impacts of effluent discharges continues to yield more accurate information on the real effects to the nature. Today's concern is the chlorinated organic compounds that result from using chlorine based chemicals as the bleaching agents of chemical pulps.

"Effluent Free" pulp mills have been a topic of discussion for a long time. The closer studies and even mill scale trials have resulted, so far, in a conclusion that the technology is not yet available to build an effluent free pulp mill that would produce pulp to meet the quality criterias set by the current paper manufacturing technology and the end users of the paper products.

While research for effluent free pulping processes will continue, it is quite obvious that drastic changes in pulping processes will take a long time to implement. The bleached kraft pulping capacity in North America alone is today about 30 million tons per year. Therefore, technology available to reduce the environmental impact of a kraft pulp mill is of great interest.

Effluent Characteristics from "Conventional" Kraft Mill

Most of the current bleached pulp capacity in North America was built in the 1960's and the 1970's. About fifty percent of the bleach plants have five stages, sequence $C-E-D-E-D$. In the discussion below, we refer to a "conventional" bleached kraft mill having the following features:

- Softwood pulp production.

- Digester Kappa number level 33. 
- Brown stock washing equipment are four stage drum washing or equivalent. Washing losses before screening $15-20 \mathrm{~kg}$ $\mathrm{Na}_{2} \mathrm{SO}_{4} / \mathrm{ADt}$.

- Screening is partially open. Washing loss carry over to bleach plan $8-10 \mathrm{~kg} \mathrm{Na} \mathrm{SO}_{4} / \mathrm{ADt}$ (total).

- Bleaching sequence $C / D-E-D-E-D$.

- Brightness target 88-90 degrees ISO.

- Total active chlorine consumption $110 \mathrm{~kg} \mathrm{Cl} / \mathrm{ADt}$.

- Chlorine multiplier 0.2 .

- Chlorine dioxide process is R3 and its capacity limits the $\mathrm{ClO}_{2}$ substitution to maximum $10 \%$ in the first bleaching stage.

- No condensate stripping at the mill.

The effluent characteristics from the "conventional" softwood kraft pulp mill are given in Table 2 .

Table 2. Effluent Characteristics from Conventional Bleached Softwood kraft Mill, kg/ADt

\begin{tabular}{|c|c|c|c|}
\hline & & $\begin{array}{l}\text { From } \\
\text { Processes }\end{array}$ & $\begin{array}{c}\text { After } \\
\text { Treatment }\end{array}$ \\
\hline \multicolumn{4}{|l|}{$B O D$} \\
\hline - & Screen Room & & $3-4$ \\
\hline - & Bleach Plant & & $20-22$ \\
\hline - & Condensates & & $8-10$ \\
\hline- & Miscellaneous, & & $2-4$ \\
\hline \multicolumn{2}{|c|}{ Total } & $35-40$ & $5-8$ \\
\hline \multicolumn{2}{|l|}{ COD } & $130-150$ & $60-80$ \\
\hline \multicolumn{2}{|l|}{ Colour } & $200-300$ & $200-300$ \\
\hline \multicolumn{2}{|l|}{ TSS } & $10-30$ & $4-8$ \\
\hline \multicolumn{2}{|l|}{ AOX } & $6-8$ & $3 \cdot 5-5$ \\
\hline
\end{tabular}


Proven Technologies for Reduction of Effluent Discharges

The main factors that determine the amount of dissolved material from bleached kraft pulping operations are the lignin content of the pulp to chlorine based bleaching (measured as Kappa level) and the saltcake carryover to the bleach plant. Liquor losses from open screening and accidental liquor spills may also have a contribution to the $\mathrm{BOD} / \mathrm{COD}$ content of the effluent to the treatment plant.

Condensates from turpentine recovery and black liquor evaporation are major contributors to the effluent BOD. Proper reuse of the condensates may reduce the levels. Because of the tightening air emission targets, a major fraction of the volatile compounds released in digester vents and blow and liquor evaporation, will end up in the liquid effluent, unless a separate treatment process is applied.

Detailed descriptions of process technologies for reduction of process effluent discharges can be found in numerous publications related to the specific topics. The following is a brief summary of the measures available in the design of a new kraft pulp mill or in the improvement of the existing operation:

Brown Stock Washing:

Typically 98-99\% of material dissolved in the kraft cooking process is recovered in brown stock washing for evaporation and combustion in the recovery boiler. The dissolved material left in the pulp out of the last brown stock washing stage will either be discharged with the screen room filtrate overflow or enter the first bleaching stage. The dissolved solids sewered from the screening room typically has BOD content of about $0.4-0.45 \mathrm{~kg} \mathrm{BOD} / / \mathrm{kg} \mathrm{Na} \mathrm{SO}_{4}$. The liquor carryover to the bleach plant typically as an effect as follows:

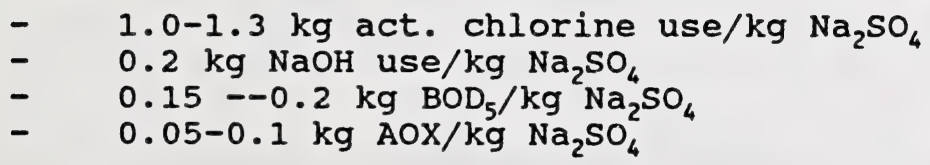

Several Scandinavian mills have added an "open" washer to the brown stock or post-oxygen stage washing system. This implies that pulp is washed prior to the first bleaching stage and the filtrate from this washer is sewered. This technique increases the BOD content and flow of process effluent but allows lower chlorine use which in turn lowers the discharge of chlorinated organic substance and risks for dioxin formation. 
Extended Delignification:

Extended delignification facilitates cooking to lower Kappa level than conventional kraft cooking. Lower Kappa level in turn means more organic substance recovered to the recovery cycle and less bleaching chemicals use. As a result, both BOD and chlorinated organic compounds to effluent will decrease.

In a continuous cooking process, the extended delignification is implemented by introducing white liquor at several points. The final cooking is carried out countercurrently to reduce the lignin concentration at the end of the cooking zone. The process in known as Modified Continuous cooking.

In a conventional batch digester operation, the extended delignification would be not practical because of, e.g. increased cooking time and steam use. Extended delignification can, however, be implemented together with so called cold blow techniques. With these techniques, digester liquor can be displaced in the middle of the cook with liquor containing more fresh chemicals and less liquor.

Oxygen Delignification:

oxygen delignification is a widely approved method to reduce the chlorine based chemical use and effluent discharge levels. There are about 50 oxygen delignification systems in operation today. Early installations were high consistency units operated at pulp consistencies of about 25-30\%.

Today, the definite tendency is towards medium consistency (10-12\% consistency) units. There has been some concern about the pulp strength properties after oxygen delignification. However, it appears that the strength properties of the pulp are not harmed as long as the degree of delignification stays low enough. Several market pulp mills operate at delignification rates below $40 \%$, although laboratory scale testing would indicate that the delignification degree could be up to $50 \%$ before the strength of pulp is deteriorated.

The effluent quality from a bleach plant preceded by oxygen delignification is substantially improved. Because the material dissolved in the oxygen stage is recovered and incinerated, less chlorine based chemicals are required and less organic substance will be discharged with the bleach plant effluent, as illustrated in Figure 3. 
Figure 3. $\mathrm{BOD}_{5}$ and $\mathrm{AOX}$ from Bleach Plant as a Function of Unbleached Kappa

\section{BOD AND AOX FROM BLEACH PLANT}

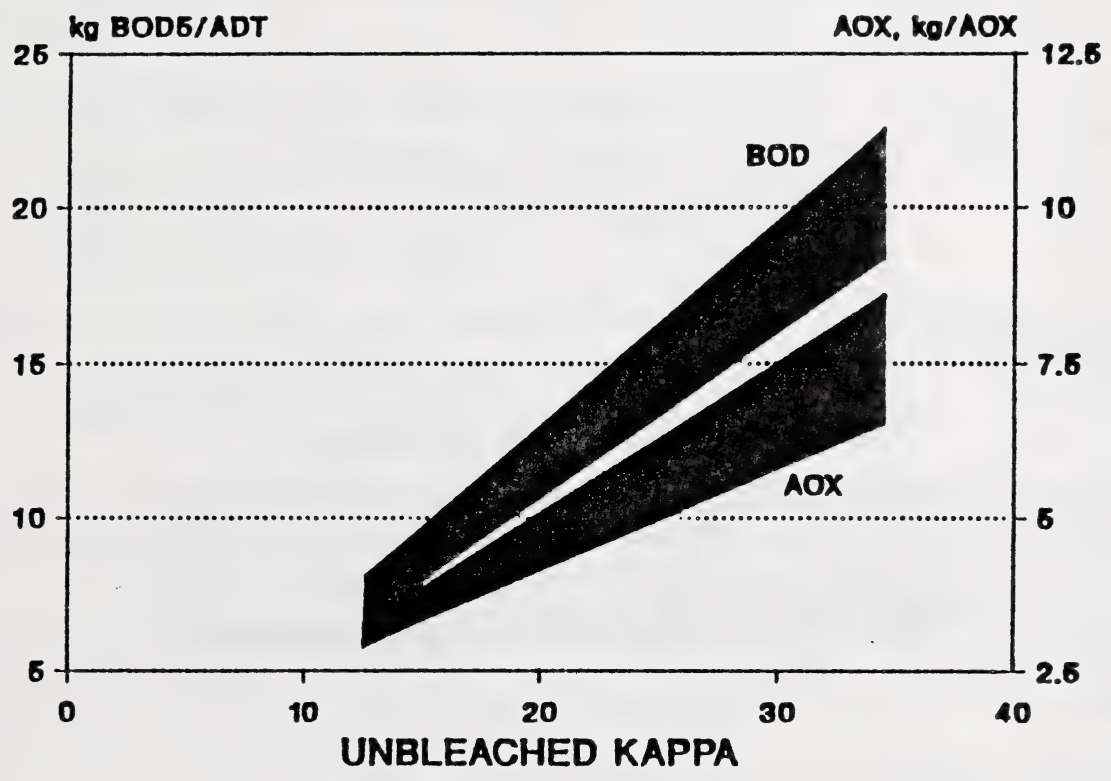

oxygen delignification has a major impact on the loading of the recovery processes. Figure 4 illustrates the additional loading of evaporators, recovery boiler, lime kiln and recausticizing. Although the additional load is only 4-7\%, it may be significant in a mill with recovery processes as the bottleneck. 
Figure 4. Loading of Recovery Cycle Processes as a Function of Kappa Reduction in Oxygen Delignification

Recovery Loop Load, \%

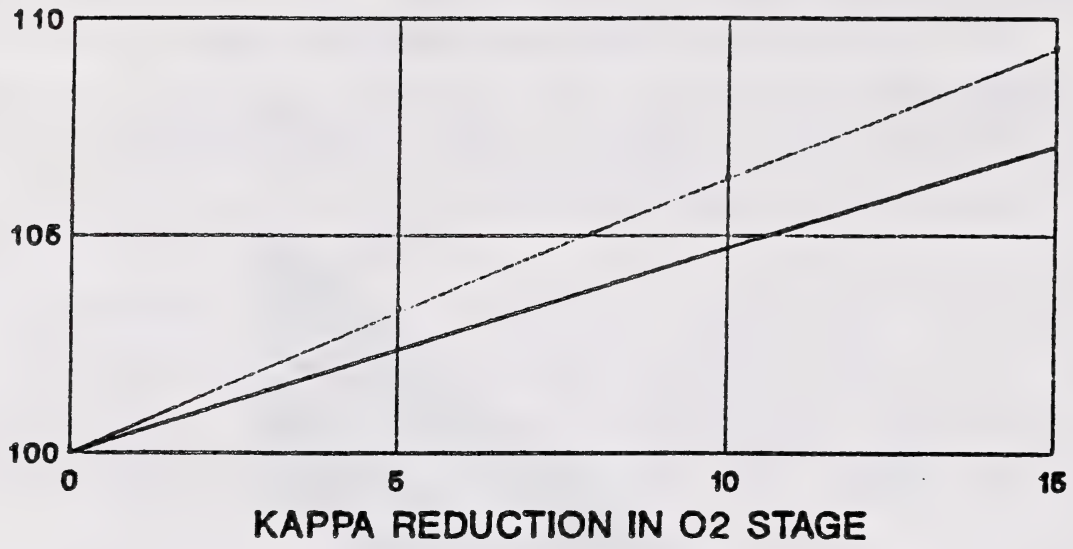

LOAD, $x$

- Recovery Boller Load Co Caust/LIme Klin Load

E/O Stage:

Oxygen enriched first alkaline extraction, E/O stage, has become common for bleached kraft mills over the past few years as a result of advances in the mixer technology allowing efficient mixing of oxygen and pulp in medium consistency. It is a low capital cost improvement option to existing bleach plants, which can increase bleach plant capacity, improve bleaching economy and improve effluent quality without adversely affecting the quality of the product. It is also a standard technique for a new bleach plant.

From the environmental point of view, colour and organically bound chlorine $(A O X)$ are the main parameters that are improved with E/O stage. Other parameters such as COD and BOD will not change. Typically, bleach plant colour reduction has been in the range 15-30\%. AOX reduction, as well as the reduction in chloroform and chlorate, depends on the selected bleaching strategy, i.e. whether oxygen is used to replace chlorine, chlorine dioxide, hypochlorite or a combination of these chemicals. The biggest reduction in AOX is realized if oxygen is used to replace chlorine. 
High $\mathrm{ClO}_{2}$ Substitution:

The replacement of chlorine by chlorine dioxide in the first bleaching stage has been proposed since the 1950's. A multitude of publications have examined the impact of total or partial substitution of chlorine by $\mathrm{ClO}_{2}$ on pulp quality and effluent properties.

The main benefits of adopting substantial substitution of chlorine dioxide are:

- Improved bleach plant effluent quality:

- Less chlorinated dioxins and furans.

- Less chlorinated organic compounds.

- Lower effluent colour.

- Improved pulp quality, especially:

- Viscosity.

- Strength.

During the last couple of years, the main driving forces behind the high $\mathrm{ClO}_{2}$ substitution have been environmental concerns; dioxins, furans and AOX (TOC1). As a result of this, the target substitution level has been increased at some mills up to 50-70\%. There are some mills producing hardwood pulp and operating the first bleaching stage with $\mathrm{ClO}_{2}$ only. It should, however, be noted that when the substitution level exceeds about 50\%, the bleaching chemicals consumption will increase.

Condensate Stripping:

Most of the BOD in the condensate is caused by methanol and other volatile compounds, which can be stripped off from the condensates with steam. In existing mills, steam stripping has often been shunned because of fear for increased mill energy usage. By using innovative ideas however, it is in most cases possible to install a stripping column in an existing mill without or with very minor increase in the mill energy cost. In fact, in some cases the energy cost can even decrease.

Stripping of all condensates is not practical. only the fractions having the highest concentrations need to be treated. These fractions include:

- Digester area condensates from relief and blow vent condensing systems (one or two stages). 
- Selected streams from the evaporator area.

In the evaporator area a high amount of methanol can be captured in a small volume by stepwise condensation of the first liquor vapours (e.g. by installing walls inside the condensing section of the evaporator body receiving the first liquor boil off, or by adding external liquor heaters).

Typically 60-80\% of the condensate BOD can be contained in a volume of 20-30\% the total condensate volume. By using a steam to feed ratio of 1 to 5 , the stripping column removes over $90 \%$ of the methanol. The total methanol and BOD removal is then 5-8 kg ADt of pulp.

Achievable Process Effluent Quality Levels Using Proven Techniques BOD:

Table 3 illustrates the differences in $B O D_{5}$ contents of effluent from a conventional mill and from a new bleached kraft mill. As shown the $\mathrm{BOD}_{5}$ discharge from a new mill is roughly $50 \%$ from that of a "conventional" mill.

Table 3. Process $B_{5} D_{5}$ Discharge from a "Conventional" and from a "New" Bleached Kraft Mill

\begin{tabular}{|lcc|}
\hline & $\begin{array}{c}\text { Conventional } \\
\text { Mill }\end{array}$ & $\begin{array}{c}\text { New } \\
\text { Mill }\end{array}$ \\
\hline Screen Room & $3-4$ & 0 \\
Bleach Plant & $20-22$ & $12-14$ \\
Condensates & $8-10$ & $3-4$ \\
Miscellaneous & $2-4$ & $2-4$ \\
Total Process & $35-40$ & $17-22$ \\
\hline
\end{tabular}

At $85 \%$ BOD removal efficiency for the biological treatment plant, the BOD discharge from a "New Mill" to the recipient would be about $3 \mathrm{~kg} \mathrm{BOD}_{5} / \mathrm{ADt}$ as a long term average. 
AOX :

As discussed above, bleached kraft pulp mill AOX discharge can be reduced e.g. through:

- Improved brown stock washing.

- Extended delignification.

- oxygen delignification.

- $\mathrm{High} \mathrm{ClO}_{2}$ - substitution

At Kappa level 20 to the bleach plant and $\mathrm{ClO}_{2}$ - substitution of $50 \%$ the process AOX discharge is $2-2.5 \mathrm{~kg} / \mathrm{ADt}$. Biological treatment typically reduces AOX by some 30-50\%. On this basis, the AOX discharge achievable for a "New Mill" on a long term basis would be $1.5-2.0 \mathrm{~kg} / \mathrm{ADt}$.

It should be noted that the above effluent discharges are rated for typical softwood pulps that meet the market pulp quality criterias. AOX, especially, is very different for hardwood pulps. Because of a lower lignin content of hardwood pulps, the bleaching chemicals use is much lower resulting in a lower Aox discharge. This difference between softwood and hardwood pulps is significant enough that separate discharge limits are normally set. Figure 5 illustrates the situation in Sweden. The TOCL limits that, in most cases, become effective by the end of 1990, are determined based on the ratio between hardwood and softwood pulps. All Tocl limits are typically given as annual averages. The trend shows that for $100 \%$ softwood pulp, the TOCL limit is around $2 \mathrm{~kg} / \mathrm{ADt}$ (or $2.6 \mathrm{~kg}$ $A O X / A D t)$, while for $100 \%$ hardwood, the limit would be less than 1 $\mathrm{kg} / \mathrm{ADt}$. There are variations from this trend depending on local circumstances. For example, some of the mills produce semibleached pulps part of the time, etc. Also, like elsewhere, the requirements of the recipient are considered when establishing the limits.

Although the AOX discharge levels discussed above are noted for a "New Mill" case, a "Conventional Mill" can be upgraded to meet almost equal AOX limits as a "New Mill." 
Figure 5. TOCL Discharge Permits in Swedish Kraft Pulp Mills

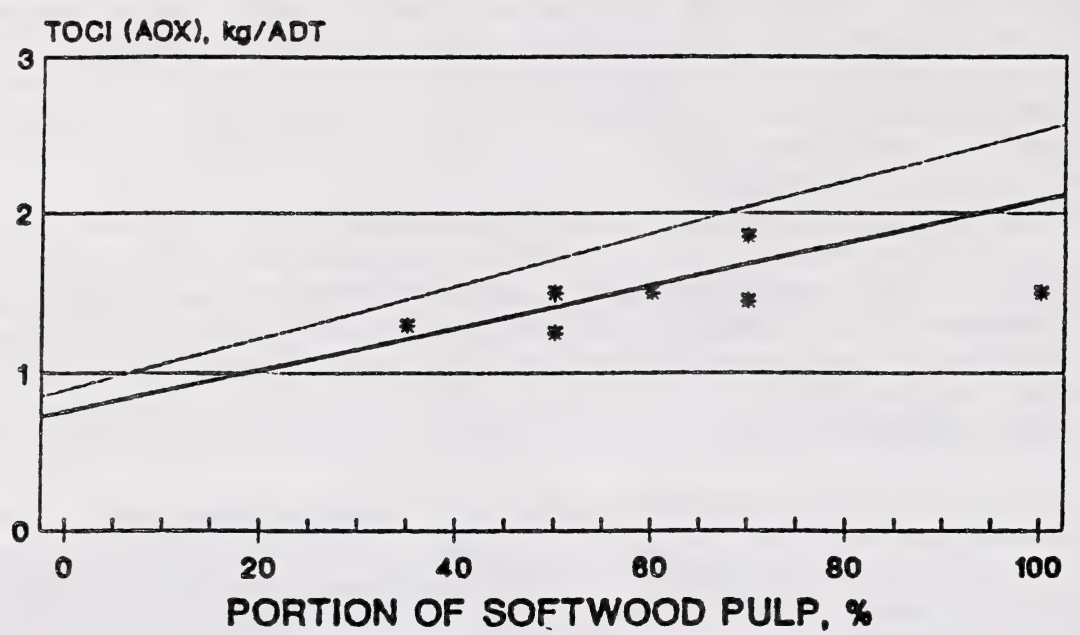

\section{- AOX - TOCI * Indiv. MIII Pormite}

Colour

Effluent colour can be reduced e.g. through:

- Improved Brown Stock Washing

- Installation of an Extended Delignification and/or oxygen Delignification system

- Installation of an E/O Stage

- High $\mathrm{ClO}_{2}$ Substitution

- Use of Peroxide as Bleaching Agent

By applying these techniques in new mill design or in the retrofit of an existing mill, the effluent colour can be reduced to about $100 \mathrm{~kg} / \mathrm{ADt}$. Biological treatment has hardly any impact on the effluent colour.

\section{Future Trends}

Large variations in environmental regulations exist today between different countries and even different states and provinces. For traditional effluent parameters like e.g. BOD, the permit limit for a bleached kraft mill varies typically anywhere between 3 and 10 $\mathrm{kg} / \mathrm{ADt}$. Although local circumstances may cause some variation to remain in the permit limits between areas and countries, more uniform practices will most likely be seen in future. 
Especially the allowable level of chlorinated organic compounds in the effluent is a developing topic. While some countries have already established the short term permit limits and future targets, some others are still trying to establish a basis for regulations on this subject. The current regulations are based on lumping all chlorinated organic compounds together and setting the permit limits for that total. However, it is generally accepted that some compounds may be more harmful than others. In future, when more details are known about the impact of specific compounds, the permit may become even more detailed and specific limits be set for specific compounds depending on their potential impact or environment.

Large volume of new bleached kraft pulping capacity is being built in the world today. It is safe to say that all the new capacity produces effluent that will have less impact on environment that the effluents from a conventional plant. As a short term trend we expect that the existing mills will be modifying their processes and equipment to approach "New Mill" from the effluent quality point of view.

New technology is being developed for further improvements of the quality of a kraft pulp mill effluent. Research is also being conducted to find new pulping and bleaching processes. Some techniques that may become available in the future include:

Pretreatment of pulp prior to oxygen delignification in order to allow further delignification without pulp strength loss (e.g. PRENOX).

- Ultrafiltration of fractions (e.g. E,-filtrate) of effluent for AOX, and colour removal. Again, the disposal of the concentrate is the most serious problem with this technique.

Chemical flocculation of effluent for BOD, colour, etc. removal. The volume and treatability of sludge are serious problems with this process.

Although there is a definite trend towards lower standards for certain environmental parameters, there will always be a need to understand the specific requirements and limitations of a given recipient. The work being carried out to model the rivers and other recipients will always be necessary in this respect. 



\title{
SAWMILLING IN THE 90's
}

\author{
R.J. Craig \\ President \\ Carroll-Hatch (International) Ltd. \\ North Vancouver, B.C. Canada
}

Worldwide political and cultural changes will adversely impact on raw material supplies in the 1990's and probably be the precursor of worse to follow in succeeding decades.

Until this time, we in North America have looked at overseas countries only as markets. Foreign exchange, foreign aid to emerging nations, and high quality fibre combined with cheap labour may all prove North America vulnerable to foreign influences beyond its control. While we may have great forests in North America, the combination of other factors will require us to be far more efficient in the conversion of our fibre than ever before.

For good commercial reasons, the whole stand of a forest, including the hardwoods, which might today be considered weeds, must be converted into value products. As well, sociological imperatives will demand it.

Reduction in the North American forest base is inevitable due to the demands of environmentalists, aboriginal groups, urbanization, inadequate pest control, infestation, wild fire, entrepreneurial groups, etc.

Consequently, there will be more bidders for less timber. Some of these bidders may include speculators (domestic and foreign), and greatly increased timber costs will result. 
The corollary is that:

- lumber manufacturers of the 90's must extract all potential value in fibre available.

- no longer will the lumber manufacturer be able to afford the wasteful procedures of the 70's and 80's either in the woods or in the conversion plant.

- stems that might have been left behind in the forest will have to be brought out, not only for sociological reasons, but simply because they have value as fibre to be used either in a solid wood product or as fibre for a pulp mill or homogenous panel mill.

If that stem, or even part of it, gets to the sawmill, the sawmill must be able to extract the greatest possible value from it, including the chips from that which will not make lumber.

Volume production sawmills of the 70's and $80^{\prime}$ 's will be replaced by sawmills whose efficiencies are measured by value and not volume. This will apply to the full spectrum of sawmill manufacture, from the mill of the south to the plants of the northwest.

Fibre that is today consigned to commodity high speed production that can yield grade and cross sections suitable for further manufacture either on the premises or elsewhere, will be redirected to facilities that can extract the full potential. This is the fundamental challenge for the primary breakdown plant of the future.

Optimization was the buzzword of the 80 's. It will become a necessity of the $90^{\circ} \mathrm{s}$, and to be profitable the operation will require optimization as a reality and not just as a buzzword. 
The manufacturer of the 90's will produce better lumber more accurately, and do it with greater efficiency. In order to improve yield and value, he must reduce the current high waste of kerf and trim.

Improved saws and saw guides can provide precision manufacture and greatly improved yields. Robotics may remove some of the inconsistencies of human effort in many places in the production line.

Fortunately, technology can now provide the tools to make optimization a realistic objective.

In the 90's we will see inside the log and know in advance where the rot is, where the knots are, which side the compression grain is located on, and where the shake or other defects are located.

We will scan the log and provide a computer printout with total detail. In milliseconds, a sawing pattern will be established. A computer will operate the primary cut, and the lumber produced will be scanned by an edger-optimizer and a trimming optimizer, and the product will then be directed to a sorting facility where it will be graded and assigned piece by piece to further processing or for shipment. It might go directly into a continuous dry kiln and be automatically stacked and tallied.

The computer will have made these decisions with full knowledge of the dictates of the market and the order file. 
The product to be further manufactured, for example to be resawn, ripped and cut, can be directed to a satellite operation, where after electronic scanning, the full potential value of a given stick of lumber is determined and processed with accuracy.

The computer will know the state of the inventory at all stages of manufacture at all times, and will relate the raw material to the order file commitments and the product in process. Overruns, reruns and shortages will be reduced to optimum infrequencies.

In the last two decades, the industry has made major reductions in the man hours of unskilled labour needed to operate a sawmill. The next decade will see even fewer man hours, but the persons on the production floor will have to be trained in specifics relating to value of fibre more than ever before. The important function will be not so much hand and eye coordination but the mind and instrument, and industry should use its influence to direct the curricula of the appropriate learning institutions in advance of the demand.

Maintenance will be monitored and probably directed by computer. The implications of continuous operation will require a most precise and diligent maintenance program. Breakdowns can be reduced to a tolerable minimum only through a program designed for such needs.

One of the most valuable employees of the management team of the future will be the person who can design and control the computer program in all its intricate implications. All departments of management and operation will be interdependent. The benefits from their interaction will be in direct proportion to their mutual effectiveness. 
In fact, where in the past cost effective labour reduction has been a prime purpose of good management, the next decades will produce worthwhile rewards only if a true synergism exists with each production unit and between that plant and the complementary raw material supply departments and the marketing functions.

The technology exists today to do these things. It remains for the manufacturer to bring them into practice.

A fully automated mill can be designed today, but the practicality of the investment may have to wait until some time in the future.

Notwithstanding, it becomes more and more essential to work toward this optimization, because the value of the fibre will not permit the waste of.a 1\4" saw kerf. It will not permit such imprecise manufacture that extra thickness and width must be planed off to get accuracy. The sawmill of the 90's will have its machinery on such solid foundations that precise sawing can be achieved and dressing of the product will only be a polishing job by a sander, if at all.

Kiln drying in the $90^{\circ} \mathrm{s}$ will have to become more efficient. The cost of energy in the form of electricity or fossil fuels will probably always make energy from wood waste and bark the only practical procedure. Drying by microwave is presently not seen to be a realistic probability, nor is drying by chemical. However, materials handling in present procedures is far too expensive and design opportunities exist to improve this aspect. Most importantly, drying must become more precise to fit the customer's needs, and it must be done to enhance the grade of the lumber and to reduce the high percentage of fibre that is currently destroyed in the kiln process. 
Optimization in the sawmill is a technical reality today and a necessity for the future. However, even more important is the computer enhanced decision making process for the log merchandising before the log ever gets into the mill. Ideally, the first computer analysis is made before the stem is bucked, preferably in the woods, but surely in the log yard or on the jack ladder depending on the practicalities dictated by the size and grade of the stem. It makes no sense to try to correct the mistakes of $\log$ bucking after the $\log$ is in primary breakdown. It is technically possible to see inside that stem and buck it to enhance the value to the greatest extent. Anything less must be considered a waste of a valuable resource, which the life of the corporation can not permit any more than the community should or will tolerate it.

The future of sawmilling in North America is encouraging. The total forest resource is one of the best in the world and we know there is more value in the fibre than we have been extracting. Technology, already vastly superior to few years ago, will continue to improve. Engineering and design expertise exists than can put these technologies to work in facilities where they can accomplish the best results. Dynamic decision making based upon computer enhanced intelligence can bring great rewards. The opportunities to change for the better are many, and it is the great challenge for the next decade. 


\section{WOOD WASTE - A DISPOSAL PROBLEM OR AN OPPORTUNITY?}

\section{BY PETER VAJDA}

The title of my talk was suggested to me and I gratefully accepted it. Actually I welcomed the chance to talk about this subject which has occupied most of my professional life, namely finding uses for wood waste, developing opportunities for products made from wood residues, in short, making silk from what was often thought to be a sows ear.

I suppose we can classify wood waste into two basic catagories: forestry or logging waste and mill residues. There is, however a third catagory which is gaining increased attention of late, namely Municipal Carbage or more specifically (in the context of this talk) it's wood content. The extent to which any of these wood waste forms are utilized or turned into usable products depends largely on the supply-demand picture for wood products in general, either in terms of local or regional conditions, or world wide supplies and markets. For instance Europe with its limited supply of timber and large concentrated markets utilized every tree and nearly all residues whereas in North America, a more complete wood utilization had to await and is still awaiting the development of a greater demand, not only in domestic but also by the export markets. 
In most cases technical solutions or product developments were available or certainly proposed decades before the market needs materialized and much of this research was originated or motivated not by market demand, but mainly to solve a waste disposal problem.

Examples of this kind of phenomenon abound. To mention a few:

- the development of particleboard made from shavings and sawdust which was originated in the early fifties but did not really take hold until the late sixties.

- The development of waferboard/OSB made from "weed species" as a replacement for softwood plywood, first thought of and actually implimented in 1954 but not accepted by the industry and the markets until the late sixties.

- Pulp chips generated by sawmills were classed as "hog fuel" as late as the 50's and not really accepted by pulpmills until the mid-60's. Some pulp mills are still reluctant to accept and use veneer chip unless forced by a limited supply.

On the whole, wood mill residues in North America were, to a large extent, always utilized except for a rather short period extending roughly from World War 11 to 1973. 
Before World War II all sawmill residues were classed as hog fuel and were used to generate heat and power for the mills and in some cases, for the surrounding communities as well. The waste problem really started with the advent of low cost oil, natural gas, and electric power, all of which rendered the use of wood-waste as fuel uneconomical.

It is in this period, between 1945 and 1973 that most of the innovation as to product development from wood waste occured - again not to satisfy a market demand, but to solve a disposal problem.

- In 1952, dry process hardboard developed mainly for the ulilization of veneer chips - not wanted by pulpmills, by the American Plywood Association.

- In the early 50's, the very concept of using sawmill chips for pulp manufacture.

- In the early 50's the use of shavings, sawdust and even dry plywood trim for particleboard and later, MDF.

- The use of sawdust and shavings - instead of chips - for hardboard manufacture.

By the late 60's, ceitainly by 1972/73, between particleboard, MDF hardboard, and, of course, pulpmills, nearly all of the "residues" generated by sawmill and plywood plants on the U.S. west coast and the 
U.S. South were utilized. There were still a lot of unused residues in the inland U.S. Western states mainly due to the remote locations of these mills from the major markets.

A lot of effort was expended to find some use for bark, none of which succeeded. As a result, bark is still burned, in some cases used for heat and fuel generation.

At any rate, the utilization of sawmill and plywood mill residues in the U.S. (except for the inland west), was nearly complete when, in 1973, the oil crisis occured. Since that time, there is no real mill residue utilization . problem in the U.S. Wood waste is used for all the various composite wood products noted earlier, plus as fuel for generating heat and power. In California for instance, several board plants have shut down because the wood waste they used had a higher value as fuel for power generation.

To make matters worse, the volume of sawdust and shavings generated by lumber mills greatly decreased over the past twenty years as new technologies permitted more accurate sawing, smaller sawcurf and less plaining. We used to figure on about 0.5 to 0.6 bone dry tons (BDT) of sawdust and shavings per one thousand board feet of lumber output. Today the average is more in the order of 0.3 to 0.35 BDT. In addition, a number of new uses were developed for mill residues.

In the U.S. southeast for instance, most sawmills se!l the shavings to chicken famers, the bark for landscaping and some sell sawdust to brick manufacturers or other industrial users. I have actually bumped into mills 
in the Carolinas who sold every form of their waste, except chips, because the pulpmill was too far!

All of this, of course, in the U.S. What about Canada?

The mill waste utilization problem in eastern Canada is just about non-existant. Much like in the U.S., pulp chips are at a premium. Their cost at the sawmill well over $\$ 100 / B D T$. A large part of the sawdust and shavings are used in particleboard and MDF manufacture and what's left is used as fuel, as oil and natural gas costs are fairly high in eastern Canada. Of course, power generation from wood-waste is seldom feasible in most Canadian locations as Canadian electric power costs (possibly excepting the Maritimes) are probably one of, if not the lowest of anywhere in the world.

There is, however a serious waste disposal problem in western Canada where natural gas and electric power costs are low and local markets much too small to absorb the large volume of composite wood products which could be made from western residuals. Also, to date, western Canadian mills are too far from the large eastern markets.

As western Canadian mills are no further away - or at no greater freight cost away! - from say, Toronto, Chicago, New York etc. than western U.S. mills, one is justified to inquire as to the reason western Canada did not participate in the exploitation of wood-waste for composite board manufacture to anywhere near the extent the western U.S. did. 
The answer to this question, to put it simply and brutally: a rather inward looking attitude on part of the Canadian industry, a lack of interest, lack of initiative or simply a lack of foresight and courage!

While Canadian composite board consumption was always higher than in the U.S. on a per capita basis, the Canadian market is still only $13 \%$ to $14 \%$ of the U.S. demand. Despite the proximity of the U.S. markets, Canadian plants were small, designed to serve the relatively small Canadian demand. As a result they found the competition from the much larger U.S. plants hard to counter, even on local Canadian turf. It was not until the early 80 's that larger output plants were built in Quebec, (mainly by European investors!) which, helped by the favorable exchange rate, turned the negative Canadian trade balance in composite wood panels into a positive one.

The output of the western Canadian composite board industry is greater than the western Canadian demand but the industry is too small to be competitive abroad! The only exception to this is the Blue Ridge MDF Plant in Alberta which exports (to the U.S., Europe, and Asia) over 60\% of its output! Yet the supply of mill residues in B.C. and Alberta alone is sufficient to supply half of the demand by the U.S. particleboard and MDF industries!

Table 1 shows the softwood lumber production in the various regions of the U.S. and Canada, the shavings and sawdust generation by those mills 
against the particleboard and MDF production (or capacity) in the corresponding regions and the demand for wood raw material by these composite board industries.

Table 1 illustrates that the sawdust and shavings supply in the west coast of the U.S. is completely used up. The roughly 600,000 BDT of yearly surplus is used for fuel or other purposes. In fact, some Oregon mills use other forms of wood for raw material (ply trim, chips etc.) while most of the shavings and sawdust in California are used for heat and power generation. Residues are also used by the hardboard industry and for molded fibre products.

As mentioned earlier, there is a surplus in the inland states of the west, again, most of it currently used as fuel or wasted. There is a substantial shortage in the south and indeed currently around $30 \%$ of the wood supply of southern board plants is in the form other than sawdust and shavings, such as softwood or hardwood chips or even roundwood. Probably, the supply of pulpwood in the form of thinnings from the large southern plantation forests is more underutilized in the south than the residues generated by wood product plants.

In the U.S. north, there is also a shortage and most of the board plants here are using roundwood. Also, lumber mills are small and most use their waste for fuel. The greatest supply (or surplus) of wood in the north central states (Wisconsin, Minnesota, Michigan) is in the form of - 


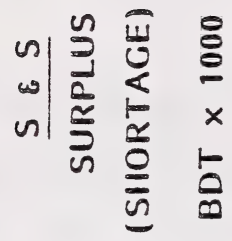

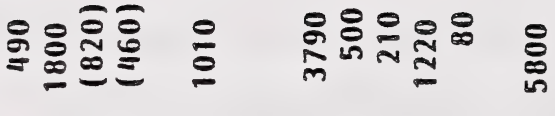

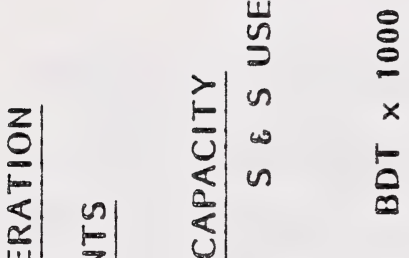

윰윯듕 \&

$\sum_{i} \sum_{5} \quad s$

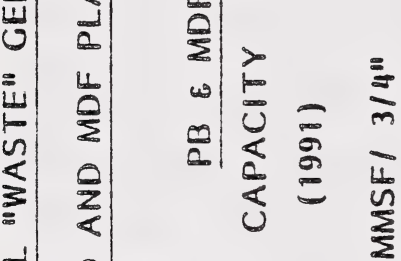

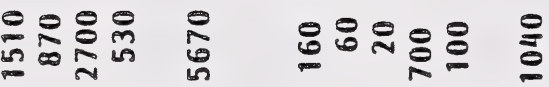

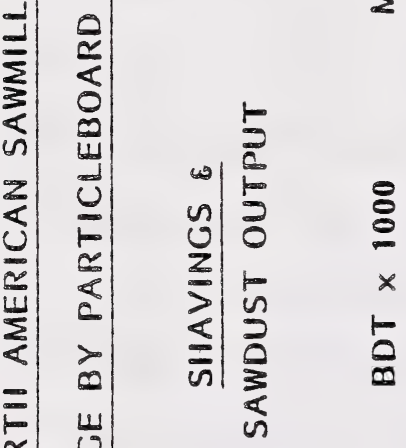

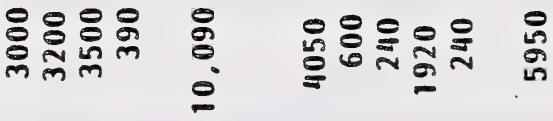

인 它

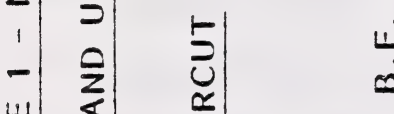

$\frac{1}{2}$

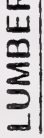

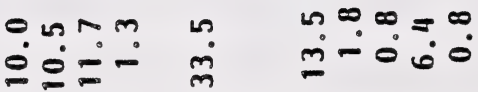

$\stackrel{\sim}{\sim}$

$z$
$\frac{z}{0}$
$\simeq 1$

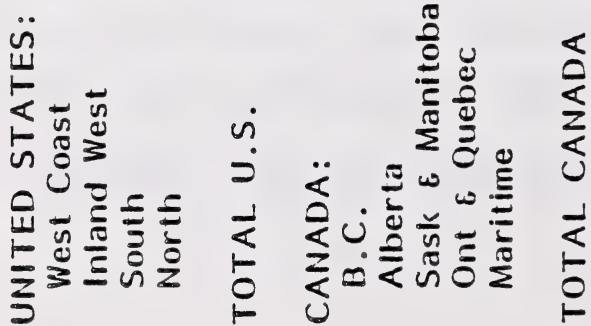


what used to be regarded as weed type hardwoods, mainly Aspen. No more! The new OSB plants and the expanded pulp mill capacity just about exhausted this supply!

While there appears to be a total surplus in the U.S. of about 1 million tons of millwaste, other than bark and chips, (against 1991 plant capacity) the actual surplus is much less and is concentrated mainly in the inland states of the west.

By the way, the sawdust and shavings generation was, in Table 1, assumed or calculated at .3 to .35 BDT per MBF of lumber output. This is about half of the figure which was valid about 15 to 17 years ago!

The surplus of $S \& S$ generation in B.C. alone is over thrice the total U.S. surplus. The actual surplus is much less as most of the sawdust and shavings generated by coastal mills - about 1.5 million BDT per year is used as fuel by pulp mills or some even fed to sawdust digesters and turned into kraft pulp. The real surplus in B.C. is more like 2.3 to 2.5 million BDT per year, still a substantial figure.

There are some selected opportunities for using millwaste in the prairies, especially in Alberta. There are some apparent surpluses in Ontario and Quebec, mainly by mills in far northern locations. Probably most of this is used as fuel, as heating by oil in these northern towns is quite expensive. The same applies to the Maritimes.

As shown by Table 1, the greatest surpluses in mill residues are in western Canada. The most profitable and largest volume user of the 
shavings and sawdust type mill residues are the particleboard and MDF industries. The demand for particleboard in North America is expected to increase (by the year 2000 to 2010 ) by about 1000 MMSF $3 / 4$ " and that for MDF a further 1000 MMSF $3 / 4 "$, resulting in an increase in the demand for raw material in the order of 3 million BDT per year. Most certainly this is a real opportunity to profitably utilize the surplus of mill residues in western Canada!

There are, however two problems which must be taken into consideration. First the distance to the bulk of the large industrial markets of North America, $80 \%$ of which are located east of the Mississipi River or east of the Great Lakes! The supply of roundwood or pulpwood of either the hardwood or the softwood species is still plentiful in some eastern U.S. locations. While the cost of this material is greater than the cost of millwaste in the west, the total of wood cost plus outbound freight costs to market may be (and usually is) more favourable for a mill located in the east, all other factors being roughly equal. The advantage in the west is the superior product quality achievable from western softwoods. The advantage of the east is mainly the proximity to the customer!

Secondly, the profit margins achievable at the present market prices of particleboard and MDF are somewhat marginal at the current capital cost of a new plant. Unfortunately the current demand is in reasonable balance with the current industry capacity. The bulk of the particleboard industry was built more than 12 to 15 years ago, is completely depreciated, is still quite efficient, and is earning a handsome margin 
against direct costs. This is tough competition for a new plant which has to service it's debt. The situation is better for MDF as at least half of the current capacity was built within the past eight years and some of the older plants are inefficient and obsolete.

In view of the above, building a new particleboard or MDF plant in western Canada aimed at the North American markets is a question of timing: questionable in financial terms at present, certainly appropriate by the year 2000. As capital costs are likely to increase over the next 5 years so that, building within the next few years is an option, provided one is willing to accept rather marginal returns over the next five years.

There is however, an alternate market opportunity for composit board plants in western Canada - (mainly B.C. and Alberta): The rapidly growing markets along the Pacific Rim of Asia.

The markets in Japan, Korea, Taiwan, as well as others currently consume over 10 million $\mathrm{m}^{3}$ of Luan plywood corresponding to a volume of about 12 billion $\mathrm{ft}^{2} 3 / 8^{\prime \prime}$ basis or, (since a lot of this Luan plywood is less than $1 / 4^{\prime \prime}$ or $6 \mathrm{~mm}$ thick about 36 billion $\left.\mathrm{ft}^{2} 1 / 8^{\prime \prime}\right)$. In comparison the total North American hardboard consumption is in the order of 6 billion $\mathrm{ft}^{2}$ 1/8". The North American plywood consumption around 30 billion 3/8" base, or 90 billion 1/8" base. This is a huge market. The supply of Luan plywood as well as Luan peeler logs is expected to decrease very rapidly and particleboard or MDF - currently mainly MDF - is expected to replace or supplement the Luan plywood supply, similar to the replacement 
or supplementation of sanded grade softwood plywood by particleboard and MDF in North America. It is not unreasonable to expect that this Asian market opportunity is just "what the doctor ordered" for the profitable utilization of the mill residues of western Canada.

There are, of course some other product opportunities for utilizing mill residues. These, however require a more specialized technology as well as marketing.

One such product line is the family of molded fibre products. This kind of technology is currently used in the U.S. and Europe in the manufacture of molded doorskins, molded fibre automotive parts and some molded furniture parts. The possibilities for molded fibre products appear to be unlimited but one needs to be quite specific about end-uses and marketing strategies. Another possiblity for the utilization of wood mill residues is the slowly developing cement, bonded board products, or gypsum particleboard or fibreboard products. As all these products are new to the North American (as well as European) markets, it may be more appropriate, however to build the initial plants close to the larger eastern North American markets.

Between the product lines noted above and the still growing proliferation of pulpmills in western Canada, all the mill residues - other than bark, should be fully utilized before the end of this century. The utilization of bark will have to await some imaginative new product development or a drastic increase in the price of natural gas and electric power in western 
Canada. By the way, European board manufacturers do use un-debarked roundwood. This is not an advisable strategy for western Canada, as it would negate the major quality advantage of a bark-free light coloured wood supply and the attractiveness of the finished product.

As for forestry or logging waste, the opportunities are much more limited. It is very costly to collect, debark, chip and transport to the mills any kind of wood - especially small diameter tops and branches. Because of this high cost, the most likely end users are probably pulpmills, since they are the only ones who could afford to justify the above noted costs. That is if pulpmills will run so short of sawmill and roundwood chips that they will be willing to accept such lower quality chips. This is much more likely to occur in Europe and in the eastern part of North America than in the west. I saw hardboard plants in Sweden and elsewhere in Europe using branch wood, including the bark, as long as twenty years ago. This kind of use however, is not likely to occur in North America on a large scale for a while, certainly not in western Canada.

There are really not very many "weed species" left in our western forests. Between OSB and CTMP pulp the Aspen resource is now quite well utilized. MDF or hardboard or molded fibre products are capable of using a lot of the scrub type denser hardwoods. The use of Aspen or lower grade softwood in laminated veneer lumber is also likely to gain greater acceptance. 
Last but not least let's consider the wood waste in Municipal Garbage, consisting of wood waste from industries in the cities, household waste and waste from demolition. This is a real disposal problem and utilizing this type of waste in composite wood and fibre products is a real possibility and opportunity. After all, waste management corporations are one of the latest stars of the stock markets. Not surprisingly, European board manufacturers are already using some wood from this source and are developing machinery to separate, de-nail, clean and break down the various forms of wood from garbage. The minimum type of end use for this kind of wood is, of course, fuel. But use in composite board products is a real possibility, especially in view of the shrinking supply from other sources.

All the authorities agree that despite the fact that wood is a renewable resource, the total timber supply is finite and is even likely to decrease with curtailed land use and tree mortality due to pollution. As a result, the more complete utilization of the wood resource, especially the utilization of mill residues for the manufacture of usable wood products will not only gain importance but will become an essential part of our total supply of forest products. 
THE NEXT GENERATION OF STRUCTURAL PANEL PRODUCTS

\author{
By \\ J.A. Shields \\ Manager, Department of Composite Wood Products \\ Forintek Canada Corp. \\ 800 Montreal Road \\ Ottawa, Ontario \\ K1G 325
}

\title{
Abstract
}

The waferboard/OSB industry in North America is composed of highly efficient and highly automated operations. The structural composite panels produced have achieved wide acceptance as construction sheathing. Evaluations of commercial products according to Canadian, United States and British standards have shown that panels easily meet North American standards but have difficulty meeting the restrictive swelling criteria of the British standard. In terms of durability it was observed that accelerated aging tests on waferboard/OSB panels were poor predictors of natural deterioration of properties suffered by panels exposed to weathering on test fences. Alternatively the creep performance of the product appears to be quite predictable and uninfluenced by the industry's tendency towards lower resin levels. In the next ten years we will see a concerted effort to increase the strength and stiffness properties of oriented panels through the use of longer strands and a high degree or orientation. Several new techniques have been developed to stabilize waferboard/OSB panels and control thickness swelling in humid environments. Stabilized panels also offer an opportunity for the development of new products such as preserved panels, siding and other higher value applications. 


\section{THE NEXT GENERATION OF STRUCTURAL PANEL PRODUCTS}

Introduction

Predicting the future normally comes back to haunt one. It is a science best left to economists and market analysts. For example, who could have forecast the beginning of a new industry back in 1961 when the first waferboard plant was built? Following a number of years of modest growth, the waferboard/OSB industry has suddenly undergone an exponential expansion in the last five years. Mr. Bernard Fuller of Resource Information Systems Inc. has been predicting substantial growth in the sector, however I'm sure he would admit to being somewhat overwhelmed by what has taken place in the last few years in North America.

With each new mill we have seen advances in composite board technology improved process control, reductions in manpower, greater efficiencies and so on. The two main products, random waferboard and oriented strandboard, however appear to have each reached a certain property and performance plateau. Market acceptance and the cost structure in place in North America of course have played a major role in establishing the products'present level of periormance.

This paper provides an overview of the properties and performance of structural composite panels on the market today with particular emphasis placed on areas where the product must be improved to maintain customer confidence and to expand into new markets. Some technological advances under development which should lead to new products are highlighted.

\section{Product standards.}

Canada, United States and very recently Britain have issued product standards which establish property limits for waferboard/OSB. As shown in Table 1 with a few exceptions these specified properties are similar in each country. The Canadian standard and the British have moved to reflect the modem trend to increase strength and stiffness through particle orientation. 
The one area where the standards differ significantly is in the area of thickness swell after water soaking. The Canadian standard has a relatively high tolerance of 20 and $25 \%$, the U.S. standard does not stipulate a maximum and the British standard has established a very low swelling requirement even though measured by a somewhat more severe vertical swelling test. There are some differences in the area of durability and it is also worth noting that none of these product standards establish a criteria for load duration.

In a recent study conducted at Forintek, the swelling properties of commercial waferboard and OSB were measured using Canadian and British soaking tests. A summary of the results for 24-hour soaking is shown in Table 2. The products tested easily met the Canadian standard, in fact the results appear to indicate that the Canadian standard could be made more restrictive. Alternatively none of the panels met the British requirements for swelling which is a concern to any North American mill wishing to access the British market.

The soaking tests were extended up to seven days and comparisons were then made with one side wetting of large panels, a test used in the Canadian performance standard for Construction Sheathing CSA-0325.0-M88. Half sheets $(1200 \mathrm{~mm} \times 1220 \mathrm{~mm})$ of three nominal thicknesses were measured for thickness at the edge and various locations up to $75 \mathrm{~mm}$ from the edge to determine how waferboard responded to a simulated rain soaking. The panels were observed to swell progressively more towards the edge, exhibiting the so-called "flaring" tendency. The results for the two national standard swelling tests were plotted against measurements of oneside wetting (Figures 1 and 2). These results point to a close relationship between horizontal soaking and one side wetting with measurements taken 12.5 to $25 \mathrm{~mm}$ from the edge and provide a means of predicting durability of panels placed in a high moisture environment. The British or vertical soak test simply indicates how much the edge of a panel may swell but does not 
relate well to one side wetting measurements. After prolonged wetting the edge of the large sheets were found to swell to levels approaching the vertical soak tests.

Product durability.

Although it is recommended that waterboard panels be protected from lengthy outdoor exposure, they will nevertheless be exposed to weather during construction delays, improper installation, or negiect in storage. Altemating climatic conditions and the ensuing swelling and shrinkage affect the internal structure of waferboard, thus causing dimensional changes and strength losses. A reasonable level of durability, therefore, should be expected from these and other structural building materials to ensure that they remain serviceable for the expected lifetime of the structures involved. Accelerated aging tests are an essential step in evaluating the durability of composite panel products, however, there are no reported satisfactory techniques which adequately measure bond degradation as it relates to field periormance.

A study was initiated in 1983 to evaluate the durability of waferboard as measured by various accelerated aging tests and under outdoor environments at several locations across Canada. The accelerated tests included:

- CSA The Canadian 2-hour boil test, CAN3-0437.1 M85

- ASTM The American Society for Testing and Materials, six cycle aging, 01037-78

- AFNOR Association Française de Normalisation V313 test, NF B 51-263

- APA American Plywood Association, six cycle test, APA Test Method D-5 
The exterior weathering tests (Figure 3) were conducted in a dry prairie environment in Saskatoon, Saskatchewan, a variable climate in Ottawa, Ontario and under humid maritime conditions at the Acadia Forestry Station in Fredericton, New Brunswick.

The deterioration in panel properties has been monitored for up to five years of exterior exposure and comparisons have been made with accelerated aging tests. Overall the accelerated aging tests were unable to predict, with any degree of accuracy, the durability of waferboard panels and specimens in exterior weathering. Figures 4,5 and 6 present some of the comparisons drawn from this study. Aging tests were found to cause an exaggerated level of thickness swelling compared to actual outdoor exposure. Also the bending stiffness or modulus of elasticity of panels exposed to the elements for 5 years were reduced much more severely than predicted by standard tests. For strength or modulus of rupture some of the more drastic accelerated tests showed similar reductions to the outdoor weathering.

It is interesting to note that the Fredericton location with the higher average relative humidity expected of a marine climate, caused noticeably more weathering and subsequent deterioration of panel properties.

Data generated from this study has helped to evaluate how well various accelerated aging tests simulate the effects of actual outdoor weather conditions. Information on the long-term service life of waferboard/OSB over a wide geographic region is essential to determine probable limitations of the products and to identify new markets in all types of building construction. For example, bending properties of weathered waferboard specimens were reduced from 33 to 41 percent suggesting that durability must be improved if more demanding exposed applications are to be exploited.

\section{Time Dependent Behavior (Creep).}

The creep behaviour of waferboard/OSB is more complex and generally more pronounced than for solid wood and veneer products. With a tendency for 
industry to reduce adhesive levels a concem was expressed that this practice could have further detrimental effects on the long-term performance of waferboard/OSB.

A cooperative study between Forintek and the University of Toronto was established to determine the extent to which reductions in adhesive content might influence the creep behaviour of waferboard panels under various environmental conditions. A series of random waferboard panels were prepared in the laboratory with phenol formaldehyde resin levels varying from 1.5 to 3.0 percent. As property changes were expected to be slight, a highly efficient and accurate creep test apparatus was developed specifically for this study, Figure 7.

Reducing the adhesive content in waferboard from 3.0 to 1.5 percent was observed to have significant adverse effects on thickness swelling, bending strength and stiffness, linear expansion and internal bond strength. Waferboard bonded with different adhesive contents did not however vary significantly in terms of its various creep properties. Being random formed panels, they showed significantly higher creep than soitwood plywood controls. Figure 8 . It is anticipated that highly aligned composites would have creep properties very similar to plywood.

Waferboard/OSB in the 1990's.

Composite processing technology offers great flexibility and the opportunity to improve and extend the markets for waferboard/OSB. The product can be engineered to meet very high performance levels for demanding applications or it can be adjusted to simply meet minimum product standards. I believe we will see industry and mill standards climb steadily in the next decade. Standards will have to be revised to properly represent the improvements in properties and periormance criteria. 
Increased Strength and Stiffness.

The inability to produce long strands (six inches and greater) and dry them effectively has restricted orientation technology. The recent advent of large single pass dryers and waferizers capable of generating $300 \mathrm{~m}$ (12 inch) strands will enable the industry to move rapidly to much stronger, highly aligned products.

Highly aligned, three layered strandboards produced in the laboratory have demonstrated some of the potential in this area. Strength and stiffness of panels produced with $150 \mathrm{~mm}$ (6 inch) strands easily outperform CSP plywood in both parallel and perpendicular directions (Figures 9, 10). A parallel-to-grain modulus of elasticity (stiffness) of $10,500 \mathrm{MPa}$ (1.5 million psi) and modulus of rupture (breaking strength) of over $57.5 \mathrm{MPa}$ (8000 psi) are easily produced. A better control of particle geometry, degree of alignment and layer percentages will permit the producer of tomorrow to react to opportunities in a variety of applications specified by engineers. Structural composites will take on a whole new role as the engineered products of the future.

\section{Control of Thickness Swell.}

.Waferboard/OSB is a densified wood product. Composed of small discrete pieces of wood bonded together with a small amount of adhesive under moderate heat and pressure, waferboard/OSB must be highly densified to develop adequate properties. Densified wood normally tends to spring back when it is exposed to high humidity or immersed into water and strength properties tend to decline. At Forintek, we have spent a great deal of effort to understand and try to solve this tendency for composites to swell excessively. During the past few years we have applied for 3 particularly relevant patents as well as preparing numerous papers on the subject. The control of thickness swell referred to as stabilization can be achieved by pretreatment of the wood furnish, treatment during the pressing stage or by a post-heat treatment. Each of these techniques have now been tested in commercial operations or under pilot plant conditions. Some results for 11.1 
$\mathrm{mm}$ (7/16 in) panels are shown in Table 3. Resin levels and pressing conditions with the exception of steam pressing were typical industry levels.

Extremely low thickness swelling of less than $4 \%$ also means these products would potentially meet the rigorous swelling levels set in the British standard. Stabilized structural boards would solve many of the concerns in regards to swelling during the application of sheathing at construction sites.

\section{Stabillized Structural Products.}

The ability to produce a product under typical mill production conditions that does not swell should enable the industry to move into many new product applications. For example we have initiated a development project to consider the production of preserved products. Conventional panels and stabilized panels were produced then subjected to a short vacuum impregnation by CCA, a waterborne preservative.

The stabilized paneis absorbed sufficient levels of preservative without excessive swelling or property loss. Upon redrying the thickness increase was less than $5 \%$ (Table 4) and the suriaces of the panels were found to be quite smooth with only minimal wafer roughening due to the impregnation. This type of post presenvation is highly favoured by the industry since any type of pretreatment of the wood furnish with preservatives presents great environmental concerns, (hot pressing toxic chemicals, disposal of trim, toxic dust, etc.). The decay resistance of stabilized panels post-treated with CCA and other preservative formulations is presently being evaluated.

Projects are also in progress to evaluate stabilized panels for other applications such as exterior siding, fire retardant treated products and composite lumber.

\section{Conclusions}

Improved product quality and higher industry standards with increased consumer confidence will lead to a universal acceptance of waferboard/OSB 
in North America and parts of Europe. The production of stabilized panels and the progress of the industry towards high strength aligned panels will open new markets for waferboard in the 1990's.

The inclusion of chemicals for flame resistance, preservation, resistance to insects etc. will produce a whole new generation of products to perform in many diverse environments. The realization by engineers that this product can be produced to their specification will open up new markets in light industrial applications. In the next generation we will see structural composites such as waferboard/OSB move from being the cheaper substitute to the "high tech" building product of the 1990's. 


\section{Table 1}

Properties of Structural Board

Propertles

MOR (MPa)

MOE

IB

MOR after

after aging

Thickness swell (\%) $\quad 20.25$

24 hours

Linear expansion (\%) $\quad 0.20-0.40$

$17.2 \cdot 29$

$17.2 \cdot 12$

17.2

17.2

$3100 \cdot 5500 \quad 3100$

$3100 \cdot 1500$

3100

0.345

50

50

0.345

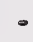

$22^{\mathrm{a}} \quad 22^{\mathrm{a}}$

$(10)^{\circ}$

$\begin{array}{lll}17.2 & 29 & 30\end{array}$

$\begin{array}{lll}17.2 & 12.4 & 15\end{array}$

$31005500 \quad 5000$

$3100 \quad 1500 \quad 2000$

$\begin{array}{lll}0.34 & 0.34 & 0.46\end{array}$

0.20

0.20

Vertical soak method.

Estimated thickness swell (CAN 0437) using data base developed by Forintek. 


\section{Table 2}

Thickness Swelling of Waferboard/OSB

Following 24 Hour Soaking

\begin{tabular}{|c|c|c|c|c|}
\hline $\begin{array}{l}\text { Test } \\
\text { Method }\end{array}$ & $\begin{array}{l}\text { Max. } \\
\text { Requirement } \\
(\%)\end{array}$ & $\begin{array}{l}\text { Waferboard I } \\
\text { Mean" } \\
(\%)\end{array}$ & $\begin{array}{l}\text { Waferboard II } \\
\text { Mean" } \\
(\%)\end{array}$ & $\begin{array}{l}\text { OSB } \\
\text { Mean" } \\
(\%)\end{array}$ \\
\hline
\end{tabular}

$7.9 \mathrm{~mm}$ nominal thickness

$\begin{array}{lllll}\text { British }^{\circ} & 22 & 38.8 & 26.3 & 37.0 \\ \text { Canadian }^{\circ} & 25 & 16.6 & 10.8 & 16.6\end{array}$

$11.1 \mathrm{~mm}$ nominal thickness

$\begin{array}{llrrr}\text { British }^{\text {b }} & 22 & 34.4 & 26.9 & 32.8 \\ \text { Canadian }^{\circ} & 25 & 12.0 & 8.5 & 10.7\end{array}$

$15.9 \mathrm{~mm}$ nominal thickness

British $^{b}$

13

33.7

19.2

31.5

Canadian $^{\circ} \quad 20$

8.3

4.8

7.4

ample size for each mean value is 30 .

- British Standards Institute (BSI) BS 5669.

- Canadian Standards Association (CSA) CSA-0437.1. 


\section{Table 3}

Thickness Swelling of Dimensionally Stable

Waferboard (7/16 in. thick)

\begin{tabular}{lccc}
\hline & \multicolumn{3}{c}{ Thickness Swelling. \% } \\
\cline { 2 - 4 } & $\begin{array}{c}24 \text { hour } \\
\text { water soak }\end{array}$ & $\begin{array}{c}72 \text { hour } \\
\text { water soak }\end{array}$ & $\begin{array}{c}72 \text { hour water soak } \\
\text { then reconditioned }\end{array}$ \\
\hline Steam pretreatment & 3.2 & 6.6 & 0.9 \\
Special steam pressing & 3.5 & 8.3 & 2.4 \\
Heat post treatment & 3.9 & 9.2 & 3.7 \\
\hline
\end{tabular}


Table 4

Post Treatment of $19 \mathrm{~mm}$ Stabilized

Waferboard (CCA)

\begin{tabular}{lcccc}
\hline Board Type & $\begin{array}{c}\text { Density } \\
\mathrm{kg} / \mathrm{m}^{3}\end{array}$ & $\begin{array}{c}\text { Retention } \\
(\mathrm{CCA}) \\
\mathrm{kg} / \mathrm{m}^{3}\end{array}$ & $\begin{array}{c}\text { Treated } \\
\text { Thickness } \\
\text { Swell } \\
(\%)\end{array}$ & $\begin{array}{c}\text { Re-dry } \\
\text { Thickness } \\
\text { Swell } \\
(\%)\end{array}$ \\
\hline Conventional & 670 & 11.9 & 27.7 & $\begin{array}{c}\text { not } \\
\text { available }\end{array}$ \\
Stabilized & 670 & 10.0 & 15.5 & $<5$ \\
Stabilized & 640 & 10.7 & 15.3 & $<5$ \\
\hline
\end{tabular}


Figure 1. Thickness Swell Plots of Small Specimen Horizontal 25-mm Tests Versus Large Specimen $(1220 \mathrm{~mm} \times 1220 \mathrm{~mm})$ One Side Wetting Tests

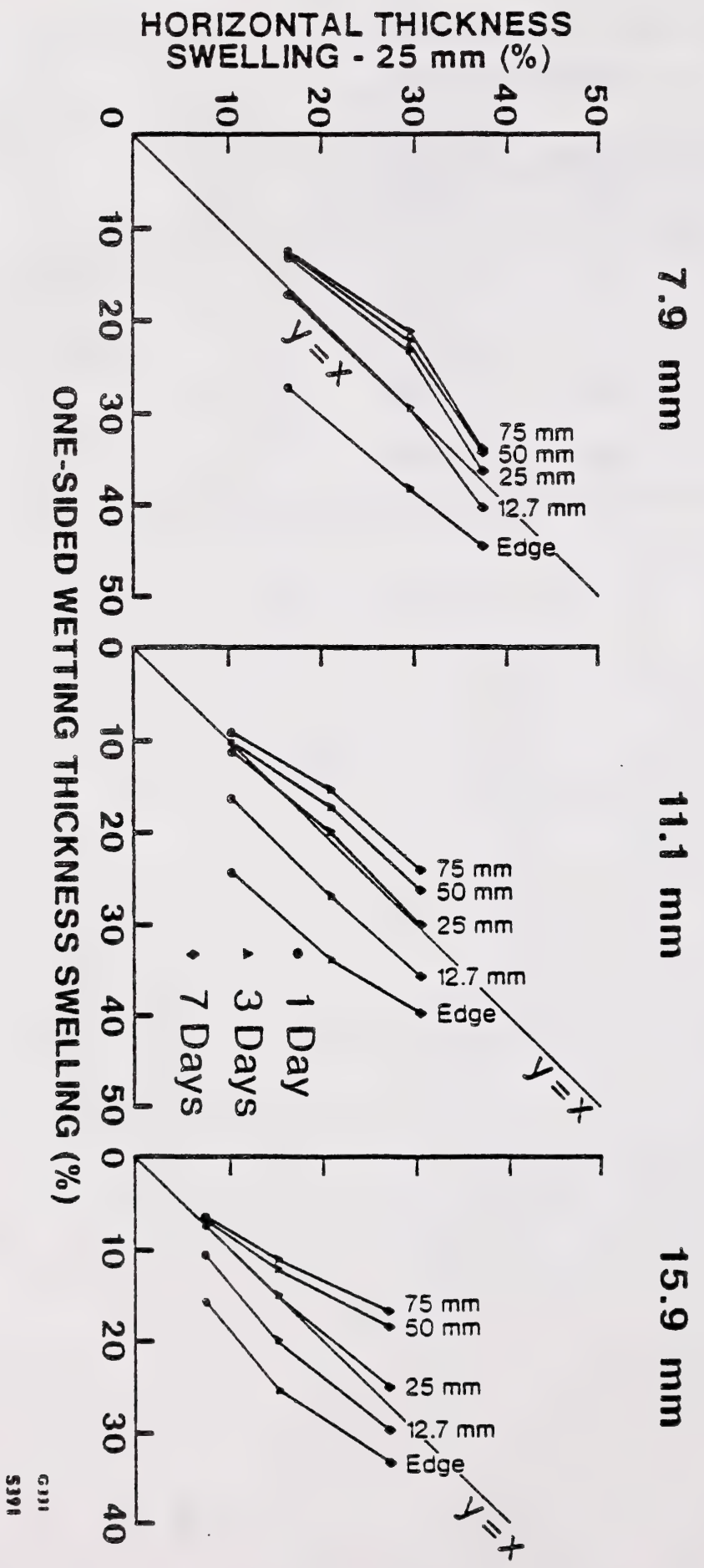


Figure 2. Thickness Swelling Plots of Small Specimen Vertical Edge Tests Versus Large Specimen $(1220 \mathrm{~mm} \times 1220 \mathrm{~mm})$ One Side Wetting Test

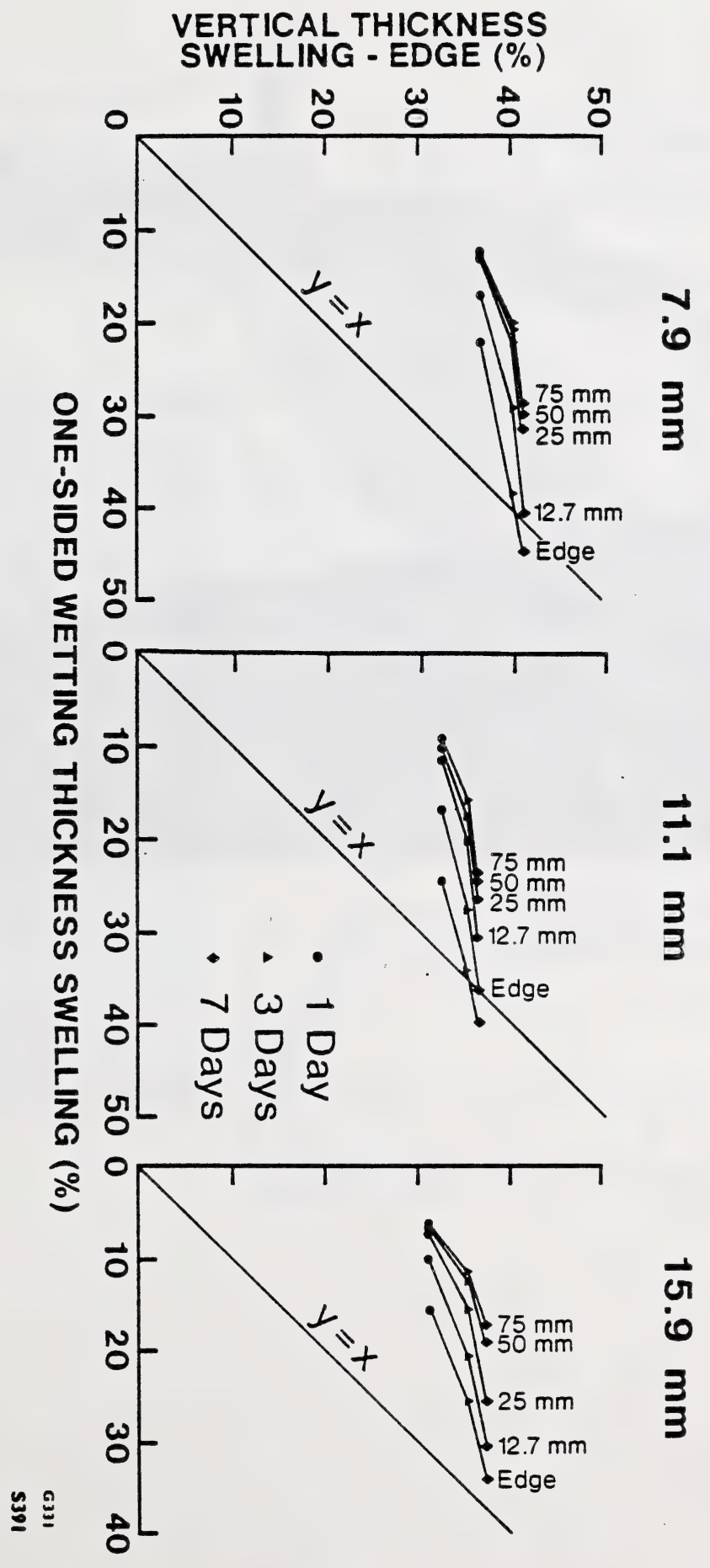


Figure 3. Outdoor Weathering Test Fence Facility

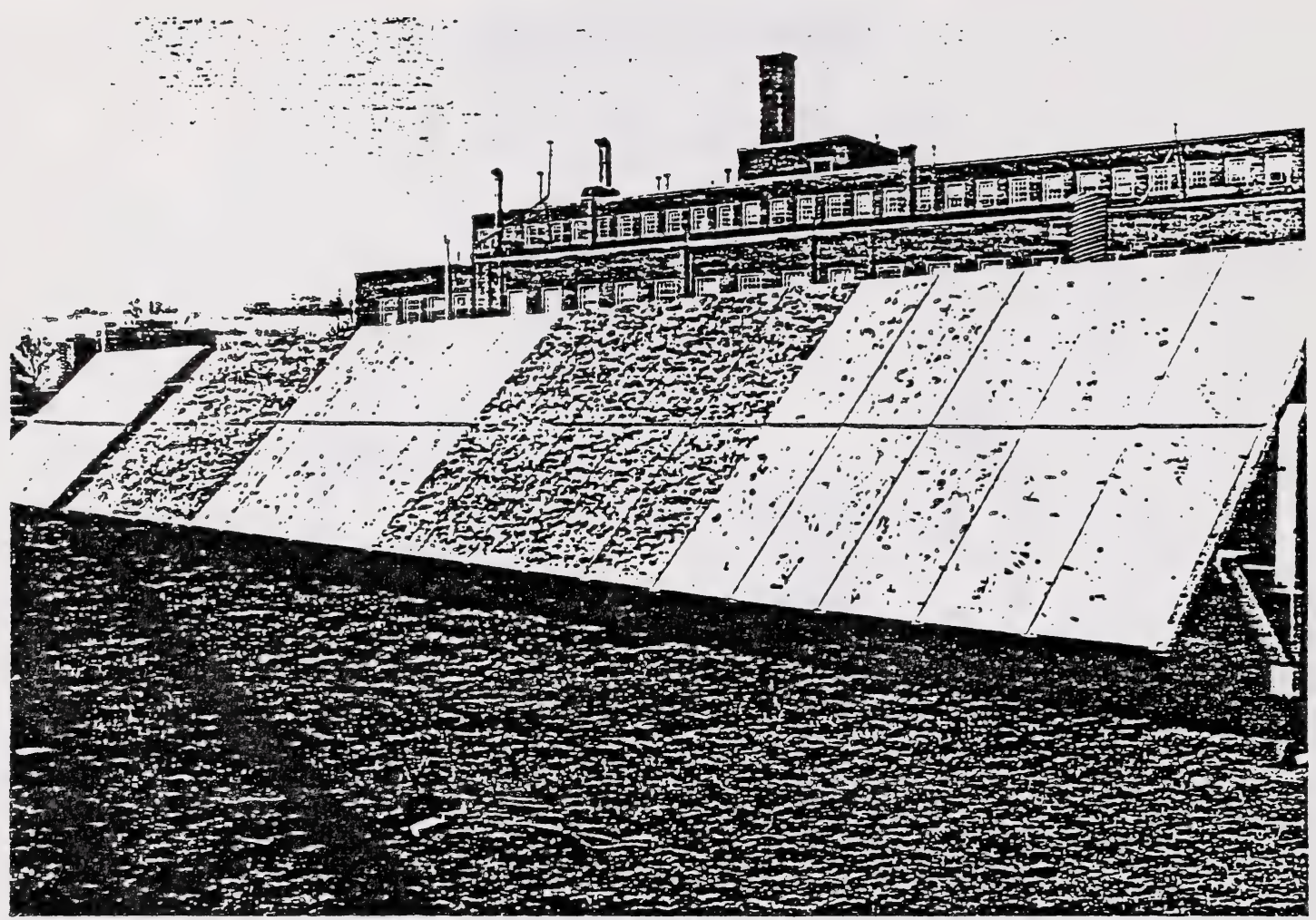

$83 \times 1+12$ 
Figure 4. Thickness Swelling of Exposed Waferboard Specimens

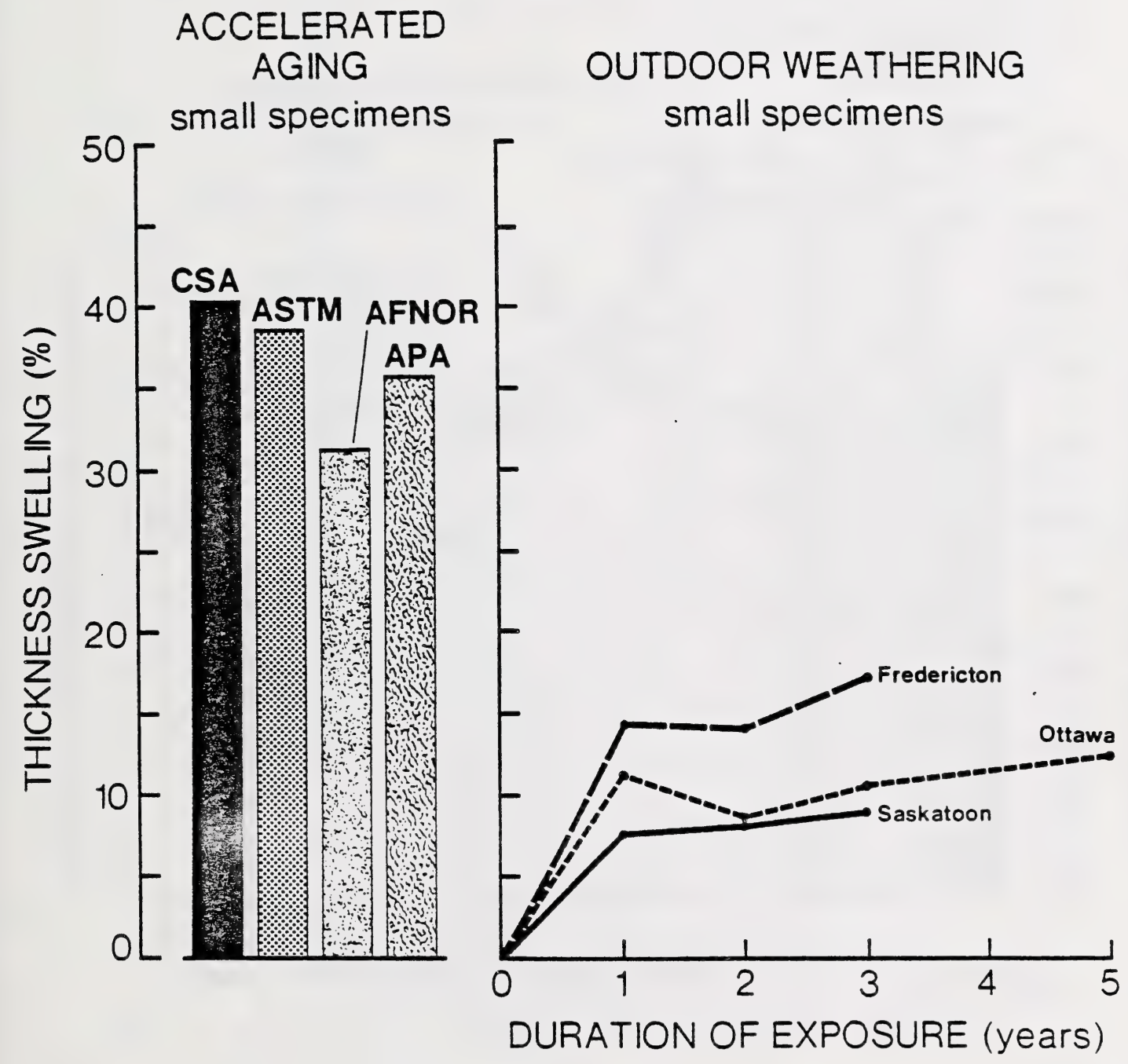


Figure 5. Modulus of Elasticity for Exposed Waferboard Specimens Expressed as a Percent of Controls

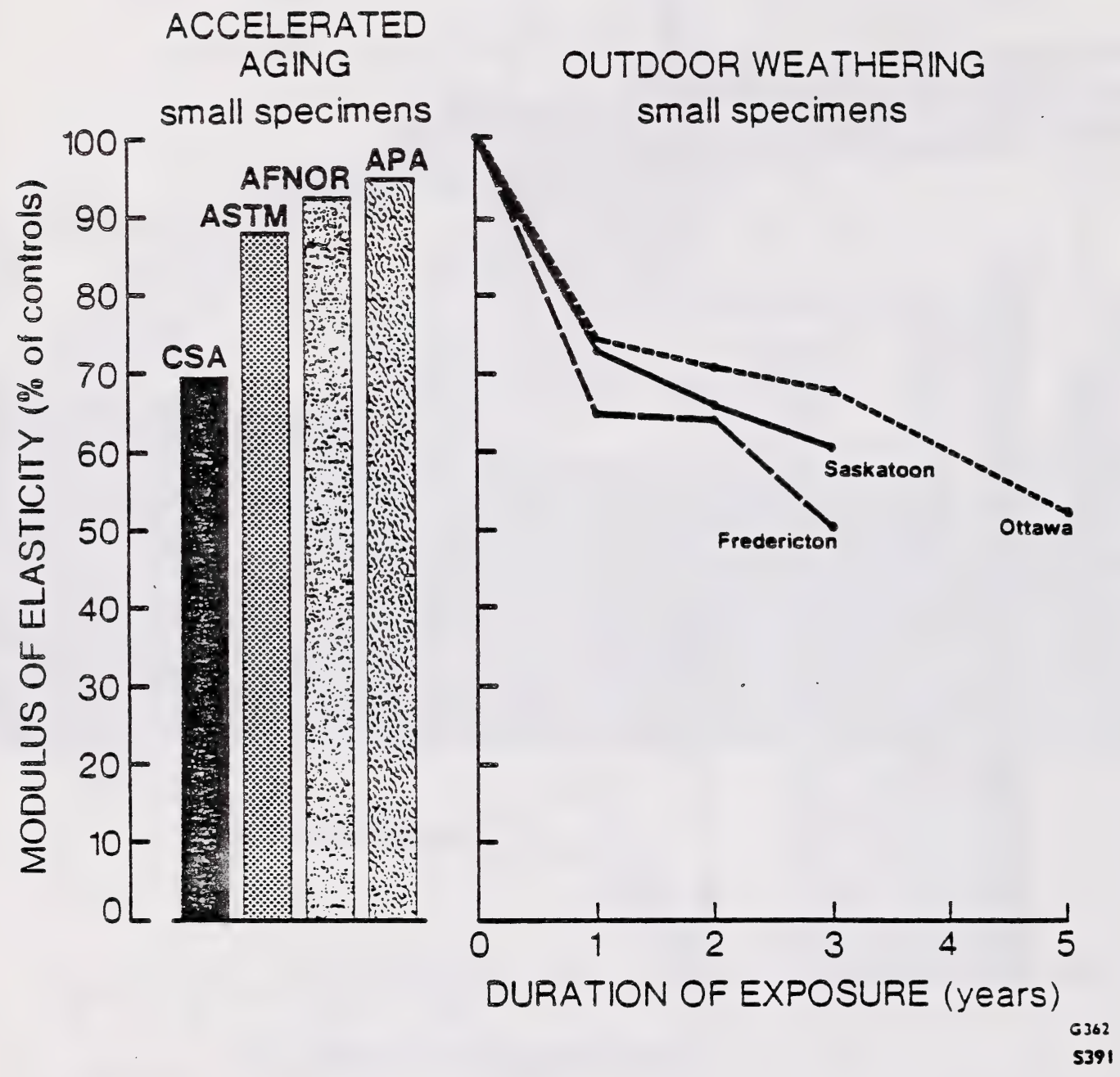


Figure 6. Modulus of Rupture of Exposed Waferboard Specimens Expressed as a Percent of Controls

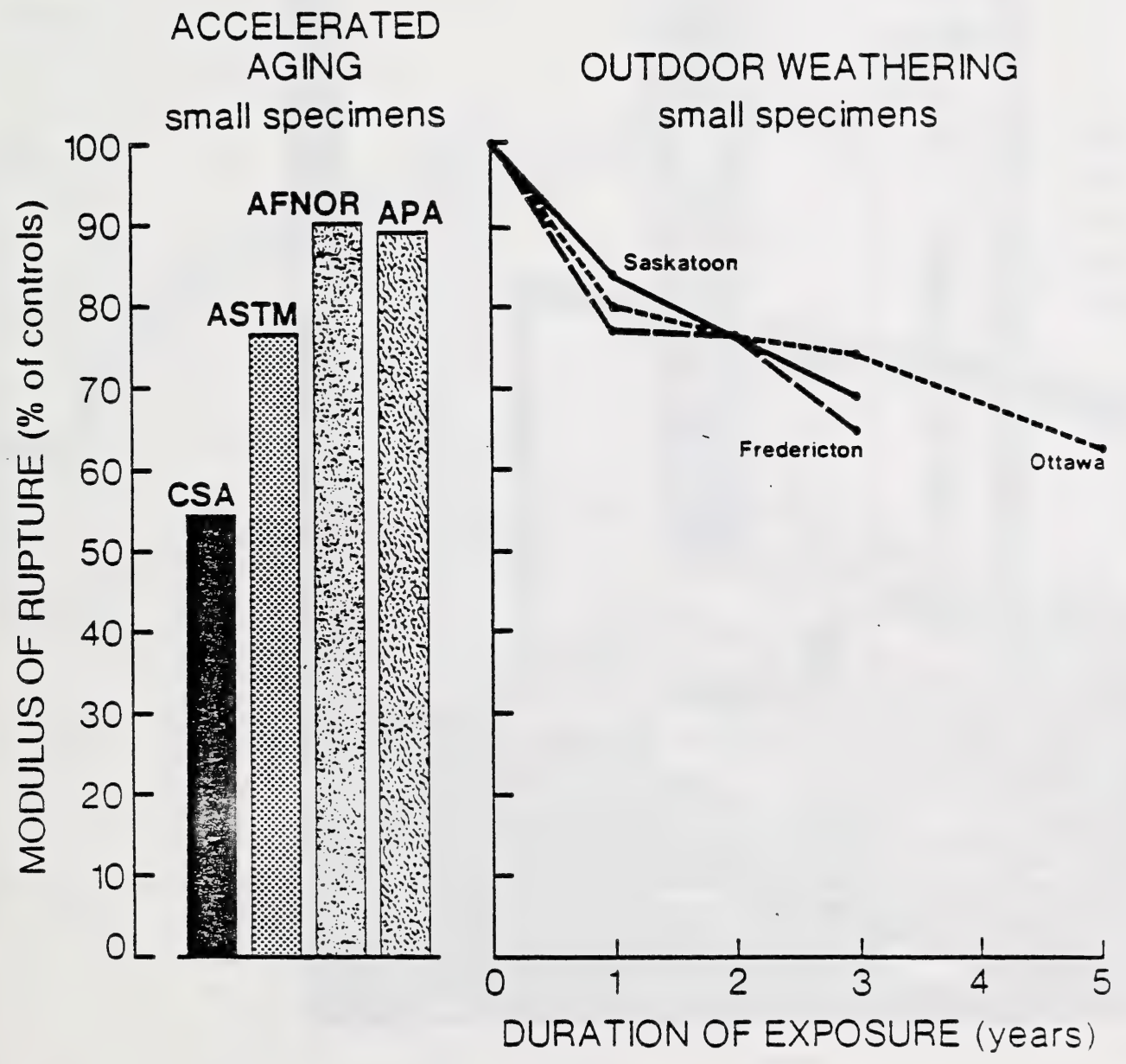


Figure 7. Method of Loading and Measuring Creep
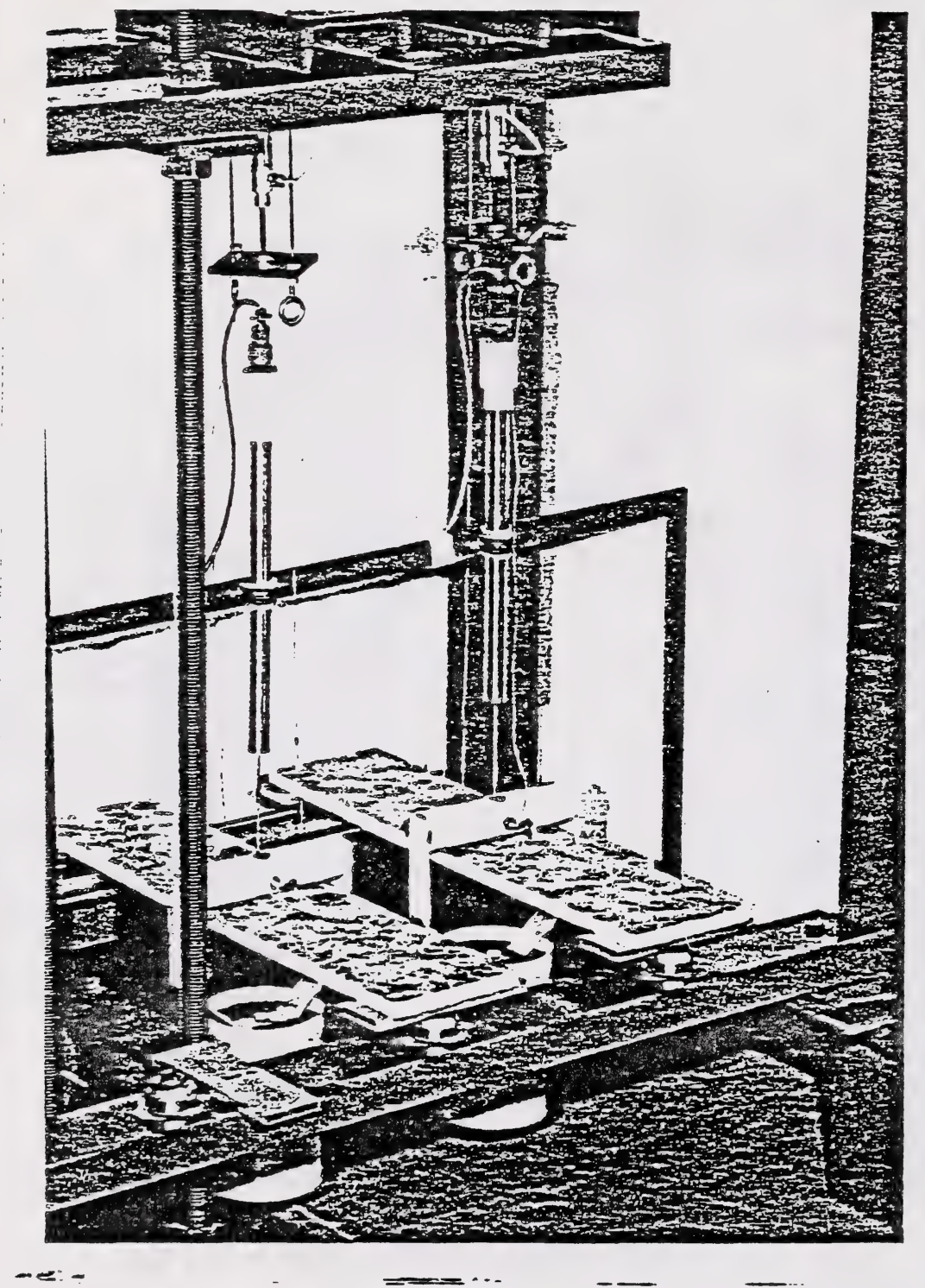
Figure 8.

\section{AVERAGE STRAIN-TIME CURVES FOR WAFERBOARD AND PLYWOOD SPECIMENS TESTED AT $20^{\circ} \mathrm{C}, 65 \% R H$}

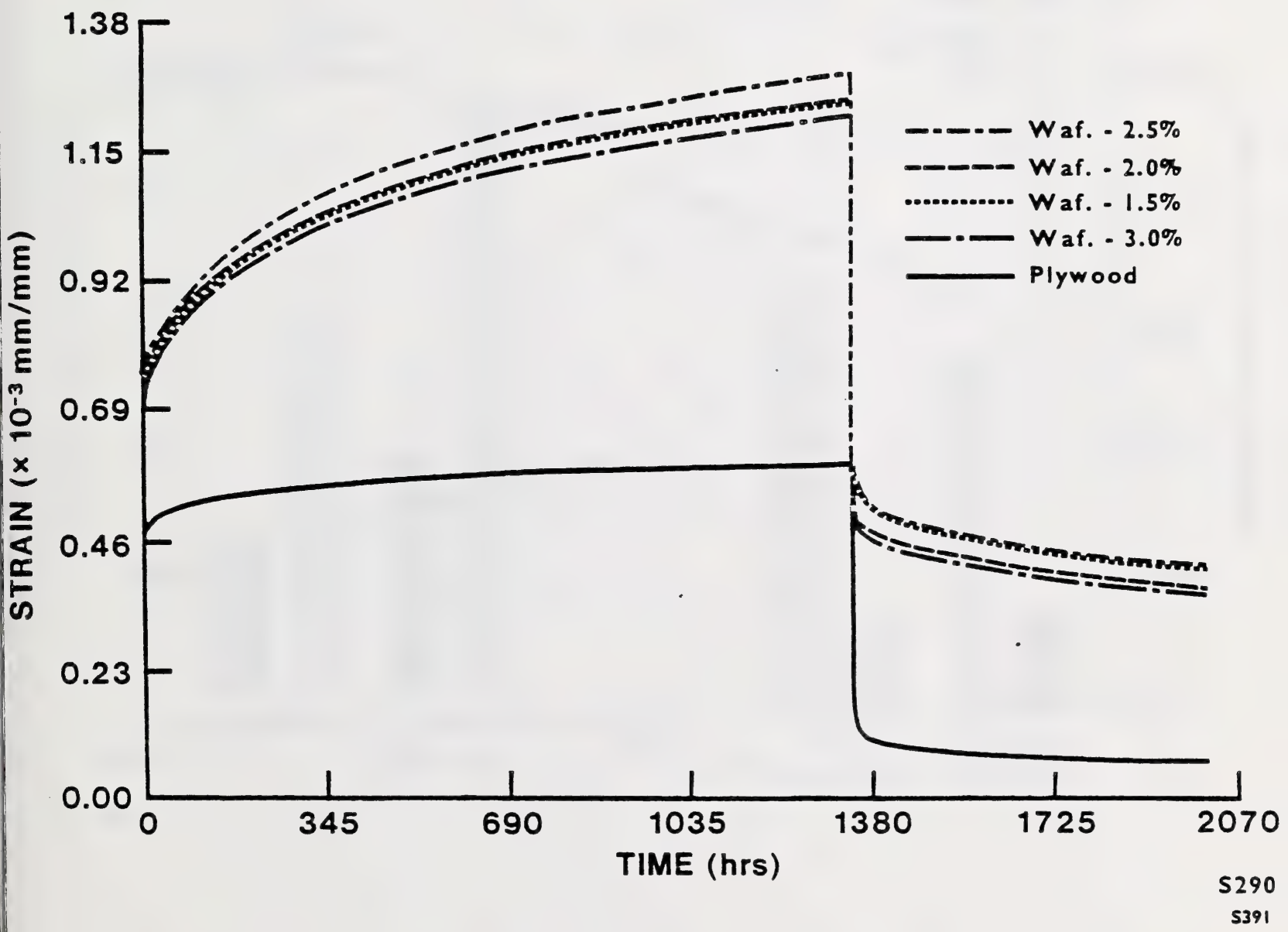


Figure 9. Modulus of Elasticity of Highly Aligned, Three Layer OSB Panels Prepared with $150 \mathrm{~mm}$ (6 inch) Stands
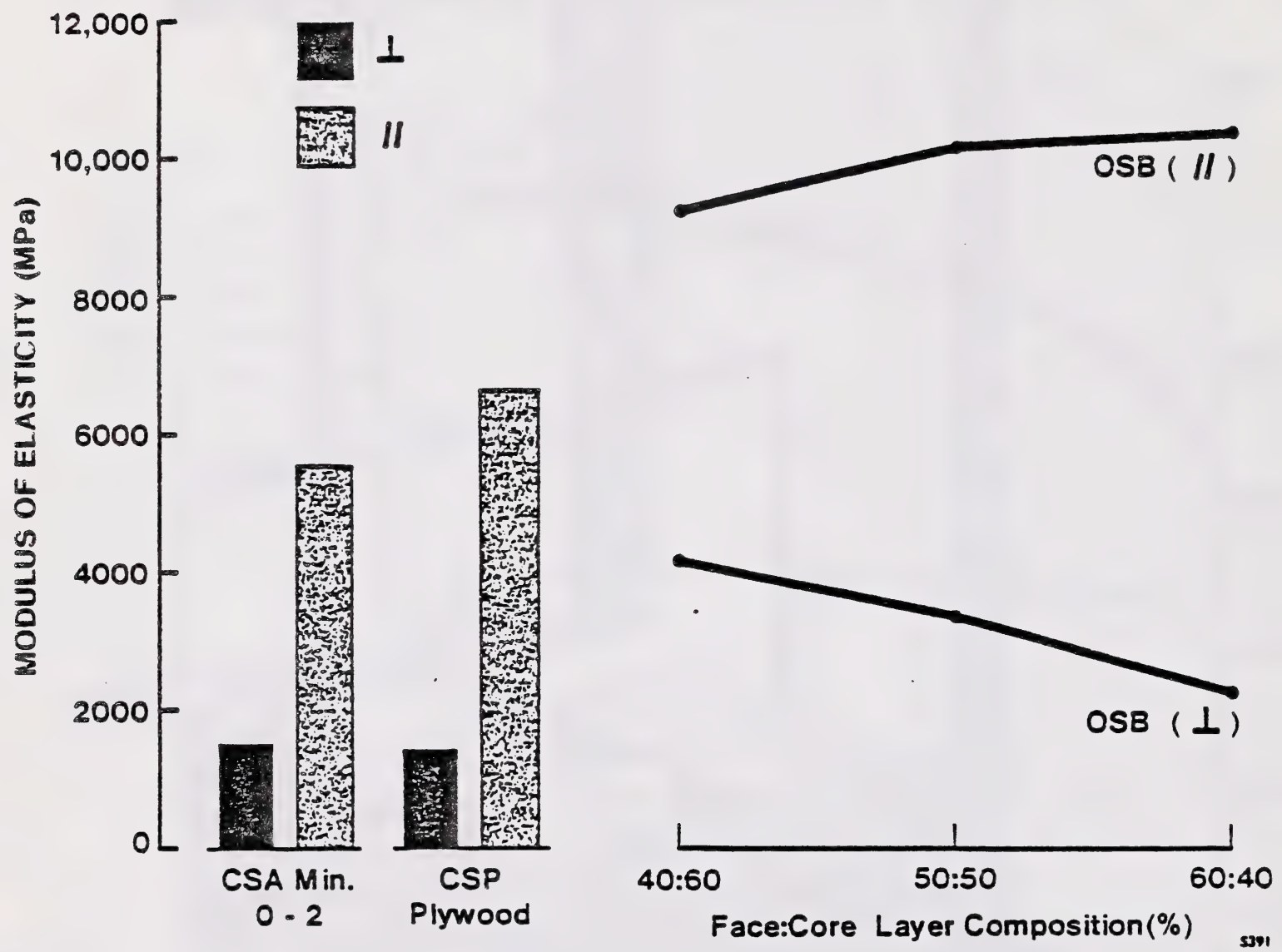
Figure 10. Modulus of Rupture of Highly Aligned, Three Layer OSB Panels Prepared with $150 \mathrm{~mm}$ (6 inch) Strands
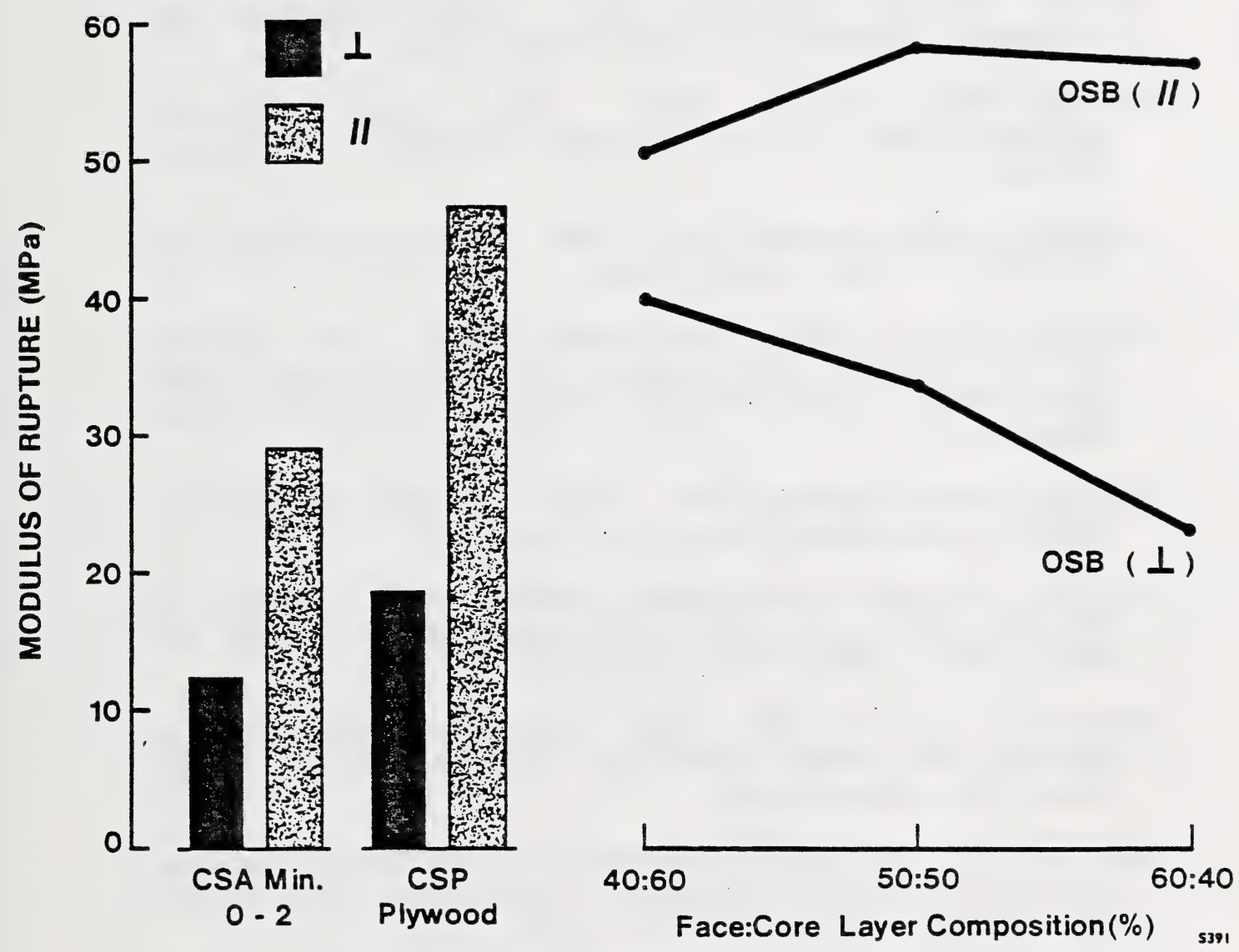


\section{References}

British Standards Institution (BSI). 1989. Part 3. Specification for Waferboard and Oriented Strand Board (OSB) BS 5669. BSI, London, England.

Canadian Standards Association (CSA). 1985. Waferboard and Strandboard. CAN3-0437.0-M85 CSA, Rexdale, Ontario.

American National Standard (ANSI). 1989. Wood Particleboard. ANSI/A208.1-1989. National Particleboard Association. Gaithersburg, Maryland.

Canadian Standards Association (CSA). 1988. Construction Sheathing CAN CSA-0325.0-M88 CSA, Rexdale, Ontario.

American Society for Testing and Materials (ASTM). 1984. Standard Methods of Evaluating the Properties of Wood-based Fiber and Particle Panel Materials. ASTM D1037-78, Section 4, Volume 4.09: Wood. Philadelphia, PA.

American Plywood Association (APA). 1984. Performance Standards and Policies for Structural-use Panels. APA, Tacoma WA.

Association Française de Normalisation (AFNOR). 1979. Panneaux de Particules, Epreurie de Vieillissement Acceleré par le Méthode Dite "U313". NF B 51-263, AFNOR, Paris, France.

Alexopoulos, J. and F. Pfaff. 1988. Comparative Swelling Tests on Waferboard and Oriented Strandboard. Rep. 38-10-D-012. Forintek Canada Corp., Ottawa, Canada.

Alexopoulos, J. 1989. Effect of Accelerated Aging and Outdoor Weathering on Various Properties of Waferboard. A Status Report. Rep. 38-10-D. 010. Forintek Canada Corp., Ottawa. Canada.

Alexopoulos, J. 1989. Effect of Resin Content on Creep and Other Properties of Waferboard. Rep. 38-10-D-008. Forintek Canada Corp., Ottawa, Canada.

Unpublished report. High Performance OSB.

Hsu, W.E. 1986. Canadian Patent 1215510. Method of Making Dimensionally Stable Composite Board and Composite Board Produced by Such Method.

Hsu, W.E. 1986. Canadian Patent 1213707. Method of Making Dimensionally Stable Composite Board and Composite Board Producted by Such Method. 
Hsu, W.E. United States Patent Application 1988. Apparatus and Method for Steam Pressing Compressible Mat Material.

Unpublished report. Preservation of Stabilized Panels. 
UTIIIZATION OF WOOD IN THE 1990 'S

BY

F.T. MCDOUGALI

GENERAL MaNAGER

ALBERTA OPERATIONS

WEYERHAEUSER CANADA ITD.

\section{ABSTRACT}

The paper reviews the anticipated growth of the forest industry in Alberta during the next decade. This growth is discussed in relation to various types of forest products which will be or are being produced in Alberta. The growth is placed in an historical perspective. There is some discussion of possible constraints and limitations which could occur and which arise from problems currently being experienced in Alberta. 


\section{TTIIIZATION OF WOOD IN THE 1990 'S}

\section{Introduction}

The following paper is specific to the province of Alberta, and does not pretend to represent or consider what may occur in other areas of North America, except as. such external developments determine the markets and set the competitive environment in which we work. This paper is really a review of what is expected to happen in Alberta's forest industry in the next decade.

\section{The present Decade, the 1980 's}

The 1980's have been the most dramatic decade ever for Alberta's forest industry. At the beginning of the decade, timber production was about 5 million $\mathrm{m}^{3}$ with a product value of about $\$ 400$ million. This has increased dramatically, to a harvest level of about 9 million $\mathrm{m}^{3}$, with an annual product value of $\$ 1$ billion this year.

The present decade has seen dramatic diversification in our forest industry. Two new oriented strand board plants, and the conversion of the previous flakeboard plant to oriented strand board have made Alberta a leading producer in the Canadian panel board industry from modest beginnings in spruce-pine plywood. The outstanding success of mediun density fibreboard has brought a whole new product into our industry. Millarwestern introduced an entirely new pulping process to the 
province, with the start-up last year of its modern new chemi-thermo-mechanical pulp mill at Whitecourt, the largest such mill in Canada.

While all of this was happening, the decade has also seen unprecedented growth in traditional softwood dimension lumber production in Alberta, with production volumes doubling from about 800 million board feet at the start of the decade to a projected 1.7 billion board feet this year.

The 1980's have been dramatic indeed. But what of the decade ahead?

\section{The 1990's - A Major Expansion}

The 1990's, will start with a bang in Alberta. In 1990 alone we will see the softwood kraft mill at Hinton expand production by almost 200,000 metric tonnes per year. Lumber production at Hinton will be increased by 100 million board feet. Daishowa will start up its new hardwood kraft pulp mill at Peace River, adding 340,000 metric tonnes of annual pulp production. Lumber production will expand with new mills at Rocky Mountain House and a hardwood sawmill at Lac La Biche.

1991 will be a banner year. Alberta Newsprint will start up its new newsprint mill, capable of producing 220,000 metric tonnes of high-brightness newsprint annually. lumber production will expand again with new lumber 
production from Procter \& Gamble's long awaited mill at Manning. And towards the end of the year, Alberta Energy Company will start up the second CTM pulp mill in the Province at Slave Lake, Alberta. This new mill will have the capacity to produce 110,000 metic tonnes of hardwood CTM pulp annualiy.

In 1992, Alberta-Pacific, having solved its environmental problems, will start up what will be the largest kraft pulp mill in the Province, producing more than 350,000 metric tonnes annually.

In 1993, Procter \& Gamble, having solved their effluent discharge difficulties, will start up a major new hardwood Kraft pulp mill next to their existing mill at Grande Prairie. This will add 250,000 metric tonnes of high quality hardwood pulp production. Daishowa will start up a second hardwood Rraft pulp mill adjacent to their Peace River mill, adding a further 340,000 metric tonnes of pulp production, making their Peace River site the world's largest single production centre for hardwood Kraft pulp.

There will be incremental pulp expansions in 1994 and 1995 and the possible addition of a paper mill by Alberta-pacific in the immediate vicinity of their Athabasca pulp mill.

In 1996 the Alberta Energy Company will complete a major expansion to their slave lake CTM pulp mill, which will 
double its production to 220000 metric tonnes annually.

In 1997, Alberta Newsprint will double their newsprint production from 220,000 metric tonnes to 440,000 metric tonnes, making it one of Canada's major newsprint producers.

So the 1990's look impressive indeed. There will be $\$ 3-$ $1 / 2$ billion invested in new capital projects. The annual value of forest products made in Alberta will raise from $\$ 1$ billion today to almost $\$ 3$ billion by the end of the next decade, measured in 1989 dollars. The annual production of the Alberta forest industry at the end of the next decade, will be:

2 billion board feet of lumber,
$2-1 / 2$ million tonnes of wood pulp,
500 thousand tonnes of newsprint,
200 thousand tonnes finished kraft paper,
1 billion square feet ( $3 / 8$ " basis) of
reconstituted panel board (oriented strand
board, fibre board and particle board).

There will be seven or eight pulp mills, two newsprint mills, and one or two fine paper mills in the province. There will be several major new sawmills. The total timber harvest by the year 2000 will be about 24 million $\mathrm{m}^{3}$ which means that Alberta will be utilizing $92 \%$ of its total allowable cut of 26 million $\mathrm{m}^{3}$. Logging will be a major industry in the Province. Something like 500 feller 
bunchers will be working with 700 skidders to prepare tree length logs to be moved to the mill by a fleet of more than 1,200 log trucks.

\section{Reasons for Development}

Why is all this development occurring in Alberta? It is because Alberta has extensive timber reserves from which timber can be obtained at a competitive costs. The Aberta Forest service is a recognized leader in forest fire control and forest management. Forest fires have been kept under control, and Alberta's allowable annual cuts are seen as secure. Alberta's timber tenure systems provide long term security of supply at reasonable cost. So Alberta is a good place to come for wood supply.

The demand for, wood is growing world wide. There is an exceptional world demand for hardwood pulpwood. Recent advances in paper-making technology have enabled paper machines to use short-fibred hardwoods. Previously, they required the strength from longer-fibred softwoods in order to get a sheet of paper to run at high speed through the paper machine without breaking. once paper makers were able to make hardwood paper effectively, printers found that it offered better opacity and pristability than some of the softwood papers. Paper made from aspen pulp offers the further advantage of very high brightness, based on an abundant, low cost wood supply. The only real competition for aspen in the hardwood pulp business is eucalyptus. There are a number of large pulp 
mills around the world producing eucalyptus pulp. Eucalyptus can be grown to merchantable size in 6 to 9 years in many areas of the world, so it is possible to build a pulp mill based on an eucalyptus plantation within a few years of planting the trees. Eucalyptus plantations are being established all over the world, in Brazil, Portugal, and spain to name a few. Fortunately for us, there are insufficient plantations in place to meet the current demand, so there is a temporary shortage of hardwood pulp fibre. Companies are turning to our abundant supplies of aspen to meet their immediate needs. We have been able to capitalize on an exceptionally strong pulp market before alternative fibre suppliers are developed elsewhere.

\section{What about the solid Wood side of the Business?}

While pulp and paper have been getting all the media atterition, the solid wood products industry in Alberta has continued to maintain vigorous growth, doubling its production every decade. This will continue into the 1990 's and it will be compounded by the introduction of new and improved panel board production, by increased diversity in the lumber industry and by the manufacture of products with increased value and higher profit margins.

Another medium density fibre board mill is a distinct possibility, based on the success at Blue Ridge. Several particle board plants are likely to be established. There 
may be further expansion into third generation oriented strand board, once overseas markets expand to alleviate the current production surplus in North America. We could see reconstituted board used to replace the wider widths of framing lumber, based on consistent engineered strength and span values.

The forest resource itself is likely to be used more ciscretely. As the supply of timber tightens, we are likely to see specialized opportunities arise. Already, lodgepole and jack pine are beginning to be differentiated into treated wood applications. As we log huge volumes of forest into one location, as at large pulp mill locations, species which constitute 1 or $2 \%$ of the forest inventory begin to show up in volumes adequate to support specialized manufacturing facilities. Where we have 2 million $\mathrm{m}^{3}$ coming into one location, $1 \%$ of the wood supply will support a specialty sawmill producing 5 million board feet per year of birch or tamarack production, aimed at particular market needs.

Many of the medium sized sawmills in the Province will find it profitable to differentiate away from standard North American framing lumber to meet specific export and individual customer needs. Some mills are already serving Japanese specifications, and others to meet European market requirements. In spite of high freight costs to these markets, this business is expected to increase.

There are also opportunities in the North American market to expand lumber sales by producing new types of lumber 
product. A more vigorous timber engineering program at the Alberta Research Council could facilitate the increased use of wood in instructural applications in medium sized commercial and industrial buildings. The success of Western Arch-rib is an indication of what can be done.

\section{Secondary Manufacture}

Secondary manufacturing in Alberta has been limited by the relatively small size of the Alberta market, by high freight and handling costs to outside markets and by the strong orientation of Alberta mills to the United States commodity markets.

As labour costs rise in Europe and Japan relative to Canada, opportunities will rise to manufacture housing components here to serve these markets. Window and door assemblies, and cabinetry suggest themselves as possible growth areas. The increasing diversity of our forest industry, and the increased willingness of sawmills to manufacture lumber to individual specifications, will help to support this growth. This area is very competitive, and requires highly developed marketing capability as well as advanced transportation technology.

Furniture manufacturing has potential for growth, but is likely to be oriented to regional markets, as freight costs remain a constraining factor in terms of access to very large markets like Toronto or Los Angeles. Design 
is a critical factor, and more could be done to support furniture and housing component engineering and design in Alberta.

\section{Constraints to Development}

Much of Alberta's timber is pulpwood. Much of the forest is composed of extensive stands of very small diameter lodgepole pine, too small for economic lumber production. There are also huge tracts of small diameter poplar (both aspen and balsam poplar) often of poor form (crooked stems, limby) and with cull factors running over $20 \%$. This timber resource is used to good effect when it is manufactured into high value pulp, such as kraft pulp, or better yet, paper. Yet the use of this marginal resource for the manufacture of such high value products is threatened by environmental concerns and emotionalism, I am not advocating that we pollute our rivers in order to use marginal forests. Any pulp development must be engineered, operated and regulated to meet standards which insure continued good water quality in our rivers. No one ever intended anything else. Unlike some, I have always believed that the Alberta Department of Environment working with the pulp mills, will develop the necessary effluent treatment technology and in fact this is happening.

My concern is that environmental emotionalism has gone beyond legitimate concerns and rational debate to a "stop the mills" mentality which is irrational and could deny 
Alberta major economic benefits from pulp and paper development for no good reason.

On the solid wood side of the industry, things are going to be extremely competitive for the next five years. The inflationary impact of high taxes and the new general sales tax could have a significant impact on labour costs. Wood costs will be increased by much heavier forest management and reforestation costs, some of which are the result of governments refusing to allow the use of cost effective, environmentally safe, herbicides. Timber supplies will be constrained by protectionist pressure for more wilderness and park areas.

Finally, the entire industry in Alberta is dependent on efficient, low cost transportation to both the United States and off-shore markets. It is absolutely vital that transportation costs not be allowed to escalate dramatically for any reason.

\section{Conclusion}

In conclusion, the future for Alberta's forest industry is bright. There are problems, but many of these problems are shared by our competitors. The key is to solve them through hard work and innovation; and not to give up by walking away from the excellent opportunities that our forests will continue to provide. 


\section{REFERENCES}

MCDOUGAIL, F.W., 1989. Speech to Grande Prairie Chamber of Commerce. 
GREATER UTIIIZATION OF WOOD THROUGH POLYMIER MICROCRYSTIAS

\author{
BY \\ O. A. BATTISTA \\ PRESIDENT AND CEO \\ AND \\ S. SOOTI IFE \\ MANAGER OF RESEARCH
}

THE O. A. BATTISTA RESEARCH INSTITUTE

(Consultants to MICROTECH MCP's (CANADA), INC.)

\begin{abstract}
Commercial uses of single colloidal polymer microcrystals were first demonstrated in 1955, using various celluloses as the raw materials. A world-wide, multimillion, pounds-per-year industry emerged from this discovery. The Market is still growing in annual demand more than 30 years later. As of 1988, an estimated 600 million pounds of microcrystalline cellulose from wood pulp alpha-cellulose alone were sold worldwide. Today, this specialized field of polymer science is undergoing a major new surge of commercialization based on past as well as never-before-available colloidal polymer microcrystals including meltable polyamide and polyester "virus sized" microcrystals as aqueous suspensiods.
\end{abstract}




\section{GREATER UTILIZATION OF WOOD THROUGH \\ ROLYMER MICROCRYSTAIS}

Commercial uses of single colloidal polymer microcrystals were first demonstrated in 1955, using various celluloses as the raw materials. A world-wide, multimillion, pounds-per-year industry emerged from tbis discovery. The Market is still growing in annual demand more than 30 years later. As of 1988 , an estimated 600 million pounds of microcrystalline cellulose from wood pulp alpha-cellulose alone were sold worldwide. Today, this specialized fleld of polymer science is undergoing a major new surge of commercialization based on past as well as neverobefore-available colloidal polymer microcrystals including meltable polyamide and polyester "virus sized" mierocrystals as aqueous suspensiods.

One particularly new broad-based opportunity that is being developed has to do with the conversion of hundreds of millions of pounds of waste plastic polymer products (non-cellulose) into new colloidal aqueous suspersoids or dry colloidal particles. Some of these new forms have greater value than their natural or manmade polymer precursors.

For example, conservative estimates based on 1988 data project at least 1,000,000,000 pounds of waste plastic polymer products will be available in North America alone as a reservoir of acceptable, reusable, polymer, raw materials. The toxicity and environmental hazards created by the incineration of waste polymer materials have become of international concern. The cost of burying them in "graveyards" many miles from the site of their origin has been estimated conservatively at 15 
cents a pound! But they are non-biodegradable. Our landfills are already over-burdened with the current dumping of these materials, not to mention the anticipated tremendous increase in disposable products that will add to this problem.

The recycling of polymer products, either by the use of toxic solvents as vehicles of conversion or by mechanical grinding using liquid nitrogen refrigeration, present environmental problems and lor they are not cost effective. A new industry designed to give a "second Iife" to these valuable natural materials and man-made waste polymer forms - an industry to recycle specific waste plastic polymer forms using water alone - is about to leave the heel of an exponential growth curve.

The commercial potential of recycling waste polymer materials in colloldal forms is not a "pie-in-the-sky" projection. Producing countless millions of pounds of microcrystalline cellulose from a single polymer raw material - wood pulp alpha cellulose - is a proven reality worldwide. It would be very hard to find anyone in the food and/or pharmaceutical industry from New York to Paris to Moscow or to Tokyo who has not used or at least heard of microcrystalline cellulose. A recent computer printout of literature references about microcrystalline cellulose alone contained about 4,000 separate publications.

What are some of the raw materlals of primary commercial interest for colloldal polymer microcrystals? They are: alpha cellulose and cotton, waste cellulose (rayon, cellophane), nylons (especially nylon6 and nylon-66), polyesters (in fibrous, textile, and 
structural forms), crystalline amylose, and even silk and wool wastes! In addition, millions of pounds of valuable discarded cotton, nylon and polyester fabrics are hanging in the household closets of people living in the $U$. $S$. and Canada, not to mention the rest of the world.

How will new polymer microcrystals play an important role in helping the wood industry maintain an edge in "Technology for the 1990's"?

Microcrystals of cellulose and of amylose starch will not melt. Their uses are largely restricted in wood-related technology such as coatings for paper and related products.

Only two species of polymer microcrystals currently available will melt. They are polyamide (nylon) microcrystals and polyester (PET) microcrystals, respectively. Each of these microcrystals can be homogeneously dispersed to give agueous suspensions varying in thickness from homogenized milk to heavy creams as thick as butter. The uniqueness of these meltable virus-sized polymer microcrystals is that they can be converted into useful forms using water alone as the vehicle for application. What we are projecting is that both polyamide microcrystals and polyester microcrystals will permit partial (or ultimately total) reduction of the use of formaldehyde-based chemicals for the stabilization of countless wood and/or cellulose based commodity products by allowing for a new type of melt-cross-linking that uses physical rather than chemical means of binding and can be carried out in an aqueous media without the use of any toxic chemicals what-so-ever.

Let us look first at FIGURE 1 so that we may orient 
our thinking about the available particle sizes of polymer microcrystals.

As you will note, there are 254,000,000 Angstroms in one inch or 10,000 Angstroms in one micron. These new families of pure polymer microcrystals range in particle size from $50 \AA$ up to $3000 \AA$. Over one million single microcrystals of nylon-6 could be lined up side-by-side and fit comfortably in one inch.

FIGURE 2: These are microcrystals derived from wood pulp alpha cellulose. They average about $3000 \AA$ in length and $250 \AA$ in thickness. FIGURE $2 \mathrm{~A}$ shows cellulose microcrystals in the process of dislodging from a wood pulp fiber.

FIGURE 3: Here we see single cellulose microcrystals recovered from regenerated cellulose such as rayon and cellophane. The tiny spherical microcrystals range from about $200-300 \AA$ in diameter, about the size of a single flu virus.

1 FIGURE 4: Here we have amylose starch microcrystals. Their dimensions are almost the same as alpha cellulose microcrystals. They posses a unique helical microcrystal structure because the molecules are linked together by alpha-1-4 glycosidic chains, whereas cellulose molecules are linked by beta-1-4 glycosidic bonds.

FIGURE 5: Microcrystals of polyamide (nylon-6) are in the 250 - $300 \AA$ diameter range as shown in this slide. This microcrystal can be melted for coatings or as the binder in our new melt-bonding concepts at about $230^{\circ} \mathrm{C}$. FIGURE 6: Microcrystals of polyester PET (Dacron) also are in the $250-300 \AA$ diameter range. Their melting point, after being dried on a surface from an 
aqueous suspensoid ranges in the 255 - $260^{\circ} \mathrm{C}$ range.

Two relatively unexplored avenues for each of the newer colloidal polymer microcrystal species are:

1. Commercialization of much smaller microcrystals by selective use of new and/or chemically modified precursor raw materials, and

2. Topochemical derivatization at very low degrees of substitution of derivatives of polymer microcrystals.

The emerging new technology will provide increasing market opportunities for the wood-based industry. Colloidal water suspensoids and/or dry, colloidal aggregates or cluster of submicron, single, nearperfect, polymer microcrystals open up new vistas by blending polymer microcrystals in wood and cellulose based finished products.

Among the industrial end uses now being evaluated are non-toxic, water-based systems of binders and coatings for paper; board and pulp molded products, including particle and chip boards for building industries; prime coatings for glass, aluminum, wood, ferrous, and other non-ferrous surfaces; thickeners for waterbased paints; etc. In dry form, the colloidal microcrystals may be used for fluid bed and electrostatic coatings, as binders for industrial and agricultural tableting, and as additives for changing the characteristics of existing molding and casting polymers. Some of the more unusual uses will be in concrete products, synthetic ivory (FIGURE 7), and catalytic substrates to name a few.

Without a doubt, the utilization of microcrystalline 
polymer sclence will definitely be on the "cutting edge" of technology for the 1990's. 
1 INCH $=251,000,000$ ANGSTROMS

1 MICRON $=10,000$ ANGSTROMS

1 MICROCRYSTAL $=50$ TO 3000 ANGSTROMS

1 MILLION NYLON-6 MICROCRYSTALS FIT EASILY IN AN INCH

FIGURE 1: The Comparative Size of an Angstrom

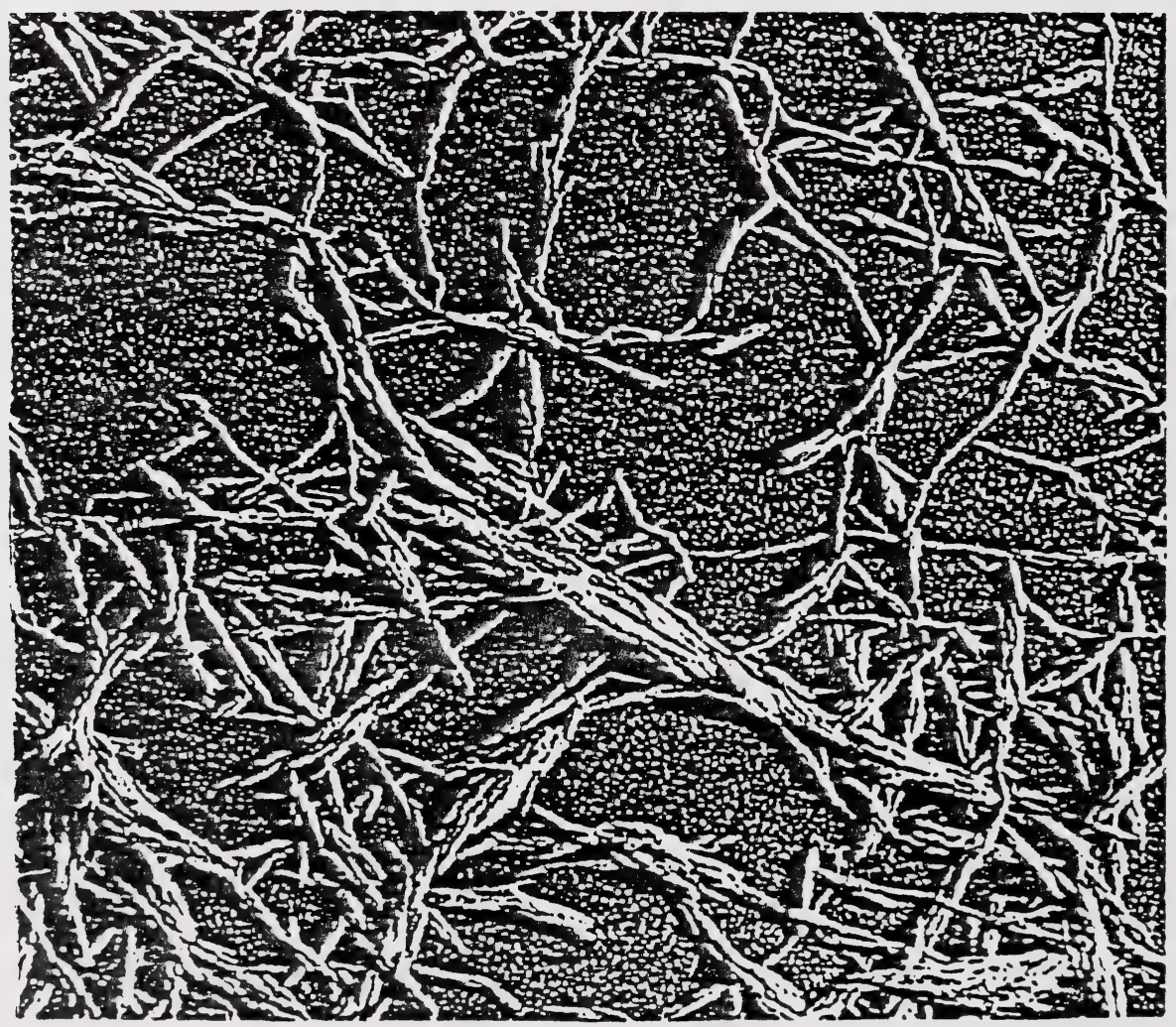

FIGURE 2 Microcrystals of Cellulose 


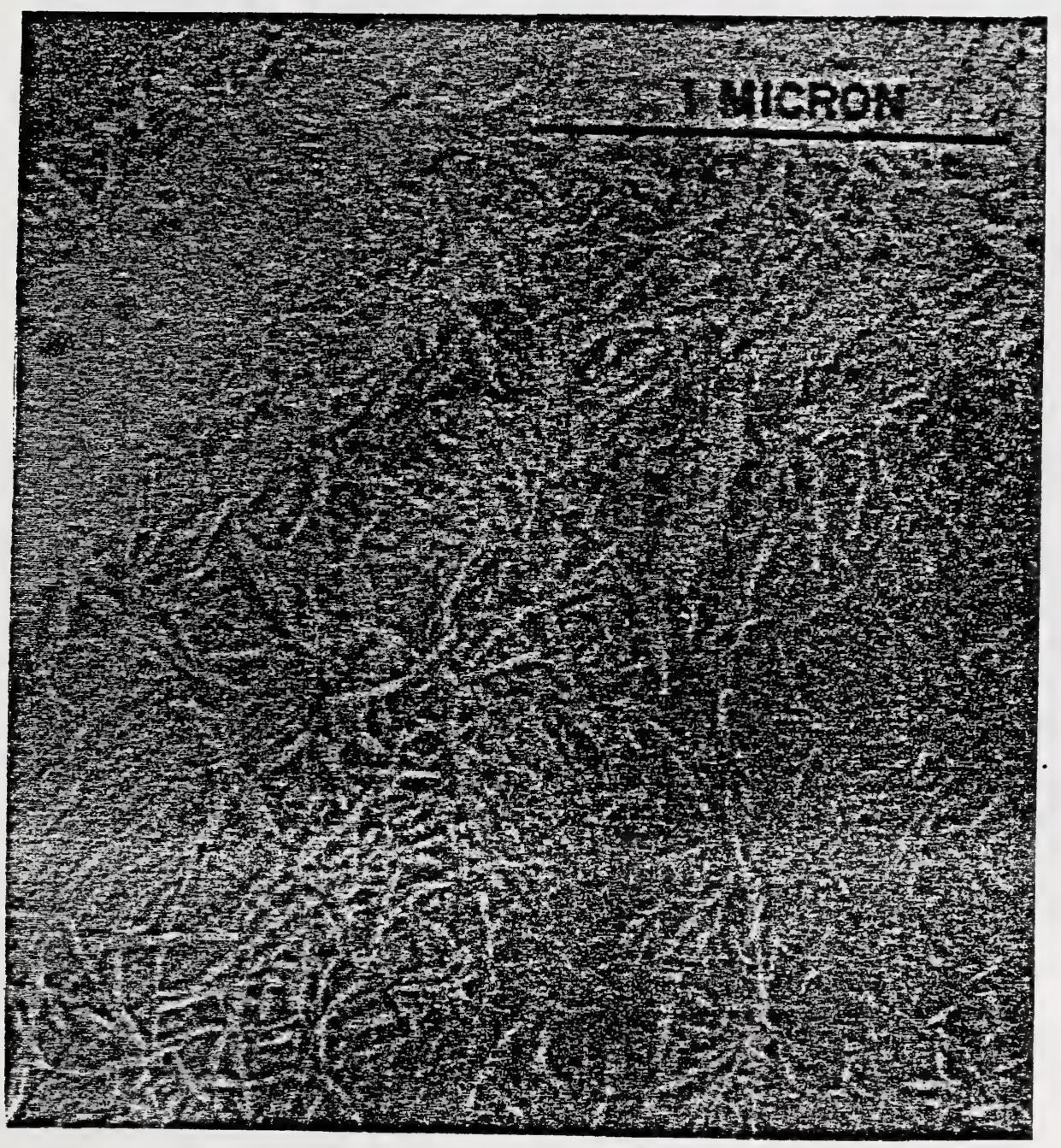

\section{FIGURE 2A Microcrystals of Cellulose Dislodging from a}




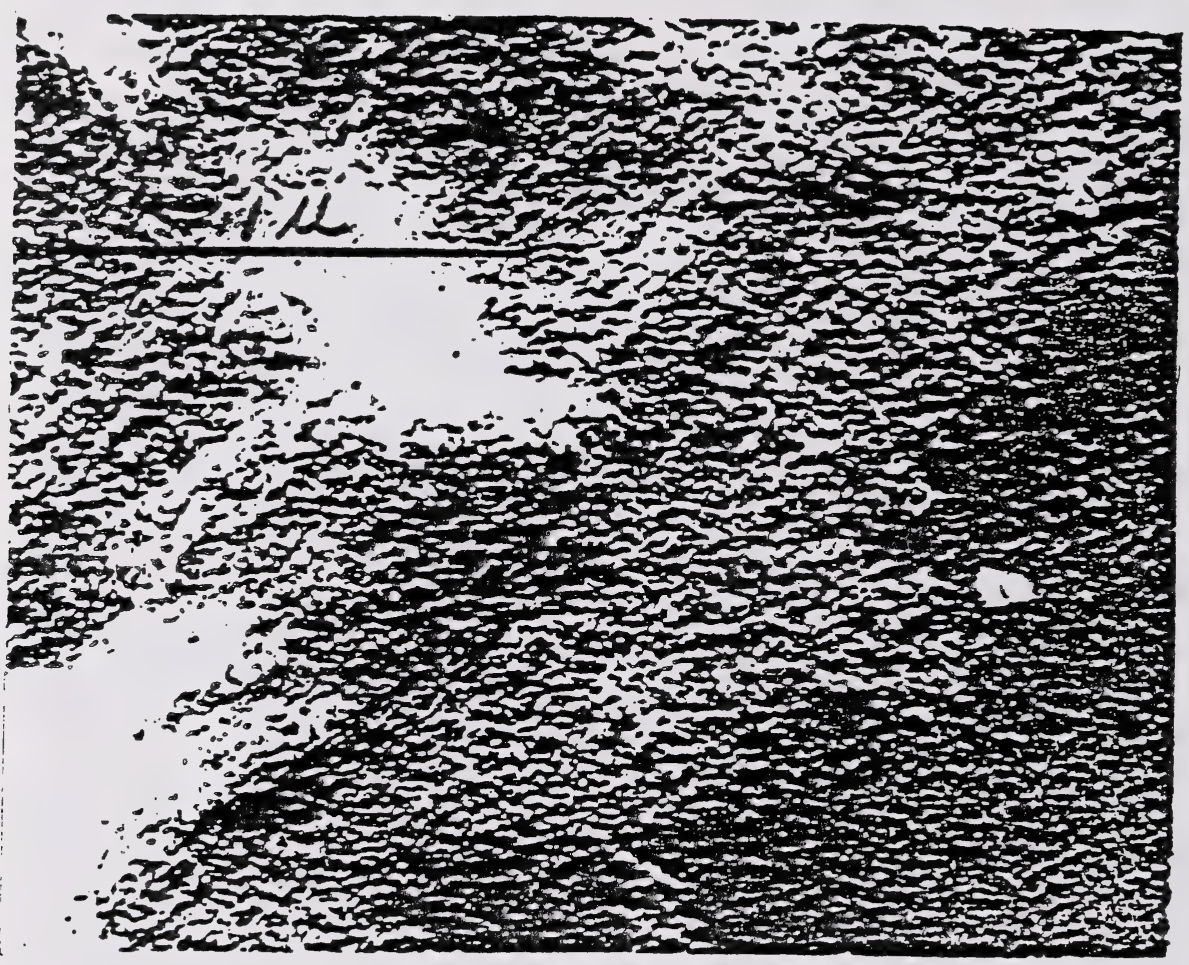

FIGURB 3 Cellulose Microcrystals From Rayon 


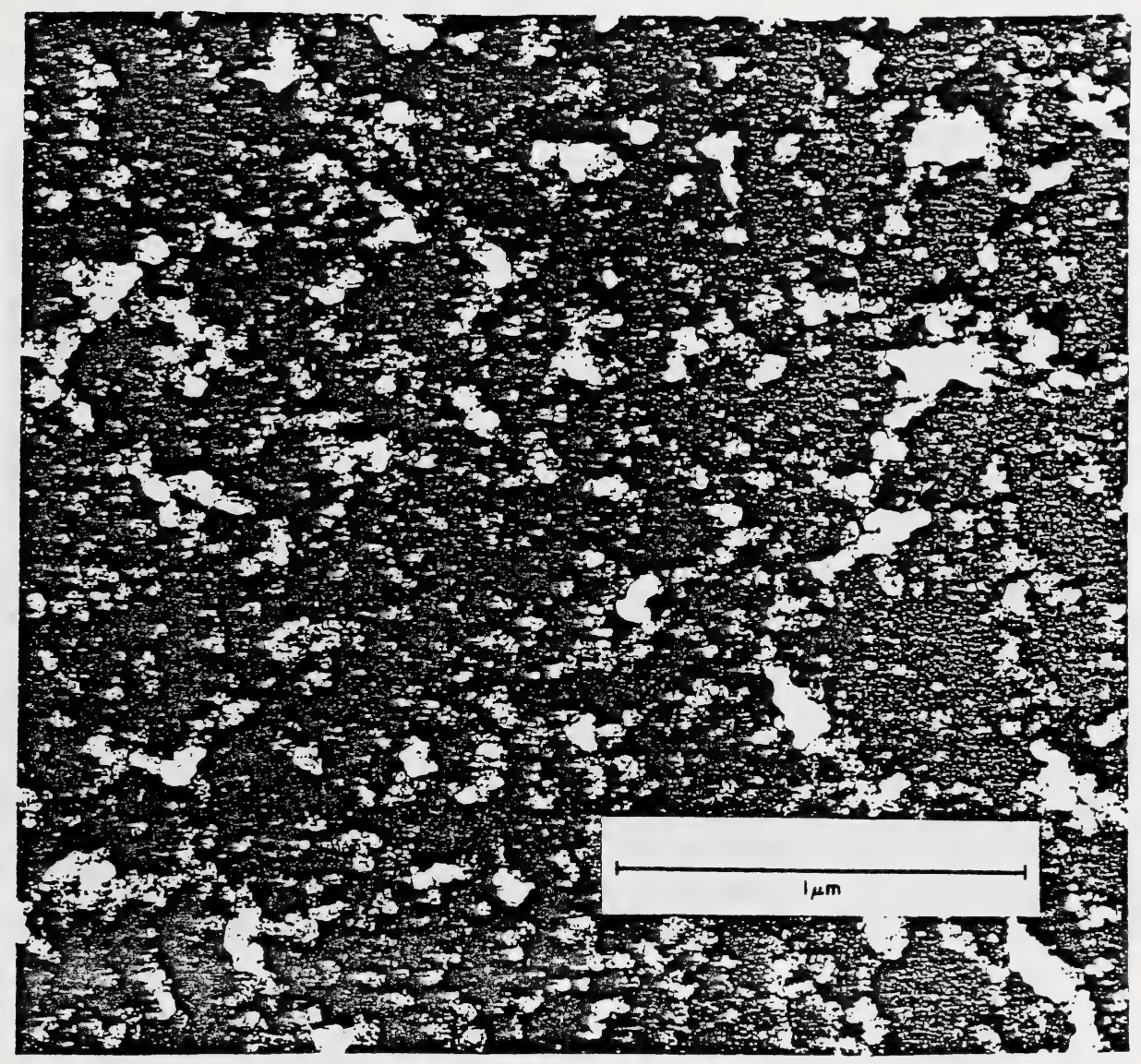

FIGURE 4 Microcrystals of Amylose 


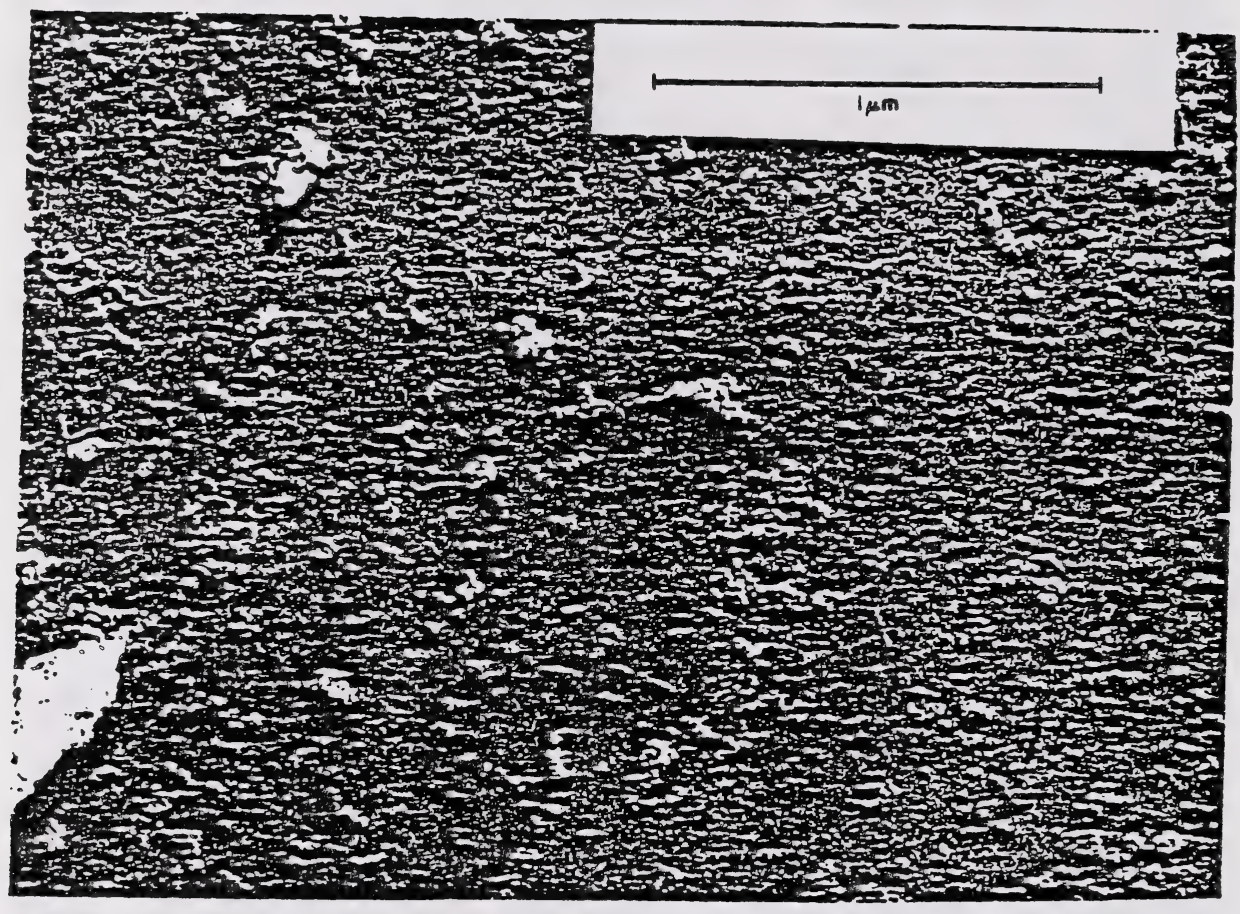

FIGURE 5 Microcrystals of Nylon-6 


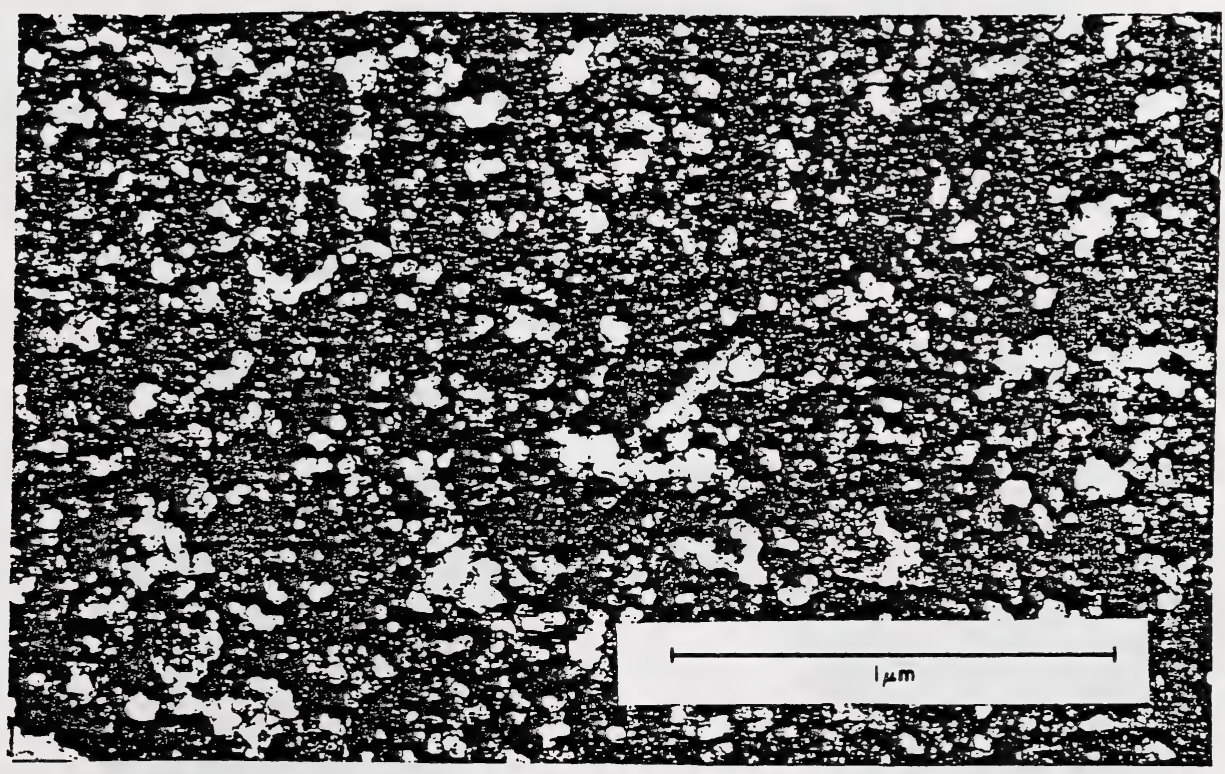

FIGURE 6 Microcrystals of PET 

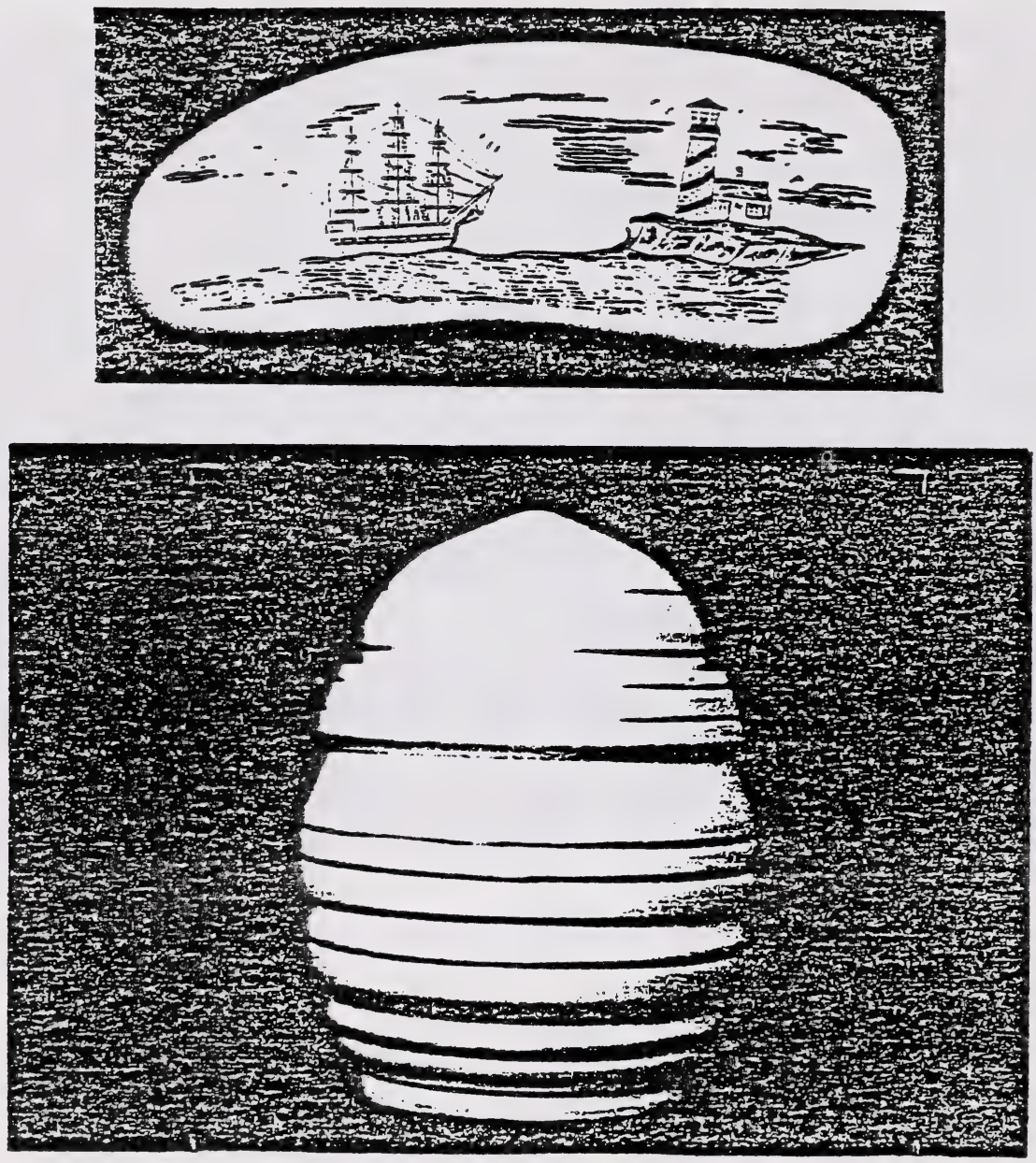

FIGURE 7 Avory, Man-Made I vory 
HIGH-VALUED ENGINEERED LUMBER FROM SMALL LOGS

\author{
by \\ C. Bowering \\ Vice-President \\ Durand-Raute Industries Ltd.
}




\section{Text}

\section{Intreaduetian}

This afternoon we have heard about some very important advances in the art and science of sawing round logs into rectangular lumber. Now I would like to challenge you with a statement that many of you may find hard ta accept.

\section{"The sawmill af the future will have a lathe fir a}

\section{headria".}

[1. SMALL LOES] What I would Iike to present to youd is a concept that canverts small, short, logs inti mare lumber, and better lumber, than any sawing system cidrrently available.

\section{The Cancegt}

Let's take a look at the overall concept. We all know that a conventional sawmill cannet make a $2 \times 10$ from a E-inch 19g. [2. LUMBER, CHIPS, QSB] These lags are eurrently processed into commodity praducts such as $24^{\prime} 3$, QSEWaferboard, or chips. We also know that the wide variatian Gf naturaliy-eccurring defects in sawn lumber limit its struetural properties so that it is unable to compete successfully with steel and concrete in many engineered applications. Unfortunately, sawmillers are also painfully 
aware of the problems of a timber resuurce that is declining in size, quality, and availability.

[3. LVL] The eancept that I am about to describe allaws the sawmilier to convert these readily-available, small, defective lags into Laminated Veneer Lumber (Gr LVL) - a lang-length, wide-dimensian lumber product with superiar structural properties that ensure its continued high-value and competitiveness with Eteel, concrete, and specialty structural lumber.

What IE LVL? WhiE IE Maling It?

LVL is structural lumber made fram veneer glued tagether with the grain running parallel ta the length af the plank. [4. LVL CONSTRUCTION] The Ends gí the individual sheets are joined by either a lap, butt, gr scarf jeint, and these joints are staggered thrbughout the eross-sectian gi the biard. The mist camman veneer thilknesses used are $1 / 8$ " and 1/10", with 13 to 15 plies used to make inch and a half thick product. Glueing and pressing tectinglagy is very similar to that found in a plywogd plant.

Mast LVL is praduced an a cantinubus press line with no theoretical limit to the length of the final product. A few plants use a non-continugus press with a fixed preduct length in the 50 - 80 fout range. 
LVL is purchased far its structural properties and dimensions with relatively less importance given to word species. The mast commeniy used species are Douglas fir, southern pine, and Nirway spruce. Tests conducted by Forintel have shown that ather species such as aspen are wel 1 suited to LVL.

Structural grade LVL is suprently procuced in the United States by three companies (Trus Jilist, MiTek, and Tectan) with a cembined tatal af $230 \mathrm{MMEM}$ fron $\equiv=3 a n t \equiv$. In addition, there is a plant in Finland and ansther in Australia. Three more plants are eurrently under canstructian in the U.S., bringing the total Narth American capacity to approximately 400 MBM.

How Dees LUL Campare With Ottier Structural Praducts?

[5. WHAT MAKES LVL ATTRACTIVE] Here we see a list of some af the features that make L'VL attractive in the marketplace. One of the main advantages of LVL is its struetural strength. This strength cames from the fact that the natural defects of wend are widely distributed and their effects are therefore minimized. 
[6. COMPARISON OF STRUCTURAL LUMBER] This slide shiws a comparisen between LVL and ather structural woud products. The mast important property is the Madulus of Elasticity and you can see how it campares to camman grades af machine stress graded lumber and glued laminated timbers.

In addition to competing with Gther woud products, LVL can compete successfully with steel and cancrete in many applications. This entiances the ability of woud to be used in madular systems such as light frame industrial and cammercial building systems.

Where Is LVL Eeing Used Todav? Where Will It Ee Ueed?

[7. END USES] This graph shows how LVL is being used today. As you can see, the main uses are for wowd I-beam flanges and for residential beams and headers. Other uses are for scaffold planks, truss members, tensian members in glulam beams, and joinery components. 
LVL is becoming a very commen sight in construstibn projects al guer Narth America. [8. WHISTLER CONDOJ We recentIy took some slides of LVL used in a cendaminium project at Whistler, near Vancouver.

\section{[9. HIP RAFTER]}

\section{[10. HEADER]}

[11. JOIST]

\section{[12. JOIST]}

\section{[13. I-BEAMS AND SCAFFDLD PLANK]}

Marketing and distribution git this produet is tiraugh normal contractar-griented building supply distribution channels, and alsi through truss fabricators. The product has been an the market fir aver tan years and has matured to the pint that it is now becoming well pecognized and aceepted by designers and builders.

[14. SEGMENTS OF THE US MARKET] This graph helpS is to predict the Guerall market potential for LUL in the US market. As you can see, about one quarter bif the sawn lumber market censists at wide-width dimension and structurally graded specialty items. These are tie segments in which LVL will be mast campetitive and represent a huge market that up until new has been untapped by the veneer producer. 
[15. LVL-FRAMED INDUSTRIAL BUILDING] THis is a large industrial building that has a clear span cif 100 ft with 50 ft. headroum at the peak. It appears to be typical steel canstructian, but an elaser inspectian yeu will see that the entire frame, including bridge crane beams, is made af LVL. These frames were all made up in the field by nailing together $21 / 2$ inch thick material into box sections which were then formed inta an arch and tilted up inta place with a crane. The designer told me that he was able to complete the entire job using anly carpenters, and was able to $\equiv a v e$ a considerable amount compared to using steel. Thint: sient it! The LVL far this structure was praduced fram small pine lags; the kind that are normally used only for studs br chips. My message taday is that you can take these lags, and using readily-available, well-praven technolggy, produce a Etructural I umber product worth many times mare than studs Gr chips - and at a higher recavery besides! 
The future far LVL is extremely promising. [16. MARKET PRICE GRAPHI At this point its selling price is about $\$ 800-$ 1000 per MEM at the mill and about double that at the lumber yard. This slide compares the selling price of LUL with bther wigd products such as chips, lumber, and plywand. Even at these premiums gver sawn lumber, builders tell me that the total installed bost is competitive for many applibations and that the mapket is growing es evidenczd by the eanstruetion of new plants. We believe that as mors product is produced and as production eosts defing, the sales price will slowly decrease and LVL will become competitive in additional arEas. [17. PROJECTED MARKET GROWTHI This slide shows ane consultant's view bif the future market for LVL as a finnction ef price. The graph shows that the market in ten year's time could be ten times the size of the eurrent market it the price were to desine $40 \%$ in relative terms. 
Hiw Is LVL Made?

LVL, by definitian, is made fram veneer. [18. LVL PRDCESS CONTINUOUS LAYUP] Veneer is peeled farm lags, elipped inta sheets, dried, and graded much as in a conventianal plywgud plant. These sheets are then coated with glue and layed up inta a cantinugus billet af LVL which is then pressed and sawn inta lumber. [19. SPINDLELESS LATHE - INFEED] VenEer peeling tectinglagy has steadily improved to the point that six and seven-inch lugs can be peeled an a spindleless latia [20. SPINDLELESS LATHE - OUTFEED] with better rec:yery productivity than could be achieved with sixteen-inch IGgs anly a few years agi.

The veneer is dried and graded just as in the plywind process. It is then glued and layed up intg a continubus billet, usually two ar four feet wide by $11 / 2 "$ ar $13 / 4 "$ thick. The glueing and pressing mettids are similar to plywind but adapted far LVL. [21. LVL SYSTEM - SHORT SHEET] This slide shows ane method whereby the veneers are first scarfed and graded, and then autamatically fed onto tie layup line in the preper grade sequence. [22. LVL SYSTEM LONG SHEETJ In a few Gperations, the individual veneer sheets are first scarf-jointed inta a lang sheet before glue application and layup. In these cases the resulting billet is not cantinugus, but some discrete length to match the press. [23. LAYUP STOP] This slide shiws the traveliing 
layup stop used in the short-sheet, continueus process. [24. LVL PRESS] This is a single-opening 4 fout by 80 foot hat press.

[25. RIP SAW] After gluing and pressing, the billet is sawn with crasscut and pip saws to the required market sizes. The mest common sizes are similar te dressed lumber except that header stack is eften $13 / 4 "$ so that the thickness af a double plank is equal to the width of a stud wall. Virtualy all of the production is homegeneous, on-grade, and ready for use. There is no need for further planing. grading, and trimming. Same product is shipped in long lengths to the dietributian yards far eutting to length at time of sale.

In greder to guarantee the structural properties, the veneer gheets are aften strength tested pribr to layup. This is usually dane with an ultrasonic veneer grading machine which bperates by measuring the length ot time a sound wave takes to travel the sheet fram end to end. The various grades of veneer are then arranged in the layup to give the finished product its desired preperties. Statistical testing at the finisted LVL is carried but by plant persannel backed up by an independent agency to certify the properties stamped on each piece. 
Whiv Shiuld Youl Ceinsider Mating LVL?

If you have a timber supply problem, ar you are louking at ways to realize a better return from your present log supply, you stiuld cansider the LVL alternative. The next few slides show same projected cost camparisans between industry-scale plants producing LVL plywerd, and lumber.

[26. MANUFACTURING COST COMPARISON] The first chart compares the manufacturing cost of LVL and lumber assuming the same lag supply. Althiugh LVL casts a little mare ta produce, remember that the value of the finished product is far higher than the commidity lumber that can be made from these smal1 1Gg5. [27. MANUFACTURING COST COMPARISON] This chart compares LVL manufacturing costs to plywigd made with a conventianal lathe and plywagd made with a spindleless lattie. As you can see, the higher recovery and productivity mean that LVL can be produced at a lower cast than stieathing-grade plyweid, but, thanks tig its excellent structural properties, be sold at a much higher price. [28. MANUFACTURING COST COMPARISON] This slide nEw campares all three alternatives, lumber, plywbid, and LVL, with all measurements converted ta cubic feet to make for easier eomparisan. At this point, you will recall an earlier slide that stubwed cammadity lumber selling ex mill fir araund 4 dollars a cubic foot, sheathing plyweid far about five dollars a cubic foot, and LVL for fourteen dallars a cubie 
figt. You ean see that someane manufacturing LVL from small

lags will enjay a far higher margin than any competing

product can deliver from the same lag mix. You can also see

that he will be well protected as the praduct continues to

maturg and as the seling price decreases bver time. 


\section{Summary}

The traditional wogd products industry is threatened by the declining availability af large and medium-sized logs. At the same time there is an ever-increasing demand far improved structural perfirmance from Gur products. With LVL technolggy, Gur industry niw has the ability to meet the market's mast sophisticated structural demands, and da it effectively with small logs. Thanks to the high value that the marlet has placed an LVL, the high recevery and productivity of the process, and the lower raw material cost Gf small logs, there is an excellent profit Gpportunity available to the woud producte producer. We challenge you ta seribusly cansider it. 
• 
MARKETS, PRODUCTS AND TECHNOLOGY IN THE 2Ist CENTURY - A CANADIAN SOLID WOOD PRODUCTS PERSPECTIVE

by

Albert Schuler

Manager, Economics and Market Research

Jamie Meil

Economist

Forintek Canada Corp.

800 Montreal Road

Ottawa, Ontario

KIG $3 Z 5$

\section{ABSTRACT:}

knowledge of the relationship between technology, products and markets is key to gaining a better understanding and appreciation for what the future may hold for the Canadian wood products industry. This paper explores those relationships and evaluates pertinent trends related to the future development of technology, products and markets. The focus is on the identification of implications to the industry and a presentation of our view of the major changes in store for the 2lst century. In our view, markets or customer needs are the critical factor. Technology must have a market orientation and products are simply the means of satisfying customer needs.

Our findings suggest that the Canadian wood products industry will experience significant changes that are driven by a more competitive global economy, less favorable resource situation, environmental and health issues, and rapid technological advances in computers, advanced industrial materials and communication technology. The wood products industry of the future may be characterized as follows: Smaller economic units; vertical and horizontal integration to better utilize the resource and add value; market diversification; large multinational corporations; shift from commodities to engineered wood products; resource neutral conversion and product technology; shift from structural to semi-structural applications and a move to more environmentally acceptable products and conversion technologies. In order to compete in the future, firms must adopt a more aggressive marketing stance, spend more on R\&D and do a better job in merchandizing the resource. 
MARKETS, PRODUCTS AND TECENOLOGY IN TEE

2IST CENTURY - A GANADIAN SOIID WOOD PRODUCTS PERSPECTIVE

\section{INTRODUCTION}

Knowledge of the relationship between technology, products and markets is key to gaining a better understanding and appreciation for what the future may hold for the Canadian wood Products Industry (CWPI). This paper will explore these relationships and evaluate pertinent trends related to the development of technology, products and markets. The focus will be the identifieation of the implications to the CWPI and a presentation of ouI view of the major changes in store for the lst quarter of the 21 st century.

Figure I depicts a realistic relationship between technology, products and maykets 1 In essence, customer needs or markets are the key! Technology must have a market orientation, with products not an end in themselves, but the means of satisfying customer needs or desires. The product becomes the carrier of the technology and the form it takes is defined only after the technology and need have been clearly matched.I/

There are two types of technology - the incremental category which facilitates improvements in price/value of existing products; and enabling technologies that are capable of creating new products and services and transforming production methods. A chipper canter headrig is an example of the incremental variety whereas biotechnology, information and communication technology and advanced industrial materials exempiify the latter. 2 /

The role of technology in purely practical terms is:

- "to improve competitiveness

- to accommodate future growth

- to overcome environmental challenges

- to make new products"

I/Twiss, B.C. 1986. Managing Technological Innovation. 3ra Edition.

Longman Group Itd. England 238 pp.

2/science council of Canada. 1989. Enabling Tehnologies: Springboard

For A Competitive Future. Ottawa, Canada.

3/Noranda Forest, Inc. 1989. Annual Report - 1988. Toronto, Canada 
To stay in business, you have to produce the right product at the right price at the right time. In essence, we must anticipate the technoeconomic environment of the future. The remainder of this paper will address just that, but first we will briefly describe today's environment for in it lies the clues for future changes.

\section{CURRENT MARKETS, TECHNOLOGY AND PRODUCTS}

Today's products are heavily oriented to commodity grades for North American markets. Production and marketing strategy is predicated on demand growth and cheap timber.

Lumber and panel products are geared to North American construction markets. Sixty-seven percent of softwood lumber and eighty percent of structural panels go to such markets with the remainder going to growing industrial markets. Within the construction sector, there are two distinct subcategories - residential (including new housing and repairs and alterations) and non-residential (including building and non-building construction). The residential sector is the most important as it consumes approximately eighty percent (value basis) of wood products consumed.

Technology in use today emphasizes cost minimization via economies of scale, product standardization, labour reduction, capital intensity, etc. Consequently, there is little flexibility in the conversion process.

The products are primarily commodity construction lumber and panels. To date, there has been little value added, however there are increasing signs that value added is being considered by more firms particularly in high cost resource areas such as the B.C. Coast. 
FACIORS PRECIPITATING CHANGE IN WOOD USE AND IMPIICATIONS FOR THE INDUSTRY

Four trends are having major impacts on the international competitive position of the Canadian Wood Products Industry (CWPI). Those trends can be grouped into the following categories:

- Resource related factors

- Socio-economic/market factors

- Product related sactors

- Technology related factors

\section{Resource Factors and Implications}

Eactors. The availability and low cost of the softwood timber resource has been Canada's major source of international competitive advantage for the past twenty-five years. However, there are significant trends that suggest the advantage is weakening (Fig. 2):

- Delivered cost of softwoods will continue to increase in real dollars:

- The softwood harvest is approaching the ansual allowable cut (AAC) for Canada while B.C. and Quebec harvest exceed AAC;

- The future $A A C$ will be less than today's assuming current levels of management, multiple-use considerations, acid rain and other environmental considerations and loss to other non-forest uses;

- There will be a decrease in average size and quality of future softwood harvests.

The story for hardwoods is considerably different with harvests accounting for less than half of the AAC. The current surplus ( $37 \mathrm{milion} \mathrm{m}^{3} / \mathrm{yr}$ ) is concentrated in lower value species such as aspen/poplar and birch in Alberta, Ontario and Quebec.

Another factor that is threatening to shift Canada's position as the world's leading supplier of internationally traded commodity wood products is aditional supplies from other sources such as New zealand, Chile and Australia. Furthermore, some of our trading partners (England and Japan e.g.) are working hard to reduce theil reliance on foreign resources. 
Finally, environmental concerns re: residue disposal, both in the bush and at mill site are beginning to play a more prominent role in crown policy decisions on forest management and utilization practices.

Implications. The major implications of the above factors are:

- Increased pressure to improve fiber utilization via higher product recoveries, and reduced fiber waste;

- Increased pressure to add more value to an increasingly expensive raw material;

- Restructuring of the industry to secure and better utilize available raw material

- more corporate concentration

- more horizontal (the resource) and vertical (value added) integration;

- Manufacturing and marketing strategies will no longer be based on a cheap and abundant raw material - i.e. volume oriented technologies and strategies (with little consideration of value) will fall into disfavor;

- Environmental concerns will force us to manage and utilize the resource with conservation the underlying theme. In the short run, this will mean higher costs!

- The CWPI must develop a new mix of production and marketing strategies that is consistent with its changing resource situation and to facilitate competition with new suppliers in the important Pacific Rim growth markets (Fig.3).

\section{Socio Economic/Market Factors and Implications}

\section{Factors.}

- Demographic trends suggest less housing demand as the population ages in response to greying baby boomers and lower birth rates;

- Polarization of the midale class in the developed economies is progressing at an alarming rate - the rich are getting richer and the poor are getting poorer; 
- Global competition, already a reality, is being fostered by almost instantaneous capital movement, combined with the integration of computers and communication. New alliances are being formed in an attempt to jockey for better position e.g. Canada-U.s. Free Irade initiative; "Europe 1992"; etc.;

- Increasing energy costs will affect the relative competitiveness of products dependent on petroleum for production, delivery, and raw material procurement:

- Envirommental trends suggest a quickly mounting concern by society for the environment. The concerns range form acid rain, air and water quality, work place environments (formaldehyde emisions, wood dust, roise), chemical usage (forest chemicals, wood preserving, wood finishing and coating chemicals), waste disposal, and greenhouse effect.

\section{Implications. Major implications include:}

- Demographics point to a long term decline in North American housing starts and a leveling off in expenditures for repair and alteration;

- Niche marketing of housing products to satisfy afforabble housing concerns of the poor and luxury and convenience desires of the rich;

- Competition in the international market place will continue to escalate and will be based on customer satisfaction, li.e. value for money);

- Production and distribution efficiencies will become even more important as energy costs continue to escalate; and

- Environnentally acceptable products, and conversion technology will prevail in spite of increased costs. In addition, polluting firms and industries will have to "clean up theil act" or suffer the consequences.

\section{Product Trends and Imolications}

Eactors. There are several important trends affecting both structural and non-structural applications: 
- There is a shift away from products dependent on resource size and quality to products dependent on fiber availability (Fig.4);

- Toward products that yield higher finished product recovery;

- Toward products with more uniform properties;

- Toward products derived from the hardwood resource;

- A product shift from commodities to specialty products to components to building systems is underway;

- From solid wood products to composites including wood and nonwood combinations;

- Trend to semi-structural products such as stress-skinned panels, molded fiber products such as "spaceboard", new exterior siding products, etc.;

- Trend to increased use of "industrial design concepts" combining aesthetic values with functional performance at acceptable costs.

Implications. The major implications of the above trends are:

- Semi-structural markets may be able to provide the CWPI with an acceptable ROI in spite of rising wood costs because such products combine the aesthetic and structural/strength attributes of wood;

- Product attributes must be added if tomorrow's wood products/systems are to compete with non-wood products;

- Higher value products/systems will require a strong marketing infrastructure with emphasis focused on customer satisfaction.

\section{Technology Related Factors and Implications}

For ease of exposition, technology has been divided into three categories including conversion, end-use and product technology.

Conversion Technology Factors and Implications. The economic feasibility limits of softwood lumber and veneered panels technology is quickly reaching the limits of its profitable life (Fig. 5). This is due to a cost/price squeeze with resource costs going up while commodity prices decrease in real terms. There have been two responses to this trend: 
- Further entrenchment into commodity markets/products. In essence, many firms are utilizing the latest productivity enhancing technology to reduce unit costs even further. e.g. microprocessor and scanning technology is now used to:

- characterize/merchandize the resource prior to breakdown

- optimize breakdown, edging and trimming

- automate drying process, and

- improve product quality control

- A movement away from a commodity product focus to one that favors a market orientation. Again, microprocessor technology is prominent, however it is used to enhance procuct value. Some examples include technology to:

- merchandize the resource in terms of value;

- enhance flexibility in the mill to economically produce small orders of components or specialty products;

- adition of more product finishing capabilities.

There are several important implications that evolve from the above trencis:

- Eventually, the two strategies will merge to form efficient, flexible, small scale economic units;

- The CWPI must match available resources (cost) to appropriate markets via best conversion technology;

- New processing technology is needed and it will be characterized by computer integrated manufacturing, flexible manufacturing systems and CAD/CAM design tools.

End-use Technoloov Factors and Implications. There are several interesting trends that are affecting the way wood products will be utilized in the future: 
- Industrialization of the construction process is having a major impact. Factory built housing/manufactured housing systems will continue to gain market share, particularly in the USA with its large urban centers. Tilt-up technology is here to stay! Panelization will continue as component manufacturers will be able to provide a more flexible and cost effective alternative (to existing building techniques);

- The trend to building materials and systems that have reliable and predictable engineering and other properties is gaining momentum. Reliability based design procedures are becoming the norm in international building codes. It is being ariven by developments in computer technology (CAD/CAM) and litigation trends;

- A systems approach to building construction is also gaining momentum in an effort to promote efficient building practices that will reduce life cycle costs of housing and commercial buildings;

- Fire regulations will continue to stiffen in the face of increasing litigation problems.

Implications of the above trends to the CWPI include the following:

- The wood products industry will face increasing pressure from non-wood building materials both in residential and non-residential markets. To compete, it must develop knowledge of wood products/systems that is on a par with non-wood materials with respect to duration of load, thermal and moisture performance, and other system performance factors, i.e. we must prepare ourselves to compete in a reliability based design world where life cycle costs on a system basis is the criteria of success.

Product Technology Factors and Implications. There is a materials revolution going on primarily outside the wood products industry. The North American wood products industry must realize that it is part of a much larger materials community. Advanced industrial materials (AIM) such as ceramics and advanced composites are leading the transition 
from traditional materials by offering better performance and competitiveness on a life cycle cost basis. A major advantage of AIM is thei= attitude - they work with other suppliers and materials to combine structural abilities, gain market acceptance, and share distribution networks. $\leqslant$ /

Some examples of recent product substitutions are:

- Optical fibres replacing copper wire;

- Composites (metal, plastics, ceramics and high performance reinforcements such as S-Glass, kevlar, graphite and boron fibres displacing aluminum in aircraft: and

- Plastics and new alloys replacing steel in automobiles and buses.

New colloidal microcrystal products (using cellulose as a raw material) are being developed that may enhance wood product applications. These products can be recycled which is becoming a big advantage. Some industrial uses include: non-toxic, water based systems of binders and coating for paper, board and pulp molded products; and prime coatings for glass, a) unisum and wood.

Within the wood products industry, we are witnessing an explosion of new product introductions. Improved products for traditional applications include the transition from plywood to waferboard to oriented strandboard and most recently stabilized reconstituted panels. In the nonstructural and semistructural area, we have witnessed transition from plywood to particleboard to MDF to new MDF based products with heat applied overlays. Other examples include gypsum board wrapped in paper, gypsum fiberboard and laminated veneer lumber products.

4/Binsacca, Richard. 1989. Products that will shape the 90 's. Builder, July 1989, pp. 205, 208, 209, 212. 
Examples of new products for new markets include polymer enhanced wood products (true composites), cement bonded fiberboard and molded fiber products such as FPI's spaceboard.

Some implications from the above developments are:

- man made materials will continue to get better;

- wood product technology must be developed with a focus on uniform properties that are competitive on a life cycle cost basis;

- new products will combine the best qualities of man-made materials with wood to produce superior "true composites". Resulting material properties will greatly change/expand end use applications.

\section{CONCLUSIONS - A CRYSTAL BALL VIEW OF THE 21st CENTURY}

The wood products industry will experience significant changes in its markets, products and technology in the next twenty-five years. The changes are being driven by a more competitive globalized economy; a less favorable resource situation, environmental and health issues; and rapid technological advances in computers, advanced industrial materials, and communication technology. The wood products industry of the future may be characterized as follows:

- Smaller economic units - operating units will be smaller, more flexible and fully computerized. Informatic technologies will create a transition in industry strategy from a high volume, low value product produced to stock, to a smaller volume, higher value product produced to order. i.e. Economic mass production of variety in small order quantities. - Vertical and horizontal integration - vertical integration will facilitate the efficient production and distribution of value added products while horizontal integration will promote better utilization of an increasingly expensive resource (wood, capital, etc.); e.g. primary manufacturers will move into territory traditionally serviced by remanufacturers (mouldings, joinery, doors, windows, decks, privacy fences, siding, components, treated wood products, etc.) - vertical 
integration. Furthermore, resource merchandizing and better informatic technology will result in a sharing/redistribution of the resource among various conversion units within a firm in order to obtain a better match between resource, product and conversion technology - horizontal integration.

- Market Diversification - The CWPI industry must diversify its product line and geographic reach to promote both growth and profitability. - Large multi-national corporations - current reorganization trends will continue as fims reorganize to compete in a global economy; e.g. vertical and horizontal integration will require large canital inflows.

- Shift from commodities to engineered wood products - Engineered, composite (wood only, wood plus non-wood materials) materials will make up an increasing share of the industry's output. These products will be more uniform in engineering properties, competitive on a life cycle cost basis, and capable of providing a reasonable ROI in spite of rising resource costs. Such products will help wood hold onto existing residential markets and penetrate "non-residential" markets.

- Resource neutral conversion and product technology - Non-veneered panels, parallel strand lumber ("Parallan", "Scrimber"), laminated veneer lumber, FPI "Spaceboard", molded fiber products, overlayed stabilized OSB and MDF products are a few examples of products that are resource neutral. Such technology will allow the industry to effectively deal with rising resource costs, lower resource quality and the seed to convert manufacturing systems to a more efficient, refined, uniform (pulverized) flow process.

Shift from structural to semi-structural and non-structural applications

- Stress skinned panels, moulded fiber products and wood/non-wood composites will increase in favor as they blend the positive features of various materials. i.e. The functional and visual appeal of wood will be married to decay and fire resistant non-wood materials to produce new products for new customers. 
- Shift to environmentally acceptable products and conversion technologies

- Energy intensive technology will lose favor as will those technologies

\& products that pollute the environment. These changes will be

legislated and costs will be allocated to the "guilty party".

- Customers in the future will be better educated/informed and looking

for good value for their money. Product quality and durability

will be used to measure long-term performance.

- Hand-built housing may be a luxury commodity available only to a privileged few. Manufactured housing techniques will provide the major share of "affordable housing" that tomorrow's customers demand. Finally, if the Canadian wood products industry is to embrace vertical \& horizontal integration, value-added and flexible production, the prevailing practice of processing as many logs as possible must give way to the practice of product value maximization in terms of performance, function and aesthetics.

\section{Firms must}

- adopt a more aggressive marketing stance towards the demands of the marketplace

- spend more on technology - its development, absorption and use especially information technologies

- better understand the inherent values of the resource and match it to markets more efficiently. 


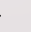




\section{Technology - Product - Market INTERFACE}

MARKETS

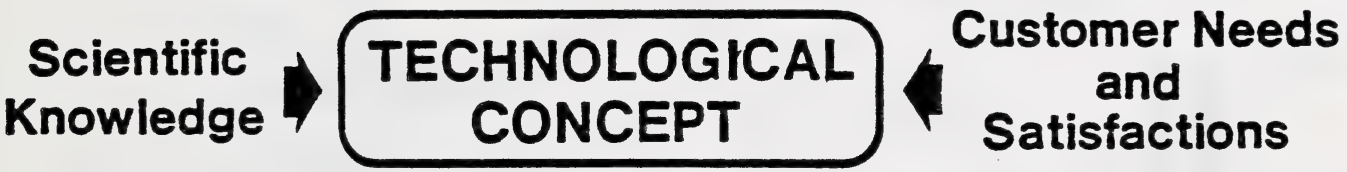

Inputs

PRODUCT

DESIGN

Materials MANUFACTURE Products

Conversion

SOURCE: B.C. Twiss

Managing Technological Innovation

3rd Edition 
ANNUAL ALLOWABLE CUT, HARVEST AND PHYSICAL SURPLUS OF HARDWOODS AND SOFTWOODS FOR SELECTED YEARS IN CANADA (1970-1988)
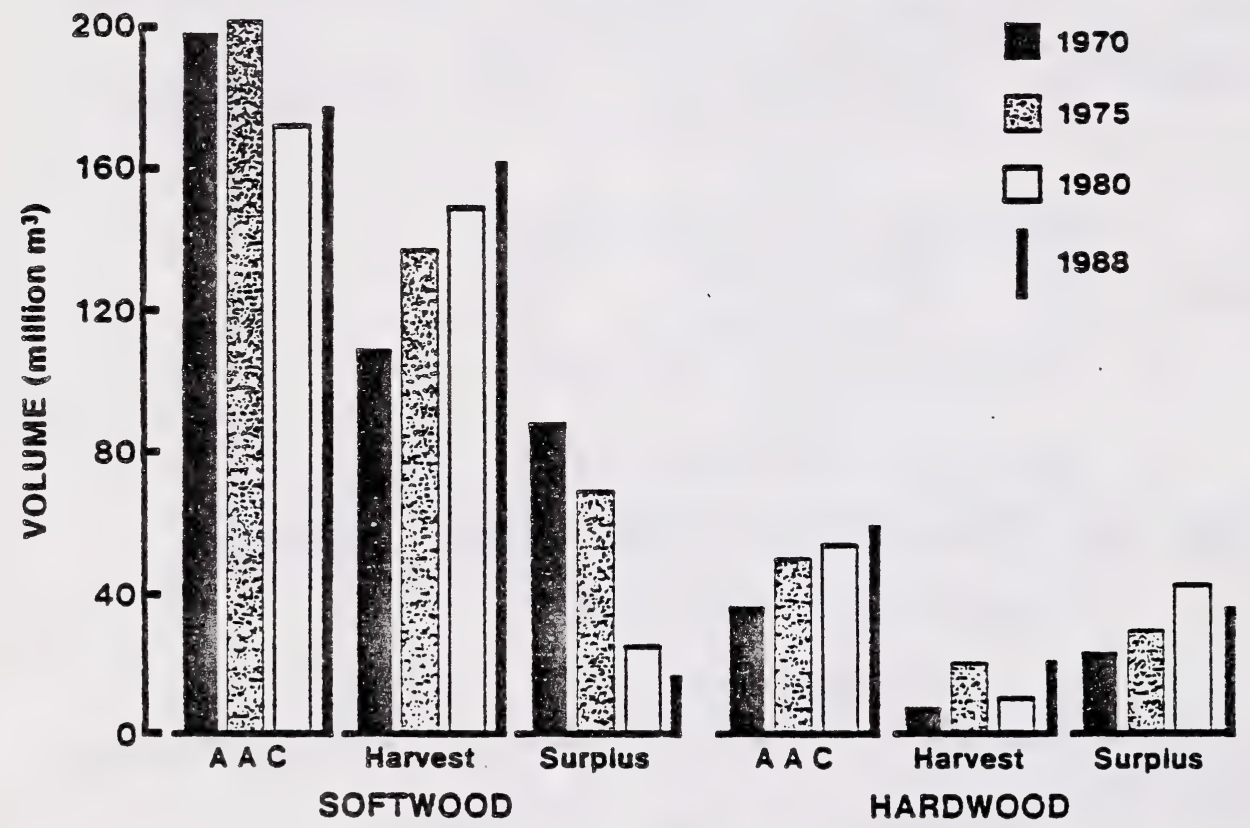

538s

Figure 2. 


\section{PACIFIC RIM MARKETS}

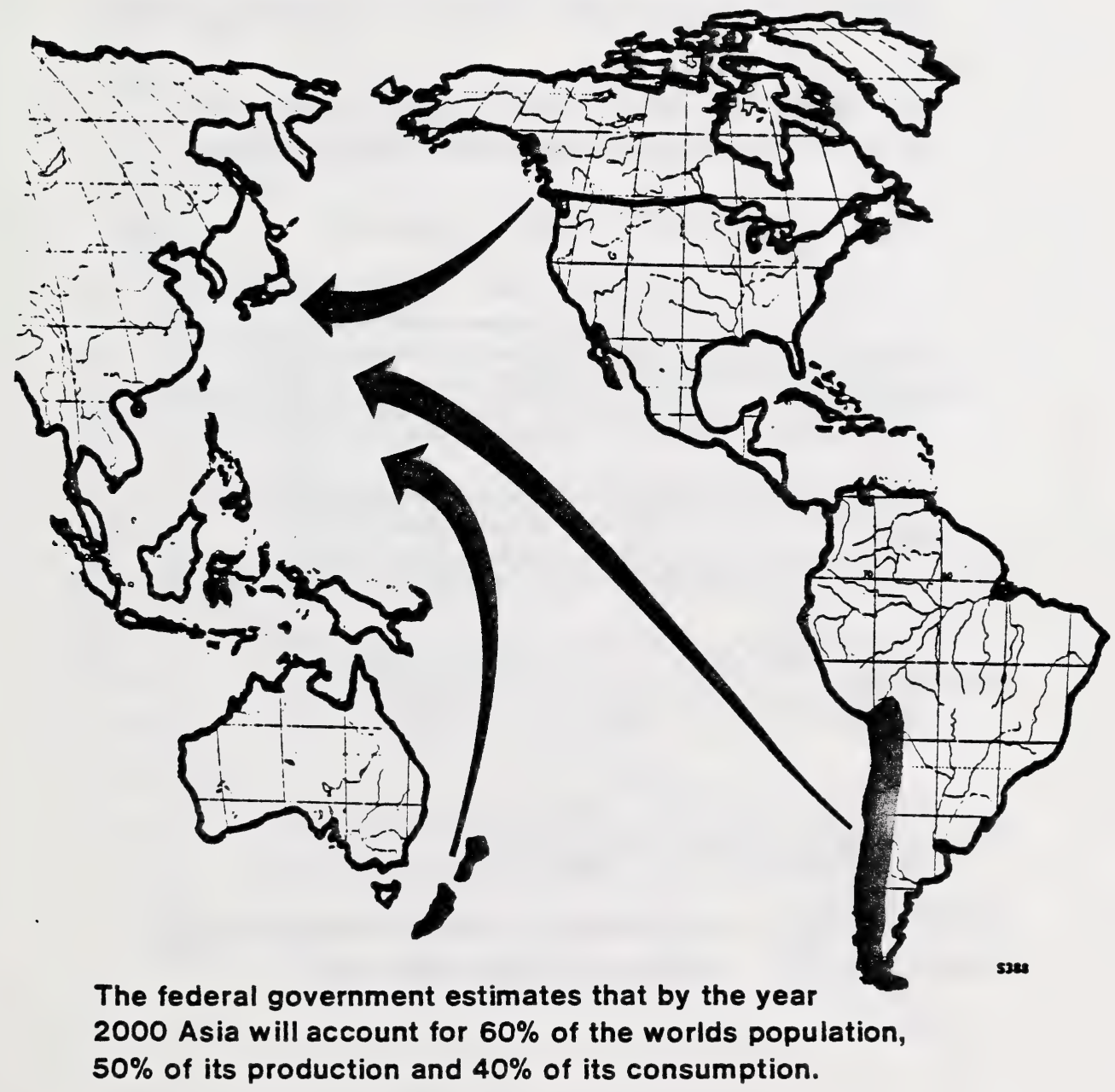

Figure 3. 
Composition of Forest Product Demand -3 year averages, solld-wood equivalent-

PERCENT SHARE BY VOLUME
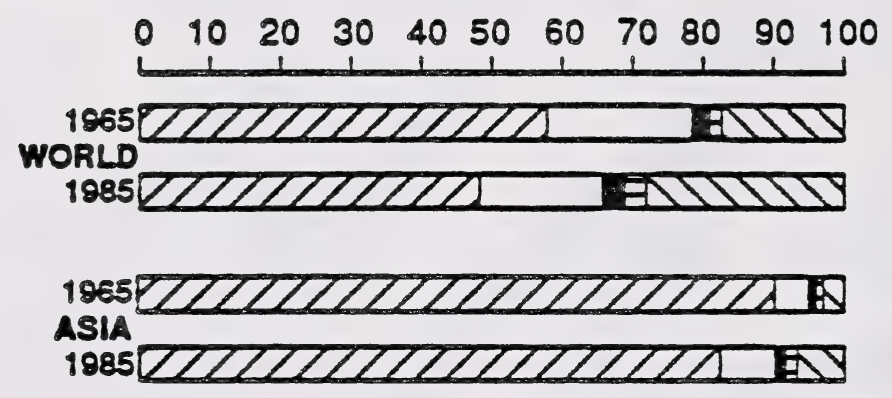

พ. EUROPE

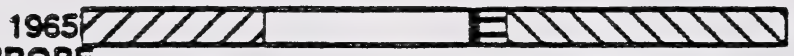

$1985221019 M$

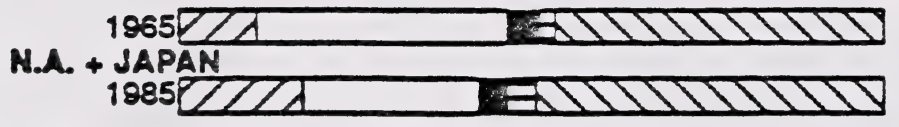

FUELWOOD $\triangle$ PLYWOOD SAWNWOOD $\square \quad$ PARTICLE \& FIBRE BOARD $\equiv$ 


\section{TOTAL PRODUCT-MIX FEASIBILITY LIMIT}

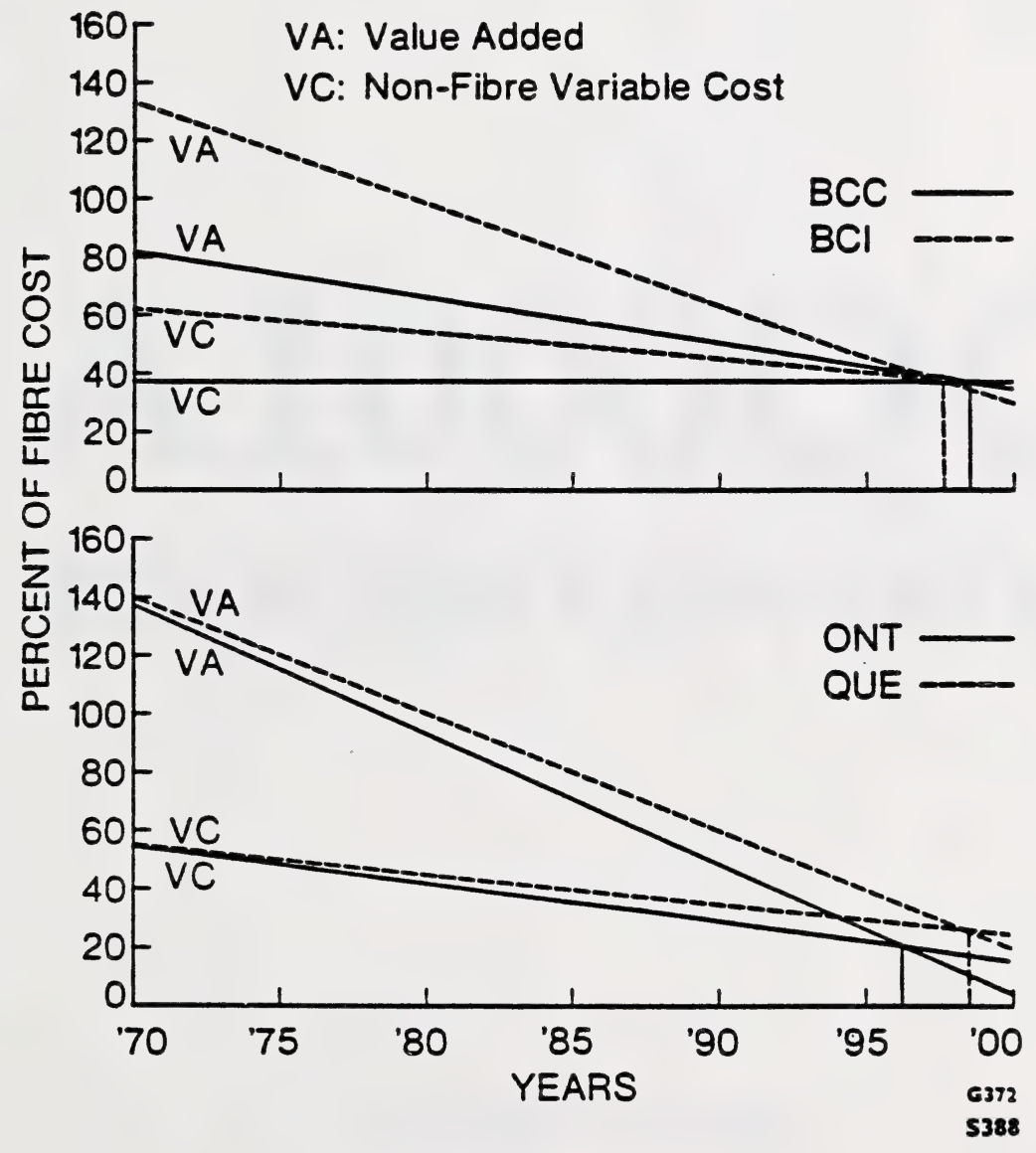

Figure 5. 



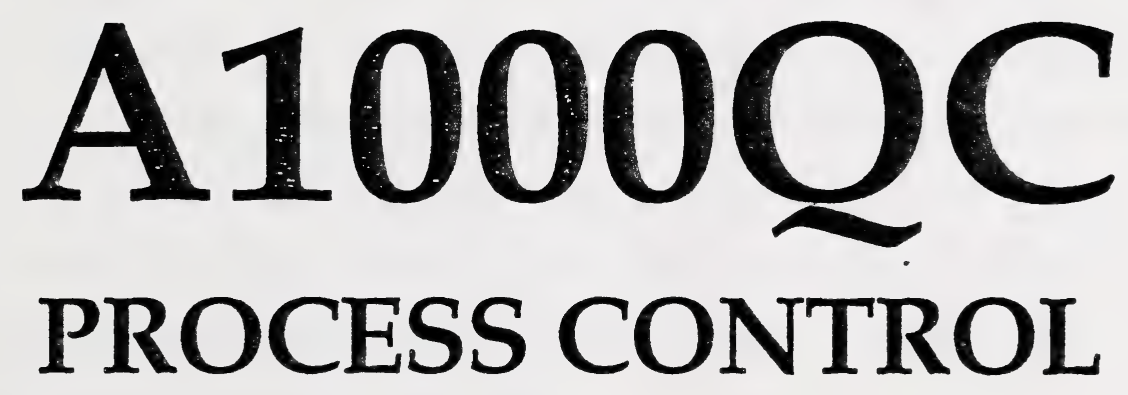

David Andrew \& Associates

Technical Solutions

(403) 437-5984 Edmonton, Alberta 


$$
-1 L=T-B-T
$$

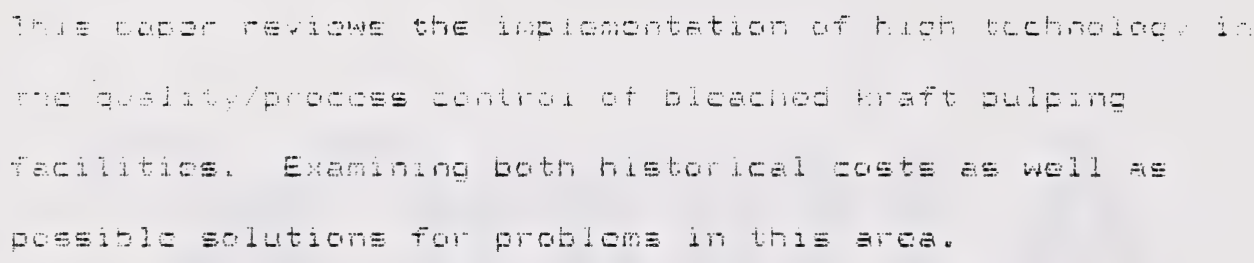




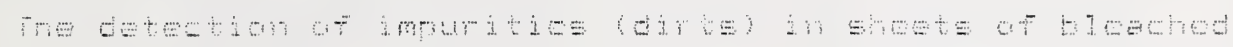

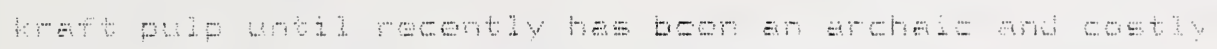

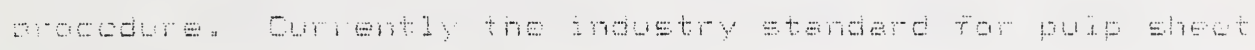

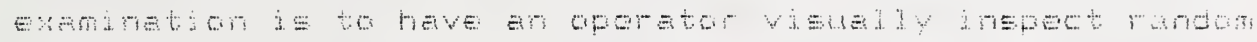

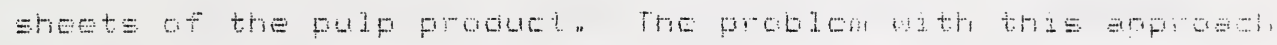

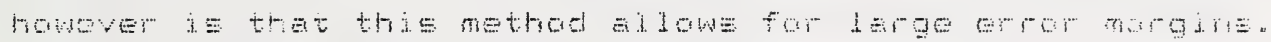

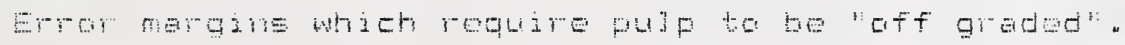

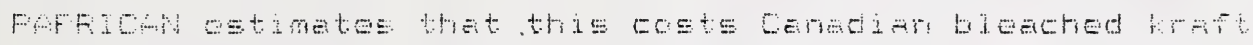

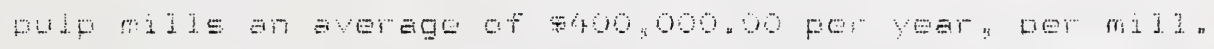

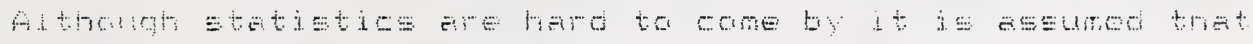

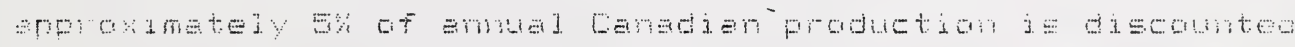

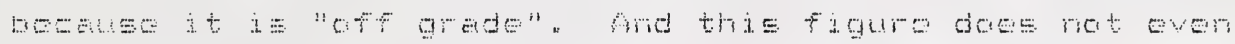
begin to eceount rom the casts of buffer stocts arde

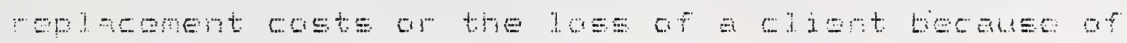
diseatefection with the pulf product. In the past this whe

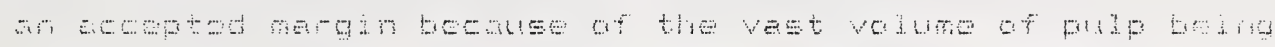

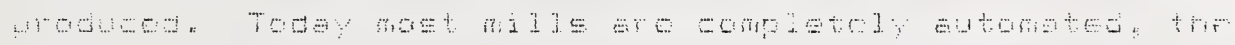

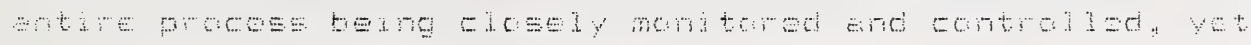

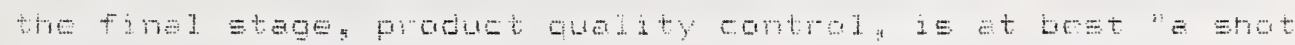

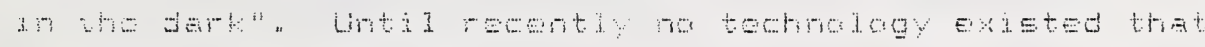

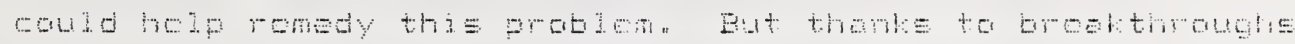

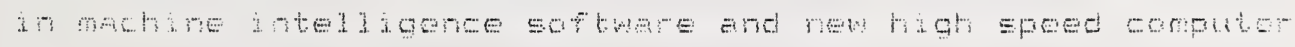
nerobare there are now solutions solutione thet are accumete reliatle and proven.

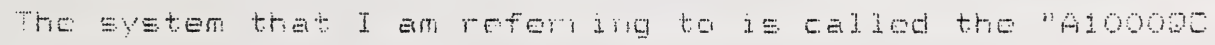

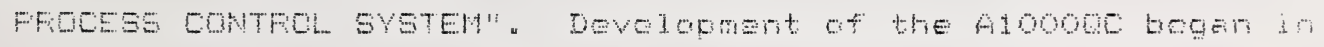




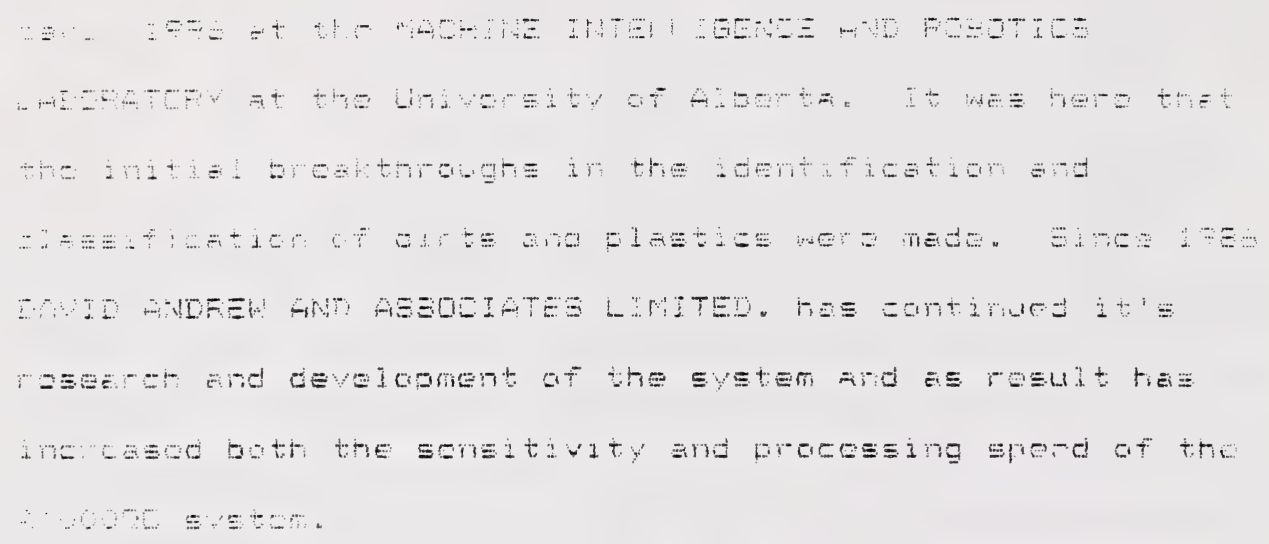

DESCFIFTIG OF THE A1OOOOC RAOCESS COHTRO GVTEM

The Aroged is a completely autemated on-line "turn tey" Eyeren. Frimerily the Alogod is mede up of two camponente.

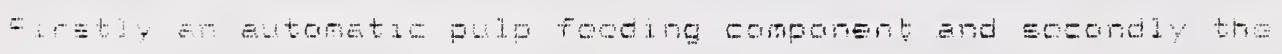
conouterized centrals of the system. The autamitir pulp

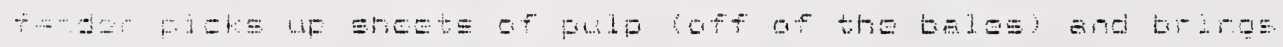

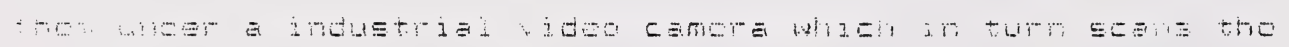

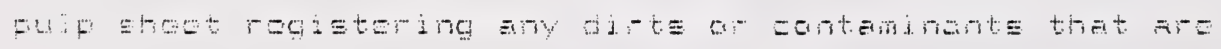

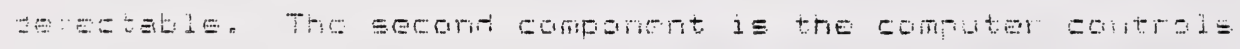

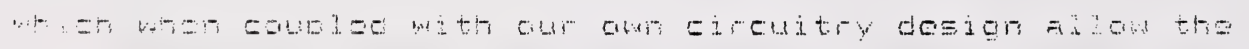

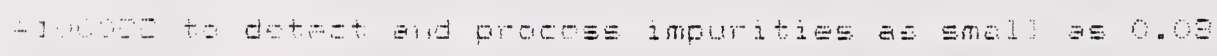

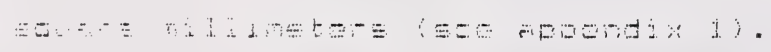

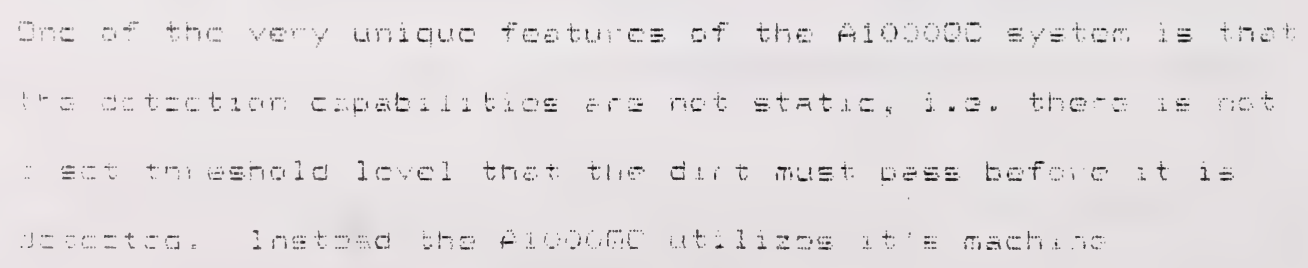




\section{$-176-$}

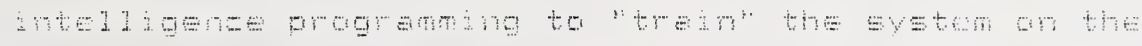

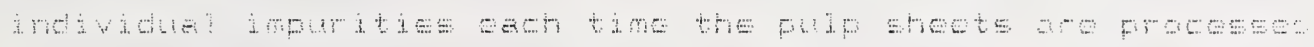

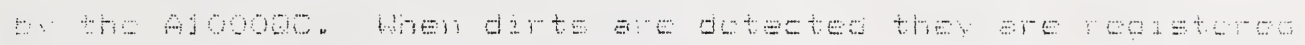

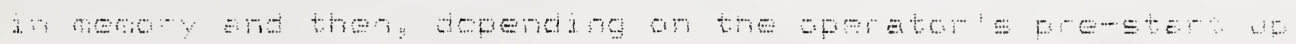

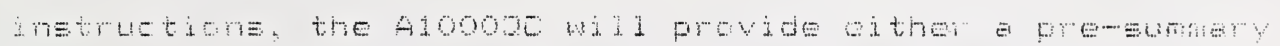

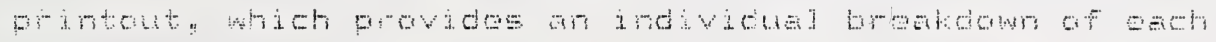

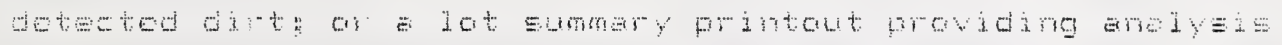

totale of al the detectod mptraties claseiried by sam am

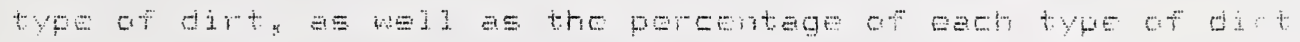

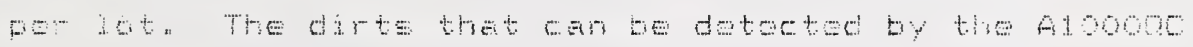

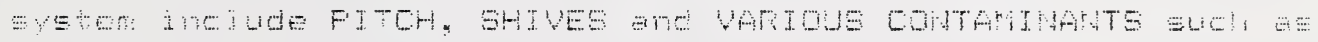

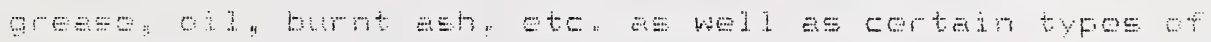

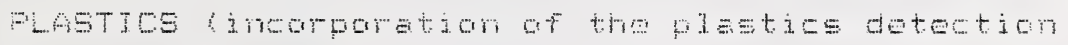

- apebilities TEA

TEST FESUTS

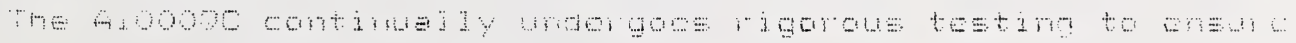

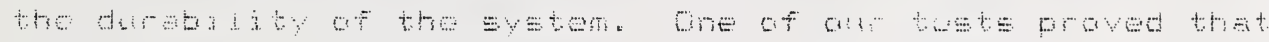
twanemitting ight though the pulp shest allowe for full

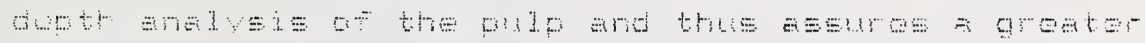

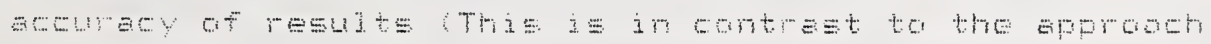

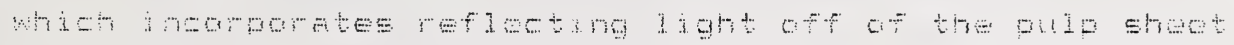

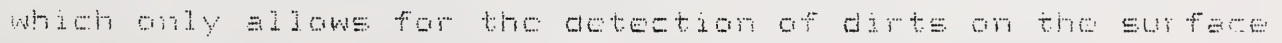
of the pulp shet).

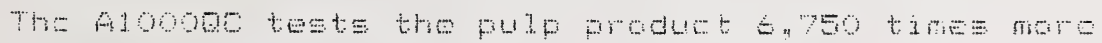




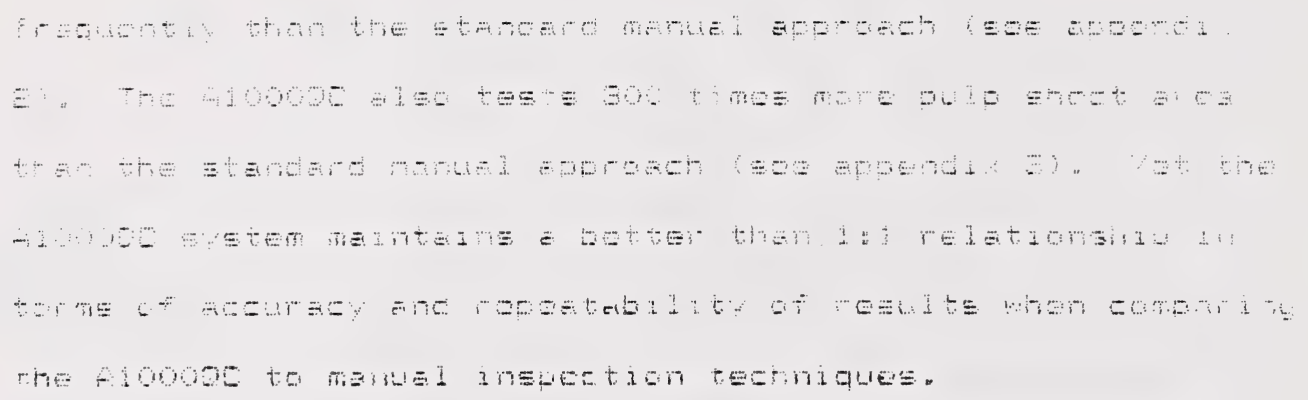


एपंस्:

Emotis of the flopoe inelude:

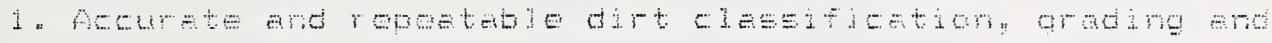
Eumting

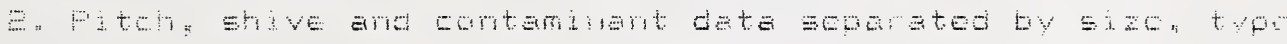
count and pereentage.

3. Fu1 dopth andysis af the pup product.

4 4.

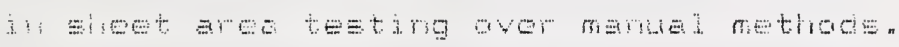

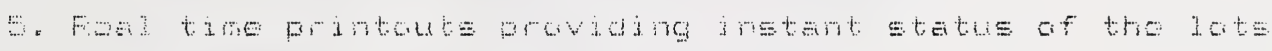
beine tested or sumary data eporte.

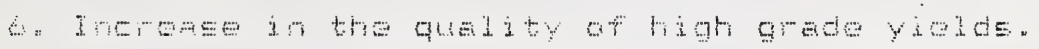

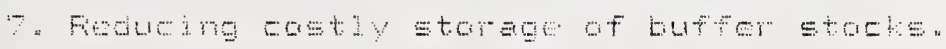

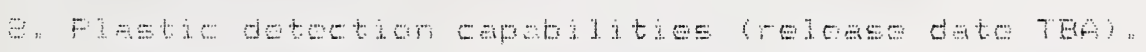

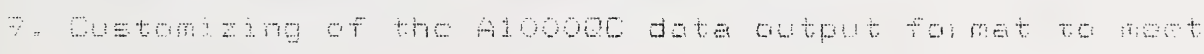
Aolvidel pulp mil regunemonts.

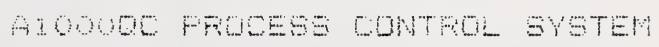

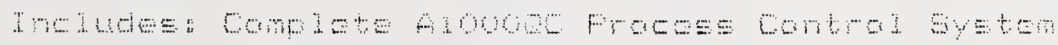
Tremeportetion

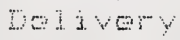

In=tejeticin

Trandrg 1 year warmanty 
$-179-$

AFFNDIX 


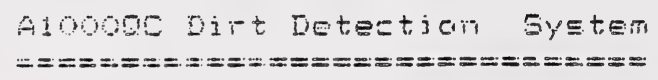

Firo - Summety Ereab: down

Lot Numbar: 12345673 Eale number: 1 Threshold Value: 39 Area \#1 is $=-20.655$. mm (medium piteh)

Tatal area is 0.65 $59 . \mathrm{mm}$.

Aloogod Dirt Detectian System
$==========:====:=======$

Lat Number : 12345673

Dirt : XL: $L: O M: 1$

Fercentage Shives: 0.00 Fercentage Fitch: 100.00

Fets per H1140\%: 1.0837 
$-181-$

AENDIX 


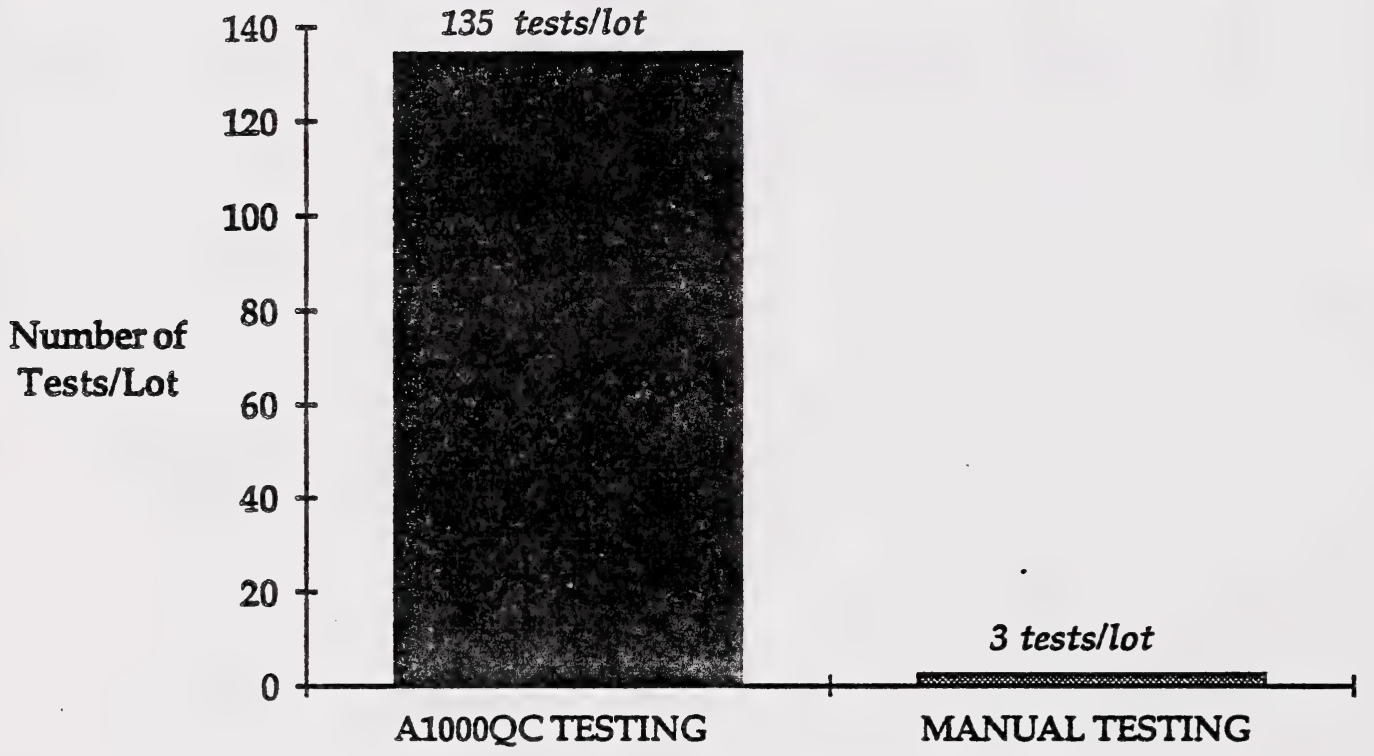

1 Lot 
-183-

AFFUDX 


\section{BAR GRAPH COMPARISONS}

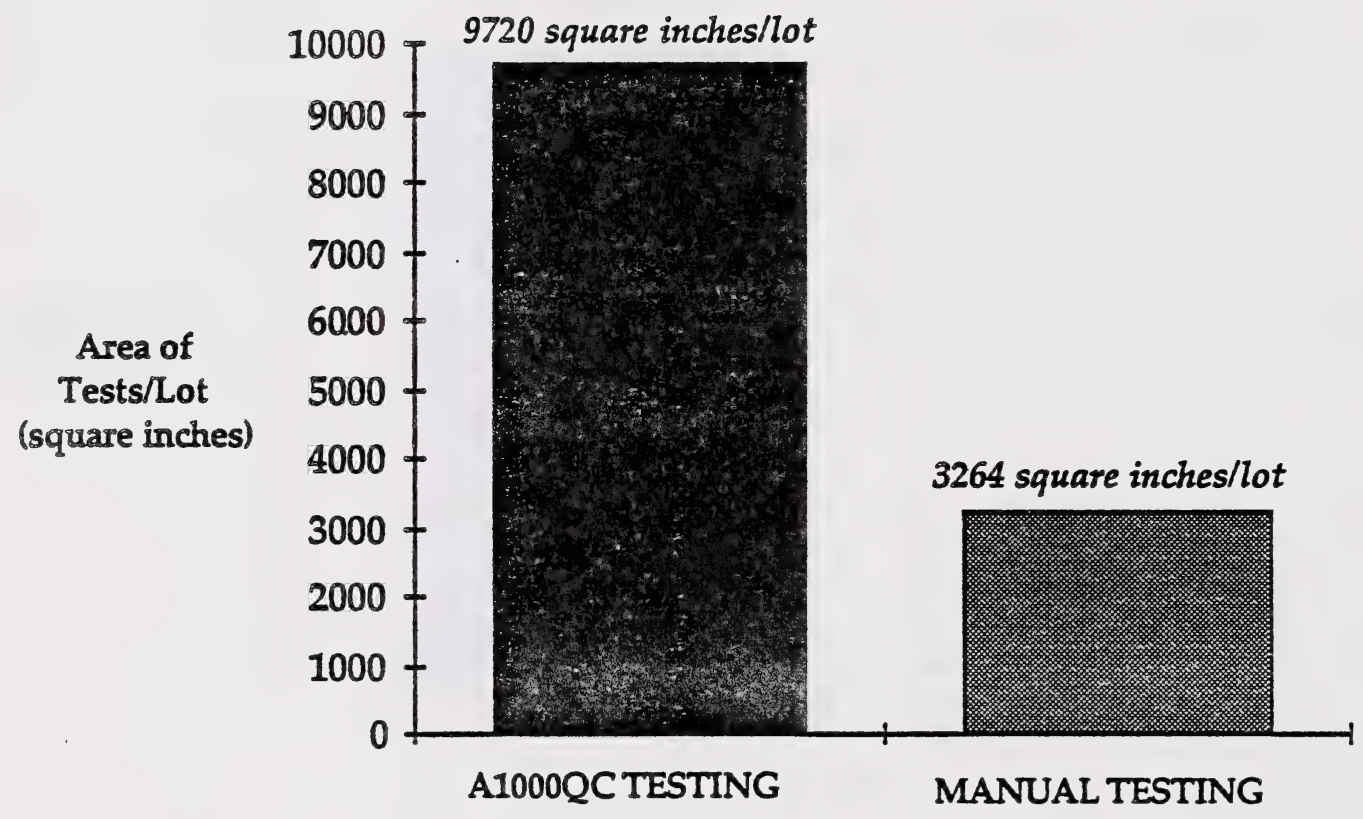

1 Lot 
THE GRADER-OPTIMIZER

A MAJOR DEVELOPMENT PROJECT

BY

WILL N. BAUER

SOFTWARE MANAGER

VISIONSMART INC. 
Introduction

Sor the past two years, Visionsmart Inc. has cevozed substantially all of its efforts to the cevelopment of a Grader optimizer system for planed lumber. The development oz the electronics and software has so far consumed over $\$ 2$ milizon and 20 man years worth of effort. considering that this was done from a cold start - a new company, and a new project - and =ne= the technology involved is on the leading edge, this has been a development project with considerable risk and incredible technical complexity.

\section{Mill Partners}

Erom the beginning, we considered it extremely important to work directly with customers and potential customers. We contacted the mill managers, planer superintendencs, quality assurance managers, and owners of over 20 milis before we even stabilized the concept of the grader - optimizer.

It was very important to us that the product meet a real market need. Our original concept was modified from that of a compureraided lumber grader to include more optimizarion - hence the grader - optimizer.

We have continued to work directly with the milis who wili be our lead customers in refining the product to meet requirements.

The Grader-optimizer

The problem of automating the visuai grading and trimming o: -umber is of significant importance to the lumber industry. 三 solved, it ożers a potential for less wastage, sign: improvement in profits, potentially betzer customer acceptance oj more uniformiy graced lumber, and most important - an increased $y=€ d$. 
The development of the system is a direct extension of previous work by Carl flatman, one of Visionsmart's founders. He had designed a grade mark reader, and a headrig optimization system. Technical advances in signal and image processing have created an opportunity to automate and optimize the grading of lumber.

A large portion of the lumber produced in western canada is SPF random dimension. It was decided the first Grader-optimizer System we would develop would address the NLGA rules for SPE studs, light Framing and structural light Framing lumber. This restriction would limit the visual range of features we have to detect, but at the same time accesses a very large market.

\section{System Function}

Visionsmart's Grader-optimizer system automatically grades dimension lumber at planer speeds of up to 1200 ft. per minute or at a maximum of 120 lugs per minute. In addition it will handle profiled $2 \mathrm{x} 8$ lumber. It runs under the supervision of one check grader/operator who monitors the lug belt and trimmer saw area.

Grading is done visually, detecting board features and evaluating each one to find its impact on board grader. The trimming software analyzes each of the different possible trimming scenarios (over 100) and chooses the one which will return the most money for the board in question. The computer then instructs the trimmer saw as to which saws to drop.

\section{Grader-Optimizer Equipment}

As shown by Figure 1, the grader hardware consists of:

1) A Scanning Ring located between the planer outfeed and slowdown belts.

2) A scan Computer which processes the images. 

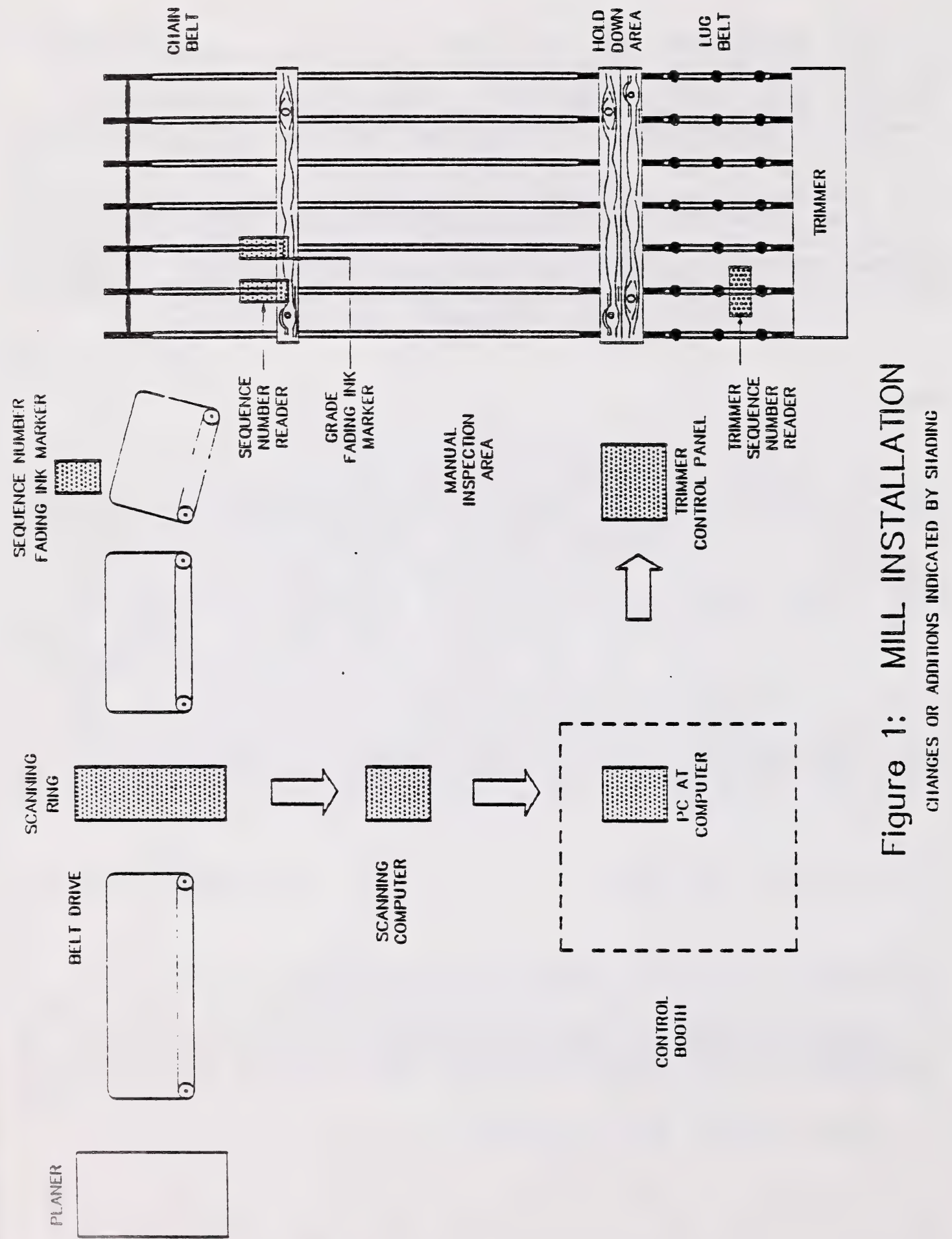
3). A PC AT computer located in the control room area.

4) A Sequence Number Ultra-Violet Fluorescent Ink Marker which marks each board with stripes of Ultra-Violet Fluorescent ink indicating the sequence number.

5) A Sequence Number Reader coupled to a fading ink marker which marks the boards with numbers and letters indicating grade and trim for the check grader.

6) A Final sequence Number Reader which synchronizes with the trimmer controller.

7) A Trimmer/stamper control interface which controls the saws and the grade stamp.

The Scanning Ring, and Scan Computer

Boards are scanned by the scanning ring, shown in Figure 2 using twelve cameras and one x-ray unit.

The scanning Ring, shown in detail in Figure 3, consists of four sets of standard commercial CCD cameras and an x-ray. Each set views one side of the board. As shown in Figure 4, there are four cameras in three groups. Each of the three groups will detect a slightly different image due to the different lighting each receives: the first uses side lighting to highlight shadows from edges; the second uses a floodlight to receive a normal image; the third group (the two colour cameras) uses colour filters to detect unsound wood and stain. The X-ray detects knots. Combining information from the twelve cameras and $\mathrm{X}-\mathrm{ray}$ provides a means of differentiating among features.

The scan computer is comprised of high speed image processors designed by Visionsmart. There is a separate image processor for each camera image as well as one for the X-ray. Figure 5 shows how the processing is split between the multiple image processing computers. 


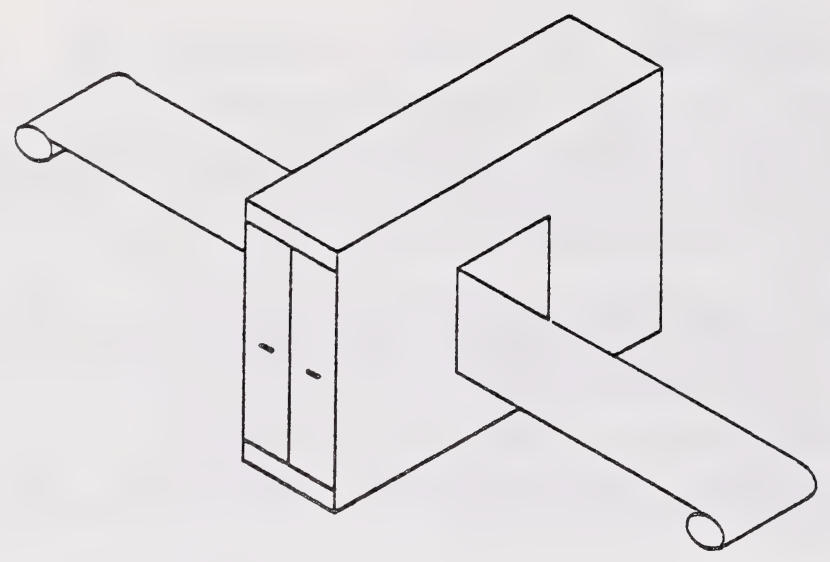

Figure 2: SCANNING RING

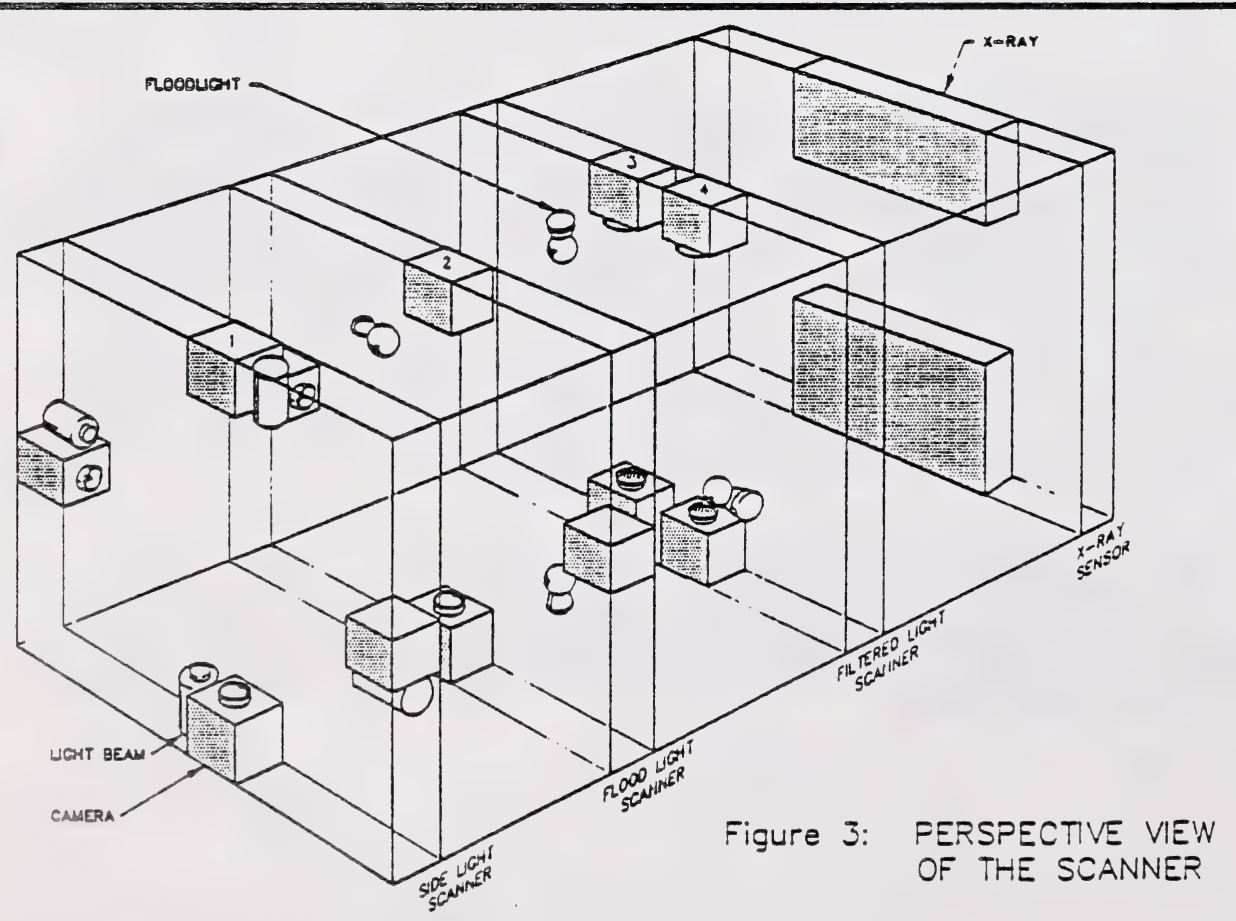




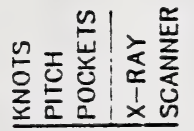

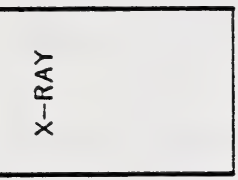

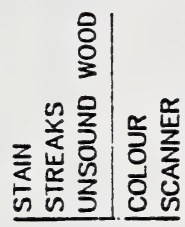

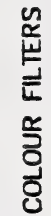

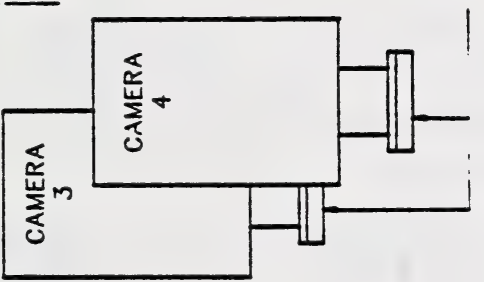

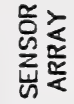

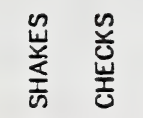

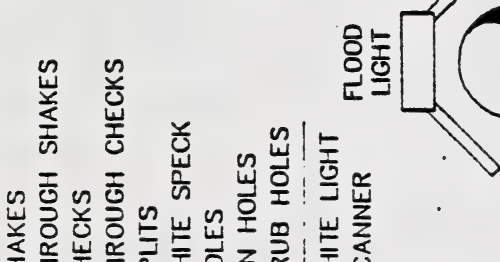

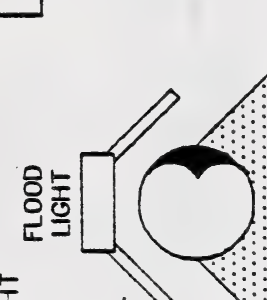

宑

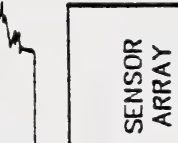

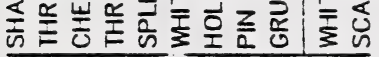

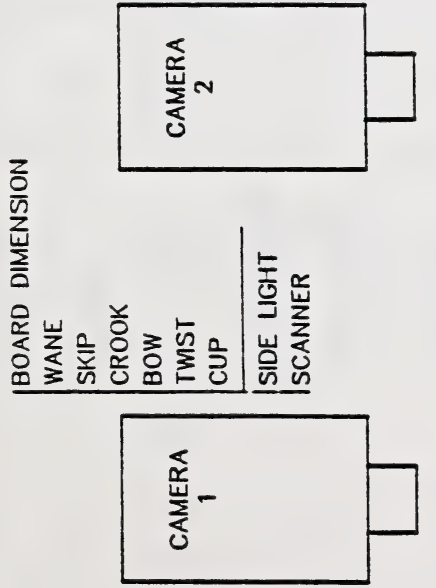

(1)

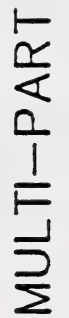

$\frac{1}{\square}$ 


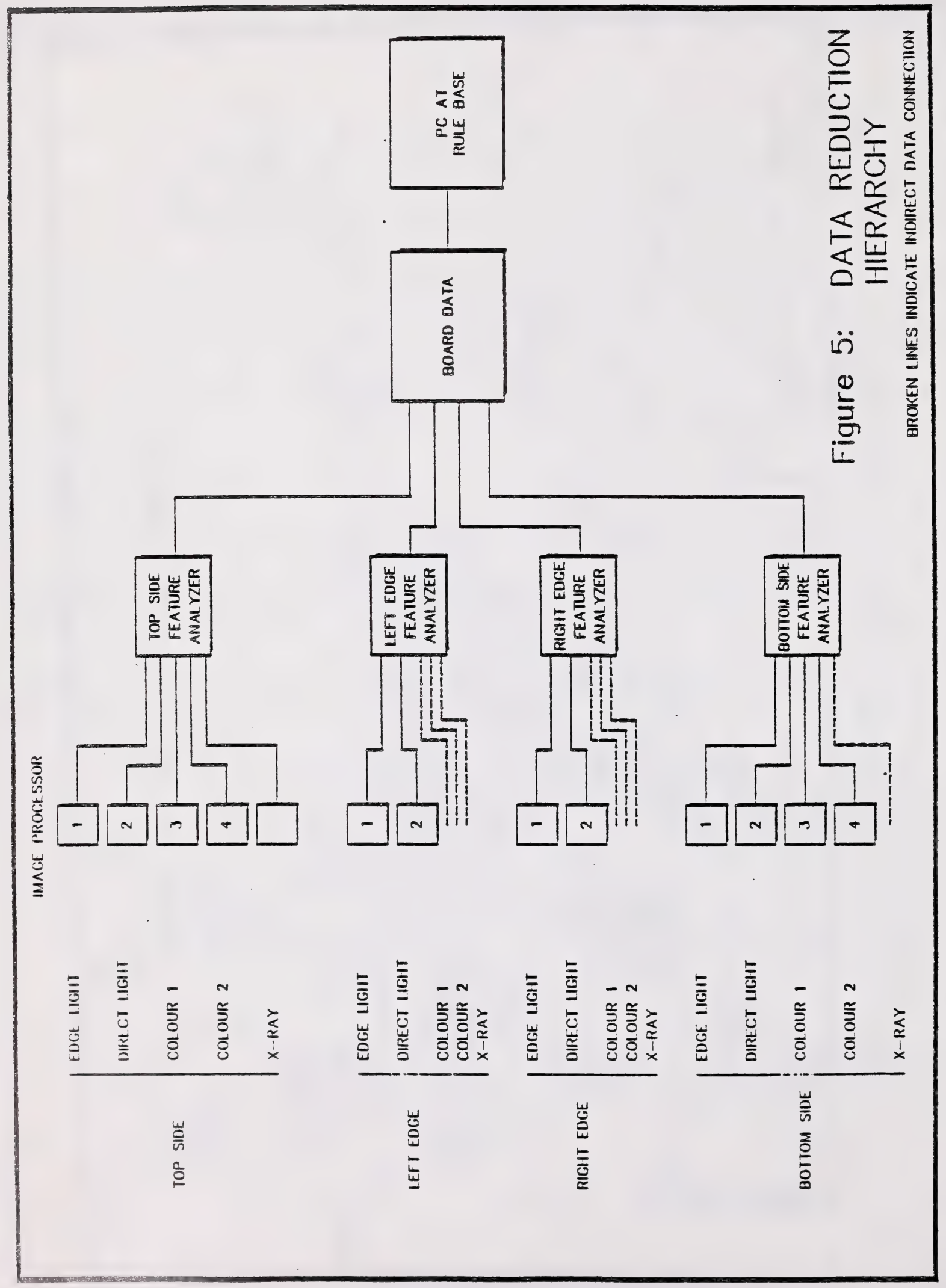


For each side of the board there are five images: direct lighting, edge lighting, two colours and $x$-ray. The five image processors for each side of the board feed a feature analyzer. The feature analyzer compares the feature information gained from each of the differently illuminated cameras and the $x-r a y$ and makes decisions as to the types of features on the lumber.

The twelve camera images, and $\mathrm{X}$-ray image, each of more than one million pixels, are collected, and processed by proprietary hardware comprised of a an array of 300 autonomous processors. The system processes real time visual data and operates at a speed of in excess of 3000 MIPS (million instructions per second).

The information from the four sides is fed to a board data computer which looks for features which run through from one side of the board to another.

The PC AT

The total board information is fed to a PC AT computer which analyzes all defects and produces an optimum grade and trim solution. The precise measurement of all defects allows for optimal trimmer solutions.

The PC AT rule-based computers will function both as the host of the optimization and grading programs and as a means of operator communication and control. Price information for each grade, length, and dimension is used to ensure maximum doliar value relative to the latest market prices. The computer selects the best grade/length combination on a board by board basis for maximum dollar value. Production and value statistics are accumulated as each board is processed.

This terminal will also display the diagnostics report, which identifies first level hardware malfunctions and software failures. 
The Trimmer Optimization and Data Logging

optimization will be based upon an evaluation of each possibie saw/fence combination using the features noted on tie board and a dollar value table supplied by the mill. The taile Will contain the current value of boards as a function oj lengti., cimension, and grade. An optional inzerzace with the mill computer is available.

once trim instructions have been sent to the trimmer interface, the length, grade, estimated board value, and whether an operator override occurred, are added to running totals which are recorded regularly. These numbers allow accurate mil: production injomation to be maintained on a regular basis.

\section{Ink Markers and Sequence Readers}

The first ink marker will be located near the ring outfeed and uses ultra-violet Eluorescent ink (see Figure 1). It will mark each board with a series of marks. These marks uniquely identify each board and allow it to be tracked through the system.

After the boards are on the chain belt the sequence marks are read and a second facing ink marker labels the board with the grade and trim selected by the computer. These letter markings are clearly visible to the operator and aliow him to overrice the system trimmer and grade stamp setting if he thinks an error has been made.

The area operacor performs lhis override by fipping tia board over. Since the sequence marks are read one last lime az ine board dealer, flipped over boards with sequence marks on the bottom face will not be processed by the Visionsmart system, but can be handled separately. 
Process of Implementation

The development of the grader - optimizer has had to proceed through several iterative steps:

1. The definition of the original concept.

2. Capitalization and investigation of market and technical problems.

3. Definition of product concept on the basis of customer needs obtained through direct contact.

4. Development of a job model to prove the technical concept.

5. Field testing the lab model at a mill.

6. Direct test work with regulatory authorities to insure that the actual system being developed conforms to, or can be accomodated by the NLGA rules.

7. Re-design of the system on the basis of field test results, regulatory and mill requirements.

8. Assembly of a full scale prototype.

9. Testing of the full scale prototype with hundreds of defect samples.

10. Modifications to the full scale prototype for mill installation.

At this point we have completed the full scale prototype, and it has graded accurately at full speed. Final modifications are being made before mill installation.

The dollar value increase from early tests varies with the lumber but is usually in the 3 to $8 \%$ range.

The process of implementation to date has been much slower than we had originally anticipated for several reasons: 
1. We are dealing with a highly variable product. Defects are a little difEerent in each species, each wood stand, and even for each piece. The system must be accurate in all cases.

2. The reliability requirements for mili installations are extremely high. In a mill, 50,000 to 100,000 pieces will pass through the scanning ring on a daily basis. Although not aiz cefects will be caught, accuracy must be betzer than $95 \%$.

3. The only way to insure accuracy and reliabilizy allowing for the variability of the wood is to do repeated tests with larger and larger samples of wood.

Testing

Testing has been a major issue in our development program. Initial plans assumed that the grader-optimizer project wollid Follow well defined engineering steps to reach a complezed product. As we repeatly discovered new forms of defects in wood. and specific requirements for milis, we had to rest increasing volumes of lumber at increasing frequency.

Erom the beginning it has been our belief that the grader optimizer should not be installed in the mili until it worked well in our shop. Many products have been installed in mills before they were proven, and the start-up glizches have otter. killed what could have been otherwise workable solutions. steps:

To ensure that our product works well we have taken several

․ Pried to simulate mill conditions closelv in our shoo. We have been running at 1200 Ec/ minute Eor more than 0 monchs, and have gone so tar to purchase a " minplaner-mill" complete with break-cown hotst, boera dealer and lake-awey belts jus for resting. 
2. Built the system to allow for non intrusive testing within the mill. Since our scanning ring does not interrupt the flow of lumber or create new jams and blockages, we can install and verify operation in the mill without disrupting the current grading process.

3. Allowed for direct comparison testing in the mill. The way each board is marked by our system prior to reaching the trim saws, allows for human graders to check the grader - optimizer operation on a board by board basis.

4. Built in statisical data accumulation and performance analysis. The grader - optimizer records aggregeted volume, actual grades, values and through-put to insure that its performance can easily be measured.

Conclusion

Technology for the forest industry deals with a high volume high value product. Total industry output reaches bilitions of dollars on an annual basis in Alberta alone. Any new technology that is introduced must be carefully tested and measured, because improvement or worsening by a few percent is a multi billion. dollar issue to mill owners and operators.

Any major technology developments must allow for extensive testing over a wide variation of wood supply to insure that their system performance meets owner/operator requirements. Partnership or active involvement of mills in product development is a necessity.

Finally, in a high volume industry like ours, technology developers must allow a considerable extra amount of time in their planning, for the verification and testing which must be done prior to and during the first phases of mill operation. 



\title{
Manufacturing of Cement Flakeboard (CFB) With An Entirely New Superfast Method
}

\author{
by \\ Pentti K. Lahtinen \\ President \\ Raumac, Inc. \\ Subsidiary of Rauma-Repola
}

\begin{abstract}
Cement flakeboard combines the best properties of two important construction materials: cement and wood.
\end{abstract}

Together with the Hungarian timber company Falco Fakombinat, RaumaRepola has developed an entirely new technology for the production of cement flakeboard. Featuring a sensationally short press time, the new technology offers board manufacturers several major advantages in terms of press technique, low energy consumption and the exceptionally high quality of the finished boards.

The original cement flakeboard (CFB) technology was presented in the USA in 1962. That technology was further developed in Europe and the first commercial CFB production line was started up in Switzerland in 1973.

Although conventional CFB technology has been around for sometime, it has not reached the same level of sophistication as, say, chipboard. For one thing, conventional CFB technology suffered from the longer time required for curing. 
Rauma-Repola joined forces with one of Europe's most important cement flakeboard producers, Falco Fakombinat of Hungary, with the aim of improving conventional CFB technology. The result is a new generation technology for the production of cement flakeboard.

The Rauma-Repola \& Falco cement flakeboard production process differs from the conventional process in many respects:

1. The thickness tolerance of the board is better.

2. Thinner boards can be produced.

3. CFB production is a straight-line process.

4. The material flow is simpler.

5. The space requirement is smaller.

6. Quality assessment of boards can be carried out immediately af ter pressing.

In the conventional process the press time for CFB is up to eight hours, which means that a normal cycle press is out of the question. To raise the plant capacity the mats are laid up in stacks of 60-80. During pressing, the compressed stacks are locked in clamping devices designed to secure a specific board size even when the board has left the press. The clamping cradle is moved to the hardening tunnel for eight hours at a temperature of $80^{\circ} \mathrm{C}\left(175^{\circ} \mathrm{F}\right)$. The stack emerging from the hardening tunnel is unclamped and the boards taken to the maturing section.

There are usually $20-30$ clamping devices circulating in the "rail yard," depending on the plant's capacity. 
When boards are pressed to the desired thickness in stacks of $60-80$ mats, thickness tolerances inevitable suffer. The total stack thickness is correct, but the thicknesses of the individual boards may vary somewhat.

In the Rauma-Repola \& Falco CFB process the press cycle has been cut to a staggering 4.5 minutes. This permits the use of a single-opening press instead of several clamped cradles. This in turn means that CFB can be manufactured on a straight-line process in which the material flow is simpler, the space requirement smaller and the thickness tolerance of the boards better.

The new process permits the production of thinner boards $(4 \mathrm{~mm} / 1 / 6$ in.) than with the conventional proces ( $10 \mathrm{~mm} / 0.39 \mathrm{in}$.). 


\author{
Manufacturing of Cement Flakeboard (CFB) \\ With An \\ Entirely New Superfast Method
}

\title{
INTRODUCTION
}

Cement flakeboard is made of thin wood particles and cement. Due to this raw material combination, $C F B$ has many properties not found in other board materials. Because no resin or asbestos is used in the manufacture of CFB, no harmful matters such as formaldehyde or asbestos powder emissions will occur.

Although Conventional CFB technology has been around for sometime, it has not reached the same level of sophistication as, say, chipboard. For one thing, conventional CFB technology suffered from the longer time required for curring.

Rauma-Repola joined forces with one of Europe's most important cement flakeboard producers, Fakombinat Falco of Hungary, with the aim of improving conventional CFB technology. The result is a new generation technology for the production of cement flakeboard. This new technology offers the board manufacturers many advantages in terms of example press technique, energy consumption and the quality of the finished boards.

The first CFB plant in the world based on the Rauma-Repola \& Falco CFB technology is in production. 


\section{CHARACTERISTICS OF CFB}

The specific properties of $C F B$ are determined by the basic properties of wood and cement (see page 16.9):

- Wood is light-weight, elastic and can easily be machined.

Cement is non-combustible, water, humidity, rot, fungus and termite resistant.

It is obvious that CFB has all the properties needed for a good building board.

Cement flakeboard is:

Fire Resistant

Resists fire (standard A 2 of DIN 4102) and can be used in constructions requiring fire resistance.

\section{Sound Absorbent}

Excellent sound proofing due to the homogeneous structure and high density.

\section{Fungus and Insect Resistant}

The high alkalinity of CFB makes it extremely resistant to insects, such as termite, as well as to attacks by fungi.

\section{Chemically Stable}

CFB is produced by means of an irreversible process combining cement and wood particles into a chemically stable building material, which retains its strength for a long time even when exposed to the elements. 


\section{Machinability and Workability}

These are similar to the working methods for particleboards bonded with synthetic resin. The same tools and processing machines are used. CFB can be sawn, drilled, milled, sanded, nailed, screwed, stapled and glued.

\section{Finishing}

The surfaces can be primed, painted or sprayed. Suitable dispersion coatings, synthetic resin coatings, mineral and synthetic plasters are easy to apply.

Foils, synthetic resin, ceramic tiles and mosaic can be used with suitable adhesives without any problem. The surfaces can be overlaid with wood veneers and a wide range of synthetic films.

\section{APPLICATIONS OF CFB}

There are numerous applications for CFB where other board types such as chipboard and gypsum cardboard do not resist humidity and climate, or when the resistance could only be obtained by expensive overlaying, or when insufficient static values limit their use.

Typical applications for internal use are fire doors, sound insulation, partitions, shower and toilet cubicles, floorings, ceilings and bathroom and kitchen wall linings.

Outdoor applications are cladding panels, weather boarding, fascias, in fill panels, roof decking and sound insulation walls along roads and highways. 


\section{RAUMA-REPOLA \& FALCO CFB PRODUCTION METHOD}

How the Rauma-Repola \& Falco CFB production method differs from the conventional method.

In the Rauma-Repola \& Falco CFB process:

The thickness tolerance of the board is better.

- Thinner boards can be produced.

- CFB production is a straight-line process.

- The material flow is simpler.

- The space requirement is smaller.

- Quality assessment of boards can be carried out immediately af ter pressing.

- $\quad$ No hardening tunnel is needed.

In the conventional method, the press time is extremely long, about eight hours. Because of this the normal cycle press is out of the question. To raise the plant capacity, the mats are laid-up to stacks of $\underline{60-80}$ mats. During pressing, the compressed stacks are locked in stable clamping devices designed to secure a specific board size even when the board has left the press. The clamping cradle is moved to the hardening tunnel for eight hours at a temperature of $80^{\circ} \mathrm{C}\left(175^{\circ} \mathrm{F}\right)$. After the hardening tunnel, the stack is unclamped and the boards taken to the maturing section.

There are 20-30 clamping devices circulating in the "rail yard" depending on the plant's capacity. 
While the boards are pressed at required thickness in stacks of $60-80$ mats, it is obvious that the thickness tolerance cannot be the best possible; the sum thickness of the stack is correct, but the thickness of each individual board may vary somewhat.

In the Rauma-Repola \& Falco CFB manufacturing process the press cycle takes onlv 4.5 minutes. This short press time permits the use of a single-opening press instead of several clamped cradles. This means that $C F B$ can be manufactured on a straight-line process in which the material flow is simpler, the space requirements smaller and the thickness tolerance of the boards better.

The Rauma-Repola \& Falco CFB manufacturing process enables the production of thinner boards (i.e. $4 \mathrm{~mm} / 1 / 6$ in.) than the conventional manufacturing process (i.e. $10 \mathrm{~mm} / 0.39 \mathrm{in}$.).

\section{PROCESS DESCRIPTION}

See Flow Chart on page 16.10 and Line Drawing on page 16.11 .

From the mixer and through a distributor, the cement flake mix arrives at the forming station on tow belt conveyors. The screw conveyors drop the mix in portions through a turnable bottom, open at tone side, into the forming bin. From the bin, the mix is dropped evenly like a mat through the wind chamber onto the cauls. In the wind chamber, the finer fraction is gathered on the bottom and top surface of the mat.

The cauls are placed after one another so that the end of the previous caul is under the head of the next one, and the cake is formed as the mat is cut at the caul joints. 
The waste is returned to the predosing bin by a belt conveyor. The cake is conveyed on the caul into the press. The caul, which is relieved from the finished board, is conveyed under the press and the forming conveyor to the line start.

The board is taken from the press to a belt conveyor which conveys the board through the length saw. The length saw trims the sides of the board and cuts it into two parts. The two boards obtained are transferred to the cross cut station by roller conveyor, where the boards, after having stopped, are aligned against the edge stop. The cross cut saw evens the ends of the boards and cuts them at desired lengths.

The cut boards are stacked and transferred to the intermediate conveyor.

After cutting to size, the boards are stored in the maturing section in which the boards remain for 14-28 days. By then the boards have almost obtained their final properties.

Before the boards leave the plant, their moisture content is balanced in a board dryer in relation to the air humidity. 
PROPERTIES

\section{Property Board Type}

Density $\mathrm{kg} / \mathrm{m}^{3}\left(\mathrm{lb} / \mathfrak{f}^{3}\right)$

M.O.R. N/mm (psi)

M.O.E. N/mm (psi)

Internal bond $\mathrm{N} / \mathrm{mm}^{2}$ (psi)

Thickness swelling

$\left(24 \mathrm{hr}\right.$ at $\left.68^{\circ} \mathrm{F}\right)$

Weather and frost proof

Resistant to fungus

Resistant to termites

Resistant to rot

Von-combustible

Fire resistant

(DIN 4102)

Resistant to impact

Good glueability

Can be laminated

Good processability

Thıckness tolerance

Possible panel thicknesses
CFB

$1250(78)$

min. 11

(1580)

min. 4000

$\left(5.8 \times 10^{5}\right)$

$0.5(73)$

1.4

1.4

$(2460-4060)$

15000

$\left(21.75 \times 10^{5}\right)$

Asbestos
Cementboard

1800 (112)

$17 \cdot 28$

700 (44)

$13 \cdot 19$

$(1800-2760)$

2500

$\left(3.63 \times 10^{5}\right)$

0.5 (73)

10

$\begin{array}{lll}1.4 & 1.4 & 10\end{array}$

Gypsum

Cardboard

$875(55)$

// $2.5(360)$

// $5.0(7=0)$

// $2.5(360)$

L $2.0(290)$

\pm 0.012 in.

$1 / 6^{\prime \prime}-1-1 / 2^{\prime \prime}$ 
FLOW CHART

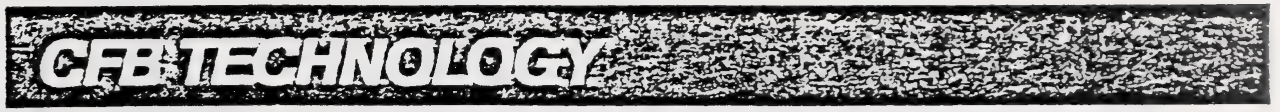

Wood-cement-board plant
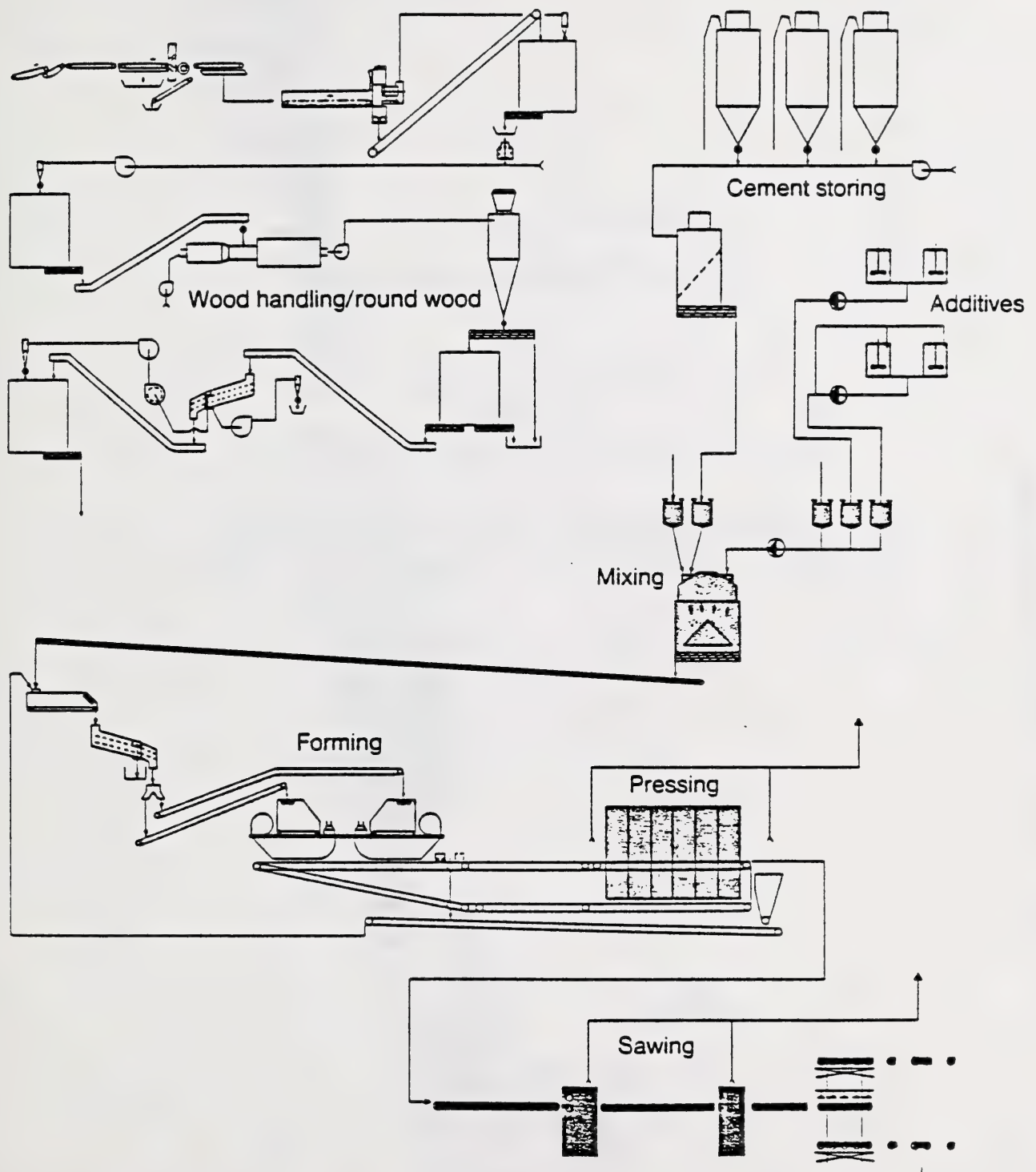

Board drying

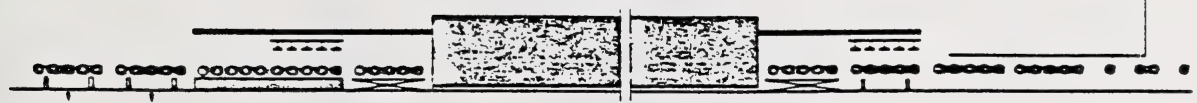




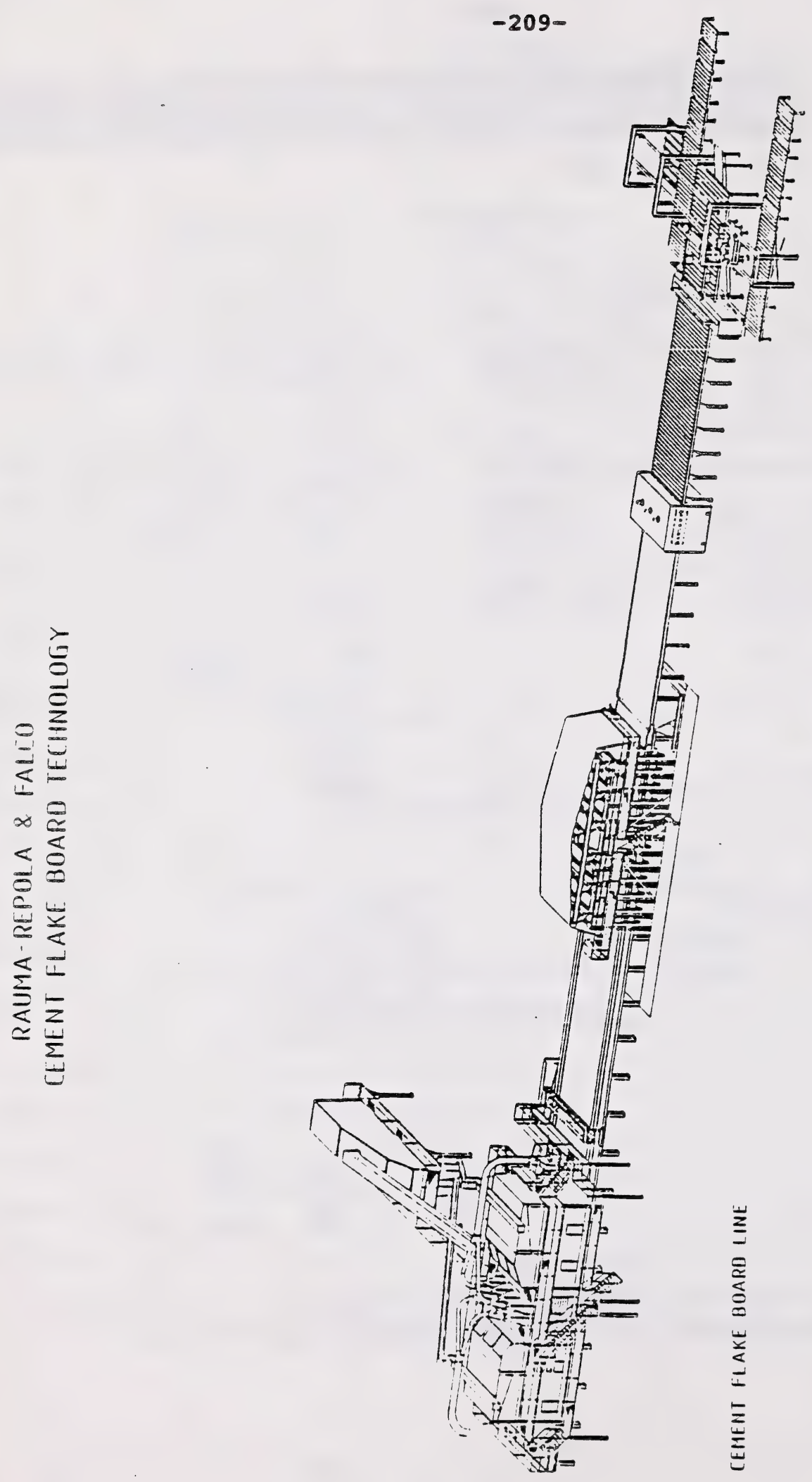


" SAWSIM"

\author{
Solving Problems \\ with \\ Sawmil Simulation \\ by \\ Jean Louis Cayer \\ Manager \\ Business Development and Marketing \\ Quebec Industrial Research Center \\ Centre De Recherche Industrielle Du Quebec
}




\section{What is sawsim?}

- Very flexible computer program.

- Capable of accurately modeling the transformation of logs in any sawmill.

- A management tool to assist operations and management personnel to make better decisions.

\section{Practical Apolications}

- Evaluation of bucking policies.

- Evaluation of optimum bucking.

- Validation of process and sawmill layout.

- Evaluation of market opportunities.

- Comparative scenarios for different wood supplies, mill layouts or markets.

- Support to mill modernization.

- Diagnosis of sawing practices.

\section{Cepabilities}

Sawsim can process either straight or actual logs with:

- crook,

- sweep,

- ovality,

- variable taper,

- etc.

For each log, printout information includes:

- a log plot, (showing log shape and lumber produced),

- log specifications, (diameter, length, taper, sweep),

- lumber recovery.

- by-product recoveries,

- total value recovery,

- machine piece count and time requirements,

- total and averages, - showing the cumulative results for log distributions (stems) which represent statistically the mill supply.

\section{Program Features}

- Optimum bucking of stems.

- Production of different lumber sizes with different wane rules.

- Different saw kerf and target sizes for every machine.

- Different lumber values (size and length). 
- Log and lumber positioning:

full-taper, half-taper, centering roll,...

- Use of resaw, edger, trimmer, cant optimizers.

And applications such as:

- mill lay-out, and

- breakdown policy.

\section{Procedures}

- Model development.

- Model validation.

- Production and analysis of results.

- Recommendations

\section{Model Development}

- To obtain results input data must be:

- sufficient, and

- accurate.

- A special team records data directly on site.

1. 0 Raw materials (stems and logs)

2. 0 Products and by-products (lumber, wood chips, sawdust,...)

3. 0 Manufacturing process (sawing pattern, bucking specifications, positioning flow, machinery specifications and evaluation, etc. )

4. 0 Economics (sales price, production policies, annual production report,...)

Sawsim works with real values, requiring accurate measurements of:

- Measurements of;

- stems,

- logs, and

- lumber.

Including;

- sweeps and crooks, taper,

- ovality,

- under and over length of logs,

- lumber target size,

- machines precision,

- drying shrinkage,

- Planing allowance,

- saw kerf,

- etc.

\section{Sampling}

When the mill is supplied with trees:

A sample of 125 to 175 stems is precisely measured. logs:

A sample of 300 to 400 logs is required. 
THE DIMENSIONS OF EACH STEM OR LOG ARE GATHERED WITH THE AID OF A LASER REFERENCE LINE

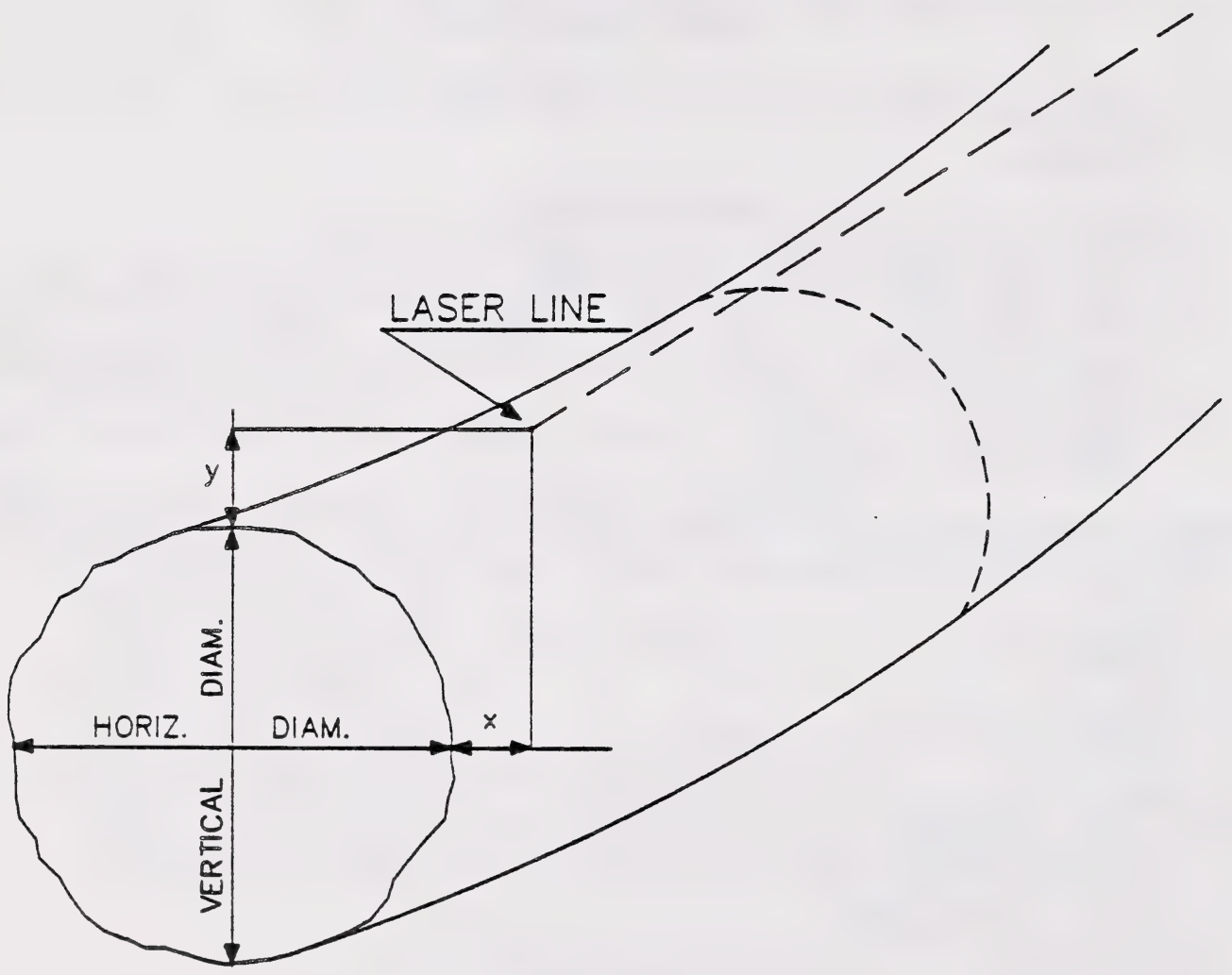

AS A RESULT, SAWSIM WILL HAVE A THREE DIMENSIONAL REPRESENTATION OF THE STEM OR LOG 


\section{Model Validation}

Compares the mill results to the computer results.

Validation occurs;

When an agreement has been reached between the computer results and the actual mill performance.

\section{Production Results Analysis}

This reference base case can be applied to real simulation studies.

For instance:

"Verify and calculate the impact of any variations and parameters (introduced in the computer) that can affect lumber recovery, productivity and profitability of the mill."

* This is how a simulation study becomes a management tool. 
SAWS IM Programme de Simulation de Seierie

\begin{tabular}{|c|c|c|c|c|c|c|c|c|c|c|c|c|c|c|c|c|}
\hline 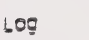 & Sawing & $-\infty$ & et - & Dia & Len & Taser & $--5 m=$ & eep-- & Pes & $\mathrm{Fbm}$ & פַ & LET & סיר & bunber & c5: & \\
\hline & 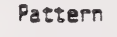 & Her & Ver & in & . & (n) & Edge & Cyi & & Lbr. & Vol & Recov & :uft: & $s$ & 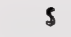 & \\
\hline & ก141 & .000 & .359 & 84 & 16.33 & 0.176 & 0.9 & 0.0 & & 29.7 & 3.82 & 7.76 & 1.1 & .01 & .00 & \\
\hline
\end{tabular}

-Chios-- -Saweust- Shavings Dry trimg Tor byord Rg̣n ium iotal Ne: log

euft $\$$ euft $\$$ euft $\$$ euft $\$$ euft $\$$ euft euft vaine

$\begin{array}{llllllllllllll}1.09 & 0.76 & 0.54 & 0.00 & 0.44 & 0.00 & 0.00 & 0.00 & 2.08 & 0.76 & 2.19 & 3.82 & 7.89\end{array}$

Machine ironcen Eccreer Mult_bl Mult_b2 Se_uuml Desosse Deig_bl Delg_b2 Deig_b3 Refh_bl Refh_b3 Fes_eol

$\begin{array}{llllllll}\text { Passes } & 1 & 1 & 1 & 1 & 2 & 2 & 5 \\ \text { Seconos } & 7 & 7 & 4 & 4 & 7 & 9\end{array}$

Machine Pe!_to: Pes_ed Pez_sot Deshrọ

Passes 6 ।

Seconds 3

3

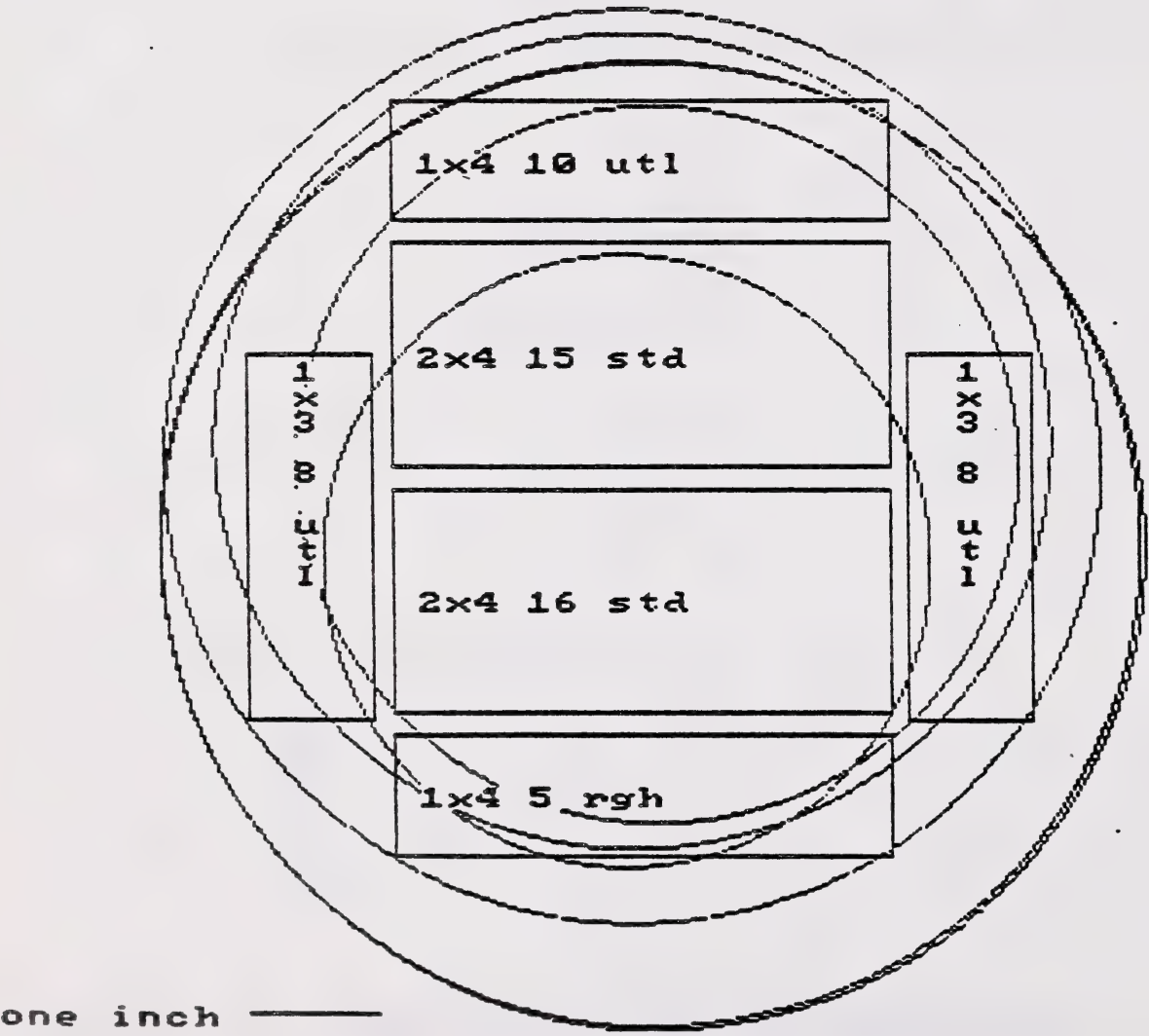




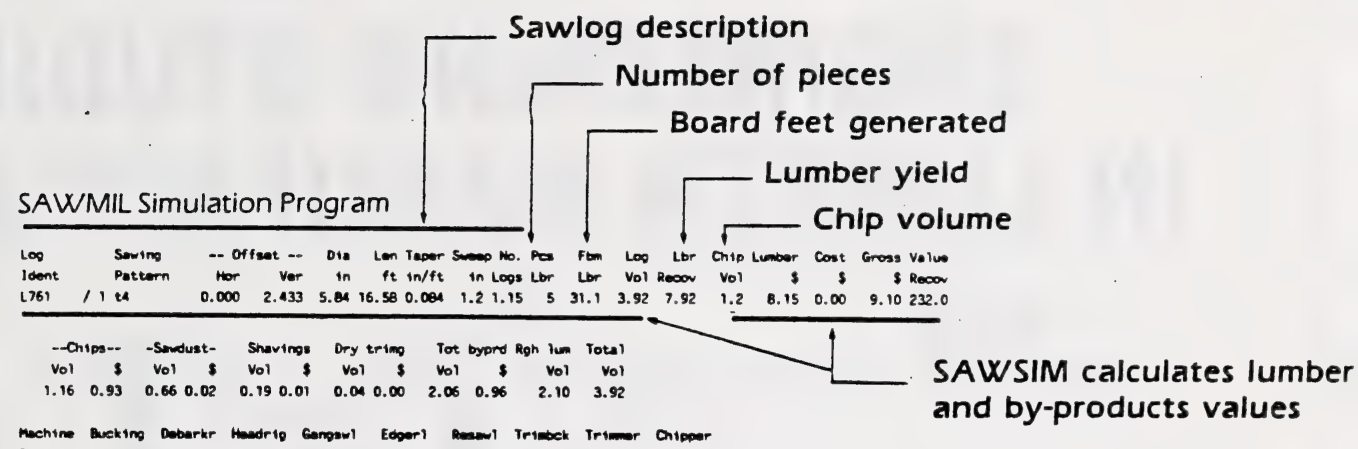

SAWSIM considers sweep and shape of trees/logs

(model accuracy depends on that)

USIM considers wane allowances sawing deviations, shrinkage and planer settings
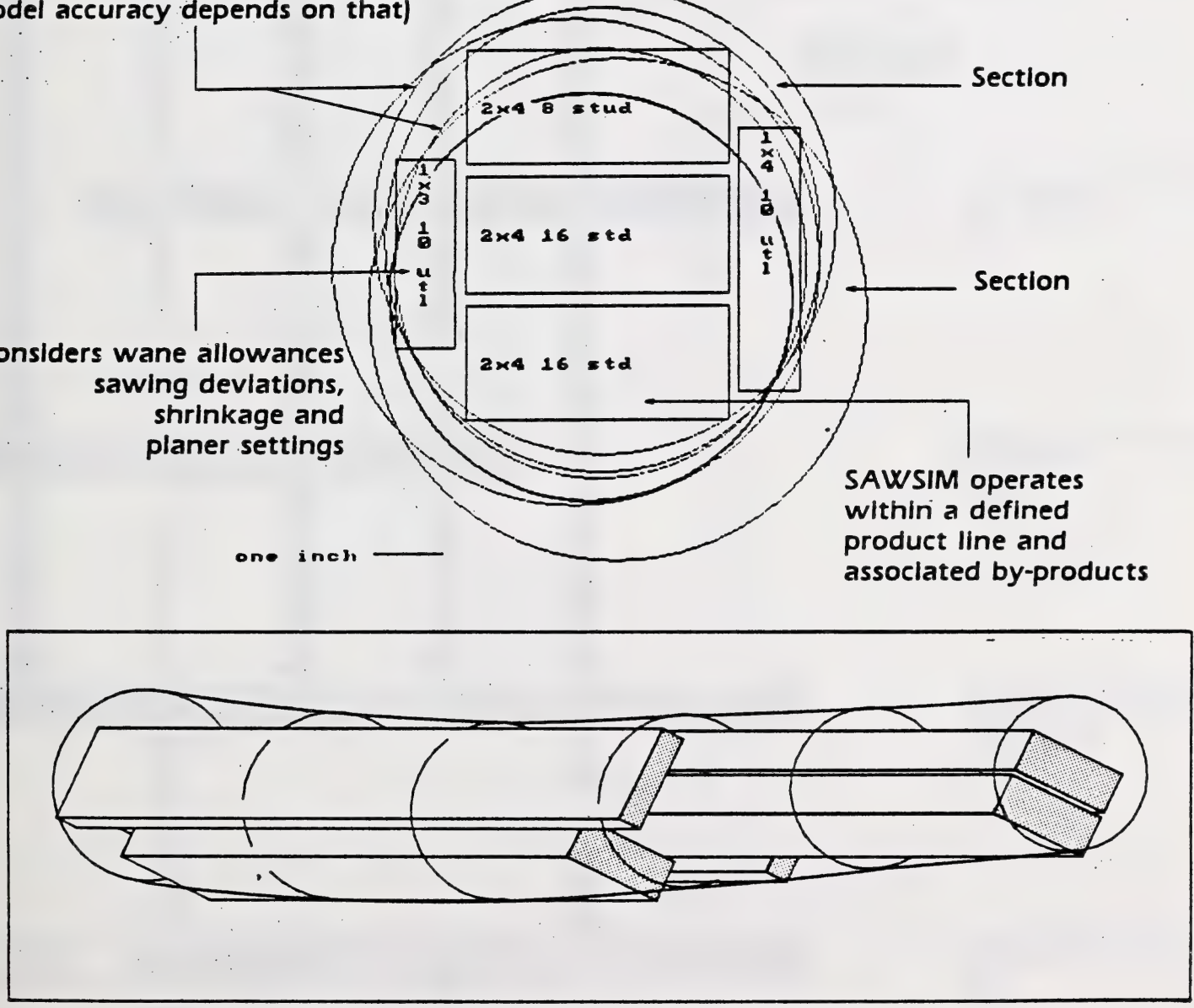

SAWSIM uses information on equipment, process sequences and sawing times. 


\section{ENGINEERING STUDIES IN LUMBER MANUFACTURING}

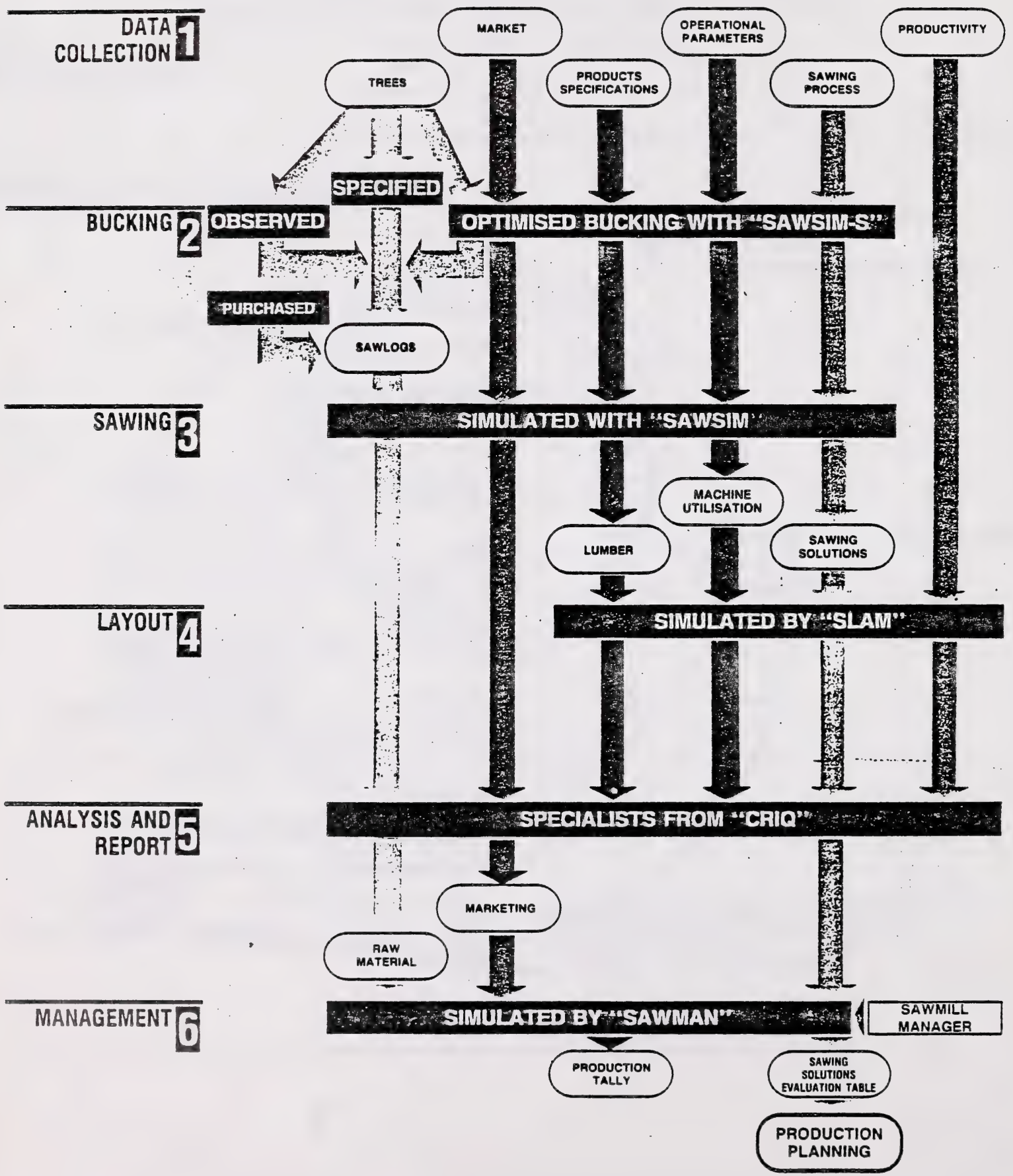


THE SAWSIM SAWMILI SIMULATION PROGRAM by

B. J. Turner Vice-President Halco Software systems Ltd. 


\section{The SAWSIM' Sawmill Simulation Program}

The SAWSTM ${ }^{\circ}$ Sawmill Simulation Program is a very flexible computer program which can accurately model the breakdown of logs in any sawmill. It is a management tool, used to assist operations and management personnel to make better decisions.

\section{Applications}

Typical applications of SAWSIM include study of the following:

- Effects of a change in log breakdown policy (eg. wide center cant vs. narrow center cant plus sideboards, full-taper vs. half-taper, etc.).

- Effects of a change in mill log diet.

- Value of alternative mill log supplies.

- Effects of a change in lumber products produced (eg. production of 1" lumber, production of export sizes, etc.).

- Evaluation of alternative mill modemization options (eg. addition of edger, cant, trimmer or primary breakdown optimizers or optimum bucking, saw kerf reduction, etc.).

- Effects of log supply allocation to different breakdown lines, different mill sites, pulplog vs. sawlog considerations, etc.

\section{SAWSIM Capabilities}

SAWSIM can process either straight logs or actual shape logs with crook, sweep, ovality, and variable taper. Solutions are calculated individually for each log, based on its particular geometry.

For each log, the SAWSTM printout information includes:

- A log plot, which shows the log shape and lumber produced.

- Log specifications (diameter, length, taper, and sweep).

- Lumber recovery.

- Byproduct recoveries.

- Total value recovery.

- Machine piece count and time requirements.

"Totals and Averages" may be printed to show the cumulative results for a distribution of logs which may represent, for example, a complete shift's production. In addition to the printout information above, the "Totals and Averages" will show the overall lumber product distribution. 


\section{Specific Program Features}

Specific features of the SAWSIM program allow simulation of the following:

- Optimum bucking of stems.

- Production of many different lumber sizes with different wane rules for different products.

- Different saw kerfs and target sizes for different machines.

- Production of many sizes of timbers.

- Different lumber values for each size and length.

- Any type of log and lumber positioning, including full-taper, half-taper, "centeringroll" infeed positioning, etc.

- Sweep-sawing.

- Addition of edger, trimmer, and cant optimizers, plus ability to account for imperfect manual edging, manual trimming, and other sources of mismanufacture.

- In grade sawing mills, different grade regions within the log can be defined, and the volumes of different lumber grades and the total product value produced by different sawing policies can be determined.

- Specification of products by vertical grain, flat grain, mixed grain, heart-center, and free-of-heart-center, and production from the appropriate position in the log.

Many other features allow simulation of virtually any mill layout and breakdown policy.

\section{Program History}

SAWSIM ${ }^{\circ}$ was originally written over 15 years ago by Howard Leach, President of HALCO Software Systems Ltd. It has been continuously updated since then. Hundreds of studies have been done with the program.

\section{Brief Technical Details}

SAWSIM is written in standard Fortran-77 programming language, and includes more than 20,000 executable Fortran steps. It can be used on IBM-PC or compatibles which have a math coprocessor chip installed. It has also been installed on corporate mainframe computer systems.

\section{Program Sales and Consulting Services}

The SAWSIM program may be purchased, or studies can be undertaken on a consulting basis by staff of HALCO Software Systems Ltd.

For further information, please contact Brad Turner at HALCO Software Systems Ltd. 


\section{Example SAWSIM` Printouts}

In the following pages are example SAWSIM printouts which illustrate some of the program features and which show a range of breakdown types that can be simulated with the program. The breakdown types shown are:

1. Chip-N-Saw

2. Canter-Twin

3. Headrig (with grade distribution within the log considered)

4. Profiling ("Linck System").

In addition, an example of a shift summary "Totals and Averages" printout is included.

The example printouts are for actual shape logs measured by the SAWSIM measurement procedure, which considers crook, sweep, ovality, and variable taper.

For each breakdown type above, two example logs are shown. For each log, a Case 1 "existing mill" breakdown is shown, followed by a Case 2 "modified" breakdown. The plot for Case 1 and Case 2 are shown adjacent to one another for ease of comparison. This illustrates the use of the program to show the effects of a change in mill equipment or breakdown policy.

A "typical" SAWSIM study consists of simulation of the existing mill breakdown for a sample of logs to generate a shift summary "Totals and Averages". This is the "Base Case" (existing mill) simulation. A change in mill equipment or breakdown policy is then simulated for the same log sample to generate a revised mill "Totals and Averages". This shows the effects of the mill change on lumber recovery, total value recovery, product distribution, machine piece counts, etc.

Before the examples, a brief description of how to read the printouts is included. 


\section{How to Read the Printouts}

The "circles" seen on the log plots are in fact ellipses, and are the shape of the log crosssections at the points measured along its length. The rectangles of course show the lumber produced by the breakdown pattern used, and its position in the log.

Following is a brief description of the information tabulated at the top of each SAWSIM log plot. Please refer to the printout for the Chip-N-Saw example, Log 1, Case 1:

Line 1 (Log and Recovery Summary):

Log Ident: This identifies the sawlog, and the stem from which it was bucked. In this case, it is sawlog 2 from stem $25 T F$

Sawing Pattern: The breakdown pattern used on this log (from the mill breakdown patterns defined to the program). In this case, it is pattern cns2-s8 (set number 8).

-- Offset: - The horizontal and vertical pattern offsets. In this case, the vertical offset is 0.500 inches.

Dia: $\quad$ Log top diameter (7.07 inches).

Len: $\quad$ Log length (16.50 feet).

Taper: $\quad$ Log taper (0.204 inches per foot of length)

Sweep: $\quad$ Log sweep (0.9 inches)

No.Logs: The "weighting factor' for this log, which may specify, for example, the number of logs of this type which occur per shift. By changing the weighting factors for logs of different diameters, the effects of a change in log diet can be shown.

Pcs Lbr: The number of lumber pieces produced.

Fbm Lbr: The board feet of lumber produced (after deduction of trim-loss volume).

Log Vol: The log volume $\left(0.189 \mathrm{~m}^{3}\right)$. Different program options allow calculation of the volume in Scribner scale, Alberta scale, etc., and in $\mathrm{ft}^{3}$ or $\mathrm{m}^{3}$.

Lbr Recov: Lumber recovery (237.6 fbm/ $\left.\mathrm{m}^{3}\right)$.

Chip Vol: Chip volume (0.034 units). Program options allow calculation of byproduct volumes in cubic feet (or metres) solid wood equivalent.

Lumber \$: The total lumber value (\$11.99).

Cost S: $\quad T h e$ total penalty cost for machine usage (such as a reman cost). In this case, this is zero.

Gross \$: $\quad$ The sum of the lumber and total byproduct values.

Value Recov: The gross value divided by the $\log$ volume as described above. In this case, $77.2 \mathrm{~S} / \mathrm{m}^{3}$.

Lime 2 (Byproducts Summary):

-Chips-o: The chip volume and value produced. In this case 0.0338 units and $\$ 2.60$.

-Sawdust-:

-Shavings--: As above, for sawdust, planer shaving, and dry trim end volumes. Again, byproduct

-Dry trimg-: volumes may be specified in cubic volume solid wood equivalent, if desired.

Shrinkage: The lumber volume lost to shrinkage in drying. In this case $0.004 \mathrm{~m}^{3}$.

Fin Lum Vol: The actual volume of the finished lumber (in this case $0.072 \mathrm{~m}^{3}$ ).

Total Vol: The log volume

Note: The byproduct summary also shows the percentage recovery of lumber, chips, and other byproducts.

Line 3 (Machine Summary):

Passes: $\quad$ The number of passes required at each machine center for this log.

Seconds: The time in seconds required at each machine center.

S: $\quad$ The penalty cost for machine usage at each machine (not used in the example printout). 


\section{Example : Chip-N-Saw Breakdown}

The Chip-N-Saw breakdown example illustrates the following:

Case 1: "Existing Mill" breakdown, with a fixed bed-set for each Chip-N-Saw pattern set.

Case 2: $\quad$ "Modified" breakdown, with the optimum bed set selected for each log. 
Chip-N-Saw Breakdown

8AW8IK Samill simulation Program Log 1 - Case 1

ens-sent.prn 3

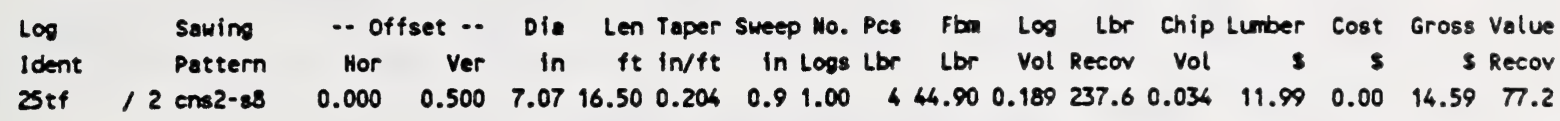

--Chipe-. -Saudust- Shavings Dry-trimo Shrinkage Fin-lum Total

Vol $s$ Vol $s$ Vol $\&$ Vol $\&$ Vol Vol Vol

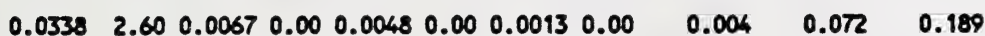

$\begin{array}{llllllll}\times 43.30 & 8.63 & 6.16 & 1.69 & 2.37 & 37.85 & 100.00\end{array}$

Machine ChipwSaw CWS-vag Pomyedgr Trimbeck Trimmer

Passes $\quad 1 \quad 1104$

Seconds 8 8 6

$s$

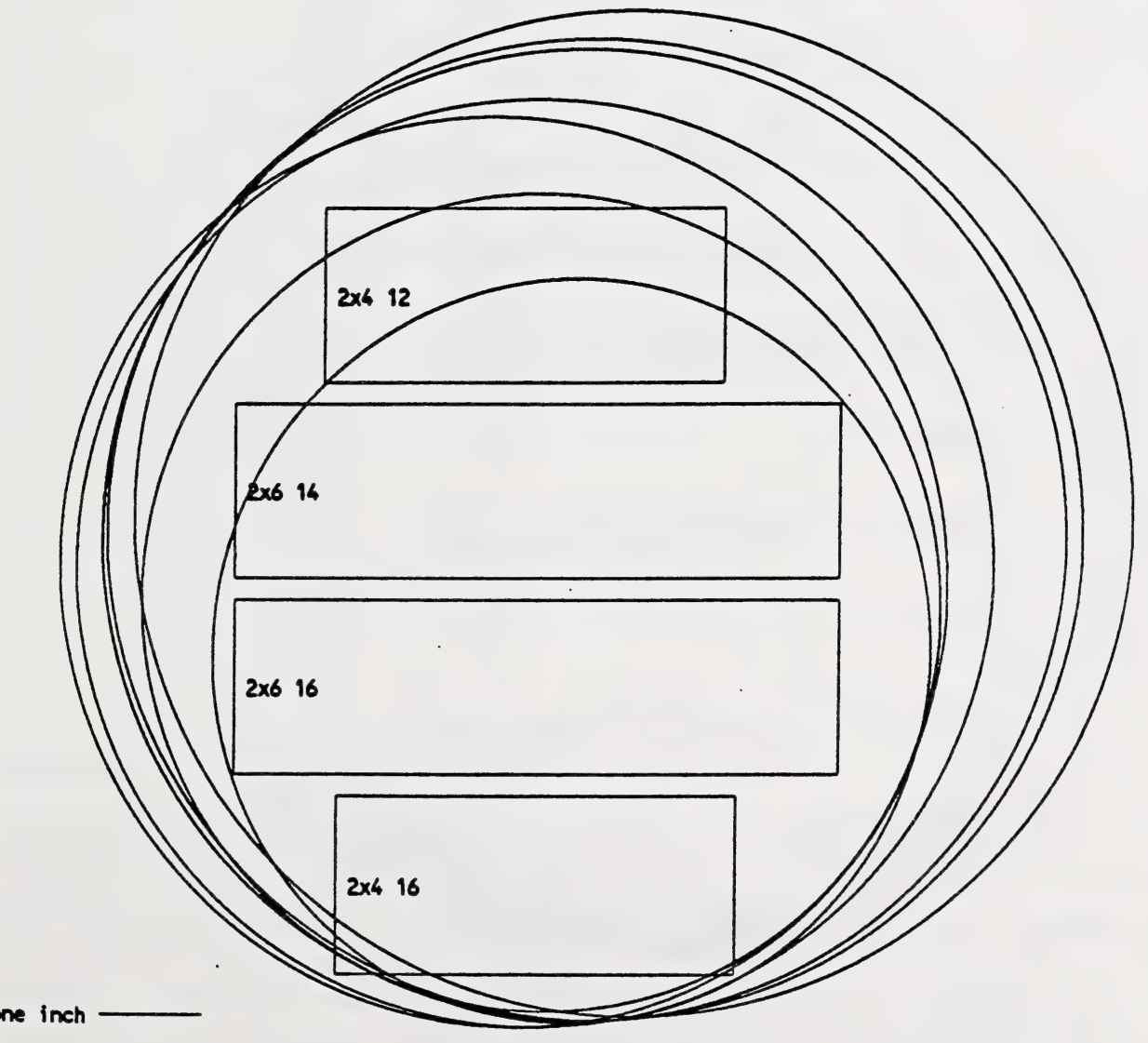




\section{Unip-N-saw breakaown}

BAF8IM Samill simulation Progran

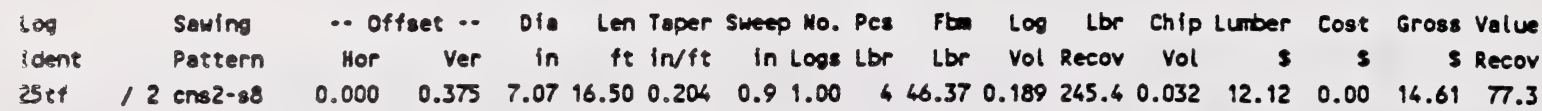

-Chipe. -Saudust- Shavings ory-trimg Shrinkage fin-lum Total

vol $s$ Vol s vol s vol s vol vol vol

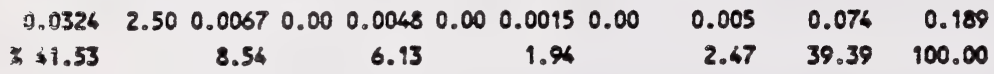

*achin Chipusaw Cus -vas Pomyedar Trímbeck Trimmer

Passes 9 I 4

Serconds 8

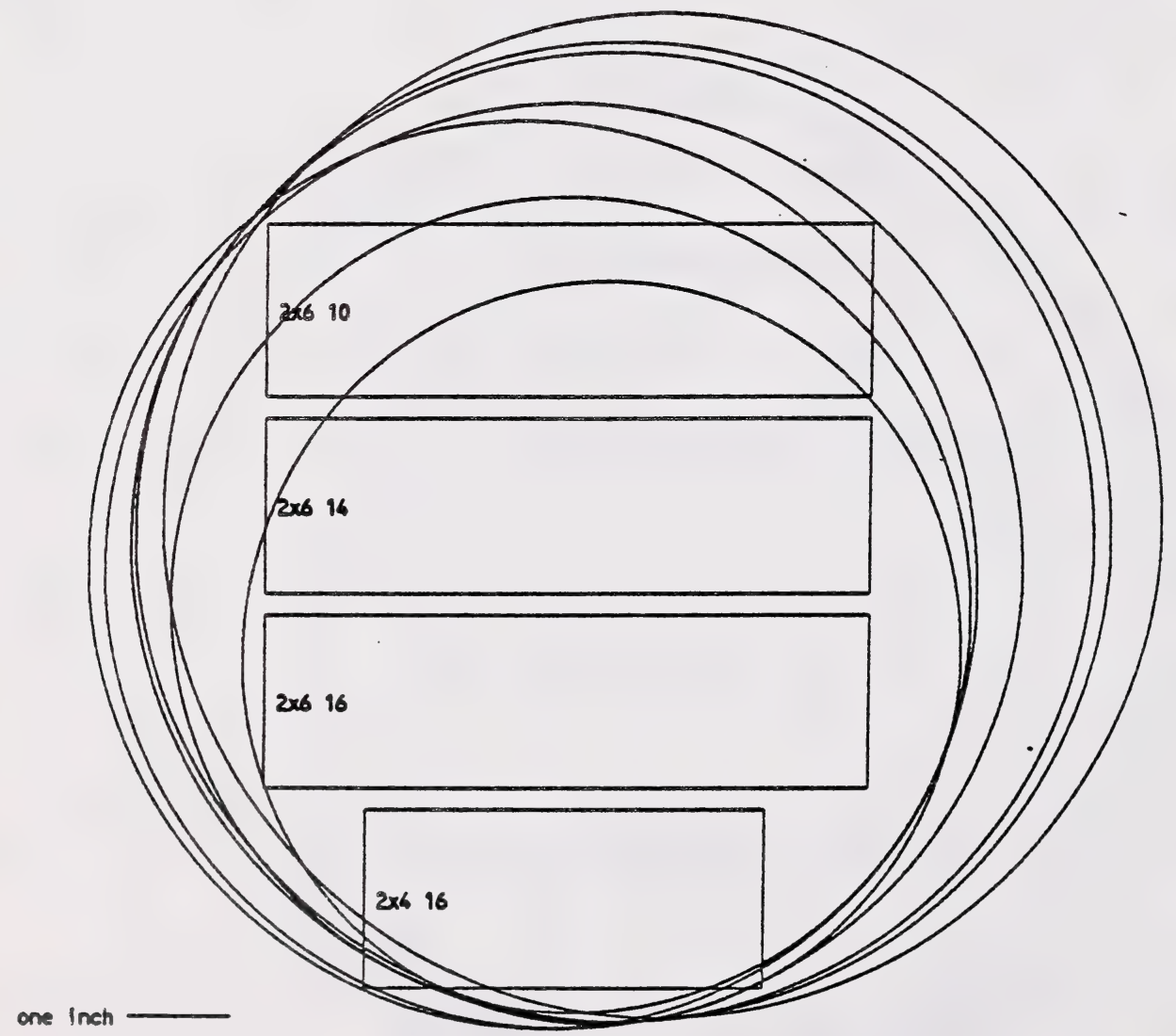


IHPLEMENTING HIGH TECHNOLOGY

"FRIEND OR FOE"

IN TODAY'S

ORIENTED STRAND BOARD HILLS

BY

R.i. (BOB) OLSON, P. ENG.

ENGINEERING AND TECHNICAL MANAGER

PELICAN MILLS, A DIVISION OF

HEYERHAEUSER CANADA ITD.

\section{ABSTRACT}

Oriented strand board, or 'usb' is an engineered uoou product villch requires a great deal of process co:trol and monitoring for precise manutacture. "High-Tech" has Deer the buzz vord for years nou. Unfortunateiy, there are certain pitiaiis of which a company needs to be avare. Some important considerations are; iocation anci size of the mil, budget, company management information system requirements, operating personne: and maintenance personnei. 


\section{HIGH TECH IN OSB}

\section{BACRGROUND}

The most important thing to remember in any ney facility or retrofit, is that the company is in business to make a PROFIT.

In manufacturing industries, profit can be affected by a variety

o: costs, yhich to some extent are beyond cont:0l:

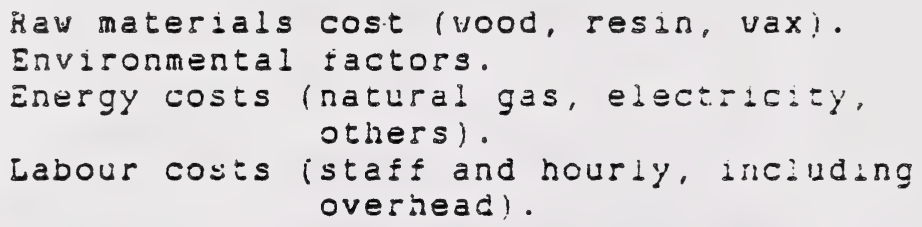

Protits can also be attected by things vich are moztiy controilable:

$$
\begin{aligned}
& \text { Labour productivity inan-holis/unit } \\
& \text { productioni. }
\end{aligned}
$$

Produce quality lcomodity or added vaiue?). Rav material conversion Etaliency. Production volumes (debottienecking?. inininzeration costi.

\section{EOCUS}

Tyo inportant components are needed to optamize production, eficlencly couvert rau materiai anci malataln product quality.

Reliable, motivated personnel.

Reldabie lnormation and controi systems.

The ilist, reliabie, motivated personrel, is not tie tocus of thas paper. 
The second item, reliable information, is the key.

Examples o: process intormation needed are:

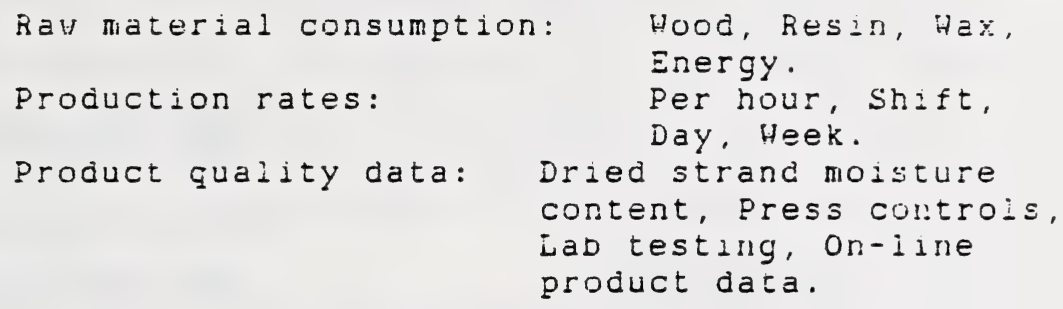

\section{A LOOR IHSIDE AN O.S.B. HILL}

In order to understand technology inside an O.S.B. production jacility it is useful to ilst look at the component areas afiecting the cperation. The fuiluving "OSE Fioy Chart" shows the major product and equipment centers throughout the process (see Figure l). 

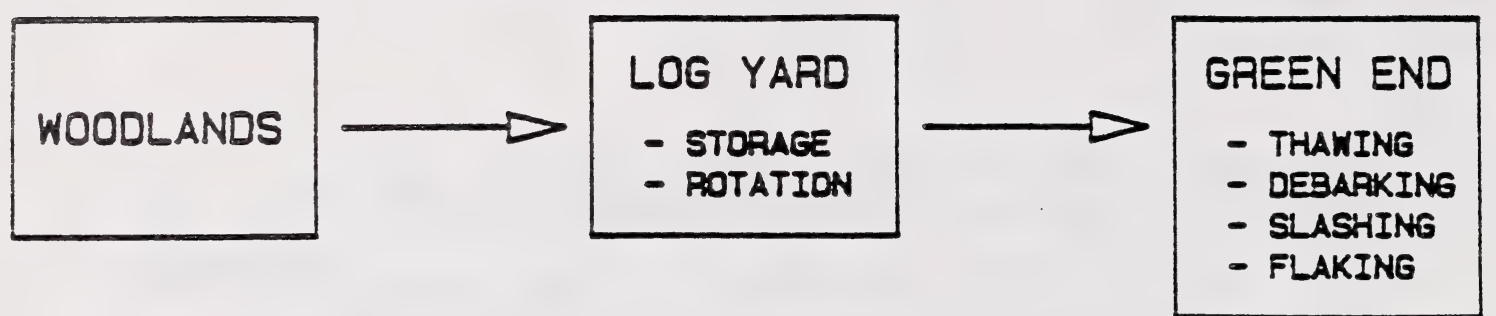

WET STRANDS $\downarrow$

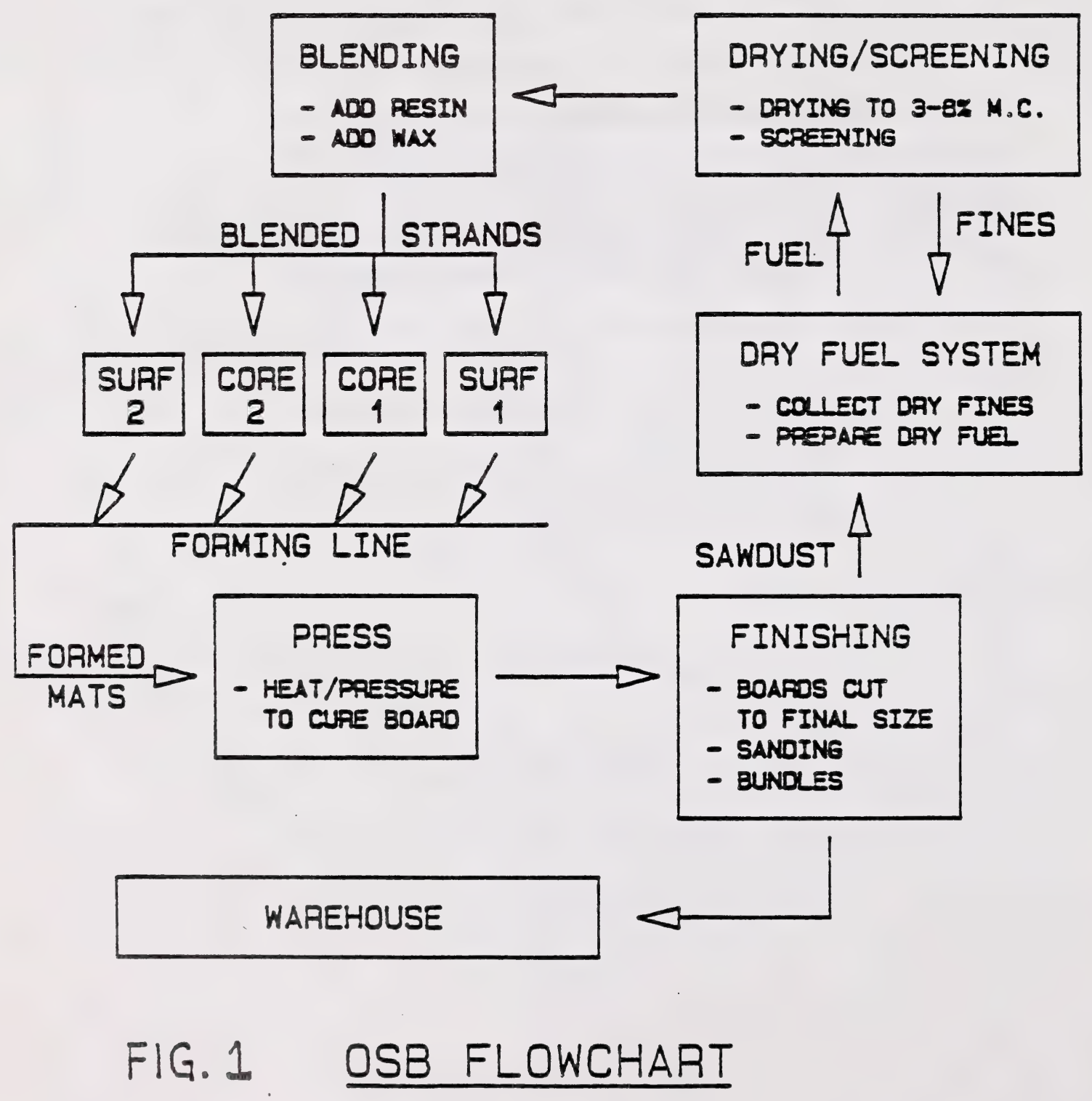


It is obvious that in an O.S.B. Mili today, there must be reliabie control systems, which wili controi the operation and interiace with the operalors. Typicaily, the more automated the process gets, the more consistent the product. Unfortunately, vith sophisticated technology the system is more compiex to instali, maintain and controi. So, "High Tech" typically carries with it some high personnel costs for maintenance and operation.

Back just seven years ago, as the Edson facility vas coming on stream, it vas one of five U.S.B. milis running in North imerica. Today, there are almost fifty. This tenfold increase has made most O.S.B. a commodity product and put severe downard pressure on OSB prices. Wilis that ran at great proilts zeven years ago have to be very caretul today.

\section{OPPORTUNITIES FOR THE 1990's}

Commodity products such as '́x8' roofing, vali sheathing and tongue and groove flooring are produced by most manufacturers. They are fairly generic products and are produced to mid-quality standards for the Horth mimerican market.

Value added products are products that are stronger, more moisture resistant, cut to any size and/or

speciality sanded. Finere is adied cost of exulpment and iabour to produce these products.

Ine vay I see the industry going, there vili be iov cost comodity milis and vaiue adied milis uhach run

commodities as a filier product.

Technology for each of these milis vill be similar.

Both types of milis wili need to be more eficient at:

\section{1) REDUCING PRODUCT VARIABILITY}

Thickness of the the product is of prime importance.

For example, a 7/i6" panel has a targeted thickness o: $0.427 "$ with a standard deviation of $0.015^{\prime \prime}$ and a minimum allovable thickness of $0 . \pm 0 \pm ", 0.023 "$ beioy target.

This is precise enough for a roof manufacturer, but not for an I-beam manufacturer who requires a tighter

tolerance. 
The Eirst Opportunity here is to reduce the products' variabiity so the target thickness of the iot is closer to the minimum. If the mill has the ability to more tightly control finished board thickness and density. then targers for each can be lowered, saving money on yood, resin and wax.

The second opoorturity is to make a seiect product vish tight thickness tolerances, by using a tinckness monitoring machine to grade under or over toierance boarus.

Our company is already doung this for i-bean web manuiacturers vho require tight thickness tolerances.

\section{2) IFPROVIHG COLTROL SYSTË INTEREICING}

Y!jen ouf ilrst mill tas being built sever years ayo, discrete ( $1 / 0$ controis) and analog control systems vere done separately with uperator interfacing by control panei (see Flgure 2i. The operator ls a very busy person at times and duries such as trending, quality cuntro: and process optimization suffer. nil analog devices are separate from the discrete process control. This means the operator initiates, optinizing forming line speeds vith press time, moisture control, resin and Hax addition and dryer seeds. Typlcally, the milis electrlcians do the proyramming and troubie shocting on :ontori systems.

idever mils, buld yath controd systems having analog and isscrete control in the same controi netuork a: ioy for more trending and tuning. For exanpie; it it is foud from trending that flnshed board censity drops btf when high moisture content strandi are on the forming line, then the set point for mat velght ca: automaticaily be bumped up. correcting the error. Hany such possibilities arise.

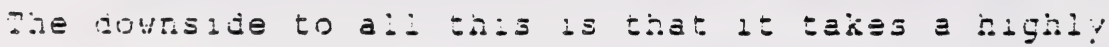

s.

Lp-kesp on the system. It a tecinician ieaves and tae coniro- systen majfunctions it creaces a mejor jrobiem jor the piant. Forcunateiy, harduare ra:iu:ses are less irequent now than they lere ine years ego. 
is a Trire opportunity retrofitting an existing mili or building a ney mill today, the system shown for i990 vould be ldeai (see Figure 2). In order to get the system running quickiy, start vitin a basic graphics system used as just an interface for plant operation. Once running and trouble shooting complete, vork couid begin on predictive control, irending and process uptimization. 

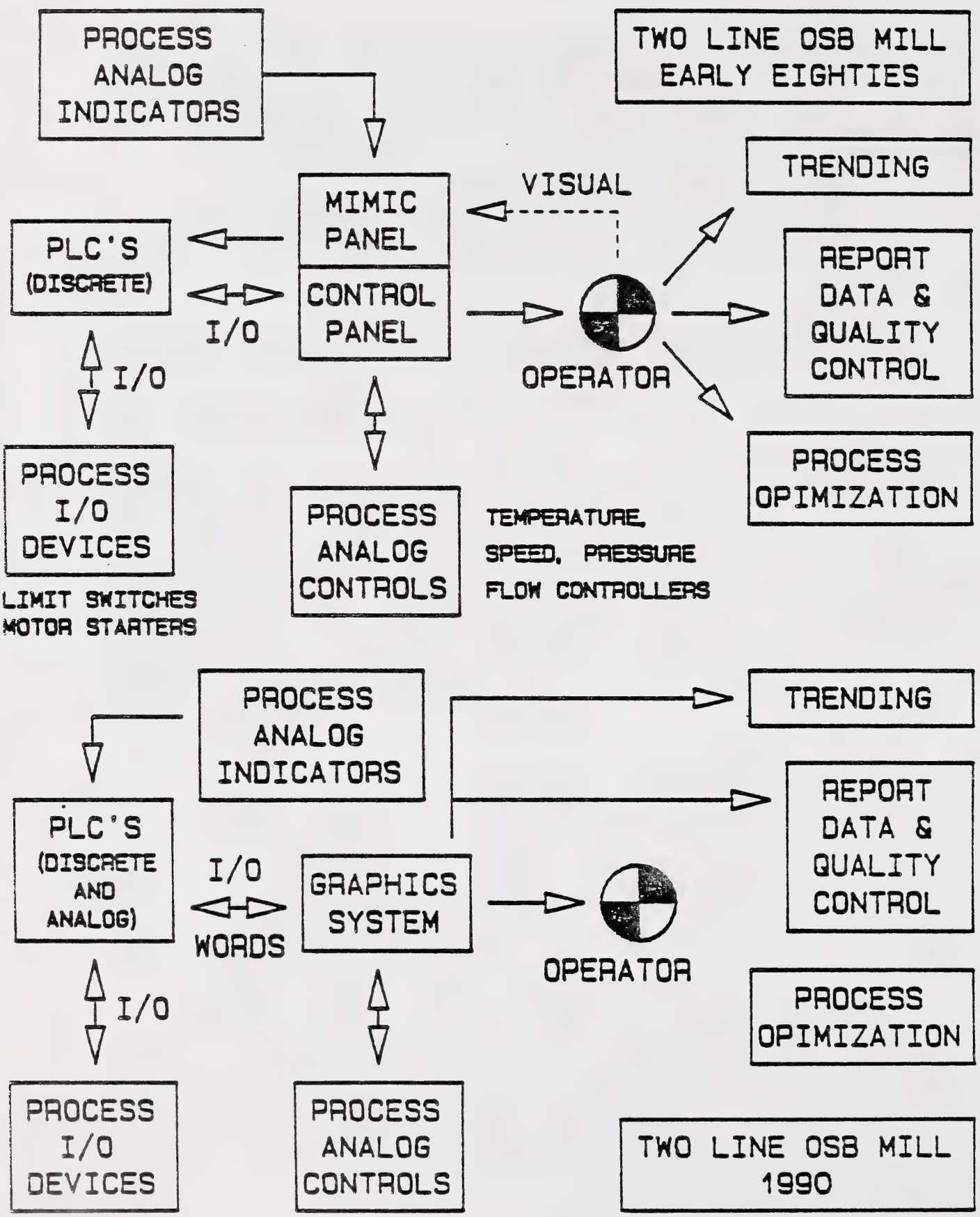

FIG.2 OSB FLOWCHART 


\section{SUMHARY}

This has been a general sketch of O.S.3. Mili technology

today. If retrofitting or bullding a net facility. I'd

vant to utilize an integrated control system and make

sure I could optimize my process after stert-up.

Utilizing the graphics systems, trending, report

generation and quality control can be a nuch more

valuabie and accurate means of optimizing a process,

ratiner than relying on overtaxed operators. 
. 


\title{
HIGH TECH IN PANELBOARD INDUSTRY
}

\author{
by \\ Dam Nguyen \\ Technical Director, Waferboard \\ Weldwood of Canada Ltd.
}

Oliver Foot, the project leader of Orbis with his team of surgeons on a mercy mission of healing the blind, converted a plane into an operating room, a classroom and a clinic. They have rescued 7,500 among the 46 million blind. Said Foot; "If Orbis can do it with a crew of 25 , the world can do it."

We process trees into wood products without realizing sometimes there are better ways of increasing the wood yield and perfect the end-use products, simply because there are a lot of unknown questions. Let me cite a few examples:

1. We saw logs on a straight line. The technique of sawing crooked $\log$ along its curvature has just begun.

2. We stop peeling the last 3-4 inches of log. Only recently there are spindleless lathe in a few plants.

3. Within a decade the young waferboard and OSB industry can produce boards with the same if not better strength, using $1 / 2$ the amount of resin and press time.

And the list goes on. Like the Orbis team, making use of the evolving high technology.

of particular interest to our discussion today, I would like to share with you some thoughts on the role of high tech in solving one of the most important problems in the wood panel industry: moisture content. (For those who are unfamiliar with moisture content, it is the amount of water bound inside and outside the wood fibers.)

To every industry, one particular element plays the most important role in the manufacturing process. If you make glass, constant temperature is essential. If you make pulp and paper, water and its quality must not be neglected. If you make panelboard from reconstituted wood, moisture content plays a very important role.

In the manufacture of panel products, veneer or flakes must be dried quickly from as high as $140 \%$ moisture content down to $2-5 \%$ moisture content to facilitate proper bonding by resin. Pressed panels leave the plant at $0-4 \%$ moisture content while the equilibrium moisture content is $10-12 \%$ in the field. 
We use a lot of heat energy in drying wood, exert a lot of hydraulic energy to squeeze the wood elements together to reach the final thickness... to see that thickness expand later as the board gets wet or reaches its equilibrium moisture. Because the wood fibers are compressed under high pressure in the consolidation process, they later try to recover their original shape with the help of ambient humidity. This process called "springback" or fiber relaxation from compression is a common but critical defect in wood composition board.

Many of us have dreamed of cold pressing or low pressure pressing of panel products. The advance in high tech will one day help to realize this dream.

For those of you who are following up with research in this field, the day when panel products could be made at low pressure and temperature, with or without binder, at a moisture content near equilibrium, is not wishful thinking. If the Orbis team can make the blind see, so can high tech help us to achieve this insurmountable task.

There are already research progress in that direction:

1. Robotic arms and $\log$ scanners are becoming effective tools in log conversion process.

2. Drying programs with dedicated processors will ensure better distribution of moisture in wood after arying beside being more energy-efficient.

3. Computer-aided analytical chemistry will provide better tools to accelerate the development of new and more versatile resin formulations, especially high moisture resins.

4. Electrostatic powder coating or gluing is emerging and provides more uniform distribution of resin on wood interfaces.

5. Vision technology will improve accurate veneer lay-ups or mat formation to required weight and layer ratio.

6. High moisture veneer or furnish will be controlled by smart presses at lower pressure and shorter press cycle.

7. Nuclear scanners will monitor density profile of pressed mats to produce engineered panels for specific strength requirements.

8. Steam injection pressing will stabilize panels and increase tremendously productivity level. 
9. Image analysis will better sort and repair material prior to finishing.

10. Space-science technology will coat boards to enhance their stability and allow field application with more stringent requirements such as concrete forming and foundation, sidings, industrial pallets, etc.

11. Optimization of high moisture pressing and resin bonding will allow drastic reduction in board density and cost without loosing strength.

12. Fiber-optics technology combined with smart devices will allow not only managers and supervisors to be on the top of plant operations, but will simplify and speedup communications throughout the entire operations.

13. Smart micro-processors will save the workers from monotonous or repetitive jobs to spend their valuable time in more interactive inputs in the form of "high-touch" human responses, thus avoiding delays or breakdowns in production process, increasing efficiency in material recovery, and ensuring more consistency in the quality of final products.

14. In-line quality control devices (MSR, IR, laser technology, etc.) interfaced to high-speed computers will enable nondestructive testing at much higher frequency in sampling, increasing the confidence level in quality assurance.

15. Artificial intelligence (AI) programming will help managers and supervisors come to grips with crisis in production and trouble-shooting.

Those are but a few examples of what high tech when, properly harnessed and implemented, can transform the way we process wood material into panel products.

As the theme of today's discussion suggests: "High Tech, friend... or foe", the introduction of high tech into a production line cannot happen without some risks and resistance because of:

a) the high costs of initial investment and maintenance;

b) slow progress on the learning curve;

c) danger of obsolescence;

d) lack of adequate preparation or training of operating personnel.

However, in an age of 4-megabit chip by INTEL when 48,000 capacitors can fit in an area of a dot, let us not be surprised in the dawn of the 21 st century that my above predictions will turn out to be true. 


\section{CLOSING REMARKS}

by

Mr. C. Dermott

Director

Timber Management Branch

Alberta Forest Service

On behalf of the attendees I would like to express my appreciation to the speakers for their excellent presentations and to the steering Committee for the organization of this Conference.

Next I would like to emphasize how important it is for the forest products industry to maintain their technology on the leading edge for survival in the future.

In closing, I would like to remind everyone to visit the Forestry Show and I wish you all a safe journey home. 
. 
$-239-$

APPENDIX I

List of Attendees 

NAME

Adams, Michael

Arechuk, Ken

Bak, Brenday

Bauer, Will

Beard, Robert

Beggs, Rosemary

Bohning, Russel

Boylen, Diana

Bradley, Fred

Brennan, J.A.

Brown, Conn

Buck, Claudia

Chabillon, Dave

Champagne, Percy

Chappell, Doug

Charrett, Elizabeth

Choi, Josephine

Chu, Gordon

Clark, Thomas

Colbert, Ken

Craig, R.

Cretain, R. M.

Danes, Vern

Dermott, Conway

Drachenberg, Bruno

Ennis, Roger

Faloon, Peter

Fedorchuk, Bob

Ferdinand, steve

Fessenden, Robert

Fisher, Tim

Garner, Andy

Gillespie, Ed

Gibson, David

Gouthro, Dan

Grabowski, Tom

Hambrell, Brent

Harris, Philip

Hill, David

Hert, Reynold

Hossinger, Gloria

\section{COMPANY}

ICI Polyurethanes

ICI Polyurethanes

Procter \& Gamble Cellulose

Visionsmart Inc.

Grande Cache Forest Products

Regional Tourism \& Trade Society

Forestry Canada

Northern Forestry Centre

Alberta Research Council

Alberta Forest Industry Development Division

Canadian Forest Products Ltd.

Northern Development Agreement

Career Development \& Employment

Weyerhaeuser Canada Ltd.

Grande Cache Forest Products

Industry, Science \& Technology Canada

Economic Development \& Trade

Vancouver Port Corporation

TKM Wood Products Itd.

Nfld. Deptarment of Forestry \&

Agriculture

Carroll-Hatch (International) Itd.

R. M. C. Engineering Ltd.

Alberta Forestry Services

Alberta Forest Services

Zeidler Forest Industries Itd.

B. C. Government Industry Development \& Marketing Branch

Info-Tech

Forester, Nelson, B. C.

Alberta Forestry Services

Alberta Research Council

Coe Manufacturing

PAPRICAN

Ed Gillespie Forestry Consultants Inc.

Northwestern Utilities Itd.

Borden

Silvacom Ltd.

Alberta Vocational Centre

Alberta Research Council

Oregon Economic Development Dept.

Procter \& Gamble Cellulose

Alberta Forest Industry Development Division 
NAME

Hume, Alister

Isherwood, Trevor

James, Larry

Jankowski, Ted

Jennings, Sarah

Joel, Harvey

Johannson, John

Johnston, William

Juhlin, Tim

Karaim, B.W.

Klotz, Paul

Kordyban Sr., William

Kordyban Jr., William

Lahtinen, Pentti

Lee, S. Scott

Iindberg, Dennis

Little, Kevin

Loberg, Roger

Loh, Joe

MacDonald, Paul

Mak, Kelvin

Maloney, Thomas

Marcichiv, Peter

Mauch, Anne

Mc Intyre, Bruce

McArthur, David

MCDougal1, Fred

Mclaughlin, David

McQueen, Ray

McWilliams, J.

Meil, Jamieson

Mjolsness, Barry

Morrison, James

Muhly, Bryon

Nelsen, Reg

Newman, John

Nguyen, Dam

Obal, James

Oikawa, John

Olson, R. M. (BOb)

Pachal, Derek

Parolin, Robert

Pinnell, Brian

Quintillo, Graig

\section{COMPANY}

H. A. Simons Itd.

Ministry of Natural Resources

Procter \& Gamble Cellulose

Homtech Research \& Development Lta.

Rural Economy, $U$ of $A$

Noranda Forest Sales Inc.

Sunds Defibrator Lta.

Weldwood of Canada Ita.

Northem Forest Industries Lta.

Alberta Forest Industry Development Division

Carrier Lumber Lta.

Carrier Lumber Ltd.

Carrier Iumber Ltd.

Raumac Inc.

O. A. Battista Research Foundation

Thurber Consultants Itd.

Vancouver Port Corp.

Procter \& Gamble Cellulose

Jasper Millworks Ltd.

Southam Forestry Network

Alberta Forest Industry Development Division

Washington State University

Lamont Two Hill Community Futures

Western Economic Diversification

Price Waterhouse

Canada Alberta Northern Development Agreement

Weyerhaeuser Canada Ltd.

Fairview College

Rivtow Equipment Itd.

International Forest Products

Forintek Canada Corp.

Spray Lake Sawmilis (1980) Itd.

Daishowa Canada Co. Ita.

Weldwood of Canada Ita.

$U$ M A Engineering Ltd.

Weldwood of Canada Lta.

Weldwood of Canada Ltd.

Reichhold Itd.

Reichhold Ltd.

Pelican Mills, A Division of

Weyerhaeuser

Regional Economic Dev. Council

Industrial Forestry Service

zeidler Forest Industries Lta.

Alberta Forestry Services 


\section{NAME}

Rabik, Brent

Ramanauskas, Horst Redekop, A.

Ricketts, Ronald

Rochefort, Dave

Roos, Kenneth

Russell, William Saunders on, Jim Schober, Stephen Schramm, David Schuler, Albert Schwab, Greg Sebbas, Eva Shaw, Doug Shields, Jack Sibert, John

Simpson, R.

Sinclair, Alex

Sklar, Doug Sleet, George Smith, Wilfred Stephen, John Stephens, R. W. Stephenson, Norman stewart, R. B. Swaffield, Doug Szabo, T.

Teague, Thomas Thorp, Wayne

Tindall, Richard Underhill, Brian Vajda, Peter Viggo, Holm

Wan, Simon

Way, Danny

Wearing, Jim Wilkes, Douglas Williams, Peter Woodbridge, Peter Wright, Norman

\section{COMPANY}

Ed Gillespie Forestry Consultants Inc.

Alberta Economic Development \& Trade MacMillan Bloedel Research

Fairbanks Indust. Develop. Corp.

Pardee Equipment Ltd.

Natural Resources Research

Institute, University of Minnesota Solutions Management Group

Western Economic Diversification

Canadian Imperial Bank of Commerce

David Andrew \& Associates Ltd.

Forintek Canada Corp.

Woodpro Engineering Ltd.

Ekono Ltd.

Industry Science \& Technology Canada Forintek Canada Corp.

Alaska Science \& Technology Foundation

Alberta Forest Industry Development Division

Forest Engineering Research

Institute of Canada

Grande Cache Forest Products

American Plywood Association

Reichhold Ltd.

B. C. Ministry of Forests-Timber

Forintek Canada Corp.

Ministry of Natural Resources

Polyboard Manufacturing Corp.

Louisianna Pacific Co. Ita.

Alberta Forest Industry Development Division

HCMA Consulting Group Inc.

Daishowa Canada Co. Ltd.

Peace River Pulp Division

Tindall Enterprises

Weyerhaeuser Canada Ltd.

Columbia Engineering International

B. C. Government Industry Development \& Marketing Branch

Alberta Economic Development \& Trade Louisianna Pacific Co. Ltd.

PAPRICAN

Weyerhaeuser Canada Lta.

Alberta Research Council

Woodbridge, Reed \& Associates

Canadian Imperial Bank of Commerce Corporate Banking Centre 



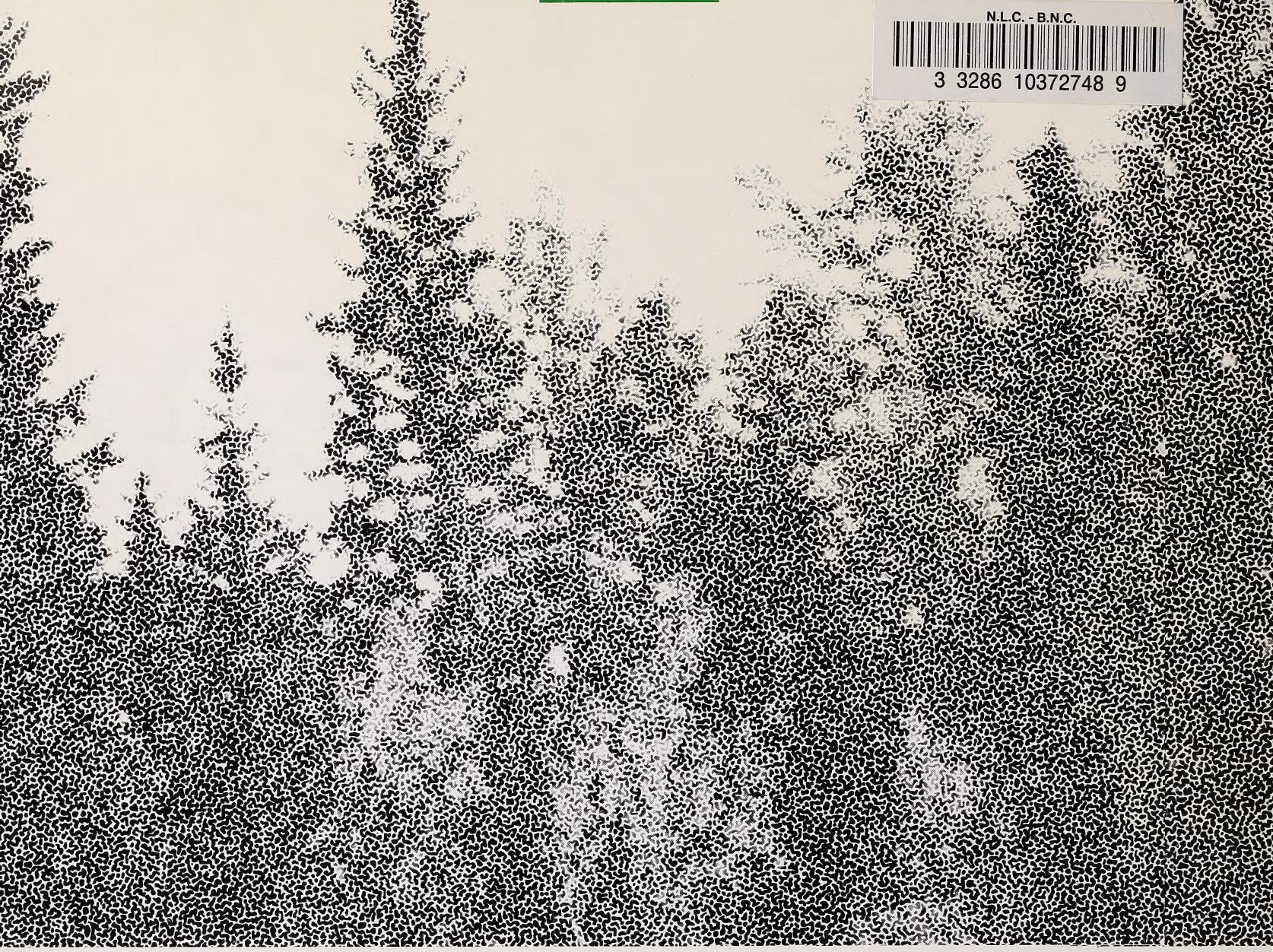

